\title{
Edmond ORTIGUES (1917-2005)
}

Théologien et philosophe,

Auteur d'un ensemble important de travaux en philosophie et en sciences humaines

(1981)

\section{Religions du livre. \\ Religions de la coutume}

Un document produit en version numérique par Jean-Marie Tremblay, bénévole, professeur de sociologie au Cégep de Chicoutimi

Courriel: jean-marie tremblay@uqac.ca

Site web pédagogique : http://www.uqac.ca/jmt-sociologue/

Dans le cadre de: "Les classiques des sciences sociales" Une bibliothèque numérique fondée et dirigée par Jean-Marie Tremblay, professeur de sociologie au Cégep de Chicoutimi Site web: http://classiques.uqac.ca/

Une collection développée en collaboration avec la Bibliothèque Paul-Émile-Boulet de l'Université du Québec à Chicoutimi

Site web: http://bibliotheque.uqac.ca/ 
Cette édition électronique a été réalisée par Jean-Marie Tremblay, bénévole, professeur de sociologie au Cégep de Chicoutimi à partir de :

Edmond Ortigues

Religions du livre. Religions de la coutume.

Paris : Les Éditions Le Sycomore, 1981, 191 pp.

[Autorisation formelle accordée par Madame Marie-Cécile Gélenier, psychanalyste, épouse et ayant-droit des œuvres de son défunt époux, M. Edmond Ortigues, le 27 juin 2007 de diffuser cette œuvre dans Les Classiques des sciences sociales.]

Merci à M. Vincent Descombes [EHESS] et à M. Pierre Lequellec-Wolff, Président de l'Association des Amis d'Edmond Ortigues pour toutes leurs démarches entreprises pour que nous obtenions la permission de diffuser ce livre.

Merci à Mme Catherine Verger, nièce de Mme Gélenier, pour ses démarches auprès de sa tante, ayant-droit des œuvres d'Edmond Ortigues.

Courriels : pierre.lequellec.wolff@wanadoo.fr catherine.verger@neuf.fr

Polices de caractères utilisée :

Pour le texte: Times New Roman, 14 points.

Pour les citations : Times New Roman, 12 points.

Pour les notes de bas de page : Times New Roman, 12 points.

Édition électronique réalisée avec le traitement de textes Microsoft Word 2004 pour Macintosh.

Mise en page sur papier format : LETTRE (US letter), 8.5’’ x 11'’)

Édition numérique réalisée le 21 juillet 2007 à Chicoutimi, Ville de Saguenay, province de Québec, Canada. 


\section{Du même auteur, chez d'autres éditeurs}

Le Temps de la parole, Delachaux \& Niestlé, 1954.

Le Discours et le symbole, Aubier, Ire édition 1962, 2e édition 1977.

Oedipe africain, 1re édition, Plon, 1966 ; 2e édition revue et augmentée, U.G.E., coll. 10/18, 1973 [en collaboration avec MarieCécile (Gélinier) Ortigues]. 


\section{Edmond ORTIGUES (1917-2005)}

Théologien et philosophe,

Auteur d'un ensemble important de travaux en philosophie et en sciences humaines

\section{Religions du livre. \\ Religions de la coutume}

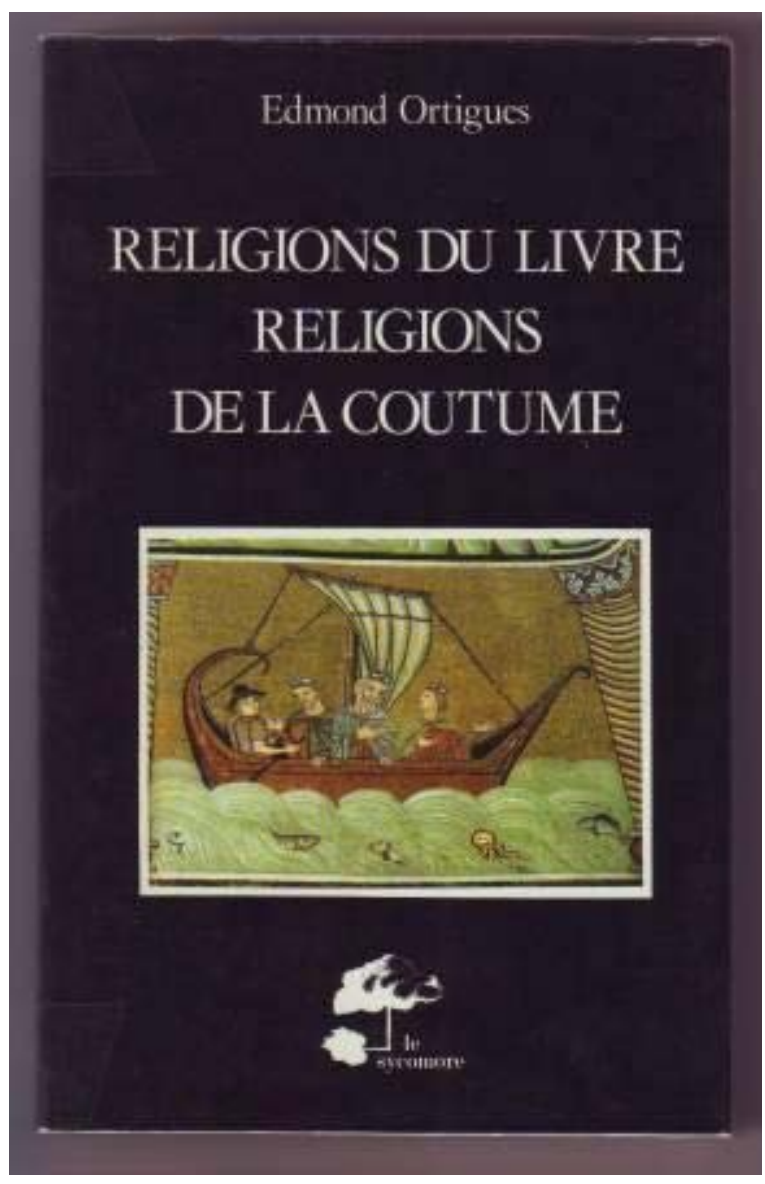

Paris : Les Éditions Le Sycomore, 1981, 191 pp. 


\section{Table des matières}

Présentation du livre (Quatrième de couverture)

Introduction

I. Le monothéisme

II. Le destin et les oracles

III. La destinée individuelle chez les Tallensi

IV. Le mythe fragmentaire

V. Gémelléité inceste et folie chez les Bambara et les Dogon

VI. Les origines augustiniennes de la philosophie de l'esprit

VII. Philosophie du langage et philosophie du droit

VIII. Écritures et traditions au Concile de Trente 


\section{Présentation du livre (Quatrième de couverture)}

Ce livre réunit deux sortes d'études qui traitent alternativement des religions bibliques (origine du monothéisme, Trinité chrétienne, Ecritures et Traditions) et des religions coutumières comme celles que l'on peut encore observer en Afrique. Quel rapport y a-t-il entre le culte des Ancêtres et celui du Dieu unique ? Entre la justice des oracles et la justification par la foi ? En quoi l'élément mystique qui accompagne de façon discontinue les créations de l'esprit se distingue-til de la Coutume et de la foi qui assurent la continuité d'une tradition ? Le sentiment religieux n'a rien qui l'apparente à la nature d'un projet, mais, comme l'art, il construit des formes vivantes à travers lesquelles se révèlent certains aspects durables de la condition humaine. Dans l'histoire des arts de vivre, l'analyse ne peut prétendre à autre chose qu'à éduquer la perception. Des rapprochements qu'il pourra faire entre les divers chapitres de ce livre, chacun en tirera ses propres conclusions. 
Religions du livre. Religions de la coutume

\section{Introduction}

Deux sortes d'études composent ce recueil : les unes concernent les religions du livre, principalement le judaïsme et le christianisme ; les autres traitent des religions de la Coutume, comme celles que l'on peut encore observer quelquefois en Afrique, malgré le déclin des civilisations villageoises. Bien que ces études puissent être lues indépendamment l'une de l'autre, je les ai présentées dans un ordre qui permette d'entrevoir la continuité d'une même recherche.

L'histoire des religions est l'histoire des détours lointains auxquels les hommes ont dû s'astreindre pour arriver à faire ce qu'ils avaient à faire : s'associer, se reproduire, chasser le gibier, cultiver des champs, construire des villes, etc. De tous temps, les hommes ont considéré leurs rêves comme sacrés, et leurs actions utiles comme profanes.

L'une des principales questions que l'on retrouvera tout au long de ce livre pourrait se formuler ainsi : d'où vient que la, pensée religieuse est inséparablement liée à des formes institutionnelles et rituelles de transmission ou de tradition? Il existe en histoire des religions une difficulté que l'on ne rencontre pas au même degré dans l'histoire des 
sciences et des arts. L'historien de l'art, par exemple, est assuré d'avoir un domaine spécifique d'étude dans la mesure où l'objet esthétique peut être spécifié par la facture de l'oeuvre et la psychologie de la perception c'est-à-dire par des moyens autres que ceux de l'histoire. Le fait qu'une statue ait pu être considérée comme une Madone c'est-àdire comme une représentation sacrée, non comme un spectacle destiné à des jouissances profanes, n'empêche pas l'historien de l'art de s'intéresser à la facture de l'oeuvre pour elle-même. Il dispose pour cela de critères logiquement indépendants de l'histoire. Quant à la science, elle tend à formuler des énoncés contextuellement libres dans leurs construction logique ; elle se donne pour tâche d'expliciter les arguments et d'en soumettre les conclusions à l'épreuve de l'expérience. C'est à partir de critères qui sont logiquement, sinon psychologiquement, indépendants de l'histoire que l'historien des sciences et des arts cherche à délimiter son domaine d'étude. L'historien des religions est beaucoup moins assuré d'avoir un domaine propre. Pour spécifier ce domaine il n'est pas certain que nous disposions de critères indépendants de l'histoire. C'est pour cette raison sans doute que l'on a classé les religions d'après la façon dont .elles se communiquent ou, se transmettent, en distinguant les religions ethniques qui se transmettent par voie de coutume ancestrale et les religions de salut qui se transmettent par voie de prédication doctrinale à vocation universelle. En fait, il n'existe pas de religion universellement admise mais seulement des religions missionnaires et d'autres qui mettent leur confiance in aris et focis, dans le foyer et son double, l'autel. Les religions mystiques elles-mêmes se transmettent par l'autorité d'un Guru. Ne faut-il pas chercher dans le contenu des croyances religieuses ce qui les rend inséparables des formes rituelles de la communication?

Les religions ethniques sont un héritage. La coutume est de soi religieuse car elle enveloppe le culte des origines, origines du ciel et de la terre, des signes et du mal, des usages et des lois, des peuples et des lieux-dits. Le culte des ancêtres devrait être appelé plutôt le culte de l'ancestral, car il s'adresse moins aux géniteurs naturels qu'à leurs Mânes surnaturelles. Les généalogies font elles-mêmes partie des fonda- 
tions pour la même raison qu'il ne suffit pas de naître pour être un homme mais qu'il faut être reconnu par un rite d'imposition du nom. Le domaine ancestral se peuple d'entités cultuelles que nous appelons des génies, des esprits, ou des dieux ; il est peuplé de craintes et d'espoirs, de phobies et de contre-phobies. Le dieu est-il un parent ou un allié ? C'est un privilège divin de pouvoir être à la fois l'un et l'autre et d'exister avant l'interdiction de l'inceste. Ainsi le Dieu père (Zeus Pater) peut-il être aussi le Dieu des serments (Zeus Orkos). Les dieux se définissent par leurs "Puissances" c'est-à-dire par les fonctions qu'ils remplissent à l'égard de la communauté des hommes. Pourquoi parlezvous de dieux solaires ? Ce n'est pas l'auréole qui distingue un saint d'un autre, mais un certain pouvoir d'intercession et de miracle. La Toute Puissance elle-même est le pouvoir d'être unique, d'élire qui elle veut et d'endurcir les coeurs de ceux qu'elle condamne. La Toute Puissance n'est donc pas socialement indifférenciée.

La religion des ancêtres n'a pas de Credo ; elle n'est pas exportable par principe comme l'est une Doctrine. Quand les individus éprouveront le besoin d'être sauvés chacun pour son compte, naîtront les religions missionnaires, mais à quoi bon prêcher quand l'espoir est seulement d'être réuni à ses ancêtres ? Les romains de l'antiquité ne demandaient pas aux chrétiens de "croire" à ce qu'Ovide appelait "les mensonges des anciens poètes", mais ils leur demandaient de sacrifier aux dieux de l'empire, ce qui était un geste civique d'allégeance. L'existence des religions ethniques est le seul fait religieux absolument universel, non seulement parce que ces religions coutumières ont existé partout mais parce qu'elles continuent à nourrir de leur sève populaire les grandes religions missionnaires qui n'auraient pu longtemps subsister sans elles. Il n'y a pas de peuple sans religion, parce que la religion est ce qui unit les vivants et les morts dans un seul et même peuple. Les chiens marquent leur territoire par quelque libation naturelle, les hommes par des emblèmes divins, des clochers, des fanions, des temples, des oeuvres d'art, des symboles où l'âme se révèle pour soi, au-delà de ce qui sépare les vivants et les morts. Les raisons de vivre sont les raisons de vivre là, en un lieu consacré par la patine 
des âges et le compagnonnage, un lieu où le temps cyclique, comme l'on dit, est le temps utile avec ses alternances de jour et de nuit, de saisons, d'années, de siècles... La coutume est raison, parce que les seules raisons de vivre qui puissent être qualifiées de religieuses sont les raisons d'être là, d'habiter quelque part, plutôt que d'être une âme errante comme les morts sans autel ou les fous sans raison qui partent s'égarer dans la brousse. Pour vivre sur un sol déshérité à faut une raison divine, un héritage incorruptible. On demandait un jour à une intellectuelle musulmane pourquoi elle faisait circoncire son fils.

Après avoir cherché toutes sortes de raisons qui lui parurent vaines, elle conclut: "Parce que c'est la coutume chez nous. Je fais ce qu'ont fait mes parents". Pourquoi Dieu préférerait-il l'eau baptismale à la chair des prépuces ? La coutume est raison parce qu'elle institue l'humanité de l'homme comme un héritage qui se transmet à travers les générations. Dans une situation d'incertitude, comme celle qu'illustra l'âne de Buridan, quand tous les choix sont également aléatoires, décision vaut raison. Que faire quand on est son propre enjeu et qu'on aime la vie ? Dieu joue aux dés. Lorsqu'il n'y a pas de raison préexistante pour choisir, création vaut raison.

Quand on parle de "croyances religieuses", il faut prendre garde que le mot "croyance" est destiné à distribuer les pensées entre nous, les miennes et les tiennes. Une croyance est une assertion tenue pour vraie. Elle est une expression que l'on peut désigner, sans quoi nous ne pourrions. l'identifier comme étant telle croyance plutôt que telle autre. Elle se définit par sa structure logique et ne se reconnaît comme réalité psychologique que secondairement, à travers l'inquiétude ou l'interrogation. Il y aurait un cercle vicieux à vouloir définir la croyance psychologiquement alors qu'elle nous sert à introduire les problèmes psychologiques. Le concept de croyance est un instrument d'analyse par lequel nous distinguons les conditions de vérité d'une proposition et ses conditions subjectives d'acceptabilité. Nos persuasions se reconnaissent à nos actions. C'est pourquoi la conscience que nous en avons est intermittente. Il ne faut pas confondre les croyances 
imputables en troisième personne avec les croyances professées ou assumables en première personne. Tel est le sens du dicton : "Je n'y crois pas mais quand même Dans les religions coutumières il n'y a guère de sens la plupart du temps à demander: "Croyez-vous aux masques ? Croyez-vous au soldat inconnu ?". Et il n'y a guère de sens à attendre un "Je crois" à moins qu'une désaffection pour la coutume ait rompu le charme. Les divers états (conscients ou inconscients) de la croyance sont intrinsèquement liés aux possibilités de différencier les positions de chacun dans une conversation. Or cela n'est pas toujours faisable. Le sens du mot "opinion" ne s'est-il pas formé au moyen des règles institutionnelles de la discussion publique ? Au contact des autres nous découvrons nos convictions. Et il y a de multiples façons de croire et de ne pas croire c'est-à-dire de consentir ou de ne pas consentir, ou encore d'esquiver. Toute croyance n'est pas une foi. Ni la coutume ni la mystique n'exigent une foi, alors que les religions de la foi tiennent souvent en suspicion la coutume et l'illuminisme. Bien que l'idée de "foi" se trouve dans la littérature védique et la tradition indo-européenne ${ }^{1}$, c'est dans la religion du Livre qu'elle est devenue "scripturaire", obéissance confiante à Dieu révélé dans les saintes Écritures. La foi est une croyance à la deuxième puissance, le chrétien croit qu'il faut croire pour être sauvé ; la nécessité de la foi pour le salut est elle-même un dogme, un objet de croyance. La conception de la foi varie suivant la conception que l'on a des Écritures : dans le judaïsme, l'Islam, le catholicisme ou le protestantisme. L'Écriture est, dans tous le cas, le lieu de l'Autorité. Sans le christianisme, l'idée d'un messie souffrant a rendu possible la distinction entre le spirituel et le temporel. Mais la loi divine est un oracle, elle n'a pas la fonction utilitaire d'une loi civile ; elle requiert l'allégeance personnelle à un Seigneur, non la discussion d'un contrat social ou d'une règle du jeu impersonnelle. Il y a là deux conceptions très différentes de la loyauté, et par conséquent de la morale. La question des rapports entre la raison et la foi repose sur ce malentendu.

1 Cf. G. Dumézil : Idées romaines, I, c. 2, Paris NRF, pp. 48-59. 
La troisième composante de la religion, après la coutume et la foi, est la mystique. Elle se conçoit comme un expérience directe, intuitive ou extatique, une illumination. La mystique est partout solidaire de considérations cosmologiques plutôt qu'historiques (bien qu'elle se donne des références historiques chaque fois qu'elle se rattache à une institution religieuse). On notera que les "démonstrations de l'existence de Dieu" reproduisent la voie négative des mystiques, laquelle n'implique pas de soi la croyance à un Dieu personnel. Quand le mystique est aussi un croyant, l'expérience du négatif se combine avec la crainte de Dieu et l'espérance, mais quand l'élément mystique s'idéalise dans la connaissance du monde, l'acceptation de nos limites devient une réconciliation avec le présent ; alors la suprême instance de la sensibilité humaine ne se trouve plus dans la crainte et l'espérance mais dans l'amour intellectuel de ce qui existe.

Les textes réunis dans ce recueil ont été écrits à des dates différentes et la plupart d'entre eux se trouvaient dispersés en diverses publications.

La première étude traite du monothéisme biblique dans ses rapports avec les religions de l'ancien Orient. Depuis le siècle dernier, on a beaucoup spéculé sur les origines du monothéisme. La question méritait d'être reprise à la lumière de ce que nous savons aujourd'hui des religions babyloniennes utilisant elles-mêmes de plus vieilles traditions d'origine sumérienne. En essayant de répondre à la question : "Qu'est-ce qu'un Dieu unique ?", nous serons amenés à introduire un certain nombre de notions qui seront reprises, sous un autre éclairage, dans les études suivantes. Il en est ainsi, en particulier, pour le concept de "révélation" dans son rapport à la fonction des oracles et des prophètes, et pour le concept de tradition dans sa référence aux ancêtres.

La seconde étude sur le destin et les oracles est le texte d'une conférence faite à Cerisy-La Salle à l'occasion d'un colloque sur la 
psychologie du destin de Szondi (1977). Cette conférence est une réflexion sur l'ouvrage collectif Divination et rationalité, édité par J.P. Vernant (Paris, Le Seuil, 1974). La distinction entre la divination inductive ou mantique et la divination inspirée ou prophétie apportera quelques compléments. au premier chapitre.

La troisième étude intitulée La destinée individuelle chez les Tallensi est le texte d'une préface à la traduction française d'un petit livre de Meyer Fortès : Oedipe et Job dans les religions Ouest-africaines, publié en 1974 aux éditions Mame. Pour écrire cette préface je m'étais appuyé sur les divers travaux de Meyer Fortes, dont Oedipe et Job. ne donnait qu'un bref résumé. J'avais surtout utilisé : The Dynamic of Clanship among the Tallensi (1945) et The Web of Kinship among the Tallensi (1949). Il en est résulté un texte qui déborde largement les circonstances occasionnelles de sa rédaction. Alors que le chapitre précédent analysait les conceptions du destin dans le cadre des religions sémitiques principalement, nous retrouvons maintenant le même problème à l'intérieur d'une religion africaine.

La quatrième étude est le texte (polycopié) d'une conférence faite à Lyon en 1971 à l'occasion d'un colloque sur la parole dans les religions africaines. Son titre Le mythe fragmentaire fait allusion à l'usage rituel des croyances mythologiques à l'intérieur des pratiques religieuses. Comment se présentent les valeurs mystérieuses d'un système religieux ? Quelle est la différence entre raconter et prier ? En outre ce chapitre ébauche une typologie des religions à partir de la distinction entre la coutume, la foi et la mystique.

La cinquième étude est l'analyse d'un mythe que l'on trouve à la fois chez les Bambara et les Dogon. C'est à l'automne de 1963, en Afrique, que j'ai écrit Gémelléité, inceste et folie. Depuis lors ce texte a circulé en polycopie (comme le précédent), et je dois expliquer pourquoi je ne l'avais pas publié. Au moment où j'ai écrit ce texte, les recherches qui devaient aboutir plus tard à la publication d'Oedipe africain n'en étaient qu'à leurs premiers tâtonnements. Les traditions 
Wolof m'apparaissaient alors trop délabrées pour être compréhensibles. Il m'avait semblé utile d'explorer une mythologie plus consistante et cependant assez voisine pour fournir des points de comparaison avec ce que nous observions dans les populations du Cap Vert. Par exemple, le "sass" ou madrier rituel des Serer paraissait analogue au "pembele" des Bambara, peut-être aussi le dieu Ro avec Faro. À la rentrée universitaire 1963164, je décidai de relire tout ce que je pourrais trouver sur les Bambara et les Dogon. L'analyse de la mythologie "Mandé" ne fut donc pas un but en soi, seulement un moyen pour mieux comprendre éventuellement les études de terrain qui se poursuivaient alors dans l'équipe de Fann. Je ne suis pas allé à Bandiagara pour vérifier mes sources, M. Griaule, G. Dieterlen, Travele... "Gémelléité, inceste et folie" est resté un exercice d'analyse, et c'est comme tel qu'il faut le lire. Pour comprendre la nature de ce travail, il faut relire la présentation du mythe telle qu'elle se trouvait alors dans La religion Bambara de G. Dieterlen (Paris, PUF, 1950, pp. 16-30). C'est ce texte assez difficile que j'ai tenté de déchiffrer.

L'étude suivante, intitulée Philosophie du langage et philosophie du droit, est un compte rendu de lecture m'ayant donné l'occasion de présenter quelques réflexions personnelles dans la revue canadienne, Dialogue (vol. XVII, no 3, 1978, pp. 528-547). Le problème central est ici celui de la Loi, tout ensemble morale et conventionnelle, qui règle les rapports entre les hommes et fonde leur appartenance commune à un groupe social. Il semble que la mythologie des origines tende à réduire l'une à l'autre ces deux sortes de relations que nos concepts juridiques ont pour fonction de distinguer. C'est du moins ce que semble suggérer la comparaison entre la finale de ce chapitre VII et le chapitre $\mathrm{V}$ sur la gémelléité. On peut formuler le même contraste autrement. La plupart des sociétés anciennes tendent à privilégier une morale du statut dont on hérite (morale de l'honneur et de la honte) alors que les sociétés contemporaines accordent beaucoup plus d'importance aux valeurs d'utilité, de prévision, d'initiative. C'est peut-être par l'idée de contrat que l'on comprend le mieux comment le droit s'est distingué de la religion. 
Le chapitre sur les origines augustiniennes de la philosophie de l'esprit (publié dans les Kant-Studien, t. 63, vol. 2, 1972, pp. 163181), traite d'une question analogue à celle du premier chapitre. C'est dans le de Trinitate de saint Augustin qu'est né ce qu'en Europe nous appelons "l'esprit" c'est-à-dire la pensée qui, en se dépassant, se trouve absolument. Augustin cherche Dieu dans la façon dont l'esprit conçoit la présence à soi-même. Néanmoins la transcendance demeure encore pour lui la Belle Étrangère dont nous sommes l'image. L'esprit n'a pas encore accepté en lui-même la patience -de vivre. Ainsi quand la neige d'hiver recouvre la terre, l'enfant arrondit d'une volte la fin de sa glissade, il place la beauté où à ne peut aller. L'unique nécessaire était pourtant chez soi déjà dans le chemin.

La dernière étude, sur les Écritures et les traditions au concile de Trente, avait été présentée dans divers colloques réunissant des théologiens catholiques et protestants au cours des années 1946-1952. Je rappellerai, dans une note au début du texte, dans quelles circonstances celui-ci a été composé. On y retrouvera l'un des thèmes essentiels de ce livre, à savoir la question des rapports entre les auguria, signes de révélation, et les sacra ou sacramenta, fondements de la communauté religieuse. En outre, la controverse entre catholiques et protestants est toujours d'actualité en ce quatrième centenaire de la confession d'Augsbourg (1580).

Je remercie Jean Jamin, qui m'a convaincu de réunir ces textes dans une publication d'ensemble. J'espère seulement que leur diversité n'empêchera pas le lecteur d'apercevoir entre eux d'utiles convergences.

Octobre 1979 
Religions du livre. Religions de la coutume

\section{Chapitre I \\ LE MONOTHÉISME}

$\underline{\text { Retour à la table des matières }}$

Qu'est-ce que le monothéisme ? La réponse paraît simple au premier abord : le monothéisme est la croyance d'après laquelle il n'existe qu'un seul Dieu. On remarquera cependant que l'idée d'un Dieu suprême se retrouve un peu partout dans le monde, soit qu'elle serve à hiérarchiser un panthéon, soit qu'elle explique l'origine des choses, ou qu'elle demeure à l'arrière plan dans ce qui doit rester .mystérieux. Pour tenir compte de ce fait, on distingue habituellement "Dieu suprême" et "Dieu unique", hénothéisme et monothéisme, le monothéisme étant le culte exclusif d'un Dieu unique. Cette distinction n'est pas toujours facile à faire. Les religions bibliques se représentent Dieu environné des anges et des saints. Sans doute elles opposent radicalement le créateur et la créature, l'adoration et la piété, mais le culte n'en conserve pas moins une pluralité de destinataires. Notre calendrier liturgique n'est pas moins peuplé qu'un panthéon. Patriarches, prophètes, apôtres, docteurs, vierges et martyrs, témoignent du lien qui unit Dieu à la communauté humaine. En l'absence de ce lien, il ne serait pas proclamé le Dieu vivant, le Dieu des patriarches et des prophètes, 
le Dieu des ancêtres et des pères fondateurs. Si le culte des ancêtres accompagne en sourdine le culte du Dieu unique, c'est sans doute que la religion, sous sa forme la plus constante, la plus banale et la plus universelle, est ce qui unit les vivants et les morts dans une même communauté. C'est pour cela qu'une religion est une tradition, une coutume, un héritage qui se, transmet. Le sentiment que nous avons de nous mêmes, demeure narcissiquement lié à la terre ou à la langue de nos ancêtres. Le culte remonte vers ceux dont nous descendons. Les dieux, quels qu'ils soient, sont toujours liés d'une manière ou d'une autre à la sphère ancestrale de la coutume, suivant le vieil adage : cujus regio, illius religio. C'est seulement dans les cas où une religion s'élabore en doctrine de salut personnel qu'elle devient par principe exportable. Les religions de salut se reconnaissent une mission doctrinale universelle. Les religions missionnaires sont nées dans des empires ou des aires géographiques pacifiquement ouvertes au voyage, en des temps où le prédicateur de la nouvelle doctrine pouvait s'arracher aux liens de son lignage. Partout où elles se sont implantées, les religions missionnaires ont recouvert d'une pellicule d'orthodoxie le vieux terreau des religions populaires. L'existence des religions ethniques est le fait religieux universel, d'où émergent comme d'originales créations les religions missionnaires.

Le monothéisme fut lui-même d'abord une religion ethnique. Il n'est devenu religion de salut qu'à l'époque hellénistique, surtout à travers la diaspora d'Alexandrie et la chrétienté d'Antioche. Il convient de s'en souvenir pour comprendre le sens de la question : qu'est-ce que le monothéisme?

La croyance au Dieu unique ne suppose pas nécessairement que l'on nie l'existence des autres dieux; elle exige seulement que ces dieux étrangers ne soient pas l'objet d'un culte sur la terre d'Israël où règne seul le Dieu des ancêtres. On connaît la plainte de David lorsque Saül l'oblige à fuir en terre étrangère et donc à servir les dieux du pays où il se trouve: "Si c'est Yahweh qui t'excite contre moi, qu'à agrée le parfum d'une offrande ; mais si ce sont des hommes, qu'ils 
soient maudits devant Yahweh puisqu'ils m'ont chassé maintenant pour m'ôter ma place de l'héritage de Yahweh en disant : va servir des ,dieux étrangers! Et maintenant, que mon sang ne retombe pas sur la terre loin de la face de Yahweh" (ISam. 27, 19-30). C'est le mouvement prophétique qui transformera peu à peu le monothéisme relatif en monothéisme absolu. Avant de prendre une signification abstraite, l'unicité divine a eu d'abord une signification sociale et cultuelle : Yahweh est un dieu national dont le culte se veut exclusif, hostile à l'égard des autres dieux, ce qui donne aux serviteurs de Yahweh un statut religieux unique parmi les nations. Un seul Dieu, un seul Peuple élu. Ces deux idées sont inséparables; elles se définissent l'une par l'autre suivant la célèbre formule d'alliance entre Yahweh et Israël : je serai votre Dieu, et vous serez mon Peuple. La révélation monothéiste se résume dans une théologie de l'adjectif possessif - mon Dieu, mon Peuple. Dieu est le dieu d'Israël, comme Israël est le peuple de Dieu.

La théologie de l'appartenance élective éclaire rétrospectivement la préhistoire du monothéisme. Le peuple hébreu a su développer d'une manière originale un certain nombre de notions héritées des traditions de l'ancien Orient. C'est d'abord la vieille idée sumérienne d'après laquelle les dieux ont créé les hommes pour être leurs "serviteurs". C'est aussi la tendance des peuples sémitiques à revendiquer un dieu national : Kamosh pour Moab, Moloch (c'est-à-dire "roi", Melech) pour Ammon, Kosh pour Edom, Ashur pour l'Assyrie... Les Sémites du Nord concevaient leur dieu national comme un dieu universel dont le règne s'étend sur les peuples étrangers ; et la première dynastie sémitique de Babylone, celle d'Hammurabi, avait glorifié Marduk au point d'absorber en lui les autres divinités: "Marduk en tant que Dieu de l'agriculture, c'est Ninurta ; en tant que dieu de la bataille, c'est Ziburba ; en tant qu'illuminateur de la nuit, c'est Sin ; en tant que dieu de la justice, Shamash ; en tant que dieu de la pluie, Adad..." Pourtant la glorification de Marduk dans l'épopée de la création n'est pas monothéiste. Yahweh n'absorbera pas les autres dieux, il les exclura, il les réduira à n'être que des idoles de pierres ou de bois. D'autre part le dieu national est un dieu local, un "baal" c'est-à-dire un maître du 
pays, et bien que Yahweh lui-même ait été considéré souvent comme un "baal", la polémique des prophètes contre les cultes locaux soulignera surtout la signification sociale de l'unicité divine, le lien d'élection qui unit Yahweh à son peuple. La théologie de l'adjectif possessif, qui prendra sa forme définitive dans la doctrine de l'alliance entre Dieu et Israël, s'expliquerait mal cependant si elle n'avait de profondes racines dans la sensibilité populaire. A cet égard, l'un des faits qui nous aide le mieux à comprendre la préhistoire du monothéisme est la distinction que, selon E. Dhorme, faisaient les anciennes religions orientales entre les divinités locales (par exemple Ashur) et les "dieux personnels" (par exemple Ilabrat) attachés à une personne et à sa famille. ${ }^{2}$ L'expression "dieu personnel" est devenue chez les assyriologues une expression technique servant à désigner non pas des dieux ayant une personnalité (ils en ont une, si vague soit-elle) mais des dieux qui appartiennent en propre à tel individu et à sa famille. Le dieu personnel est appelé "ton dieu, le dieu de ton père". La thèse ébauchée par Dhorme puis reprise et développée par Henri Gazelle 3 était que les Patriarches de la Genèse ne devaient pas être. considérés comme les fondateurs d'une nouvelle religion, mais que le Dieu d'Abraham était un dieu "personnel" qui se déplaçait avec son protégé, lui accordait ses bénédictions et ses révélations, garantissait la fécondité de sa race et de ses troupeaux, suivant la coutume commune aux Babyloniens, aux Assyriens et aux Hébreux, d'après laquelle "chaque individu a son dieu gardien, précurseur de l'ange gardien des religions chrétiennes". ${ }^{4}$ Le patriarche a transmis son dieu personnel àses descendants. Plus tard lorsque les rédacteurs de la Genèse évoqueront "le Dieu d'Abraham, d'Isaac et de Jacob", "le Dieu de nos pères", ils témoigneront du lien qui rattache le monothéisme juif à la vieille coutume du dieu personnel ou dieu du père, coutume bien plus ancienne qu'Abraham. La théologie du dieu personnel est d'origine

2 E. Dhorme, La Religion des Hébreux nomades, NSE, Bruxelles, 1937, ch. XX, p. 345.

3 M. Cazelles, Le Dieu d'Abraham, La Revue des quatre fleuves, no 6, Seuil, 1976.

4 Dhorme, op. cit., p. 317. 
sumérienne ; elle a précédé d'au moins un millénaire l'avènement du peuple hébreu dans l'histoire.

La notion du dieu personnel est diversement présentée par les historiens. Dans son livre sur la Religion Babylonienne, Jean Bottéro note que la grande liste babylonienne des dieux trouvée dans la, bibliothèque d'Assurbanipal, devait comprendre plus de 2.500 noms divins, et que la liste n'est pas close, on en a trouvé bien d'autres. Il note par ailleurs la tendance bien connue des hymnes à concentrer toutes les perfections, tout le potentiel sacré, sur la personne divine à laquelle on s'adresse hic et nunc. C'est là un phénomène assez général que l'on retrouve dans l'Inde et ailleurs. Finalement Bottéro donne son diagnostic sur le sentiment religieux chez les Babyloniens : "La tradition, écrit-il, leur proposait des personnalités de dieux en grand nombre, et leur entendement n'y répugnait point, au contraire, mais dans l'exercice de leur religiosité, leur révérence et leur adoration se pointaient plus naturellement vers un individu unique, en qui se trouvait concentré en pratique tout le divin et le sacré. De nombreux textes illustrent ce phénomène, dont l'étude relève de la psychologie de la religion. C'est lui qui éclaire en très grande partie l'existence des "dieux personnels" (il reshi, mot à mot "le dieu de la tête de" quelqu'un) qui semblent jouer chacun vis-à-vis du fidèle dont il est le dieu particulier, le rôle de la divinité universelle par rapport au monde : "Tu est mon Dieu, tu es mon Maître, tu es mon Juge, tu es mon Secours, tu es mon Vengeur..." Et c'est ici que les noms de parenté appliqués aux dieux prennent peut-être tout leur sens : chacun est "fils de son dieu". On ne peut prendre cela que comme une traduction du désir de s'assurer un protecteur surnaturel particulier, quelque chose comme l'ange gardien du folklore chrétien. Mais il est très probable qu'il faut y voir davantage : une nécessité réelle du sentiment religieux de ne point disperser sa force sur une multitude mais de se projeter tout entier sur une personnalité unique, non en principe mais en fait". ${ }^{5}$ Cependant il ne suffit pas, pour expliquer une forme historique particulière, de faire appel

5 J. Bottéro, La religion babylonienne, PUF, Paris, 1952, pp. 52-53. 
à un besoin psychologique, général, comme le besoin de concentrer toute la dynamique du sacré dans l'instant d'une invocation. Cet argument prouve trop et pas assez, justement parce qu'il est vrai d'une manière trop générale. D'ailleurs le dieu personnel est souvent accompagné de sa parèdre, et il n'est pas certain qu'il soit toujours unique. La croyance aux esprits gardiens, attachés à la protection spéciale d'un individu, est courante en Afrique occidentale, et il est probable qu'elle se retrouve aussi ailleurs. La question serait plutôt de savoir ce qui caractérise les dieux personnels ou familiaux des sémites parmi tous les dieux de lignage, les Génies du Genos, que l'on trouve un peu partout et qui se distinguent aussi peu que l'on voudra de l'ancêtre comme s'il importait seulement de différencier à l'intérieur du statut ancestral une double fonction, la fonction du géniteur (celui dont nous descendons) et la fonction de l'objet cultuel idéalisé (celui vers qui le culte remonte est un "esprit", une entité culturelle, idéale ou surnaturelle). Or le concept sémitique du dieu personnel se caractérise par un mode de relation élective entre l'homme et le divin. Et, dans ce cas, nous pouvons retenir de l'argumentation de Bottéro une idée importante : c'est qu'à l'intérieur de cette relation élective, le fidèle attend de son dieu une protection singulière. Cette singularité est fonctionnelle. Ce qui nous empêche de comprendre la préhistoire du monothéisme, c'est que nous imaginons qu'à un moment dut s'opérer un choix entre "un" ou "plusieurs" dieux. Par une illusion rétrospective nous projetons ce dilemme dans le passé. Nous supposons que les hommes se sont posés le problème, puis l'ont résolu. Mais ce n'est pas ainsi qu'opère une tradition collective. Dans ce cas, c'est au contraire la solution qui fait apparaître rétrospectivement l'existence d'un problème. Tant que nous restons hypnotisés par l'alternative "un" ou "plusieurs", nous nous mettons dans l'impossibilité d'appliquer la règle formulée par G. Dumézil d'après laquelle un dieu se caractérise avant tout par son mode opératoire, son modus operandi dans la vie sociale. Et pourtant la solution est là sous nos yeux, dans la formule d'alliance entre Yahweh et Israël : je serai votre Dieu et vous serez mon peuple. L'alternative pertinente dans cette formule c'est la présence ou l'absence du possessif ou en général d'une marque d'appartenance élective. Ce mode de rela- 
tion entre l'homme et le divin peut se trouver aussi bien chez des polythéistes de principe, comme dit Bottéro, pratiquant une sorte de monolâtrie provisoire et alternative, que chez des monothéistes de principe, comme le roi David, admettant un polythéisme de fait. Nous répétons encore Notre Père qui êtes aux cieux... alors qu'on ne dirait pas couramment Notre Jupiter, bien que Dios Pater soit aussi Dieu le Père. En hébreu le mot "El" (Dieu) se décline avec la marque du possessif : Elohênou, notre Dieu, Elohêka, ton Dieu, Eli, mon Dieu. Mais si je dit "le Zeus de Phidias", vous pensez immédiatement à une statue, non à une divinité, et ce n'est pas la psychologie des religions en général, sans référence à une élaboration conceptuelle particulière, qui peut nous faire comprendre pourquoi le "dieu de Phidias" est une expression profane alors que, le "dieu d'Abraham" est une formule théologique. C'est précisément l'étude de ces formules qui fait l'objet du Livre d'Hermann Vorländer : "Mein Gott. Die Vorstellungen vom persönlischen Gott in Alten Orient und im Alten Testament. ${ }^{6}$

Hermann Vorländer a divisé son étude en deux parties, l'ancien Orient puis l'ancien Testament. L'auteur a résumé lui-même les conclusions qu'il tire de l'une et l'autre étude. Cependant, comme cette récapitulation suppose connu, dans les deux cas, le reste de l'ouvrage, je ne puis la reproduire littéralement. J'y ajouterai donc parfois un bref commentaire pour en faciliter la lecture, en espérant ne pas trahir la pensée de l'auteur. Et d'abord pour l'ancien Orient. ${ }^{7}$

1. Le dieu personnel se tient dans un rapport étroit de confiance et de protection à l'égard d'un individu et de sa famille. Ceci peut avoir été établi du côté de l'homme par une cérémonie de dédicace. Mais quels sont les dieux susceptibles de remplir cette fonction ? La plupart des auteurs, et Dhorme lui-même insistait sur ce point, admettent qu'une même divinité peut concentrer en elle les deux fonctions de dieu local et de dieu familial. Mais Vorländer va plus loin en montrant

6 Neukirchene Verlag, 1975.

7 D'après Vorländer, pp. 165-167. 
que la fonction de dieu personnel se rencontre dans tous les domaines où les dieux exercent leur juridiction : dieu du pays, dieu de l'État, dieu de la végétation, dieu du droit etc... Autrement dit, la fonction de dieu personnel est cumulable avec d'autres fonctions.

2. Peuvent remplir la fonction de dieux personnels aussi bien les "grands dieux" que les dieux subordonnés. Vorländer cite en effet des textes où Ishtar, Amurru, Ashur, Adad, Marduk, Shamash, et même une fois Enlil, sont expressément désignés comme dieux personnels. En supposant même que certains textes puissent donner lieu à des interprétations divergentes, il se dégage de l'ensemble une conclusion importante, à savoir que les dieux personnels constituent moins une espèce de dieux parmi d'autres qu'une modalité de relation ou un rôle susceptible d'être rempli par tel ou tel dieu, qu'il soit majeur ou mineur.

3. Les principales expressions pour désigner le dieu personnel dans l'ancien Orient sont les suivantes :

a. Mon (ton, etc.) Dieu (Mésopotamie, Asie mineure, Arabie, Syrie-Palestine).

b. Mon patron (Arabie)

c. Dieu d'un tel NN. (Mésopotamie, Syrie-Palestine).

d. Dieu de l'homme (Mésopotamie).

e. Le dieu (Mésopotamie).

f. Mon Seigneur vu mi Dame (Mésopotamie, Asie mineure, Arabie, Syrie-Palestine).

g. Ma déesse du soleil (Arabie).

h. Dieu de mon père (Mésopotamie).

i. Dieu de la famille (Mésopotamie, Syrie-Palestine).

j. Seigneur de la Maison (Arabie, Syrie-Palestine).

k. Mandah/Mundih (Arabie).

l. Mon créateur (Mésopotamie).

m. Mon père ou ma mère (Mésopotamie).

n. Dieu qui accorde la prospérité (Mésopotamie, Syrie-Palestine). 
o. Gardien de ma prospérité, et de ma vie (Mésopotamie).

p. Le dieu oui se soucie (de moi) (Mésopotamie).

q. Mon berger (Mésopotamie).

r. Dieu gardien (Mésopotamie).

s. Dieu de ma tête (ou de la tête de NN (Mésopotamie, Asie mineure, Syrie-Palestine).

t. Miséricordieux et Défenseur (Mésopotamie).

u. Lama et Udug (Mésopotamie).

v. Shedu et Lamassu (Mésopotamie, Syrie-Palestine) que Vorländer interprète comme équivalent aux Pénates des latins.

4. Chaque homme, et aussi le roi, a un dieu personnel ou plusieurs. Dans le cas du roi la distinction entre dieux personnels et dieux de l'État est très fluente.

5. Dans le nom théophore d'un individu, l'indicatif divin peut, faire allusion au dieu personnel soit du porteur soit du donneur du nom. Le dieu personnel peut d'ailleurs être désigné soit par un nom propre soit par sa fonction à l'égard d'un individu.

6. Le dieu personnel peut être honoré soit dans les temples publics soit dans des sanctuaires privés. La bienveillance du dieu dépend de la pratique du culte.

7. En temps normal le dieu personnel habite en l'homme, se tient à son côté, et exerce envers son protégé les trois fonctions suivantes :

7.1. Comme garant de sa prospérité 9 accorde à l'homme la santé, le succès, l'harmonie avec l'entourage et la faveur de ses supérieurs. L'homme lui doit la vie depuis sa naissance. Pour expliquer ce point, ajoutons une remarque qui n'est pas dans Vorländer: d'après une croyance à peu près universelle, les dieux ou les ancêtres contribuent à la génération humaine en intervenant dans le sein maternel. Ainsi dans la croyance chrétienne, le corps vient des parents mais l'âme est créée directement par Dieu. Les sémites pensaient qu'un dieu avait pétri 
l'embryon (comme avec de l'argile) ou l'avait tissé dans le sein maternel, en avait assemblé les éléments, puis lui avait donné le souffle et l'avait fait sortir du sein (Voir Job 10, 8-9 ; Il Mac. 7,22-23). Ce pétrissage divin s'ajoute à l'action de la semence paternelle (Sap. 7, 1-2). C'est donc en vertu d'une théorie physiologique de la gestation qu'un dieu est appelé "mon père" ou "mon créateur". La fonction divine de fécondité et de prospérité assure en outre au roi la prolongation de son règne et la succession sur le trône.

7.2. Le dieu personnel est le défenseur de l'homme contre les ennemis qui menacent sa vie, non seulement ennemis politiques et militaires mais sorciers et démons.

7.3. Le dieu personnel sert de médiateur ou d'intercesseur de l'homme auprès des autres dieux. En Mésopotamie, cette fonction apparaît sur les cylindres de victoire sous forme d'une "scène d'introduction" (le protecteur présentant son client au supérieur).

8. Les causes et les conséquences de l'éloignement du dieu personnel sont mentionnées fréquemment dans les textes mésopotamiens :

8.1. Si le dieu personnel abandonne l'homme, alors les sorciers, les démons et autres forces mauvaises ont pouvoir sur lui. Ces puissances hostiles provoquent l'échec, la maladie et le sentiment d'être devenu étranger à son entourage ("Entfremdung", dit Vorländer). En même temps, ses prières ne sont plus entendues et les oracles deviennent néfastes.

8.2. Les causes de l'éloignement du dieu personnel se trouvent dans les péchés de l'homme, qui suscitent la colère du dieu personnel et des autres dieux. Certains textes affirment que les sorciers peuvent directement provoquer l'éloignement du dieu personnel.

8.3. Le retour du dieu personnel s'effectue par l'accord de son pardon, l'expulsion des démons, la purification et l'absolution du péché. 
Telles sont les premières conclusions de Vorländer. Il apparaît que les dieux personnels sont moins une espèce de divinités parmi d'autres qu'une façon de concevoir le mode de relation de l'homme à l'une ou l'autre divinité. L'importance psychologique d'un tel mode de relation devient particulièrement sensible lorsque le dieu s'éloigne, que l'individu est malade, en proie à un sentiment d'étrangeté et d'hostilité de la part de son entourage. Voici quelques textes typiques :

Ma ville me voit environné de ténèbres comme un ennemi. Mon ami est devenu mon ennemi,

Mes compagnons comme de mauvais démons.

Mon esclave me renie ouvertement dans l'assemblée" (p. 97).

Ou encore, le malade s'adressant à la sorcière dont il est victime, déclare :

"Tu m'as séparé de mon dieu et de ma déesse.

Tu m'as séparé de mon ami, de mon amie, de mon frère, de ma sœur, de mes compagnons" (p. 98) ;

Le parallélisme est saisissant. On ne saurait rendre avec plus d'intensité le sentiment d'étrangeté d'un "Moi" dépossédé de lui-même par l'abandon de son dieu, impuissant à communiquer avec son entourage. Rien ne fait mieux comprendre l'importance que pouvait avoir dans la piété populaire et dans la vie quotidienne cette dévotion au "dieu de ma vie, dieu de mon salut". La maladie et la détresse s'expliquent par l'éloignement du dieu abandonnant son protégé. D'où les expressions "celui qui n'a pas de dieu", "celui qui est sans dieu", pour celui-là c'est le malheur, la détresse, l'isolement, la crainte au milieu d'ennemis insaisissables, le sentiment d'être incompris dans une société de menteurs. Son dieu n'a plus souci de lui. 
Dans tout ce qui précède le lecteur aura déjà pu reconnaître de nombreux traits communs avec la Bible. Voici comment Vorländer récapitule ses conclusions à propos de l'ancien Testament 8 .

1. À côté du culte officiel de Yahweh comme affaire collective du peuple et de l'État, 9 y avait aussi en Israël une piété privée, chaque individu (incluant sa famille) honorait son dieu personnel, dont à attendait d'une manière particulière soin et protection. La fonction de dieu personnel pouvait être remplie aussi bien par Yahweh que par d'autres divinités (Elim ou Bahal). Ces cultes se sont poursuivis pendant toute la période royale jusqu'à l'exil.

2. Le dieu personnel est désigné de la manière suivante

a. Mon (ton-, etc.) Dieu (ex. I Sam. 30, 6 ; Ps. 22,2).

b. Dieu de mon père (ex. Gen 31,5 ; I Chr. 28,9).

c. Dieu d'un tel (ex. Gen 31,53 ; 2 Chr. 32,7).

d. Mon berger (ex. Gen. 38,15; Ps. 23,1).

e. Mon Seigneur (ex. Ps. 16,2...).

f. Dieu de mon salut (ex. Ps. 18,47); le salut de ma face (Ps. 42,7).

g. Dieu de ma vie (Ps. 42,9).

h. Shaddaj, dans Job et le Code sacerdotal (cf. Gen 17,1), que Vorländer interprète d'après l'accadien "Shedu" qui aurait désigné les Pénates ou les Mânes.

3. Le culte du dieu personnel est célébré soit dans des lieux de culte privés (cf. Jug. 17 sq.), soit dans des sanctuaires publics (cf. I Sam. I, 3 sq.). Les images divines, Ephod et Teraphim, jouent un rôle dans le culte privé.

4. Les noms de personne peuvent faire allusion au dieu personnel du porteur ou du donneur du nom.

8 Op. cit., pp. 302-204. 
5.1. Le dieu personnel crée l'homme (Ps. 22, 10 sq. : "Tu m'as tiré du sein maternel". Même remarque que précédemment sur la physiothéologie de la génération humaine). Lie dieu se tient au côté de son protégé, lui assurant la prospérité, le succès, la nourriture et le vêtement, aussi bien que la faveur des puissants. Comme paradigmes du genre on peut citer les histoires de Jacob, de Joseph et l'ascension royale de David. Les récits montrent comment le dieu gardien assurait le succès de son protégé en dépit des embûches et des adversités.

5.2. La deuxième fonction du dieu personnel, celle de défenseur contre les forces hostiles, s'exprime en particulier dans les "Prières au dieu personnel" que sont les Psaumes $37 ; 13 ; 16$; 18 ; 22 ; 23 ; 27 ; 28 ; 31 ; 42/43 ; 59 ; 63 ; 69 ; 8691 ; 140 ; 142. Sont ici représentés comme ennemis les sorciers et démons qui menacent la vie de l'homme et qui exercent sur lui leur pouvoir par la maladie et la détresse.

5.3. Le troisième fonction, celle de médiateur ou d'intercesseur auprès des autres dieux, est absente de l'ancien Testament.

6. Les conséquences de l'éloignement du dieu personnel consistent en ceci que l'homme devient la proie des sorciers et des puissances hostiles, est affligé de maladie et de détresse (Ps. 13 ; 2227 ; 42/43). Le dieu s'écarte de son compagnon humain (Ps. 22, 7 sq. 27, 10). Les prières pour le retour du dieu personnel vont la main dans la main avec la prière pour l'annihilation des ennemis (Ps. 3,8; 31,18) et la délivrance hors de leur pouvoir (Ps. 22, 21 sq. ; 140, 5 sq.).

7. La famille de David occupe une position privilégiée dans la religion d'Israël, en tant qu'elle honore Yahweh comme son dieu personnel. La relation personnelle étroite entre Yahweh et la maison de David apparaît dans le noyau primitif de la prophétie de Nathan (2 Sam. 7, 11 b), dans les déclarations sur la relation père-fils (2 Sam. 7, 14 ; Ps. 2,7 ; 89,27) aussi bien que dans les désignations typiques du dieu 
personnel que l'on trouve dans la bouche des davidides et de leur entourage. La double fonction de Yahweh comme dieu de l'État et dieu personnel de la dynastie davidique trouve son écho dans le caractère du temple de Jérusalem qui servait à la fois de sanctuaire royal et de temple national.

8. Le "dieu des Pères" honoré par les Patriarches ne relève pas d'un type particulier de religion mais représente seulement une manifestation du dieu personnel. Cela résulte d'une analyse de la terminologie aussi bien que des récits de la Genèse. Des divinités de ce genre ont existé dans l'ancien Orient aussi bien chez les nomades que chez les sédentaires. En s'appuyant sur la comparaison entre les deux parties de son travail, Vorländer conclut que les dieux des Pères ne devaient pas être des divinités anonymes ou subordonnées, sans résidence locale (le fait que le dieu accompagne son protégé nomade n'exclut pas qu'il puisse avoir son sanctuaire). Des dieux de sanctuaire, comme Bethel (Gen 28), sont d'ailleurs nommément assignés comme dieux des Pères.

9. Le Code sacerdotal et le livre de Job utilisent pour désigner le dieu personnel des Pères le terme "El Shaddaj", qui pourrait dériver de l'accadien "Shedu".

10. À l'époque post-exilique la représentation du dieu personnel est transférée dans la relation de Yahweh au peuple d'Israël. Les désignations typiques du dieu personnel : "Mon Dieu", "Dieu d'un tel", "Dieu de mon père", "mon créateur", sont maintenant utilisées par Israël dans son rapport à Yahweh. Témoins et inspirateurs de cette transposition, les oracles du second Isaïe s'adressent à Israël comme à une seule personne à qui le prophète promet -la protection et le secours de son dieu personnel. En même temps, les prières originellement individuelles des Psaumes (voir ci-dessus) sont ré-interprétées comme prières du Peuple. 
11. Vorländer conclut en soulignant la continuité entre la religion hébraïque et les traditions de l'ancien Orient dans laquelle elle s'insère.

Cet ensemble impressionnant éclaire d'un jour nouveau bien des pages de la Bible. Sans doute il appartient au génie des prophètes écrivains et des scribes d'Israël d'avoir su exploiter les virtualités de la tradition antérieure, mais la théologie suméro-babylonienne du dieu propre, dieu de tel homme ou de la tête d'un tel, nous aide à mieux comprendre comment la religion prophétique, sacerdotale et royale pouvait correspondre à quelque chose de très profond dans la religion des gens ordinaires, quelque chose venu du fond des âges et qui, pour les petits gens, demeurait confusément vital. Dhorme ouvre son chapitre sur "les noms divins" par une remarque philologique importante : :'De même, écrit-il, que nous avons commencé par étudier les formules "mon maître", "mon seigneur", "mon roi", pour aboutir à l'idée du Maître, du Seigneur, du Roi par excellence, nous commencerons par "mon dieu" pour arriver à Dieu. Le procédé peut paraître illogique, car on voudrait connaître la signification de "dieu" avant celle de "mon dieu". Mais nous avons vu que les noms de parenté ou de domination apparaissaient généralement avec le possessif de la première personne du singulier dans l'onomastique. L'homme dit instinctivement "mon père" ou "mon maître" avant d'analyser l'idée de père ou de maître. C'est la grammaire qui isole les mots de leur détermination naturelle. L'enfant arabe ou hébreu, qui crie "ummi" ou "immi", "ma mère", ne songe point à isoler "umm" ou "imm". Et de même l'invocation "mon dieu" est plus spontanée, plus fréquente aussi que celle de "Dieu" ! Ce qui nous intéresse dans l'onomastique des Hébreux, c'est de voir "Eli", "mon dieu" remplacer "mon père" et les autres formules de Parenté, "mon maître" et les autres formules de soumission. De la sorte nous verrons comment le dieu de la tribu est envisagé dans ces noms qui gardent le dépôt des plus anciennes idées religieuses" (E. Dhorme, La religion des Hébreux nomades, 1937, eh. XX, pp. 333-334). 
Pour comprendre le rapport entre le Moi et le dieu, rien n'est plus éclairant que les textes décrivant une situation de détresse. Le mal sous sa double forme physique et morale est tout ensemble le signe et l'effet d'un éloignement du dieu personnel. En 1954 Samuel N. Kramer avait découvert, en recollant de vieilles tablettes, ce qu'il appelle le premier $\mathrm{Job}^{9}$. Ce titre est malheureusement erroné car le Job biblique proteste au contraire contre les anciennes traditions de la justice immanente; il tente de dissocier le complexe "faute-et-malheur". Quoi qu'il en soit, le texte sumérien nous fait bien sentir le désespoir du suppliant malade :

"Mon dieu, le jour brille lumineux sur la terre ;

Pour moi le jour est noir.

$\cdots$

Les larmes, la tristesse, l'angoisse et le désespoir se sont logés au fond de moi.

...

Le mauvais sort me tient en sa main, emporte mon souffle-devie,

La fièvre maligne baigne mon corps...

Mon dieu, ô Toi le père qui m'as engendré,

Relève mon visage.

$\cdots$

Combien de temps me négligeras-tu ?

me laisseras-tu sans protection?

Combien de temps me laisseras-tu sans soutien ?

On retrouve le même accent, de façon plus poignante encore, dans le Psaume 22 de la Bible :

2. Mon dieu, mon dieu, pourquoi m'as-tu abandonné ? Tu es loin de mon salut, du rugissement de mes paroles.

9 S. N. Kramer, L'Histoire commence à Sumer, Arthaud, Paris, 1957, pp. 157 sq. 
3. Mon dieu, j'appelle de jour, et tu ne réponds pas ; Même de nuit, et tu ne fais pas attention à moi.

7. Et moi, je suis un ver et non un homme, Opprobre des hommes et méprisé du peuple.

8. Tous ceux qui me voient se moquent de moi, Ils grimacent des lèvres, ils hochent la tête

9. $\quad$ "Il s'en remet à Yahwet : qu'il le délivre Qu'il le sauve, puisqu'il l'aime ${ }^{10}$. C'est toi qui m'as tiré du ventre, Qui m'as confié aux mamelles de ma mère, Sur toi je fus jeté au sortir du sein, Dès le ventre de ma mère, tu fus mon dieu.

12. Ne reste pas loin de moi, car la détresse est proche, Et il n'y a personne pour m'aider.

13. De nombreux taurillons m'entourent, Des taureaux de Basan me cernent,

14. Ils ouvrent leur gueule contre moi, Tel le lion qui déchire et rugit.

15. Je suis comme de l'eau qui s'écoule Et tous mes os se disloquent. Mon coeur est comme de la cire, Il fond au milieu de mes entrailles.

16. Mon palais est desséché comme un tesson, Et la langue est collée à mon gosier.

10 Podechard, Le Psautier, Faculté catholique de Lyon, 1949, 1, p. 107. 
On va me déposer dans la poussière de la mort.

17. Une meute de chiens m'entoure, Une bande de malfaisants m'encercle, Ils ont endolori mes mains et mes pieds

18. Ils comptent tous mes os.

Eux, ils me regardent et me voient.

Ils tirent au sort mon vêtement.

20. Et toi, Yahweh, ne reste pas au loin, O ma Force, hâte-toi de me secourir.

21 Préserve mon âme de l'épée, Mon unique de la patte du chien.

22. Sauve-moi de la gueule du lion Et ma pauvre personne des cornes des buffles

J'ai suivi la traduction de Dhorme ${ }^{11}$ sauf pour $3 b$ où j'adopte la lecture de Podechard 12 appuyée sur d'anciennes versions. Le suppliant se plaint d'avoir été abandonné par son dieu (2-3). Le peuple ne peut voir dans sa déchéance qu'un signe de l'abandon du dieu suivant les traditions admises, et c'est pourquoi les gens se moquent de lui (79). Le suppliant donne à son dieu des raisons de ne pas l'abandonner, puisque, d'après la physio-théologie admise, c'est ce dieu qui l'a fait naître (10-11). Plusieurs commentateurs (dont Podechard) voient dans le suppliant un prisonnier, mais c'est là pure spéculation. On ne voit pas, dans ce cas, ce que viendraient faire tous ces animaux (13-14 et 21-22) qui semblent tout droit sortis de la démonologie babylonienne.

11 La Bible, Gallimard, 1959, pp. 931-934 (cd. de La Pléiade), Psaume XXII a (il faudrait noter XXII b à partir du verset 23).

12 Podechard, Le Psautier, Faculté catholique de Lyon, 1949, 1, p. 107. 
Mowinkel 13 et Vorländer 14 voient dans ces bêtes malfaisantes des êtres infernaux. En effet, suivant le traité pénitentiel Shurpu : "La où gît la colère des dieux, les démons se précipitent à grands cris" $15 \mathrm{Si}$ quelqu'un est malade c'est qu'un de ces démons "a mis sa tête dans la tête du patient, sa main dans sa main, son pied dans son pied" 16 suivant une croyance que l'on retrouve aussi en Afrique, bien qu'elle y soit utilisée diversement. Dans cette perspective on comprend que les monstres infernaux ont endolori ses mains et ses pieds (17), et comptent tous ses os (18), puisqu'ils s'infiltrent en eux comme des miasmes. Le patient a la fièvre, sa langue est desséchée (16) et il craint de mourir, d'être déposé dans la poussière de la mort (16 b). Ses ennemis invisibles l'observent (18 b), et, sûrs du succès de leur entreprise, ils se partagent déjà ses dépouilles, comme des soldats tirant au sort les vêtements du vaincu (19). Enfin on notera le parallélisme : "Mon âme... Mon unique ... (21), je n'ai qu'une vie, car, suivant la tradition babylonienne (différente en cela d'autres traditions orientales, africaines etc.), la Demeure des morts est sans retour.

On aura remarqué que j'ai sauté, dans le relevé du Psaume, les versets 4 à 6. Ces versets paraissent une addition ultérieure, post-exilique, introduisant une nouvelle interprétation du Psaume. Lisons-les

4. Et toi qui résides dans le Temple

Vers toi vont les louanges d'Israël

5. En toi nos Pères ont eu confiance, Ils ont eu confiance, et tu les as délivrés.

6. Ils ont crié vers toi et ont été sauvés

En toi, ils ont eu confiance et ils n'ont pas été confondus !

13 Mowinckel, Psalmen-Studien, Kristiana 1921-1924, Il, p. 73 sq.

14 Mein Gott, pp. 273 sq.

15 Bottéro, op. cit., 1952, p. 94.

16 Bottéro, op. cit., 1952, p. 94. 
On remarquera que ce passage interrompt la suite des idées entre 3 et 7. En outre, le style change brusquement ; on passe à la première personne du pluriel : "nos Pères". C'est le Peuple d'Israël qui parle. Nous avons ici un cliché de doctrine sacerdotale, qui, se référant au Temple, répète à satiété : Confiance ! Confiance ! Pour la génération d'après l'exil, il était choquant de penser qu'un juif puisse être abandonné de Dieu au point de sombrer dans le désespoir. L'addition sacerdotale corrige (ou même contredit) la plainte angoissée du suppliant. Mais par là elle introduit une nouvelle lecture du Psaume, sa lecture liturgique. Dans l'intitulé du verset I (que je n'ai pas transcrit) on précise "Pour le maître de choeur" le psaume devra être chanté sur l'air "Biche de l'aurore", le psaume étant alors catalogué "psaume de David" pour indiquer qu'il s'agit bien d'un texte canonique adopté par la liturgie officielle. Suivons cette nouvelle lecture : c'est le Peuple d'Israël qui devient le suppliant ; il est le serviteur souffrant, le serviteur de Yahweh (dont parlait le second Isaïe), qui fait appel à son Dieu "personnel" pour sa délivrance. On sait que les rédacteurs chrétiens des Évangiles introduiront à leur tour une troisième lecture, faisant de ce psaume une prophétie du Messie souffrant.

Nous saisissons la sur le vif comment la vieille tradition sumérobabylonienne, avec sa théologie du dieu de la personne et même avec sa démonologie des monstres infernaux, a pu être transposée, réinterprétée dans un esprit nouveau. L'évolution des idées religieuses dans la Bible est bien connue, mais il importait de mettre ici l'accent sur la continuité d'une sensibilité populaire qui sous-tend le développement de la révélation. La conception du mal sous forme persécutive est une donnée très générale dans l'histoire de l'humanité. Le besoin de se poser en victime pour se faire plaindre est un art bien connu. Il serait inexact d'y voir une spécialité judéo-chrétienne, comme certains le prétendent. Ce qui est propre à cette tradition, c'est l'usage de ce thème dans une théologie où la singularité du Moi et l'unicité de Dieu sont étroitement liées. 
Nous pouvons maintenant reprendre notre question initiale qu'estce qu'un Dieu unique ? Nous pensons tous aujourd'hui que, s'il existe un être infiniment parfait, il est nécessairement unique. Mais il y a là une équivoque. L'unité de l'ordre surnaturel peut se concevoir aussi bien dans l'Un ineffable des mystiques que dans l'Unique des prophètes. Les premiers qui ont perçu cette équivoque furent les théologiens arabes Alfarabi, Avicenne, Algazali 17. L'unité de Dieu, expliquentils, peut s'entendre de deux manières. La première manière s'exprime encore aujourd'hui dans l'exclamation arabe : Allah est le plus grand. Qui est comme Dieu ? Dieu ne peut avoir à côté de lui aucun être qui lui soit comparable ; il est sans égal. Au fond, c'est ici la version monothéiste de la vieille idée babylonienne: Marduk l'incomparable, Gilgamesh le héros sans pareil. La seconde manière, explique Alfarabi, vient de ce que l'unité divine n'est pas divisible dans ce qu'Aristote appelait "les parties de la définition". C'est l'idée que reprendra saint Thomas : dans la perfection absolue tous les attributs ne font qu'un ; le justice, la sagesse, l'amour, la puissance... ne désignent qu'une seule et même chose. La distinction des attributs s'abolit dans l'infini. Aucun jugement prédicatif ne peut exprimer adéquatement la simplicité de l'Un. Se pourrait-il alors qu'au moment de penser la perfection infinie, nous ne pensions plus rien ? C'est ce qu'admet le mystique en ajoutant que ce rien est tout. Qu'y a-t-il sur la montagne, demande saint Jean de la Croix ? Todo y Nada. Sur la montagne il n'y a rien que la totale dépossession de soi dans la nuit sonore de l'amour. Cela revient à dire que le sentiment mystique n'est pas autre chose que l'acceptation de nos limites dans le monde tel qu'il est. Saint Thomas estimait pourtant que la causalité créatrice suffit à garantir l'existence d'un Dieu personnel. Mais l'argument théologique de la causalité confond signification et implication, comme l'a montré B. Russell ${ }^{18}$. Les conditions de sens d'une phrase sont en nombre fini ; par contre si l'on ne pouvait concevoir une suite infinie d'implications, la physique mathématique ne se-

17 Voir Harry Wolfson, Studies in the History of Philosophy and Religion, Harvard U.B., Cambridge Mass, 1973, 1, p. 144.

18 B. Russell, The Principles of Mathematics, Allen, Londres, 1903/64, p. 51. 
rait pas possible. Au cours des derniers siècles, la théologie naturelle a perdu peu à peu ses défenseurs. La foi monothéiste ne se distingue de la mystique ou de l'agnosticisme que par l'acceptation d'une autorité, la soumission à une Parole historiquement révélée. Le Dieu vivant est le Dieu d'Abraham et le Dieu des Prophètes. Que signifie cette dualité ? D'où vient que le Dieu vivant soit à la fois "Le Dieu des pères" et "le Dieu des oracles prophétiques" ?

Nous touchons ici un point qui intéresse non seulement l'histoire d'Israël mais la nature des traditions religieuses en général. Lorsqu'on dit que la religion est le domaine du sacré, cela n'est vrai qu'en gros. Les latins, quant à eux, distinguaient les "sacra" et les "auguria" lis ont été en cela perspicaces. Il est vrai que tout ce qui concerne la divination, les oracles, la révélation c'est-à-dire les Signes émanant de l'au-delà s'oppose en principe aux actes du culte sacré qui émanent de nous. Cette opposition distinctive éclaire même le cas, comme celui du sacrifice, où les deux valeurs sacrées et augurales se rejoignent mais sans jamais se confondre. Le sacrifice peut prendre à la fois une valeur d'offrande faite par les hommes, et une valeur divinatoire de signe fait par les dieux (ce que l'on diagnostique d'après l'observation des entrailles, la façon dont la victime est tombée etc...). L'inde ellemême joue encore sur cette opposition lorsqu'elle place dans le sacrifice primordial la source de l'ordre universel car elle utilise alors la double valeur du sacrifice pour opérer, suivant ses habitudes, la fusion des contraires. Ce serait donc une erreur de penser que la religion puisse se réduire à une solidarité sacrée assurée par un circuit de prestations et de contre-prestations entre les dieux et les hommes ou les ascendants et les descendants. Il y a autre chose. Il y a le caractère aléatoire du Signe, l'événement improbable, sans lequel on ne comprendrait rien à ces règles du jeu compliquées qui sont celles de la Coutume. La solidarité inviolable et sacrée ne se referme pas sur soi, car il y a le malheur imprévisible, le Signe venu d'Ailleurs.

C'est cette même dualité que l'on retrouve dans "le -Dieu des pères" et "le Dieu des prophètes". Il est vrai que la divination inspirée ou 
prophétique a fini par supplanter en Israël la divination inductive utilisant les techniques coutumières. Mais qu'en était-il aux origines du mouvement prophétique? Qu'est-ce qui a permis l'essor de ce mouvement ? Il faut relire ici le premier livre de Samuël. Pour comprendre comment le culte de Yahweh, Dieu des ancêtres, a pu devenir hostile au culte des ancêtres, il faut prendre garde que le débat ne porte pas seulement sur l'objet de culte, il porte sur la nature des oracles c'est-àdire de la révélation. Le premier livre de Samuel est très clair sur ce point. On y voit que l'opposition fondamentale entre la fidélité (de David) et l'infidélité (de Saül) se concentre finalement autour d'une alternative centrale : ou bien consulter Yahweh (et c'est ce que David fait constamment avant d'entreprendre quoi que ce soit), ou bien consulter les morts (et c'est ce qui arrive au malheureux Saül chez la pythonisse d'Endor) (I Sam. 28). Dans les deux cas, la consultation divinatoire utilise des techniques coutumières. Mais a faut choisir entre la consultation des morts liée aux cultes locaux ou privés, et la consultation de Yahweh, Dieu national, Dieu personnel de la dynastie davidique.

Il n'empêche que Moïse, en révélant aux hébreux le nom divin, avait pris la précaution de leur dire que Yahweh était le nom du Dieu de leurs pères : "Yahweh, le Dieu de vos pères, le Dieu d'Abraham, le Pieu d'Isaac et le Dieu de Jacob, m'a envoyé vers vous" (Ex. 3, 15). Pour abolir le culte des ancêtres, le mouvement prophétique s'appuiera sur le Dieu des ancêtres.

Les ancêtres sont des créatures. Il n'y a aucune commune mesure entre le créateur et les créatures. Yahweh est un Dieu jaloux. L'adoration n'est due qu'à lui seul. Georges Dumézil 19 a souligné le contraste entre cette formule classificatoire, "Dieu et la créature", et les formules classificatoires des trois fonctions chez les indo-européens (sagesse souveraine, vaillance guerrière, prospérité). Il cite un texte de Jérémie opposant "la voie des nations" à celle de Yahweh

19 G. Dumézil, Mythe et épopée, III, Gallimard, Paris, 1973, p. 359. 
"Ainsi parle Yahweh :

Que le sage ne se glorifie pas dans sa sagesse (1e fonction) Que le vaillant ne se glorifie pas dans sa vaillance (2e fonction)

Que le riche ne se glorifie pas dans sa richesse (3e fonction)

Mais que celui qui se glorifie se glorifie en ceci : avoir l'intelligence et me connaître, car je suis Yahweh qui fait le jugement, la justice et la miséricorde sur la terre ; c'est en cela que je me complais" (Jer. 9, 22-23).

Cependant la remarque de G. Dumézil ne concerne que la première partie du texte. Le Dieu de la révélation prophétique n'est pas seulement le créateur, il est aussi celui qui a élu le peuple d'Israël pour faire alliance avec lui. Le chapitre 9 de Jérémie reproche aux Israëlites d'avoir pratiqué des cultes locaux en apprenant à "connaître les Baals" au lieu d'avoir observé le culte de Yahweh conformément à "la connaissance" de sa Loi. Parce que les Israëlites ont abandonné la Loi de Yahweh ("Torah" verset 12), Yahweh les abandonne à leur malheur. Le chapitre 9 est la version prophétique du thème traditionnel de l'abandon du dieu personnel, comme l'annonce clairement le début de ce chapitre où Yahweh dit :

"Qui me donnera dans le désert un gîte de voyageurs

Pour que j'abandonne mon peuple,

Et que je m'en aille loin d'eux ?

Car ce sont tous des adultères, Une bande de traîtres, ...Et ils ne me connaissent pas" (Jer. 9, 1-2). 
Entre Dieu et son Peuple il s'agit donc bien d'un rapport "personnel" fondé sur la Torah. Yahweh est "le Dieu de nos pères", et c'est pourquoi les scribes du Code sacerdotal, après l'exil, se sont. complu à recenser les généalogies. En dressant ces listes généalogiques, ils ont repris à leur compte un vieux schème de pensée, le schème. généalogique, qui sert de base aux religions de la Coutume et qu'ont idéalisé toutes les "genèses" mythologiques. Le christianisme a eu, sur ce point, deux attitudes. Dans l'Église des ébionites, qui fut la communauté "primitive" de Jérusalem présidée par Jacques, frère de Jésus, et qui, ensuite, réfugiée à Pella, demeura la communauté présidée par les parents de Jésus (les "desposunoi"), on eut surtout à cœur de donner à Jésus une dynastie davidique en le considérait comme un homme ordinaire (sans pré-existence divine), et l'on sait qu'une tradition judéochrétienne de ce genre sera reprise par Mahomet dans le Coran. Par contre l'Église paulinienne hellénistique a transposé au ciel la généalogie. En proclamant Jésus fils éternel de Dieu, elle s'est détachée de l'Israël selon la chair pour devenir religion de salut, Israël selon l'Esprit. Néanmoins, quelles que soient les hésitations des premières théologies chrétiennes, l'idée fondamentale est toujours la même ; elle s'est conservée en passant de l'ancien Israël au nouveau, puis à l'Islam. Cette idée est que l'unicité divine a une fonction sociale: un seul Dieu, un seul Peuple élu. Un seul sauveur, Jésus-Christ, une seule Église hors de laquelle il n'y a point de salut. Allah seul est Dieu, et Mahomet est son prophète. Israël est un nom de personne devenu le nom d'un peuple. Le peuple élu a été lui-même personnifié suivant la leçon du second Isaïe. La même loi vaut pour la collectivité et l'individu. L'unicité divine et la singularité (individuelle ou collective) du Serviteur de Yahweh se répondent, indissolublement liées dans l'histoire. On ne peut concevoir l'une sans l'autre. L'unicité divine a une fonction sociale. Et c'est pourquoi les mêmes règles d'exégèse s'appliquent aux religions monothéistes comme aux religions indoeuropéennes, africaines ou autres. Si l'on a souvent l'impression du contraire, c'est que l'étude comparée du judaïsme, du christianisme et de l'Islam n'a pas encore retenu toute l'attention qu'elle mérite. Il est clair pourtant qu'au cours de l'histoire, la fonction sociale exclusive 
exigée par l'unicité divine, s'est prise à son propre jeu. Elle a donné naissance à plusieurs monothéismes incommensurables entre eux. Dieu a eu plusieurs façons de se révéler unique. Elles sont inconciliables, à moins que chacun ne renonce à ce que lui commande sa foi. 
Religions du livre. Religions de la coutume

\section{Chapitre II \\ LE DESTIN ET LES ORACLES *}

Le destin est devenu pour nous un problème psychologique, alors qu'il était pour les anciens philosophes, et surtout les Stoïciens, un problème de physique et de cosmologie. La puissance anonyme qui dirige les événements, ne se reflète plus pour nous dans les constellations célestes, mais dans ce que, par métaphore, nous appelons encore "des constellations familiales". L'étude des névroses et plus encore des psychoses semble imposer l'idée d'un destin familial. Pourquoi "destin" ? Parce que certains malheurs, comme l'ont dit, ne viennent jamais seuls. Il y a des malheurs à répétition, des séries néfastes. L'idée de malchance vient du sentiment que nous avons parfois d'être pris dans une série successive de malheurs qui se répètent. La répétition, l'insistance, la rechute semblent exclure le hasard; le sort s'acharne contre nous ; cet acharnement ressemble à une intention perverse, à une volonté mauvaise qui s'obstine à nous prendre pour victimes.

* Conférence au colloque Szondi à Cerizy-La Salle, 1979, sur la psychologie du destin. 
Nous sommes le jouet des événements. Joués, trompés, floués, nous sommes pris au piège, englués, empêtrés. C'est la déveine, la guigné, la poisse. Un malheur ne vient jamais seul. Jamais deux sans trois. Un symptôme ne vient jamais seul. Les symptômes se déplacent. Ils ne se déplacent pas seulement dans le cours d'une vie mais dans celui d'une généalogie. Lorsque nous parlons de destin familial, nous voulons dire qu'il faut prendre en compte au moins trois générations pour comprendre que psychose, perversion ou névrose puissent être les versions d'un problème qui se joue "entre" les individus, dans les interstices quotidiens du tissu social, de sorte que chaque version s'analyse comme une réponse à l'autre sans qu'il y ait nulle part une version absolument originale de la fatalité. Ce genre de situations où la série des événements biographiques se combine avec une constellation de rapports familiaux, ne peut être expliqué seulement par les antécédents héréditaires, puisque la série chronologique n'agit qu'à travers une constellation psychologiquement présente. Ce que nous pourrions appeler "destin" serait donc la répétition d'une figure complexe où s'enchevêtrent deux sortes de rapports, diachroniques et synchroniques, figure complexe pareille à une statue brisée dont chacun ne détiendrait par devers soi qu'un fragment indéchiffrable.

D'où nous vient ce mot de "destin" ? On peut lui assigner deux sources différentes : la spéculation métaphysique et la pratique divinatoire. C'est pour expliquer le succès présumé des pratiques de divination qu'à l'époque hellénistique on a forgé la notion spéculative d'une "heimarménè" c'est-à-dire d'une puissance hermétique soumettant l'histoire des hommes aux nécessités du Cosmos. Les Anciens percevaient un contraste entre la physique terrestre et la physique céleste. Le monde sub-lunaire était soumis au changement, au désordre ; dans le monde céleste régnait la régularité immuable des astres. L'astrologie n'était qu'une application de cette doctrine physique ; il s'agissait de discerner sous la contingence apparente des événements terrestres les nécessités de l'ordre céleste. C'est ainsi que l'idée de destin fut associée aux idées de prévision et de nécessité. 
Or, chose curieuse, lorsqu'on examine les croyances religieuses impliquées dans les pratiques divinatoires, on ne retrouve plus ces deux idées-maîtresses de nécessité et de prévision. Ces deux idées ne sont peut-être pas tout à fait exclues ; on peut toujours prétendre que si les devins avaient raisonné correctement, ils auraient adopté la physique des Stoïciens. Mais ce n'est là qu'une rationalisation secondaire. La croyance religieuse voyait les choses autrement. Pour elle, le destin n'était pas la nécessité ; à n'était pas un déterminisme. Du moins, ce n'était pas ce genre de rationalisation qui venait au premier plan. Il s'agissait d'autre chose. De quoi ? C'est précisément ce que nous allons chercher. Quels genres de croyances ou de représentations soustendent la divination ? Bien entendu, dans une matière aussi vaste, on ne peut attendre de réponse valable pour tous les cas. Quelques exemples suffiront pour remettre en cause nos idées habituelles. J'appuierai mes réflexions en particulier sur l'excellent ouvrage collectif édité par J.P. Vernant sous le titre Divination et rationalité ${ }^{20}$. Il y a dans la divination une rationalité, mais elle n'est peut-être pas où nous l'attendions.

Mon exposé comprendra trois parties : je présenterai d'abord quelques notions générales sur la divination et le destin. Ensuite, je dirai un mot de certaines techniques divinatoires. Enfin je m'attarderai sur l'interprétation des oracles, car c'est la logique même de l'interprétation qui nous fera comprendre la signification religieuse du destin.

\section{1}

Qu'est-ce que la divination ? La divination est l'art ou le pouvoir de révéler ce qui est caché, et d'où dépendent la vie et la mort, le bonheur ou le malheur, le salut ou la perdition. La divination est le moyen de découvrir ce qui est caché. Ce moyen peut être soit un art que l'on apprend, soit un don exceptionnel, un pouvoir que l'on a reçu. Il est im-

20 J. P. Vernant, (ed), Divination et rationalité, Seuil, Paris, 1974 (note D.R.). 
portant, comme nous allons voir, de ne pas confondre ces deux choses.

Il existe en effet deux sortes de divinations : la divination inductive et la divination inspirée. La divination inductive ou raisonnée est un art utilisant des techniques plus ou moins complexes qu'il faut apprendre. Pour la caractériser nous l'appellerons l'art divinatoire ou la mantique. Par contre, la divination inspirée est un don, un pouvoir surnaturel, dont la forme principale, la plus célèbre, est le prophétisme. Nos habitudes chrétiennes nous inclinent à opposer fortement prophètes et devins. Pourtant remarquez bien que les uns et les autres sont au service d'une même chose : l'oracle. C'est l'oracle qui s'exprime par des voies différentes, signes extérieurs ou inspiration intérieure. En outre, il existe de nombreuses formes mixtes où se combinent l'art et la voyance; il existe même des techniques diverses pour provoquer l'inspiration. Ce serait une erreur historique d'imaginer que les deux sortes de divinations sont toujours exclusives l'une de l'autre. Mais elles peuvent tendre à le devenir. Suivant que l'on privilégie la divination raisonnée ou la divination inspirée, on peut aboutir à des types de religion bien différents. Lorsque Platon par exemple rapproche la "mantique" de la "mania" ("mantikè-manikè"), en distinguant quatre sorte de folies (mantique, initiatique, poétique, érotique), il opte pour une religion intérieure, mystique ${ }^{21}$. Par contre, lorsque Jésus annonce les signes avant-coureurs du Royaume eschatologique (miracles, expulsions de démons), il se pose, comme jadis Ezechiel, en prophète inspiré qui est lui-même un signe, d'où naît une religion de la foi (ce qui est tout autre chose qu'une religion fondée sur la seule expérience mystique, intérieure, directe). Divers systèmes religieux peuvent se distinguer d'après les méthodes de révélation qu'ils privilégient. Reste que, dans tous les cas, la divination, inductive ou inspirée, concerne la connaissance. Quel est donc ce secret du destin ou de la destinée que l'on cherche à connaître ?

21 Platon, Phèdre 244. Le prophète au sens grec, est l'interprète (herméneute) des paroles inspirées (cf. Timée 71e et 72b). 
Divers indices nous montrent qu'il s'agit d'autre chose que d'une nécessité. D'abord on choisit les présages. On peut les accepter ou les refuser. Les romains avaient même un rituel spécial pour reconnaître officiellement le genre de présage que l'on sollicitait. En outre, si les présages sont négatifs, l'artisan-devin peut recommencer la consultation à plusieurs reprises, et l'on peut prier pour que les présages deviennent positifs. Ce serait là, une tricherie, si ce que l'on cherche à connaître avait les caractères d'une loi naturelle ou d'une nécessité générale. C'est au contraire un acte de piété si ce qui doit arriver est une chose conforme à la volonté des dieux ou des ancêtres. Les rites de consultation peuvent être combinés avec des rites d'influence ou de prière, dès lors que le destin est une volonté singulière. Nous avons là une première caractéristique : le destin est singulier, il n'est pas général. Le destin est singulier comme la liberté ; il n'est pas général comme une loi naturelle. Seul un être libre peut avoir un destin, puisque le destin est une forme aliénée de la liberté, une liberté qui se cherche dans la volonté de l'autre.

Une seconde caractéristique se trouve dans la forme de l'oracle. La décision de l'oracle a la forme d'une sentence. Il a la même forme qu'une sentence judiciaire. L'exemple le plus fameux se trouve dans le mot biblique torah, pluriel toroth, qui vient d'une racine iara, "jeter", sans doute par allusion à des pratiques divinatoires, et que l'on peut traduire indifféremment par "oracle" ou par "loi". Les deux traductions sont traditionnelles. Pour désigner l'ancien Testament, les pères de l'Église disent indifféremment : les lois de Dieu ou les oracles de Dieu. Puisque l'oracle exprime un jugement de Dieu, il peut concerner le passé ou le présent aussi bien que l'avenir. Il peut servir à reconnaître un coupable. Il ne s'agit donc pas toujours de prévision. On consulte l'oracle comme l'on se présente au tribunal, pour obtenir une décision, se soumettre au jugement des ancêtres ou des dieux. L'ordalie et l'oracle sont deux espèces du même genre. Même lorsqu'il s'agit d'obtenir une prévision, cette prévision est donnée en forme de sentence, et de sentence souvent énigmatique, requérant une interpréta- 
tion. Parlant des Babyloniens, Jean Bottéro 22 nous dit que l'avenir dont il s'agit dans la divination, est un avenir judiciaire. Il montre, et nous y reviendrons, que la divination et la jurisprudence sont inséparables, elles ont la même forme. Il arrive aussi que la sentence divinatoire ressemble à une ordonnance médicale : c'est une sorte de prescription à laquelle il est bon de se conformer si l'on ne veut pas avoir d'ennui. Divination, jurisprudence et médecine (au sens plus ou moins magique du terme) se prononcent en paroles efficaces, douées d'autorité.

Quel est donc l'ordre des choses qu'elles annoncent et auquel il convient de se conformer ? C'est un ordre du monde sans doute, mais un ordre qui s'impose avec l'autorité de ce qui doit être, et que l'on doit respecter pour ne pas être dans son tort. C'est un ordre du monde compris comme un ordre de justice. C'est ainsi que les pré-socratiques distinguaient deux sortes de justices : la dikè et la thémis. La thémis est la justice des hommes, celle qui régit les affaires courantes de la cité, c'est une justice humaine, plus ou moins autonome. La dikè, au contraire, est une justice hétéronome ; c'est l'ordre établi par les dieux ou les ancêtres c'est-à-dire par une volonté qui ne fait pas partie de l'administration humaine et qui inscrit ses décrets directement dans les événements. De même, dans la Bible, le prophète annonce la justice de Dieu. Or les justices de Dieu sont des événements, ce sont les victoires de Yahweh contre ses ennemis, les hauts faits qui démontrent sa puissance. La justice divine est une démonstration de force. La même idée se retrouve en Afrique : pour qu'un oracle soit véridique, il faut que sa force soit plus grande que les forces adverses qui pourraient en fausser le mécanisme et lui faire rendre une sentence trompeuse.

L'ordre du monde est un ordre de justice c'est-à-dire un ordre de domination, de hiérarchie entre les forces terrestres et supra-terrestres.

22 J. Bottéro, Symptômes, signes, écritures en Mésopotamie ancienne, (in D.R., pp. 70-196). 
Vous savez que dans l'antiquité les devins les plus célèbres furent des babyloniens, à tel point que l'art divinatoire fut souvent appelé "l'art des chaldéens". Or les textes cités par Jean Bottéro illustrent clairement le caractère judiciaire de la divination. Par exemple : "Le devin ayant pris place devant Shamash et Addad, sur la chaire du juge, rendra un jugement exact et véridique ${ }^{23}$. Ou encore : "Shamash, Seigneur et Maître du jugement divinatoire, Addad, Seigneur et Maître de la prière consécratoire et de l'examen divinatoire, vous qui trônez sur un siège d'or et mangez à une table de lapis-lazuli, descendez, prenez place sur la chaire et rendez la sentence oraculaire" 24 . Nous verrons plus tard quelle est la fonction de cette prière où l'on demande aux dieux de venir assister le devin. Il est clair, en tous cas, que la justice de l'oracle ressemble à la justice d'un tribunal, bien qu'elle appartienne aux dieux. Il existe en Grèce un mot qui fait bien sentir cette connexion entre le destin et la justice, c'est le mot par lequel on désigne le destin : la Moïra, la Part. Le destin est une sorte de justice distributive qui attribue à chacun sa part de bonheur ou de malheur, la part qui lui revient. À Rome, pour prendre d'autres exemples, que déclare l'oracle ? Il déclare ce qui est fas ou nefas, faste ou néfaste, permis ou interdit. Si les hommes consultent l'oracle, c'est donc pour obtenir de lui la permission de faire ce qu'ils n'osent pas se permettre à eux-mêmes. C'est une angoisse de culpabilité que l'on trouve dans les croyances religieuses à la divination. Nous sommes loin ici des spéculations hellénistiques sur les futurs contingents et les nécessités logiques. Il ne s'agit pas du nécessaire et du contingent, mais du permis ou de l'interdit. Il s'agit de savoir ce que l'on peut se permettre ou non. L'homme est coupable de démesure lorsqu'il s'élève au-dessus de sa condition, lorsqu'il ne respecte pas l'ordre des dominances, des puissances qui régissent les événements. Remarquez bien, et nous comprendrons mieux pourquoi par la suite, que les mots latins fas et nefas, comme le mot grec moïra, désignent quelque chose d'impersonnel : c'est dans la réalité même que se trouve une puissance permissive ou

23 Cité dans D.R., p. 140.

24 Ibid, p. 141. 
interdictrice, une puissance qui distribue à chacun sa part. Nous comprendrons mieux les rapports entre la volonté divine et la puissance impersonnelle du destin lorsque nous analyserons la logique interne de l'interprétation des oracles. En tous cas, ce qui est en cause dans la divination, c'est le fait qu'on ne se donne pas le droit d'entreprendre sans consulter les dieux; c'est un droit que l'on ne se donne pas, un droit hétéronome, une issue à la culpabilité.

Pour illustrer l'idée romaine du faste et du néfaste, je citerai une page de Tite-Live (1, 18, 5 -20). Il s'agit de l'intronisation du roi juste, Numa Pompilius. Vous y remarquerez l'importance des personnages assis comme dans le scénario babylonien. Vous y remarquerez surtout comment le Sénat, l'État romain, après avoir décidé ce qui devait être, ne se donne pas le droit de passer à l'action sans avoir consulté les dieux. Tite-Live écrit ceci :

"Tous les Patres, à l'unanimité, décidèrent que la royauté devait être donnée à Numa Pompilius. On le fit venir, et de même que Romulus avait pris les augures pour devenir roi et fonder la ville, à ordonna que, à son sujet aussi, les dieux fussent consultés. Alors il fut conduit par l'augure à la citadelle. Là 0 s'assit sur une pierre, face au midi. L'augure, la tête voilée, s'assit à sa gauche, tenant dans sa main droite un bâton recourbé et sans nœud qu'on appela lituus. De là, ayant embrassé du regard la ville et le territoire, il adressa une prière aux dieux et délimita les régions dans le ciel en traçant une ligne d'est en ouest (suivant la marche du soleil), et déclara que les régions de droite étaient au sud, les régions de gauche au nord. Devant lui (donc vers l'orient), aussi loin que portait sa vue, il se fixa un repère. Alors faisant passer le lituus dans sa main gauche et posant la droite sur la tête de Numa, il fit cette prière : :"Jupiter Pater, s'il est fas que Numa Pompilius ici présent, dont je tiens la tête, soit roi de Rome, toi déclare-le nous par des signes précis (certa signa) entre les limites que j'ai faites." Il énuméra ensuite les auspicia qu'il voulait voir envoyer. Quand ils eurent été envoyés, Numa fut proclamé roi et descendit du templum. 
Nous retrouverons plus loin la technique divinatoire qui consiste a délimiter des régions dans lesquelles viennent s'inscrire les signes choisis (certa, bien délimités). Mais le plus remarquable est l'atmosphère religieuse de la scène : il y a des droits que l'État même ne peut se donner sans la permission des dieux. Numa représente la souveraineté des Lois (type : Mitra), Romulus la souveraineté de la puissance indomptée (type : Varuna). La justice des Lois ne peut recevoir son "plein" de force (c'est l'étymologie d'augur, la force "pleine") sans cette autre justice insondable qui s'inscrit directement dans l'événement comme le droit des forts ${ }^{25}$. Faibles sont les mortels, coupables seraient les faibles qui ne respecteraient pas le droit des dieux.

Le droit de dieux. C'est ce qu'à l'époque hellénistique on ne comprenait plus. Pour faire contraste avec Tite-Live, je vais citer un texte de Porphyre sur la divination. Ce que dit Porphyre est très beau, très élevé, beaucoup plus proche de ce que nous pensons aujourd'hui. Mais nous sommes alors aux antipodes de la pensée archaïque. Dès les premiers mots, nous y trouvons tous les contre-sens que l'on a fait, depuis des siècles, sur les sens religieux de la divination.

Porphyre 26 écrit dans la lettre à Anébon $\S 15$ : "Les devins affirment tous qu'ils obtiennent la prévision de l'avenir grâce aux dieux et aux démons, vu qu'il est impossible que l'avenir soit connu par d'autres que ceux qui en sont les maîtres. Alors est-ce que la divinité s'abaisse jusqu'à un tel degré de servilité devant les hommes qu'il se trouve même des gens qui voient l'avenir dans la farine ?". Et plus

25 Sur l'étymologie et le sens du mot "augur", voir G. Dumézil, Idées romaines, Gallimard Paris, 1969, pp. 79-102. Le védique "ojas" désigne une réserve de force où le héros puise le pouvoir d'accomplir ses exploits. Bien qu'en latin le radical "aug-" évoque l'augmentation (augere), il ne faut pas voir dans "augur", "augustus", un procès mais un état, une perfection, une plénitude de force. "Augur" désigne le plein de force, et secondairement, les signes de cette force (pp. 95-96).

26 Cité d'après J. Carlier, Science divine et raison humaine, in D.R., pp. 252-256 (la lettre à Anébon est connue par l'intermédiaire de Jamblique). 
loin, § 48-49 : "A quoi cela sert-il d'avoir contact avec les puissances supérieures, si c'est pour leur demander si l'on doit se marier ou acheter une propriété ou retrouver un esclave fugitif ou régler une transaction commerciale ? Tout cela ne nous apprend rien sur le bonheur". Comme on voit, ce qui scandalise Porphyre, c'est que les dieux aillent s'enfariner dans les soucis des hommes. La divination a complètement changé de sens : elle n'exalte plus au-dessus des mortels le droit de dieux, elle rabaisse les dieux à servir le souci des hommes. Le contresens est radical : ce n'est plus les dieux qui ont un droit, ce sont les hommes qui ont des soucis. Autrefois, si le fiancé allait consulter, c'est parce que la justice légale du mariage avait besoin de recevoir l'augur, la force pleine de cette autre justice, divine, secrète, qui s'inscrit directement dans la réalisation d'une destinée, et sans laquelle aucun mariage ne pourrait être vraiment "bon". En présence d'une force divine surgissante et sauvage, énigmatique (comme celle qui nous saisit encore au tympan de Moissac), la culpabilité humaine prenait la forme persécutive d'une menace dont le plus fort nous délivre. Alors régnait le droit des dieux. Maintenant la culpabilité s'est faite soucieuse, elle s'est infiltrée dans le souci des hommes, elle n'est plus dans les entrailles des victimes sacrifiées mais dans nos propres entrailles. C'est exactement ce que dit Porphyre. Écoutez : "Mais le philosophe..., celui qui se détache des choses extérieures, nous sommes fondés à affirmer qu'il n'ira pas importuner les démons, et qu'il n'aura pas besoin de devin ni d'entrailles d'animaux. Car les biens qui font l'objet des divinations sont précisément ceux dont il s'est exercé à se détacher. En effet, il ne s'abaisse pas au mariage, et n'a donc pas à importuner le devin à ce sujet; il ne s'abaisse pas à faire commerce ; à ne consulte pas au sujet d'un serviteur, ou de sa réussite sociale, ou de toutes les autres formes de prétention à la gloire qui règnent chez les hommes. Sur ce qu'il recherche, ce n'est pas le devin, ce ne sont pas des entrailles d'animaux qui lui donneront des indications certaines. Seul et par luimême ainsi que nous l'avons dit, 0 s'approchera de Dieu, qui a son siège dans l'intimité de ses propres entrailles, et prendra ainsi des gages de vie éternelle, se rassemblant tout entier là-bas" (De Abstinentia, 
II, 52). "Car, enseigne Porphyre, ce à quoi l'on fait retour, n'est pas autre chose que le soi de l'être" (ibid. 1, 29).

Ce texte remarquable montre comment une expérience mystique, une révélation intérieure, peut prendre la place d'une révélation extérieure. C'est la nature même des auguria ou manifestations divines qui a radicalement changé. Ceux qui aujourd'hui croient pouvoir définir la religion uniquement par "le sacré", parce qu'ils ne perçoivent pas la différence entre les sacra et les auguria, ne peuvent expliquer la mutation du sentiment religieux que nous observons ici. La fonction sociale du sacré s'amenuise dans la mesure même où l'auguration est devenue plus intérieure. Quoi qu'il en soit, entre la religion de Porphyre et celle des anciennes Coutumes s'est creusé un malentendu radical : là où les Anciens voyaient le droit des dieux, la part réservée, le secret qui appartient aux dieux, Porphyre voit le souci des hommes. Il voit la prévision, où était la sentence, le permis et l'interdit, le fas et le nefas. Là où était une culpabilité inassumable, inexprimable autrement que sous la forme extérieure d'une dépendance, Porphyre voit (non sans raison) un intérêt égoïste, un "ordre de la concupiscence", dirait Pascal. Porphyre et les devins ne pouvaient se comprendre. La raison est impuissante là où il n'y a plus de symboles communs. Il y a dans l'histoire des situations incommunicables, comme celles que nous éprouvons dans nos vies sous forme de névroses et de psychoses. Quand la raison commune est "perdue", il n'y rien à expliquer, puisqu'il n'y a plus de jetons communs que nous puissions utiliser pour un calcul raisonnable. Nous sommes mis en demeure d'avoir à créer un nouveau jeu de langage en revenant aux sources poétiques de la raison.

Passant maintenant à la deuxième partie de cet exposé, je voudrais dire quelques mots des techniques divinatoires. 


\section{2}

Dans un livre intitulé Anthropologie et calcul, Philippe Richard et Robert Jaulin ont fait l'analyse mathématique d'une technique divinatoire, la géomancie ${ }^{27}$. Je voudrais vous en donner un aperçu très sommaire. Et voici pourquoi. Je vous ai dit qu'il y avait dans l'art divinatoire une rationalité, mais qu'elle n'était peut-être pas où nous l'attendions. La rationalité se trouve non pas dans la conception du monde, mais dans la structure même de l'appareil divinatoire. Il y a ici une raison qui n'est pas dans ce que l'on dit mais dans ce que l'on montre sans pouvoir le dire. De même que la justice augurale est une justice qui ne réside pas dans les lois écrites, dans les choses dites par le législateur, mais une puissance rectrice des événements qui se cache ou se montre plus qu'elle ne se dit, une puissance qui ajoute aux mots l'auguste plénitude de sa force augurale, ainsi la rationalité des techniques divinatoires est une rationalité qui précède tout ce que l'on peut dire et qui n'appartient à personne sinon à l'appareil oraculaire lui-même. Dans la géomancie, ce sont les pierres qui deviennent les messagères de cette raison aléatoire.

Voici l'essentiel en quelques mots. L'appareil géomantique peut être défini comme un système avec une entrée et une sortie. L'entrée est en gros la suivante : le devin ramasse des cailloux au hasard ; puis il les repose un à un en série. A la fin il lui en restera soit deux (pair) soit trois (impair). L'unité d'information est binaire: pair/impair; oui/non. A partir de là on peut obtenir diverses combinaisons. Par exemple, s'il me reste à la fin quatre pierres, je termine avec pair-pair. S'il m'en reste cinq, je termine en pair-impair.

La syntaxe du système consiste en règles de combinaisons. On a

27 Ph. Richard et R. Jaulin,, Anthropologie et calcul, U.G.E., Paris 1971, pp. 183-215. Pour une présentation plus concrète, voir A. Adler et A. Zempléni, Le bâton de l'aveugle, Hermann, Paris, 1972, pp. 50 sq. 
$\left.1^{\circ}\right)$ quatre arrangements de signes : pair-impair ; impair-pair deux fois impair ou deux fois pair.

$2^{\circ}$ ) seize figures, obtenues en combinant par quatre les unités binaires (soit 2 à la puissance 4) ;

$3^{\circ}$ ) Les seize figures sont traitées comme 16 secteurs binaires à 4 dimensions, ce qui donne 65.536 combinaisons.

Après avoir déterminé les classes de figures syntaxiques, on définit des classes sémantiques.

Pour cela, on trace sur le sol un espace divisé en "régions" ou "maisons". Chaque région est verbalement définie comme une catégorie de questions. On peut concevoir par exemple une catégorie pour chaque quartier du village, pour chaque sorte de parents, pour chaque partie du corps etc... Chaque catégorie représente une question localisée sur le sol par une case. Suivant les figures (syntaxiques) qui viendront s'appliquer sur cette case, on aura des réponses bonnes ou mauvaises, mais avec des nuances suivant les figures. La même figure peut se répéter dans plusieurs catégories, ce qui pose des problèmes de compatibilité ou d'incompatibilité. Dans ce cas, il appartient à l'ingéniosité du devin de trancher, de la même façon qu'un bon légiste doit tirer le meilleur parti possible de textes juridiques apparemment divergents. Dans les deux cas, certaines interprétations feront jurisprudence. Pour reprendre un exemple donné par A. Zempleni ${ }^{28}$, si dans la catégorie 'lait de la mère", c'est mauvais pour les femmes (deux fois pair), et si dans la catégorie "génies du lignage" c'est bon pour les femmes (pair-impair). le devin pourra dire: "Quelqu'un a jeté un mauvais sort sur le lait de la mère, mais les Génies la protègent". Conclusion, : "Prenez tel remède contre la sorcellerie, et tout ira bien".

28 Adler et Zempléni, op. cit. 1972. 
On voit que l'oracle répond par des intersections de classes, alors que le devin répond par des phrases descriptives ou anecdotiques. La rationalité de l'oracle est donc comparable à une mesure rythmique, une mesure à deux temps (pair/impair) qui permet de scander diverses figures prosodiques comme un musicien qui se mettrait à pianoter au hasard jusqu'à trouver un thème. Ici le calcul est poème, incantation d'un sens. Pensez à"L'âme et la danse" de Valéry. Pensez à ce que Freud nous propose dans l'analyse d'un rêve : dites la première chose qui vous vient a l'esprit, obéissez au rythme des associations, entrez dans la danse et l'âme viendra. Il y a dans les techniques de la géomancie l'apaisement d'un ordre qui se fait lentement, lentement, (c'est très long), sans qu'on sache bien où l'on va. Quand des paroles seront prononcées, elles s'appuieront sur le tissu vivant d'un ordre lentement institué, pas à pas, un ordre qui se montre sans rien dire en déposant sur nos questions indécises de précises figures. Car nul ne pourrait exprimer directement ce qui est en question dans l'angoisse des hommes. Mais l'angoisse en jouant se joue d'elle-même, devient rythme en se prescrivant une rime. Alors vient la parole qui convient à la rime. Si l'oracle montre qu'un organe de mon corps est en conjonction funeste, il ne sera pas réfuté par l'absence en moi de douleur, puisque d'imprévisibles circonstances pourront paraître en consonance avec l'irréfutable sentence comme à la fin d'un vers la pensée devient événement par la grâce d'une assonance. Ainsi chez Marcel Proust, afin que le temps soit retrouvé, il faut que l'acte d'écrire dépose ses figures sur tout ce qui arrive. L'araignée se balance, se balance aveuglément, s'accroche, repart, se balance, va, vient, danse tant qu'à la fin elle se retrouve au centre de sa toge, dans un espace orienté. Alors, mais alors seulement il peut être question de savoir où l'on va.

Nous pouvons maintenant aborder la troisième partie de notre étude, la logique de l'interprétation. 


\section{3}

En étudiant la logique de l'interprétation, nous allons voir se préciser la notion de destin. Dans ce qui va suivre, je m'appuierai sur les remarquables analyses que Jean Bottéro a données des tablettes babyloniennes 29 . Nous y rechercherons les principes de ce qui fut, dans l'antiquité, la science des Chaldéens, grands experts dans l'art divinatoire. La sentence divinatoire se résume logiquement dans une formule conditionnelle : si telle conjonction de signes survient, alors telle classe d'événements est voulue par le destin. Si tel présage, alors tel oracle.

La forme conditionnelle : "Si..., alors..." énonce une implication. La protase ou condition est donnée dans le présent observable : c'est le présage ou le signe. Le conditionné ou l'apodose s'annonce dans une sorte de temps judiciaire qui soumet le présent (ou même le passé) à des échéances futures. Une forme analogue de raisonnement se retrouve dans toute casuistique, divinatoire ou juridique ou médicale. Elle intéresse donc la science des Chaldéens dans ses diverses aspects.

Première question : comment les Chaldéens ont-ils élaboré leur science?

Nous pouvons être renseignés sur ce point par des tablettes didactiques, sorte de manuels destinés à l'instruction des devins. Ces tablettes didactiques donnent des listes de formules qui mettent en correspondance une division systématique des présages avec un classement des interprétations possibles. Ces correspondances peuvent être illustrées par des maquettes, comme les foies de Mari ; l'organe est divisé en sections où s'inscrit une dénomination. Comment a été établi l'interprétation des présages ? Par induction empirique, en procédant a un

29 Dans D.R., pp. 70-196. 
relevé des coïncidences. Les formules didactiques mettent en rapport un signe divinatoire avec un événement passé, en spécifiant que le signe en question est le présage de (amût) l'événement connu. Par exemple 30 :

"Si (dans le foie) la porte du palais est double, qu'il y a trois rognons et qu'à droite de la vésicule biliaire sont deux trous (pilshu) bien marqués.

Alors c'est le présage des Apishaliens que Naram-Sin (vers 2260) fit prisonniers par le moyen de sapes (pilshu, trous)".

Ou encore : "Si à droite du foie se trouve deux doigts, c'est le présage de qui est roi ? qui n'est pas roi ?" (ou disputes pour la succession de Naram Sin).

Et plus clairement encore : "Lorsque mon pays s'est révolté contre Ibbi-Sin (2027), c'est ainsi que le foie était disposé..".

Ces formules rétrospectives sont devenues une source de documentation pour nos historiens.

Deuxième question Comment a-t-on pu généraliser à partir des coïncidences observés ?

On a généralisé en supprimant les noms propres et autres détails anecdotiques, puis en inventoriant tous les cas possibles.

Pour cela on décompose systématiquement le présage en signes distinctifs : "Si sur le seuil du palais à droite se trouve une coupure... Si sur le seuil du palais à droite se trouve une coupure tout le long... Si sur le seuil du palais à gauche se trouve une coupure... Si sur le seuil du palais à gauche se trouve une coupure tout le long..."

30 D'après Bottéro, ibid, pp. 145-147. 
Et l'on décompose les interprétations en fonction des types de situations ou de questions : "Si c'est un malade, il mourra ; si c'est une armée en campagne, elle ne reviendra pas". "Si c'est un notable, à aura plus de notabilité ; si c'est un pauvre, il aura plus de pauvreté". ${ }^{31}$ Là où les savants ne s'accordent pas, le manuel donnera plusieurs interprétations possibles (i.e. plusieurs formules en "amût") : "C'est le présage des dieux Lugalgirra et Meslamtaèa qui accompagnaient l'année ; autre interprétation : il y aura une peste dans le pays". "Dans la famille de cet homme, quelqu'un mourra ; autre interprétation : il y aura une éclipse de lune". "A l'entrée du palais, un scorpion piquera quelqu'un ; autre interprétation : l'ennemi battra l'année sur un territoire pacifique" 32 .

Quel est le résultat de ces opérations ? On aboutit à une formule conditionnelle avec deux protases et une réponse binaire par oui ou par non :

1. Si telle question est posée

2. Si tel est le présage

3. Alors réponse favorable (ou défavorable).

La conclusion, comme dans la géomancie dont nous parlions plus haut, résulte de l'application d'une classe de figures (deuxième prémisse) sur une catégorie sémantique (première prémisse).

Troisième question : Sur quels postulats repose ce conditionnel ? Quelle est la nature de l'implication divinatoire qui relie le présage à l'oracle?

$1^{\circ}$ ) Il s'agit d'une implication directe où les dieux n'interviennent pas. C'est bien parce que le présage est tel que l'oracle sera tel.

31 Bottéro, op. cit., p. 181.

32 Ibid, p. 182. 
Nous voyons ici le caractère impersonnel du destin, la "Moïra".

$2^{\circ}$ ) Cette implication est de même nature que la règle de jurisprudence dans un code judiciaire

1. Si tel est le cas,

2. Si telle est la loi

Alors sentence favorable (ou non).

En résumé, l'implication divinatoire ou règle d'interprétation est une implication déontique. Elle proclame qu'il est nécessaire, au sens d'obligatoire, que si tel est le présage, alors telle doit être la sentence. C'est ici que les Stoïciens feront la confusion ; ils croiront voir une nécessité cosmologique, là où il s'agissait d'une nécessité déontique c'est-à-dire d'un ordre de justice. C'est ce que va nous montrer l'examen de la question suivante.

Quatrième question : Comment interviennent les dieux?

Ils interviennent en légiférant par décret comme les chancelleries royales. Le Conseil des dieux siège. Ses décisions sont inscrites sur les tablettes du destin, à partir de quoi elles s'introduisent dans la nature même des choses : "0 Shamash..., toi qui lis la tablette scellée et non encore ouverte, toi qui inscris l'oracle et place la sentence divinatoire dans les entrailles du mouton". "Pendant mon examen divinatoire, Shamash et Addad inscrivirent sur le foie de la victime un oracle, favorable". Et encore : "Je procédai donc à l'examen divinatoire, et Shamash avec Addad me firent une réponse véridique, en plaçant dans la chair de mon agneau un oracle favorable" 33.

33 Ibid., p. 159. 
Concluons : les dieux décident de la seconde protase. C'est pourquoi avant de consulter, on peut prier. On peut combiner les rites d'influence ou de supplication avec les rites de consultation. Le Stoïcien ne pourra que se résigner à l'ordre nécessaire du monde. Mais ici les dieux décident de la protase. Le lien de la protase à l'apodose, bien qu'impersonnel, est un ordre de justice. Cette justice (comme la dikè) n'est pas celle qui s'inscrit dans les lois humaines (themis), mais celle qui s'inscrit directement dans la nature des choses.

Cinquième question : Comment les dieux fixent-ils la protase ? Par l'écriture, comme on vient de le voir. C'est ce que déclare l'hymne d'Assurbanipal à Shamash : "Tu scrutes de ton regard la terre entière comme autant de signes cunéiformes" ${ }^{34}$. L'astrologie est appelée "écriture céleste" 35.

Quel est le rapport entre l'écriture et la divination ? L'écriture cunéiforme est susceptible d'une double interprétation: par pictogramme (dessin hiéroglyphiques) ou par alphabet phonétique (caractères monosyllabiques annoncés par un signe diacritique). Le pictogramme est un signe motivé : il représente des choses par d'autres choses (des dessins). L'ordre juste du monde sera un ordre sémiologique motivé, où certaines choses (présages, pictogrammes) représentent d'autres choses.

Entre l'écriture et la technique divinatoire subsiste néanmoins une différence importante, celle qui sépare le pictogramme de la parole. L'écriture alphabétique exprime la parole, et, certes, la parole énonce par la bouche du devin la conclusion qui résulte de l'examen des signes. Dans la Bible également c'est par l'intermédiaire des prophètes que seront publiés, oralement ou par écrit, les jugements de Dieu. Mais le procédé divinatoire, l'appareil oraculaire lui-même ne s'exprime, comme dit très justement saint Paul, qu'en figure et qu'en

34 Ibid, p. 161.

35 Ibid., p. 160. 
énigme, in figura et aenigmate. La figure se montre mais ne se dit pas. L'énigme également se montre dans ce que l'on dit, sans pouvoir s'identifier jamais purement et simplement à ce que l'on dit.

Il y a là un point capital, comme nous allons voir, pour comprendre la signification psychologique et généralement humaine de la divination.

\section{4}

Pour conclure cet exposé, je voudrais montrer comment l'analyse de la divination peut conduire soit à une cosmologie soit à une psychologie.

Pour montrer comment l'art divinatoire peut déboucher sur des spéculations cosmologiques, je m'appuierai sur l'étude de Léon Vandermersch à propos de la divination chinoise ${ }^{36}$. En Chine existait depuis la pré-histoire un procédé de chelionomancie qui utilise des ossements sur lesquels on opère, avec la braise, des éclats, des fissures par brûlage. On a d'abord utilisé pour cela des os de mammifères. mais par la suite la préférence s'est portée sur les écailles de tortue. La carapace d'une tortue offre en effet l'avantage d'être divisée en "régions", ces régions elles-mêmes pouvant être classées en diverses catégories. Pour obtenir un oracle avec cet appareil, il faut évidemment compter les régions et les fissures, classer les groupements numériques pour aboutir, comme dans la géomancie, à montrer comment les questions sur lesquelles on consulte sont fonction de certaines figures ou combinaisons. Pour effectuer ces calculs, on a trouvé plus pratique à une certaine époque de remplacer les écailles de tortue par des baguettes d'Achillée. On peut tenir plusieurs baguettes entre les doigts. Les mains agiles des Chinois purent ainsi faire preuve de virtuosité dans le calcul des sorts. Mais comment arrêter le progrès une fois

36 L. Vandermeersch, De la tortue à l'achilée, in D.R., pp. 29-51. 
qu'on a fait le premier pas ? L'esprit subtil des Chinois comprit bientôt que l'on pourrait se passer de baguettes pour calculer ; 0 suffisait d'exprimer les nombres et leurs combinaisons. Alors qu'arriva-t-il ? La consultation divinatoire fût privée des instruments matériels qui faisait d'elle une cérémonie publique, un spectacle rituel. La divination devint une sagesse qui étendit sur le monde ses spéculations arithmologiques. En devenant une sagesse du monde, la divination changea de nature, elle devint une connaissance plus intérieure. En Asie, en Afrique, un peu partout, la spéculation sur les nombres devient aisément le support d'une sagesse mystique. Même si, dans un même peuple, les procédures artisanales du devin peuvent coexister avec les connaissances cosmologiques du sage, l'exercice de contemplation est d'un autre niveau que le rituel de consultation. On remarquera toutefois qu'en rendant plus intérieure la théurgie, comme dirait Jamblique, on n'en conserve pas moins la même orientation fondamentale vers une transcendance : c'est d'Ailleurs que vient le signe, c'est de "Là-haut" qu'émane l'unité intérieure vers laquelle on fait retour dans l'extase. L'interprétation cosmologique ne suffit donc pas a expliquer la divination puisqu'elle en répète seulement à un autre niveau le même schéma.

Ce qu'il faut expliquer, en effet, c'est que le lieu de la révélation, le lieu des Signes, soit excentrique par rapport à l'homme. Lorsque nous parlons, des signes émanent de nous dans le même mouvement centrifuge qui porte notre action à s'exercer sur les choses pour les transformer. Par contre, toute divination qu'elle soit inductive ou inspirée, nous propose un mouvement inverse : le Signe vient d'ailleurs et nous en sommes l'objet. Comment cela est-il possible ? Par un certain aménagement rituel de l'espace s'ordonnant en fonction d'un lieu privilégié où siège l'oracle. C'est à partir de ce lieu central que se répartissent désormais les régions de l'espace, que ce soit par le procédé du "templum" ou par les autres procédés classificatoires mis en oeuvre dans les techniques de divination. Dans l'espace ainsi orienté tout ce qui vient s'inscrire devient signe, tout événement y arrive chargé de sens. 
Arrêtons-nous ici un instant. Si tout devient signe, il y a quelque chose d'affolant. Rappelez-vous les Mémoires du Président Schreber : l'espace dans lequel se déploie le délire est un espace où tout devient significatif à partir des rayons qui émanent de Dieu ; c'est de là-bas, du surnaturel, que naissent les signes dont Schreber est l'objet ; la valeur faste ou néfaste de ces signes varie en fonction de la distance. Si Dieu s'éloigne trop loin, surgit pour Schreber le hurlement. Si Dieu s'approcher trop, son existence divine est menacée, il risque de se fondre en volupté schrébérienne. Rappelez-vous, dans cet aspect affolant, l'importance des vibrations qui deviennent hallucinations verbales, ou des jeux forcés de la pensée qui ne laissent place à aucun loisir de "penser à rien", mais imposent toujours à nouveau d'être objet des signes qui rayonnent de l'Autre. Il fut un temps de notre prime enfance où toute parole émanait de l'Autre, où notre corps n'avait pour lui que des rythmes qui se montrent et ne se disent pas, où les vibrations de l'oracle maternel divisait l'espace en plaisirs et peines, premiers partages d'un destin. Nos impressions ne s'interprétaient, pour le meilleur ou pour le pire, qu'à travers l'oracle.

Toute les religions, qu'elles procèdent par voie de mantique ou d'inspiration, localisent la révélation dans un oracle pareil à l'Orient d'où vient la lumière qui donne, comme l'on dit, un sens à la vie, un sens qui se montre et se cache en toutes choses, et qui dépasse, comme dit l'Écriture, toute parole humaine, car il distribue à chacun en partage l'heur ou le malheur, la grâce ou l'abandon. La religion et la psychose semblent, chacune à leur façon, orienter notre espace vital vers je ne sais quelle Chose Primordiale d'où émane le sens, un sens plus ancien que la parole puisqu'il procède par figure et par énigme ; il ne propose pas les choses comme objet d'un savoir mais les répartit en classes d'équivalences de telle sorte que toutes celles qui tombent dans la même classe nous signifient un partage, une partition du bon et du mauvais, conformément à ce qui a été voulu dans le secret des dieux ou des ancêtres. Mais alors si le mystère et le délire obéissent à un même schéma général, où est la différence entre ceux que Jupiter veut perdre (Quos Jupiter vult perdere, dementat), et les âmes pieuses qu'il 
veut sauver ? Comment, demandait Saint Ignace, "discerner les esprits" ?

C'est, me semble-t-il, que les religions socialisent le lieu de la révélation en établissant quelque part un annonciateur, un messager, un être qui parle au nom de l'Autre. Peu importe que l'annonciation soit faite par un prophète ou un artisan devin, par un saint voyant ou un simple d'esprit. Peu importe même que l'annonciation faite à Marie soit une pure légende. L'essentiel est qu'on puisse la raconter. On en fait un Mémorial. Les peuples ont besoin de monuments. Un peuple ne peut vivre sans ennemi, mais il localise l'ami et l'ennemi, il transforme en honneur la disparition des disparus. Les délirants s'obstinent interminablement ("esprit obstinés", dit saint Ignace), alors que du mystère on peut faire un credo, on peut le localiser dans des "lieux théologiques" ("loci theologici"), comme disent Melchior Cano et le cardinal Bellarmin. Remarquez bien que nul n'échappe à sa destinée, en ce sens que la part qui nous est assignée dans telle famille, dans tel peuple, cela nous fut et demeure annoncé. Mais le paranoïaque est à lui-même son prophète. S'il n'a pas de disciples, il est perdu. Même les mystiques ont leur "gourou", leur maître des novices, comme les fidèles ont leur magistère. Celui que Piera Aulagnier appelle "le porteparole" doit être situé quelque part ${ }^{37}$. C'est ce que dit la sagesse des nations : nul n'est bon juge en sa propre cause, nul n'est prophète en son pays ou pour son propre compte. C'est là, comme vous voyez, une dernière analogie entre la thémis des tribunaux et la dikè des oracles.

37 P. Castoriadis-Aulagnier, La violence de l'interprétation, PUF, Paris, 1975, pp. 130 sq. Sur le rôle de l'annonciateur, voir aussi : J. Favret-Saada, Les mots, la mort, les sorts, Gallimard Paris, 1977. 
Religions du livre. Religions de la coutume

\section{Chapitre III \\ LA DESTINÉE INDIVIDUELLE CHEZ LES TALLENSI *}

Afin de présenter au publie de langue française un ouvrage connu depuis longtemps (1959), Oedipus and Job in West African Religion de Meyer Fortes, je dirai quelles réflexions sa lecture m'inspire aujourd'hui.

Oedipe et Job dans les religions ouest-africaines se propose de montrer que les conceptions du destin, c'est-à-dire concrètement les traditions relatives à la divination ou à la consultation des oracles, ne traitent pas tout à fait de la même façon les différents âges de la vie, l'enfance et l'âge adulte. Le destin qui se manifeste dans l'enfance et caractérise une personnalité dès sa naissance (comme dans l'histoire d'Oedipe), est expliqué dans la plupart des traditions ouest-africaines comme le résultat soit du destin heureux ou malheureux des parents à

* Texte de la préface à Meyer Forter : Oedipe et Job dans les religions ouestafricaines, trad. R. Renaud, ed. Marrie, 1974. 
qui l'enfant "appartient", soit d'un choix personnel effectué par l'enfant dans son existence pré-natale. Par contre, au cours de l'adolescence ou de la maturité, le destin qui se manifeste par des événements singuliers, principalement des infortunes telles que la maladie ou l'échec (comme dans l'histoire de Job), est expliqué dans ces traditions Ouestafricaines par l'intervention de certains ascendants défunts, certains esprits ancestraux, qui ont choisi l'individu en question pour lui demander de leur rendre un culte, de leur offrir des sacrifices en échange de leur protection. Il semble donc que l'idée de destin ne soit pas sans rapport avec le statut rituel des individus, suivant que ce statut est passif et subordonné (comme chez l'enfant et la femme) ou actif à des degrés divers (chez les hommes vivants) ou qu'enfin la mort ayant fait d'eux des ancêtres, ces hommes et ces femmes soient devenus à leur tour sources de destin c'est-à-dire destinataires du sacrifice, demandeurs de victimes et d'offrandes. Alors que le destin de l'enfance demeure enfoui dans les secrets qui accompagnent la génération du corps, dans la vie adulte le destin se révèle en vue de l'érection d'un autel et du culte des morts. En résumé, quand le destin se rattache à la naissance comme une composante de la personnalité, fi sanctionne le désir de fécondité des ascendants immédiats ; les parents vivants désirent que les ancêtres favorisent l'heureuse reproduction des corps. Quand le destin se manifeste dans les bonnes ou mauvaises fortunes de la vie personnelle, il montre que le désir des ascendants morts est toujours un désir de symboles, d'offrandes ; les parents morts désirent l'heureuse reproduction des autels. Mais, dans tous les cas, les aléas matériels de l'existence humaine ne révèlent leur signification, c'est-àdire le désir des ascendants, morts ou vifs, que par les aléas symboliques de la consultation divinatoire. La divination opère toujours dans le même sens : elle effectue le passage de la vie au rite ; elle va de la puissance occulte des événements aux puissances génératrices nommées sur l'autel ; elle va de l'obscure menace qui pèse sur les corps nés de la femme aux claires offrandes répandues sur l'autel qui garde les noms des gardiens de la vie. La divination révèle que les puissances du destin sont les destinataires du sacrifice et que la vie est une dette. 
Cette conception de la dette vitale est solidaire d'une conception légitimiste du droit fondé sur la coutume des ancêtres. Le légitimisme (à l'inverse du conventionnalisme) croit déduire ce que l'on doit de ce que l'on est ; mais on n'est pleinement que par investiture rituelle car l'existence naturelle n'est qu'en puissance de rite, en attente d'une actualisation de l'existence socialement marquée. La conception légitimiste du droit a pour corrélatif une éthique de l'honorabilité fondée principalement sur des droits et obligations statutaires que Meyer Fortes 38 compare à la notion d'officium chez Cicéron, au Beruf (vocation) de Luther et l'on pourrait dire aussi à la timê des Grecs : il s'agit de ce qui est dû en vertu de la place que l'on occupe dans la configuration sociale les messages de l'action sont codés par le statut dont on est investi les normes sont des marques, des nonnes de relation attestant la position respective de chacun. On pourrait dire, en simplifiant, que, dans une société comme la nôtre, régie par le pouvoir central d'une administration, nous avons une conception conventionnaliste du droit étayée par une morale utilitaire et un type d'échange où se mesure le prix des valeurs d'usage ; par contre dans un peuple comme les Tallensi, régi par le pouvoir d'une tradition, le légitimisme du droit coutumier s'appuie sur une morale exemplariste où l'idée dominante est que chacun a un statut à montrer, une légitimité à manifester, en même temps qu'elle exige un type de réciprocité exprimée par la munificence, le don ostentatoire, la prestation d'honneur, de sorte que l'échange n'apparaît qu'indirectement lorsqu'on réfléchit sur la circulation des biens dans la société globale alors qu'au niveau des individus, toute relation trop directe paraît inconvenante, grossière. À vrai dire, le légitimisme et le conventionnalisme sont plutôt deux aspects des institutions juridiques, qui, dans toutes les civilisations, se mêlent à des degrés divers pour répondre à la double nécessité collective du spectacle et de l'organisation. Chez nous aussi le lyrisme des "manifestations" populaires faisant valoir les droits "légitimes", la "dignité"

38 Meyer Fortes, "Ritual and Office in Tribal Society", in Gluckman, Essays on the Ritual of Social Relations, Manchester U.P., 1966, 2e éd., pp. 53-88. 
de ce que l'on est, précède habituellement le compromis utilitaire des "conventions" collectives. La justice est un théâtre. La procédure est cérémonieuse. Le rite sert de liaison entre le spectacle et l'administration, entre le paraître et le faire, l'officiel et l'utile. Un "office" est une magistrature publique aussi bien qu'une cérémonie. L'officiant installe l'officiel dans sa charge. Le rite produit l'investiture; il opère la transmutation du fait en droit par l'intermédiaire de la cérémonie ; il crée une existence sociale nouvelle, il fait de l'être un être reconnu. Le droit est la forme de la reconnaissance sociale.

A fortiori dans les civilisations sans écriture, dans les traditions sans administration, il sera d'autant plus nécessaire de marquer les droits et les obligations par des statuts, des rapports de positions typiques. Dans une communauté villageoise où tout le monde se. connaît sur plusieurs générations, la ritualisation du droit est inséparable du spectacle que la communauté se donne à elle-même, principalement aux jours de fêtes. Avec qui peut-on se marier ? Qui doit être présent ou représenté aux funérailles ? Avec qui peut-on partager le repas sacrificiel ? À qui convient-il ou non de paraître dans telle assemblée ? C'est en répondant à ce genre de questions que Meyer Fortes décrit la structure sociale des Tallensi et des Namoos ${ }^{39}$. La cérémonie est la mise en scène des normes de relations assignant à chacun sa place. Qu'il me soit permis de rappeler ici un souvenir. Je me trouvais un jour dans un village particulièrement misérable du Sénégal oriental, au sein d'une population affligée du ver de Guinée et autres maladies, n'ayant pour breuvage qu'une eau croupissante, entourée d'une nature hostile où s'allumaient de tous côtés les feux de brousse, ce jour-là en écoutant le chantonnement monotone des interminables salutations, je me disais qu'à la limite du dénuement, le rite est encore la dernière chose par quoi nous pouvons montrer que nous sommes des hommes, plutôt que des animaux. La ritualisation est, comme l'élégance, une façon de charmer l'angoisse.

39 Meyer Forters, The Dynamics of Clanship among the Tallensi, Oxford U.P., 1945 , ch. 7 et 8 . 
La question des rapports entre le rite et le droit, la cérémonie et l'organisation sociale, me paraît être l'une des idées dominantes de l'oeuvre de Meyer Fortes. "Les rites, écrit-il, appréhendent l'occulte non pas en le mettant à nu (comme le fait la science pour les lois de la nature et la procédure judiciaire pour les mobiles des prévenus), mais en le déguisant de façon à le ramener aux dimensions du manifeste ${ }^{40}$.

Or, l'art divinatoire est l'art de transformer l'événement subi par les vivants en signe voulu par les morts ; il donne à l'occulte un langage traductible dans les paroles de la communauté. Le devin se situe aux frontières du dicible ; il est le metteur en scène de tout ce qui arrive.

Tel est l'arrière-fond qu'il faut avoir présent à l'esprit, me semble-til, au moment d'aborder la lecture d'Oedipe et Job dans les religions ouest-africaines. C'est pourquoi je rappellerai d'abord quelle est la place de ce livre dans l'oeuvre de l'auteur, avant de proposer quelques réflexions sur les questions qu'il pose en référence à l'œuvre de Freud.

Le professeur Meyer Fortes, qui est un des maîtres de Cambridge, a publié sur les Tallensi du Ghana septentrional deux études qui comptent parmi les classiques de l'anthropologie sociale : The dynamics of Clanship among the Tallensi (1945), et the Web of Kinship among the Tallensi (1949). ${ }^{41}$ Le premier volume expose le système des lignages qui sert de cadre de référence général et permanent au peuple Tallensi. Le second étudie les relations d'appartenances communautaires qui déterminent des droits et obligations statutaires pour chaque individu, c'est-à-dire lui imposent d'agir conformément à la place qui lui est traditionnellement assignée dans la société.

40 Meyer Forter, "Les prémisses religieuses et la technique logique des rites divinatoires", in Julian Huxley, Le comportement rituel chez l'homme et chez l'animal, N.R.F., p. 253.

41 La référence à ces oeuvres sera notée par les initiales : D.C. et W.K. 
La complémentarité de ces deux ouvrages qui traitent respectivement des institutions et des moeurs, peut servir à montrer un point important de méthode :

"Où est, demande Meyer Fortes, la divergence essentielle entre le point de vue de Lévi-Strauss et le point de vue fonctionnaliste représenté par Radcliffe-Brown ? Elle dépend, à mon avis, de la place accordée à l'acteur... (Chez Lévi-Strauss), la relation de l'acteur à sa propre culture est distillée dans la substance universelle du code... Le premier principe d'une enquête orientée vers l'acteur est que cet acteur doit être proprement spécifié... Ceci nous fait comprendre ce qui est sous-jacent à la "convertibilité" ou "transformabilité" des messages d'une modalité culturelle à un autre. C'est la coalescence ou la concaténation des acteurs, des rôles et des statuts, à différents niveaux. C'est parce que le violoniste combine en lui-même les deux rôles de lecteur d'une partition et d'exécutant d'une oeuvre que la transformation de l'écrit en message musical peut se produire pour un auditoire " 42.

En ce qui concerne les institutions du peuple Tallensi, Meyer Fortes souligne que la parenté, la solidarité du lignage, couvre un champ de relations sociales plus vaste que la famille. Le système des lignages repose sur un double principe de réciprocité externe et de segmentation interne. Les relations réciproques entre lignages (attestées par des prestations) maintiennent l'unité corporative de chacun d'eux en face des autres, alors que la segmentation de chaque lignage patrilinéaire en unités locales permet au même type social de se reproduire en s'adaptant aux changements provoqués par les mariages, les morts ou les nécessités économiques.

L'ordre de segmentation en lignage maximal, médial et minimal, suit l'ordre d'ancienneté des ancêtres qui sont à l'origine de chaque segment. Les segments s'ordonnent suivant leur position respective sur l'échelle généalogique. Et comme c'est surtout à l'occasion des funérailles ou des sacrifices que se manifeste la référence aux ancêtres communs, la collaboration rituelle entre les segments de lignage fait

42 Meyer Fortes, Totem and Taboo, Proceedings of the Royal Anthropological Institute, 1966, pp. 8 et 9. 
apparaître diverses configurations communautaires; l'extension des solidarités varie comme l'ancienneté des positions dans la suite généalogique ; les plus anciennes réunissent un plus grand nombre de gens. Toutefois les choses se compliquent du fait que plusieurs segments d'un même lignage peuvent avoir entre eux une solidarité locale de clan. Sans entrer ici dans la complexité des rapports de clan, disons qu'au point de vue idéologique, le sacrifice et le mariage occupent deux positions symétriques et inverses par rapport à la ligne de la filiation paternelle: les clans sont exogames, on se marie hors du lignage paternel ; par contre le sacrifice sur l'autel du lignage suit la ligne de descendance agnatique (WK, p. 294). Un individu sacrifie à ses ancêtres paternels par l'intermédiaire de son père, si celui-ci est chef de famille, et à ses ancêtres maternels par l'intermédiaire de son oncle maternel, de sorte que l'officiant s'adresse toujours à ses ascendants : "Nous sacrifions à un même autel, comment pourrions-nous nous marier ensemble ?" (D.C., p. 97 et WX., p. 17). Cet aphorisme ne suffit pas à rendre compte de la complexité des liens claniques, locaux, mais il montre que le lignage se fonde à la fois sur la consanguinité et le culte des ancêtres. Il est une communauté à la fois généalogique et rituelle. Le sang des sacrifices en remontant vers les ascendants authentifie la consanguinité des descendants en révélant la puissance occulte de vie et de mort qui légitime et sanctionne les droits et les devoirs inhérents au statut de chacun. Les nécessités naturelles du sexe et de la consanguinité ont besoin de l'efficacité rituelle pour accéder pleinement à l'existence sociale normative et institutionnelle. C'est l'esprit rituel des morts qui seul peut transformer la relation sexuelle en relation d'alliance. Et de même que la réciprocité externe entre les lignages est attestée par la position rituellement marquée de l'oncle maternel, cette "brèche dans le lignage", comme dit Meyer Fortes, de même la segmentation interne des séries généalogiques, est attestée par la position, rituellement marquée, de l'ancêtre, cette autre brèche que la mort impose et dont l'autel du lignage demeure le mémorial à l'intérieur de la maison. Que ce soit, sous les espèces de l'oncle maternel ou sous celles de l'ancêtre, il faut qu'une position rituellement marquée soit ajoutée (ou soustraite suivant le point de vue au- 
quel on se place), aux relations naturelles du sexe et de la consanguinité pour qu'apparaisse une forme institutionnelle de communauté humaine. Pour que soient mises en forme les marques de la reconnaissance sociale, il faut que la nécessité naturelle accepte quelque chose en plus ou moins, il faut que quelque chose soit ajouté ou soustrait à la nature pour constituer une valeur d'information qui puisse être valable "en vertu de sa forme", car à ce titre seulement elle peut juger des faits, exiger qu'ils lui soient conformes au lieu d'avoir à se conformer à eux. Rien d'humain ne peut exister qui ne soit capable de donner tort à la matérialité de certains faits, de condamner certaines conduites, de sélectionner les possibles en permis ou interdits. Que le nombre des possibilités logiques (ou idéales) soit toujours plus grand que le nombre des possibilités effectivement réalisables dans un cas particulier, c'est ce qui nous permet de raisonner, c'est la loi syntaxique du calcul des propositions. Mais pour qu'advienne cette lumineuse surcharge de possibles qu'on appelle la raison, il faut que, durant le temps de la vie, quelque chose soit perdu dans les investissements de la mémoire, et laisse place au rêve. Pour que "le vivre", comme dit Aristote, se transforme en "bien vivre", il faut qu'il détache de soi les formes sociales de sa propre manifestation afin de régler les possibles dans le jeu de la vie. L'exemple le plus simple que l'on puisse donner de cette soustraction créatrice des possibles est la transformation de l'action en geste : le geste est une action inachevée qui virtualise son objet, pétrit le possible en vertu de sa forme purement gestuelle (et qu'est-ce que les psychologues appellent "pulsion" sinon une ébauche d'activité ?). Mais au-delà du geste à y a le mémorial, comme la maison, l'autel ou simplement le nom des ancêtres, qui permet à une communauté humaine de comporter toujours plus de membres possibles que de membres actuellement vivants. Ce supplément d'âmes est l'obscure clarté de la tradition.

Le social, au sens strict de ce qui est normativement commun à tous les cas semblables, n'a pas d'existence empirique ; il est ce qui se montre indirectement dans une forme transmissible, c'est-à-dire progressivement détachable de l'organisme vivant par les voies combi- 
nées de la parole et de la figuration, de la symbolisation et de la simulation. Les marques de la reconnaissance sociale se laissent logiquement ordonner dans une série qui va du geste à la parure, à l'objet rituel, au monument, comme s'il leur fallait se détacher de ce qu'il a de fugitif dans l'expression corporelle ou les jeux de physionomie pour acquérir avec la stabilité de symboles communs détachables de l'organisme, des possibilités plus larges de remémorer le passé et de projeter l'avenir dans des règles d'action capables d'engendrer une tradition commune. Les éléments du culte des ancêtres: le nom des pères morts, la victime du sacrifice, l'autel... traduisent au plus près de l'image d'un corps disparaissant le souhait de trouver dans les formes stables de la coutume les gages d'une fécondité inépuisable de la vie. La principale différence entre l'instinct et la coutume semble se trouver dans la nécessité chez l'homme de "représenter" la loi commune dans une instance capable de dominer la vie pour la juger. Mais cette représentation demeure au plus près des formes vivantes dont elle se détache : si le droit coutumier trouve dans le culte des morts la source invisible de sa légitimité, c'est qu'à son tour l'institution sociale, comprise comme un héritage, se rend visible dans la cérémonie de sorte que les normes du droit sont inséparables du spectacle que la communauté se donne à elle-même, dans la permanence rituelle des coutumes.

Sans la divination, pourtant, le culte ne pourrait pas fonctionner. Car, note Meyer Fortes ${ }^{43}$, il faut pouvoir recourir à une autorité de dernière instance pour maîtriser l'occulte, discerner quelles puissances cachées interviennent dans la vie des mortels et quels rites seront capables de satisfaire à leurs demandes.

Chez les Tallensi, chaque chef de famille aura chez lui deux autels : l'autel du lignage (bôghar) et l'autel de la divination (bakologo). L'autel du lignage est consacré à l'ancêtre fondateur et à sa mère (ainsi

43 Prémisses religieuses et technique logique des rites divinatoires, op. cit p. 258. 
qu'à leur descendance). Pourquoi sa mère ? Parce que dans cette société patrilinéaire où les pères sont le bien commun, la mère du père est l'élément différentiel par quoi un groupe de consanguins se distingue d'un autre. L'autel de la divination est dédié à une configuration singulière d'ancêtres, parmi lesquels une large part sera faite aux ancêtres maternels, très demandeurs. Les ancêtres présents dans cette configuration sont ceux qui se sont révélés dans les événements, surtout les maladies, qui ont affecté la vie de l'individu (ou de ses enfants).

Comme le remarque Meyer Fortes, la divination est singularisante : elle l'est à l'égard des événements puisqu'elle attribue une origine intentionnelle, non pas aux causes générales de l'événement, mais à la conjoncture singulière qui lui donne occasion de se produire; elle l'est à l'égard des individus, puisqu'elle assigne à chacun une configuration particulière d'ancêtres, organigramme de son destin. Alors que l'autel du lignage souligne l'appartenance de l'individu à la communauté, l'autel de la divination met en relief la place originale qu'y tient sa biographie.

Le mot Yin désigne en tallensi la destinée ou la configuration d'ancêtres qui y préside pour chaque individu. Sur cette notion, The Web of Kinship donne les informations suivantes, auxquelles se réfère Oedipus and Job.

1. "Il existe un antagonisme natif entre le Yin du père et le Yin de son fils aîné. Tant que le fils est encore jeune, son Yin est faible ; mais à mesure qu'il grandit, son Yin devient plus puissant et désire le rendre maître de ses propres affaires. Le An du fils désire détruire le Yin de son père ; mais le Yin du père désire que le père vive, se porte bien et reste maître de sa maison. Il désire continuer à recevoir du père des sacrifices. C'est pourquoi il désire détruire le Yin du fils, et s'il est le plus fort, il pourra causer le malheur du fils et peut-être sa mort. Telle est la raison pour laquelle le père et le fils doivent éviter de se réunit à l'entrée de la maison, et c'est pourquoi il est mieux pour eux de se séparer dès que le fils a atteint sa maturité, lorsque son Yin commence à être aussi puissant que celui de son père. De la même manière la prédestination (Yinbe'er) de la fille aînée est une menace pour la vie et la santé de sa mère" (WX., p. 227). 
On voit qu'ici le Yin supporte mai la contiguïté physique entre père et fils ; il introduit entre les deux une question statutaire : qui sacrifiera aux ancêtres 44 ? Ajoutons que les interdits propres à la position de fils aîné ne seront levés qu'aux funérailles de son père ; alors l'aîné accédera pleinement au statut de sacrificateur. Comme on peut s'y attendre, les devins seront pris parmi les cadets.

2. La première manifestation du Yin est appelée le nuor Yin ou Yin de la bouche car il émane, comme nous allons voir, de la bouche même de l'intéressé.

"Le Yin de la bouche, écrit Meyer Fortes, est le destin que l'individu a préordonné pour lui-même avant sa naissance. Dans son existence prénatale, il a parlé quand il était avec le Ciel là-haut. Hommes et femmes peuvent tous deux avoir ce Yin; et c'est ce Yin qui quelquefois se manifeste comme un mauvais Yin (Yinbe'er), quand l'individu est poursuivi par une malchance chronique dans les choses importantes de la vie, telles que la santé, le mariage, la fécondité. Il (ou elle) a déclaré avant sa naissance qu'il ne désirait pas avoir des parents ou des enfants ou Une épouse ou quelqu'une des bonnes choses de la vie. Un enfant affligé d'une mauvaise prédestinée est constamment souffrant ; un homme ainsi affligé ne peut pas trouver de femme ou est abandonné par toutes celles qu'il épouse ; ou il perd ses enfants l'un après l'autre en bas âge ; ou il a toujours de mauvaises récoltes ou ses greniers se gâtent. Une femme avec un Yinbe'er perdra ses enfants l'un après l'autre en bas âge, ou son mari, ou peut-être ellemême sera la proie d'une cruelle maladie. Bien plus, cette malchance qui hante ce malheureux inconscient, est un constant danger pour sa famille. Le mauvais Yin d'un enfant peut provoquer la mort d'un parent ou d'un germain, frère ou soeur; le mauvais Yin d'un homme ou d'une femme ruine la vie de son conjoint, de ses enfants de ses parents aussi bien que la sienne propre." (W.K., p. 228).

Pour tenter de maîtriser cette autoprédestination dangereuse, il faudra recourir à un rite propitiatoire effectué par la lignage maximal ou médial du patient, mais, ajoute Meyer Fortes, on n'y réussit pas toujours.

44 Sur l'importance de cette question voir M.-C. et E. Ortigues, Oedipe africain, 2e éd. (Plon. col. 10/18), p. 87 sq., 186 sq. 
"Si la prédestinée d'une femme, écrit encore l'auteur, est sans danger ou bienfaisante, elle reste latente. Cela ne soulève pas d'objection, d'autant que la femme n'a pas de statut rituel ; son Yin est subordonné et immergé dans celui de son père ou de son époux. Par contre, la prédestinée d'un homme, si elle est bienfaisante, peut se déclarer à lui, habituellement après l'adolescence, mais parfois avant. Ainsi un jeune homme peut tuer un animal à la chasse, et cet animal se révélera, par l'intermédiaire d'un devin, être le véhicule de son nuor Yin demandant au jeune homme de lui dédier un autel." (W.K., p. 228).

En somme, le Yin de la bouche, quand il est mauvais afflige mystérieusement le corps du sujet ou de son entourage familial ; et quand il est bon, à se révèle ailleurs, dans un animal par exemple, et dès lors sa demande est claire : il veut des sacrifices, il désire un autel. Le procès de la symbolisation va du Yin de la bouche au Yin de l'autel.

Dans d'autres traditions de l'Afrique occidentale, la naissance de certains enfants est interprétée comme la reviviscence d'un ancêtre, de sorte que l'interrogation sur l'intention cachée dans l'événement de la naissance est encore plus explicitement une interrogation sur le désir de l'ancêtre. On retrouve aussi un peu partout l'axiome rituel suivant lequel la même chose qui est dangereuse lorsqu'elle reste imaginairement cachée dans le corps, est bonne quand elle accède au symbolisme public de l'autel ou de l'objet sacré.

3. "Mais le Yin le plus important pour un homme est celui auquel certains de ses ancêtres sont associés. Celui-ci vient à lui dans l'enfance, bien qu'il survienne plus communément chez le jeune adulte. Habituellement il se manifeste par un accident ou une coïncidence. Ainsi un jeune homme tombe malade peu après qu'il ait acquis une nouvelle houe ou tué un animal à la chasse. Les devins alors déclarent que sa maladie fut causée par son Yin ; ses ancêtres tels et tels, un tel et un tel, se sont ainsi révélés à lui comme son Yin ; la houe ou l'animal est leur véhicule ; il lui ont apporté une maladie parce qu'ils demandent au jeune homme de les accepter comme son Yin et de leur offrir des sacrifices. Le jeune homme alors construira un autel dédié à ces ancêtres, plaçant sur lui le crâne de l'animal ou le fer de la houe, et désormais il sacrifiera pour eux sur cet autel. C'est là son premier autel personnel, le plus intime, et il jouera par la suite un rôle énorme dans sa vie. Dans la mesure où ses affaires personnelles seront en Cause, il trouvera toujours là son lien le plus important avec ses ancêtres. 
C'est à travers son Yin qu'il exercera l'influence la plus directe sur son épouse et qu'il cherchera à maintenir pour lui la bienveillance élective de ses ancêtres. Quand il deviendra chef de sa petite famille il confiera la plupart de se enfants à son Yin comme esprit gardien. Chaque pas important dans son établissement social sera enregistré dans ses relations avec son Yin, que ce soit par un sacrifice, par un changement de place de l'autel, ou par l'addition d'un ancêtre au groupe de ceux qui se sont révélés à lui comme son Yin. Le Yin d'un homme est à la fois la charte de sa vie et la barre avec laquelle il tient le gouvernail tout au long de son chemin." (W.K., p. 229).

Ces lignes de Meyer Fortes trouvent aujourd'hui leur meilleure illustration dans un petit chef-d'œuvre d'humour et de finesse que vient d'écrire son Excellence Hampate Ba ; L'étrange destin de Wangrin ${ }^{45}$. Je ne puis que renvoyer à cet ouvrage le lecteur curieux de savoir à quoi peut correspondre dans le déroulement d'une biographie ce talisman personnel qu'est l'autel divinatoire; il y verra comment un homme, parvenu au plus haut de son succès dans la vie, peut être fasciné par les présages de son destin au point de se laisser glisser doucement, pas à pas, vers la mort avec une conscience vertigineuse de l'ironie du sort.

Les études de Meyer Fortes sur les Tallensi, comme celles d'Evans-Pritchard sur les Azande, ont contribué à montrer que le culte des ancêtres et la divination sont deux composantes fondamentales des religions africaines. Je crois que l'on peut donner à cette observation une portée anthropologique très générale si l'on considère les schèmes de pensée à l'oeuvre dans ces deux composantes. Le schème de -la généalogie, qui est à la base du culte dès ancêtres, se laisse aisément transposer sous des formes diverses (généalogie céleste, genèse cosmique...) qui dans la plupart des religions pose le problème d'une origine vivante de toute chose. La divination de son côté est un moyen de connaître les volontés célestes attestées par des présages, des miracles, des oracles. Le schème est ici celui du Signe caché mais non trompeur, échappant d'autant mieux à la supercherie ou à la

45 Publié dans la collection 10/18, Union générale d'édition, Paris, 1972. 
contrefaçon que son apparition était plus improbable ; du Signe imprévisible et donc irréprochable, soustrait à la fraude par son infaillible surprise ; du Signe arbitrairement élu pour être le plus sûr. En ce sens, la généalogie et l'oracle sont les composantes les plus générales du phénomène religieux dans l'humanité. L'origine de la vie et l'épiphanie du signe réagissent l'une sur l'autre pour nous faire reconnaître dans les origines de la vie le fondement normatif d'une autorité, et réciproquement dans la souveraine liberté de l'événement non-trompeur la plénitude de la vie, le sens de son destin. Du point de vue logique, nous avons ici d'une part l'homologie d'un rapport asymétrique (permettant de concevoir la succession généalogique), et d'autre part un rapport d'équivalence (permettant la "traduction" de l'événement-signe en parole), ce qui correspond aux conditions les plus élémentaires d'une activité intellectuelle.

Reste enfui une dernière question : dans quelle mesure les conclusions tirées de l'ethnologie rejoignent-elles les observations cliniques de la psychanalyse ? Je n'aurai sur ce point aucun commentaire à ajouter ; la réponse a déjà été donnée dans les pages précédentes, principalement à propos des rapports entre le symbole et le corps, Pour le montrer, il suffira d'expliciter l'hypothèse qui a orienté Ma lecture des œuvres de Meyer Fortes.

Les hypothèses cliniques de Freud s'éclairent par la comparaison de l'anthropologie avec l'ethologie animale. Lorenz a montré qu'au moins chez un certain nombre de vertébrés supérieurs existait, durant les premiers mois de la vie, une période privilégiée de sensibilisation au congénère ; au cours de cette période, assez brève, variable suivant les espèces, le jeune animal est susceptible de recevoir de manière définitive l'empreinte ou l'imprégnation d'une certaine image qui lui servira de critère pour reconnaître désormais le compagnon-parent et rechercher la compagnie de ses semblables. Les divers modes de compagnonnage, dans la vie animale, s'appuient tous sur un système d'information où se combinent la programmation spécifique, innée, de certains rythmes cycliques (nourriture et gîte, reproduction) et la sé- 
lection des valeurs signalétiques (visuelles, auditives, olfactives, etc.) qui caractérisent l'image corporelle du partenaire. La signalisation a la même structure que la pulsion, innée dans son mécanisme, acquise dans son objet. "Le schéma déclencheur inné d'un acte instinctif, écrit Lorenz, opère dans la masse des excitations émanant de l'objet une sélection limitée à laquelle il répond sélectivement, provoquant l'acte. C'est une nécessité biologique que ces combinaisons-clefs possèdent un minimum d'invraisemblance générale 46 qui empêche le déclenchement, dû au hasard, de la réaction en présence de facteurs qui ne seraient pas biologiquement les bons" ${ }^{47}$. Pour augmenter la valeur d'information,

il a donc fallu rendre le partenaire improbable, ce que l'on obtient par la double sélection des moments pulsionnels opportuns et des invraisemblables parures du compagnon. Il est curieux de voir que pour décrire les éléments d'information qui régissent le comportement animal, Lorenz et Tinberghen utilisent un modèle de raisonnement homologue à celui que Monod et Jacob ont utilisé en micro-biologie. Les codes de l'amour et du hasard semblent reproduire au grand jour le même jeu d'enlacements subtils auquel se livre, dans le secret de la cellule, l'acide déoxyribonucléique. La vie est la programmation de l'invraisemblable. Des mécanismes homologues de sélection et de combinaison se réitèrent à divers niveaux. La prégnance de l'image signalétique chez l'animal rejoint une fonction générale de simulation ${ }^{48}$ qui lui permet soit de reproduire des comportements par le jeu soit de les transposer dans des ébauches de ritualisation, telles que la parade amoureuse ou guerrière. Chez l'homme la fonction de simulation (qui lui est commune avec les animaux) interfère avec la fonction

46 Souligné par Lorenz.

47 Konrad Lorenz, Essais sur le comportement animal et humain, trad. Fredet, Éd. du Seuil, Paris, 1970, p. 174.

48 Jacques Monod, Le hasard et la nécessité, Éd. du Seuil, Paris, 1970, pp. 164173. 
symbolique du langage sans se confondre avec elle ${ }^{49}$. Les unités distinctives du langage (ou morphèmes) se combinent de façon linéaire, alors que les unités distinctives Ide la simulation (ou figures) s'inscrivent simultanément sur plusieurs instances analogues à des portées musicales munies de clés différentes (comme dans une métaphore par exemple). il en résulte que, durant la période critique de l'enfance, la perception du congénère se construit par la production de symboles progressivement détachables de l'organisme vivant, symboles qui deviennent les éléments formateurs d'un système de communication où l'identité personnelle apparaît comme la possibilité pour un "même" individu de se reconnaître dans toutes les positions qu'il occupe alternativement à l'égard de l'acte de parole suivant qu'il parle, qu'on lui parle ou qu'on parle de lui, qu'il est auteur, destinataire ou objet de message. Les pronoms personnels sont des variables (au sens logique du terme) qui assignent aux individus des positions relatives dans l'échange des paroles, mais qui ne nomment directement aucun être. La nomination, quand elle est une désignation, appartient à la troisième personne, celle dont on parle ; et quand elle est adressée à quelqu'un, au vocatif, elle revient à lui assigner une place dans un univers de règles sociales puisque le nom propre est un titre de droit. L'acte de nommer introduit avec soi la distinction du fait et du droit, de la désignation et de la norme. Le registre délocutif ou objectif de la troisième personne est essentiel à la compréhension du nom comme à la possibilité de savoir de quoi on parle. La conscience de soi s'acquiert en même temps que l'aptitude à communiquer avec autrui et à discerner si ce que l'on dit est vrai. C'est en troisième personne seulement que l'énoncé devient détachable de celui qui l'énonce ; eue neutralise l'opposition je-tu pour présenter l'énoncé en lui-même, avec sa valeur propre de vrai ou de faux. La recognition de soi et la communication avec autrui sont régies par un système à trois positions relatives ou ordonnées qui comporte à la fois la relation allocutive, son inverse et

49 Monod se demande si ces deux fonctions ne pourraient être localisées respectivement dans l'hémisphère droit (simulation) et gauche (langage), op. cit., p. 171. 
l'élément neutre de la référence objective, de sorte qu'elle épuise toutes les possibilités de l'individu à l'égard de la parole. Ce système est en lui-même complet, car pour introduire des statuts, des rôles ou des attitudes il faudra prendre en compte la signification de certains verbes exprimant tel ou tel type d'activité dans lequel l'individu se trouve socialement engagé.

On peut distinguer trois significations principales du mot "personnalité". En premier lieu, l'identité personnelle est l'aptitude pour un individu à se reconnaître "le même" suivant qu'il parle, qu'on lui parle ou qu'on parle de lui. En ce sens le plus large, la personnalité est un élément marqué : elle n'est pas définie seulement par un élément neutre comme la nature humaine ; la façon dont elle se donne à reconnaître comme présence expressive fait partie de sa définition elle est l'appartenance de l'individu à un univers de communication ; cette appartenance résulte du fait que la fonction de communication applique sur un ensemble d'individus un ensemble de marques assignant symboliquement diverses positions dans l'échange des paroles. En second lieu, le statut personnel de l'individu est marqué principalement par la nomination ou quelque titre de reconnaissance introduisant la distinction du fait et du droit. La morale dans l'humanité se signifie d'abord par l'imposition d'un Nom. La loi humaine est un vocatif ou une vocation avant d'être un commandement. C'est précisément parce que la nomination assigne l'individu sous une loi commune que l'autorité de la loi est représentée traditionnellement par les noms des ancêtres ou des dieux ; "cause première" de notre vocation ou destinée humaine. En troisième lieu, la personnalité psychologique est l'ensemble des dispositions exprimées par la diathèse du verbe qualifiant l'individu comme agent ou patient, comme l'acteur dont on parle. Toute disposition personnelle se caractérise par la mobilité ou la rigidité des positions personnelles entendues comme jeu d'identifications à l'autre et d'investissements. La nécessité d'introduire ici des concepts normatifs (vocatif ou impératif), et des concepts dispositionnels (diathèse, caractère de l'acteur), montre que les "jugements d'attribution" applicables à"quelqu'un" se distinguent non seulement par la qualité des attributs 
mais par le mode d'attribution, par des différences dans la modalité du jugement (l'actuel et le possible, mais aussi le permis, l'obligatoire, le désirable, etc.). Or, la logique modale se distingue de la logique classique en ce qu'elle ne permet pas de savoir à quoi réfère une parole sans comparer entre eux plusieurs univers de discours ; elle introduit dans les descriptions du monde une sorte de complexité polyphonique, telle qu'une même chose se trouve inscrite sur plusieurs registres à la fois. En cela réside la principale difficulté théorique des études psychologiques ou anthropologiques 50 .

La plupart des conceptions traditionnelles de la personnalité inscrivent la présence expressive des interlocuteurs (la personnalité humaine au premier sens) dans le statut social des acteurs (la personnalité sociale au second sens). C'est ainsi que, chez les Bambara par exemple, chaque individu est doté de plusieurs puissances animées : le $n i$, le dya, le térê, le wãzo, le nyama... Chacune de ces composantes est une valeur de position, une marque de relation juridico-rituelle. Mon ni (ego) est le dya (double) d'un ancêtre mort, ce qui marque ainsi mon statut généalogique par référence à l'autel des ancêtres. Mon dya est d'un sexe complémentaire au ni et se trouve conservé dans le miroir des eaux avoisinantes, m'assignant ainsi à la double loi des mariages et des résidences. Le térê est mon caractère révélé par la divination, ce qui donne une autre référence rituelle. Le wãzo est la partie "sorcière" ou maléfique de l'individualité éliminée par la circoncision. Le nyama est une puissance obscure, éparse dans les êtres, mais que les sacrifices peuvent conjurer. Cette conception théâtrale de la personnalité inscrit les impératifs sociaux dans le vocatif (le Nom et le destin) de chaque individu en effectuant la mise en scène juridicorituelle de sa présence dans la communauté. Cette conception est inséparable d'un légitimisme du droit c'est-à-dire d'une idéalisation des

50 Sur la logique des modalités, voir J. Hintikka : Model for modalities, Reidel, 1969, 230 pp. - S.A. Kripke : Naming and Necessity, in Semantics of Natural Language, Reidel, 1972, pp. 253-355. 
nonnes sociales par le spectacle, la manifestation plus ou moins ritualisée, que la communauté se donne d'elle-même ${ }^{51}$.

Les rituels de guérison ou de propitiation montrent bien en quoi consiste ce mécanisme électif de socialisation. Le malade a dans son corps une chose errante, une puissance inconnue qui s'est fixée là. Cette chose errante peut être soit comme chez les Wolof du Sénégal un esprit ancestral désireux de faire reconnaître son nom dans le culte, soit, comme chez les Ndembu de Zambie, la dent égarée d'un chasseur mort. Dans tous les cas, il s'agira d'extraire cette chose, de la faire sortir du corps tourmenté, hors de l'innommable intérieur. Chez les Wolof, le rab sera nommé, on lui construira un autel, il deviendra tuur, obtiendra un statut cultuel sur l'autel dont l'ancien malade sera l'officiant. Chez les Ndembu la dent errante trouvera sa place sur l'autel ou la besace rituelle d'un jeune chasseur nouvellement initié. Dans tous les cas, l'alternative est claire : ou bien la chose errante, issue des ascendants, demeure incognito dans le corps, et l'on en meurt ; ou bien elle rentrera à nouveau dans le circuit symbolique des rites et des noms. Il n'y a pas d'autre issue : la symbolisation ou la mort. fi faut que l'être humain extraie de sa chair tourmentée le symbole sans lequel désormais il ne saurait vivre. Telle est la dure loi des Pères : le symbole ou la mort, parle ou crève !

Ce que la psychanalyse appelle "le complexe nucléaire de l'enfance" répond à un même problème de transition de l'image au symbole, du corps à corps maternel au "Nom" cause première de l'interdit. Entre la mère et l'enfant la puissance du vocatif intervient en tiers, assignant à chacun sa place marquée pour la vie ou la mort. L'impératif (verbal) est originellement inclus dans le vocatif (nominal).

Mais une loi commune diffère d'un commandement en ce qu'elle est impersonnelle. L'institution sociale ne peut se réduire à des ques-

51 Inutile d'ajouter que cette mise en scène s'accompagne d'une conception essentiellement persécutive du mal (cf. Oedipe africain). 
tions de personnes, comme c'est le cas dans la période enfantine de totale dépendance. C'est seulement sur le mode de la simulation ou de la figuration que la position médiatrice ou normative peut être occupée par quelqu'un : elle devient alors une place réservée aux invisibles, ancêtres ou dieux, aux êtres qui, par-delà la mort, sont les garants de ce qui nous est commun, n'ayant plus pour demeure ici-bas que des noms propres, des monuments ou des rites, des célébrations. Le propre de la simulation, comme le note finement Freud, est de dissimuler sous les apparences du mode indicatif un mode optatif 52 . Là où elle croit nommer des êtres, elle ne peut que transférer des statuts et des rôles, c'est-à-dire des positions institutionnellement marquées qui prescrivent un certain usage de la voix active ou passive des verbes c'est-à-dire exigent certaines dispositions (diathèses) morales conformes à la tradition.

Dans la mesure ou les hypothèses de la psychanalyse sont exactes, s'il est vrai que les rapports de l'enfant avec sa mère débouchent sur l'angoisse de mutilation corporelle et de castration, et que les rapports de l'enfant avec son père sont scellés d'un phantasme de meurtre, alors on peut supposer que cette production par l'enfant "d'un minimum d'invraisemblance générale" (Lorenz) appartient à un procès de symbolisation où le besoin que chacun a de l'autre pour être soi est aussi le cercle vicieux qu'il faut briser pour que s'ouvre, par-delà les questions de personnes, un univers commun. Dans l'échange qui se construit entre la mère et l'enfant, il ne s'agit pas seulement que des marques d'amour découpent en pointillé sur la peau de chacun les emblèmes corporels qui nous rendent chère l'expression humaine, il s'agit aussi de ce fait que la double possibilité de dire "moi" et de s'entendre dire "toi" s'élabore à partir des schèmes généraux de la nomination et des énoncés en troisième personne. A la différence de l'imprégnation animale, l'identification à l'autre chez l'enfant est la genèse de mécanismes régulateurs de plus en plus indirects ("normatifs") qui, pour marquer la position personnelle des partenaires, ne peuvent être représen-

52 Freud, Der Witz, G. W., VI, p. 185. 
tés qu'en un tiers, figurant une loi commune irréductible aux parties en présence. La nécessité de "représenter" c'est-à-dire à la fois de simuler et de symboliser les formes sociales de la reconnaissance réciproque, enveloppe le problème des origines de la vie (le couple géniteur) en assignant au père (c'est-à-dire au partenaire sexuel de l'autre, de la mère) la place d'un tiers, place éternellement distincte des partenaires présents puisqu'elle conditionne logiquement pour eux la possibilité d'attribuer de façon générale aux individus des valeurs de positions, des statuts personnels, des normes sociales de relation. C'est en ce sens que la théorie de l'inconscient équivaut à une critique des jugements d'attribution en psychologie. Dans le triangle œdipien, le père ne peut figurer en position tierce (en garant des attributions personnelles et des assignations nominales), il ne peut représenter la loi de la parole qui sélectionne les possibles en permis ou interdits, qu'en étant d'avance voué à la mort, puisqu'il ne peut être personnellement la loi impersonnelle qui s'institue dans le langage et les formes sociales de la reconnaissance. Le problème que pose l'identification oedipienne est homologue au problème du légitimisme qui nous donne l'illusion de justifier le droit par un "être" (une hypostase individuelle ou collective). La dramatisation naît de la puissance imaginaire et fascinante du spectacle joué en commun, bien qu'il y ait toujours un enjeu où s'inscrivent, entremêlés comme dans une figure composite ou un habit d'Arlequin, les rêves de chacun. Entre l'homme et l'animal il y a la même distance à franchir qu'entre la parade des partenaires et le mémorial des ancêtres, ou, comme dirait Aristophane, entre les plumages et les dieux. Dans Totem et Tabou, Freud soutient que la forme la plus élémentaire où se projette la structure triangulaire du désir est l'objet phobique ; il y voit le début de la théogonie. Dans l'histoire d'Adam et d'Ève, ce qui est le plus important, c'est la pomme, la pomme en qui s'est joué notre destin. Enfin si la religion est une défense contre la psychose, il faut bien qu'elle traduise à sa manière le mélange de nécessité et de hasard, de programmation spécifique et de contingences élues qui, dans le message de la vie, unit le sexe à la parole. C'est ainsi qu'à la base de toute religion se retrouve, sous une forme ou sous une 
autre, la conjonction entre la généalogie et l'oracle, l'héritage commun et l'aléa du destin.

L'hypothèse de Freud, d'après laquelle la religion des ancêtres serait assimilable à une défense obsessionnelle contre l'angoisse semble confirmée par le fait que, dans la clinique africaine, on trouve des traits de comportements obsessionnels mais très peu de structures obsessionnelles vraiment construites. Tout se passe comme si l'individu n'avait pas à construire lui-même un genre de défense que la tradition commune lui fournit d'emblée. En tout cas, si les hypothèses psychanalytiques sur la période critique de l'enfance et la complexe nucléaire des névroses ont une signification universelle, c'est dans la mesure où elles peuvent être mises en parallèle d'une part avec certaines données de l'éthologie animale (comme le problème de l'imprégnation), d'autre part avec certaines questions anthropologiques fondamentales, telles que la nature du droit et de la religion. La plupart des discussions sur les rapports entre la psychanalyse et l'ethnologie se sont malheureusement perdues dans les brumes de la psychologie des peuples. Le mérite du livre de Meyer Fortes est de maintenir la question sur son véritable terrain : il traite du culte des morts dans son rapport au droit coutumier ; il traite du destin, et non pas seulement de l'éducation ; il pose le problème de l'individuation humaine et non seulement de l'apprentissage il souligne l'enracinement de l'impératif dans un vocatif (Fatum, Beruf, Officium).

Mais je m'aperçois que je n'ai pas encore parlé d'Oedipe ni de Job. J'en demande pardon à Meyer Fortes, mais c'est le seul point de son argumentation que je ne saisis pas très bien. Lorsqu'il se demande pourquoi le destin d'Oedipe est irrévocable, j'ai envie de répondre : "parce que c'est un destin royal". Oedipe est un roi juste et bon ; il n'a enfreint aucune des lois de la cité. Mais pour qu'il ne soit plus en reste à l'égard des lois de la famille, pour qu'il ait payé sa dette vitale, il faut qu'Oedipe devienne un ancêtre. A ce moment-là seulement, la loi de la famille enfin satisfaite justifiera, sur le lieu inconnu du tombeau de l'Aveugle, la légitimité des lois de la Cité. 
Quant à Job (du moins tel qu'il apparaît dans les additions du texte canonique), il a péché, en usurpant, comme dit très bien Meyer Fortes, un statut de juge qui n'est pas le sien. Or la notion de "péché" soulève, du point de vue psychiatrique, la question difficile des rapports entre les délires à thème de persécution et les délires à thème de culpabilité. Cette question revêt une acuité spéciale dans la clinique africaine, du fait que, dans certaines populations au moins, la dépression est nettement disjointe de la mélancolie. Mais pour aborder cette question, il aurait fallu examiner de très près les rapports entre les rites divinatoires et les rites propitiatoires (ou "de guérison") chez les Tallensi. Ce serait là une autre affaire qui déborde le cadre d'Oedipe et Job dans les religions ouest-africaines, ce petit livre qui réunit en si peu de pages une extraordinaire richesse de notations, d'importance capitale pour l'anthropologie. 
Religions du livre. Religions de la coutume

\section{Chapitre IV \\ LE MYTHE FRAGMENTAIRE *}

$\underline{\text { Retour à la table des matières }}$

À l'occasion de ce colloque sur la parole dans les religions africaines, je voudrais présenter quelques hypothèse concernant l'état des paroles et des croyances mythologiques à l'intérieur de la célébration du culte.

Je commencerai par la question : qu'est-ce qu'un mythe ?

Suivant le dictionnaire de Littré, on appelle "mythe" non pas nécessairement un récit mais un trait, un trait fabuleux faisant intervenir des divinités ou des puissances du temps primordial. "Si les divinités n'y sont pour rien, ce n'est plus mythe, c'est légende" 53 . Alors que le conte et la légende sont des genres littéraires aisément repérables, le mythe n'a pas une forme constante. On le définit principalement par son objet, son domaine. Son domaine est celui des croyances religieuses ou métaphysiques, celui où l'ordre social et l'ordre des choses peuvent être réunis en un même tout par référence à des origines antérieu-

* Conférence au colloque Szondi à Cerizy-La Salle, 1979, sur la psychologie du destin.

53 Dictionnaire de Littré, art : "Mythe". 
res à l'apparition du mai ou à des fins dernières ultérieures à la mort, au-delà des limites de la condition humaine. Puisque le mythe évoque plus ou moins directement des questions de genèse, on conçoit que sa forme soit principalement narrative ${ }^{54}$. Pourtant cette forme n'est pas fixe, elle revêt plusieurs états, elle oscille depuis le récit jusqu'au simple dit allusif.

Si l'on préfère réserver le mot "mythe" pour désigner la forme pleine du récit, alors il faut dire que le mythe, en ce sens, n'occupe dans la religion qu'une place seconde, intermédiaire entre le culte et le folklore, entre les paroles à caractère performatif et celles qui sont simplement narratives. Le plaisir de raconter tend à organiser son propre scénario rituel : la tradition désigne les personnes et les moments convenables pour raconter telle ou telle chose ; les divers genres de récits peuvent être marqués d'interdits différents, il y a des récits de jour et des récits de nuit ; enfin des formules stéréotypées annoncent l'introduction et la conclusion comme s'il fallait sanctionner par une procédure les libertés qu'a prise la parole à s'aventurer dans le domaine étrange. Bien entendu, le plaisir de raconter se goûte, comme tout plaisir, entre les vivants. C'est pourquoi, même lorsqu'on évoque le souvenir des personnages de l'au-delà, on y mettra quelques prudences, voire quelques transpositions, car le plaisir de raconter tend à devenir profane c'est-à-dire à glisser parmi les choses offertes bonnement au droit de jouissance. Il faut être prudent, car on ne sait jamais. Malgré toutes les garanties officielles, on n'est jamais tout à fait sûr que les êtres de l'au-delà ne vont pas intervenir d'une manière "anarchique" dans ce qui se passe entre les vivants.

Par contre, il est entendu que l'on réserve à certaines activités rituelles, en particulier celles qui concernent les sacrifices et les "passages" institutionnels (mariages, naissances, initiations, funérailles), la tâche officielle de faire intervenir à titre d'acteurs participants les êtres

54 "Il n’est pas nécessaire (lue le mythe soit un récit de forme historique bien (lue c'en soit la forme la plus ordinaire" (Littré, ad loc.). 
de l'au-delà. On peut appeler "Culte religieux" le domaine dans lequel la participation active des êtres mythiques est officiellement prévue par la Coutume. Bien entendu, pour rendre compte du mythe, il faudra chercher à expliquer la nature de ces acteurs supplémentaires qui viennent, à pas invisibles, grossir de leur présence l'assemblée des vivants. Le mot "mythe" nous place donc sur un chemin de crête entre deux versants : plus on parle des Invisibles, plus on tend à en faire les héros d'aventures qui se sont passées autrefois, dans les lointains ; au contraire plus les Invisibles deviennent les participants actifs de ce qui se passe actuellement dans l'assemblée, plus la parole devra savoir qu'elle s'adresse à eux ou qu'elle est prononcée en leur nom.

Nous devrons donc distinguer deux états de la forme mythique la forme pleine du récit qui satisfait au plaisir de raconter en se rapprochant du folklore ou de la reconstruction littéraire ; et d'autre par l'état proprement religieux et cultuel du mythe dont la forme est fragmentaire, morcelée, allusive, dispersée en divers contextes liturgiques ou institutionnels. Ma thèse sera que les haillons de la sagesse n'ont pas besoin de couturiers.

Pour éviter tout malentendu, laissons provisoirement de côté le mot "mythe". Considérons les formes sous lesquelles s'expriment les croyances à l'intérieur du culte. Pour mieux souligner qu'il s'agit là d'une donnée universelle et non pas seulement d'une particularité archaïque, envisageons d'abord le cas des religions les plus riches en expressions littéraires. Ouvrons le missel ou le bréviaire romain. Qu'y trouvons-nous ? Des fragments de Bible, des antiennes encadrant des psaumes, des répons, des hymnes, des oraisons, des litanies, des "leçons" extraites des Pères de l'Église, des "péricopes" ou sections de l'Évangile ou de l'Ancien Testament. Pour mieux adapter la Bible à la récitation rituelle on l'a divisée en versets. $\mathrm{Y}$ a-t-il formes plus typiques de l'expression rituelle que l'invocation, la litanie, la péricope, le verset ? Partout, pour atteindre au coeur, l'Esprit casse la Lettre. Le même décousu, caractéristique d'une pensée religieuse vivante, se retrouve dans la confection des Livres Saints : des collections de Logia 
ont précédé les évangiles ; les plus vieilles sourates du Coran ont été écrites, dit-on, sur des ossements et d'autres matériaux disjoints ; la Bible d'Esdras est une marquetterie de "documents". Et même en ce qui concerne le contenu des Livres Saints, il semble que les sémites aient poussé jusqu'au sublime le génie du bric à brac. Mais avons-nous donc oublié qu'avant d'écrire, sous l'influence des philosophes païens, des Sommes théologiques, nos théologiens ont dû pendant des siècles s'exercer aux commentaires des "Sentences" ? Les dogmes du Magistère ont fidèlement conservé cette forme minimale qui permet aux intéressés de risquer leur vie pour un iota (homoosios/homoiousios).

La forme discontinue de la pensée religieuse en son état liturgique est semblable aux merveilles de l'instinct ; elle manifeste l'un des caractères les plus constants, les plus profonds de la psychologie humaine. Elle épouse les élans du coeur c'est-à-dire la discontinuité des fantasmes. Comme dans les slogans, comme dans les invectives, les objurgations, les sanglots, les appels de détresse, les traits d'esprit, les saluts de l'amitié, les maximes des sages. Les paroles vénérables sont brèves. Elles existent de la même façon qu'existe notre conscience quotidienne, scintillant dans la nuit comme un vol de lucioles qui alternativement brillent et s'éteignent.

Toutes les littératures anciennes ont cultivé le genre gnomique des sentences, proverbes, énigmes et paraboles. Le sage d'Israël dans sa Beth-hamidrash enseignait le mashal. Les sages de la Grèce parlaient par centons et aphorismes, à quoi l'on donnait précisément le nom de "muthoï" (d'une racine désignant la pensée, le contenu de la parole).

Enfin sous quelles formes s'expriment les traditions religieuses africaines ? Il arrive que de jeunes ethnologues, après un séjour prolongé dans quelques villages africains, se plaignent de n'y avoir pas trouvé de "mythes". Sans doute ils ont bien trouvé, disent-ils, quelques contes ou légendes intéressant le folklore, mais en ce qui concerne les traditions proprement religieuses, ils sont déçus, ils n'ont pu récolter autre chose que des noms d'êtres ou de puissances cachées, des invo- 
cations, des chants, des énigmes, des sentences allusives... Pourtant lorsqu'on réunit tous ces fragments épars en les replaçant dans le contexte des institutions et des rites, on voit se dessiner un système religieux comparable à ceux que l'on trouve dans les populations plus riches en littérature orale.

D'ailleurs qu'arrive-t-il lorsque l'ethnologue a enfin trouvé "celui qui sait" ? Dans les Entretiens de Marcel Griaule avec Ogotemméli, on a surtout été frappé par l'ampleur des conceptions Dogon liant l'ordre du monde à celui de la société, du coup on a presque oublié le contraste saisissant entre les propos décousus du vieux sage et la ténacité raisonneuse de l'ethnologue qui, jour après jour, au rythme des chiques à tabac, arrache bribes à bribes les éléments de ce qui, dans "les ultimes récapitulations", va devenir un système du monde, système qui, note Griaule, n'est jamais donné comme tel ${ }^{55}$. Ainsi donc quand le grand mythe fut enfin trouvé, on faillit ne pas voir ce qui dans cette découverte avait coûté tant de peines et demeurait le résultat le plus incontestable: le grand mythe n'existait qu'en lambeaux. Toutes les recherches ultérieures en pays Dogon, Bambara ou ailleurs, ont confirmé cette donnée essentielle : partout le travail de l'ethnologue consiste à recueillir -patiemment dans la lenteur des réticences, des faux semblants, des atermoiements, les lambeaux d'une "connaissance" dispersée en divers contextes cultuels ou institutionnels.

Griaule a beaucoup insisté sur le système du monde chez les Dogon. Mais un système du monde n'est pas forcément religieux. Il ne l'est que par ses conséquences pratiques et la façon dont à engage une certaine conception de la vie humaine.

Par exemple on peut montrer que, dans une religion mystique comme le bouddhisme, le système du monde s'oppose radicalement au système des lignages. L'image du monde opère ici par limitation ; elle situe la destinée humaine entre deux limites : la roue des naissances et

55 M. Griaule : Dieu d'eau, ed. du Chêne, Paris, 1948, p. 254. 
le nirvana. Dans la roue des naissances et des morts nous reconnaissons assez bien la loi des lignages. Mais pour le bouddhisme il s'agit de nous arracher à cette roue des naissances et des morts qui est le lieu de la souffrance, de même que le bouddah çakyamuni s'est arraché luimême aux liens de son lignage pour devenir moine et prédicateur itinérant. Le sujet de la religion n'est plus lai, communauté religieuse mais l'individu, Ego. Ego devra finalement s'arracher à lui-même comme il s'est arraché à son lignage ; il devra pour cela faire mourir en lui les sources du désir. Le désir a une source cosmique qui ne pourra s'abolir qu'au delà du monde. En Afrique la roue des naissances et des morts c'est-à-dire la métempsychose garde un caractère familial et amoral, en ce sens que les grands-parents défunts peuvent, s'ils le désirent, revenir vivre dans leurs petits enfants. Mais dans le bouddhisme la métempsychose est une loi cosmologique de rétribution morale qui sanctionne l'attachement du désir aux choses terrestres de telle sorte qu'Ego ne peut s'en délivrer que par la voie du détachement et de l'illumination. Dans la philosophie de Platon qui est également une doctrine mystique, il y a une corrélation stricte entre Ego et le Cosmos. Le lien direct entre Ego et le Cosmos s'appelle maintenant "Eros". Écoutez ce que dit Antigone : "Eros, invincible Eros qui tombes sur tes proies et qui sommeilles sur les joues des filles, tu vagabondes sur la mer et dans les repaires des bêtes sauvages. Nul parmi les Immortels ne peut t'échapper, nul parmi les hommes éphémères.. Par toi vient d'éclater cette querelle entre des êtres de même sang. Il triomphe, rayonnant de ses yeux, l'amour de la désirable fiancée, l'amour qui est le parèdre (l'allié) des grandes lois du Cosmos dans les origines" (Antig. 781-800). Eros, qui introduit la querelle dans le lignage, est donc l'allié du Cosmos. C'est lui qui, désormais, individualise Ego. On retrouve le mythe d'Eros non seulement dans le Banquet de Platon mais aussi dans la Théogonie d'Hésiode. Il vaut la peine de relire le texte de la Théogonie (116-201), car nous y voyons un mythe généalogique analogue à ceux que l'on trouve chez les Dogon, sauf qu'ici des entités cosmologiques abstraites remplacent les entités "ancestrales" familières aux traditions africaines. 
"Tout à fait au commencement naquit Chaos (Vide Béant), puis Terre aux larges flancs, assise sûre pour toujours, et Amour (Eros) le plus beau d'entre les dieux immortels, le délieur de membres, amour qui, dans la poitrine de tous les dieux et de tous les hommes, dompte la raison et la volonté réfléchie. De Chaos naquit ensuite Erèbe avec la noire Nuit. Puis de Nuit sortirent Ether et Jour. De son côté Terre enfanta d'abord un égal à soi, capable de la couvrir tout entière, Ciel étoilé, afin qu'il soit pour les dieux une assise solide pour toujours. Elle enfanta ensuite les grandes montagnes, aimables lits des déesses et des nymphes, habitantes des eaux. Et la mer stérile soulevée de vagues. Elle les enfanta sans tendresse d'amour.

Mais ensuite des amours d'Ouranos, elle enfanta Océan, à la profondeur tourbillonnante, Croios, Crios, Hypérion, Japet, Theia, Rheia, Themis et Mnémosyne, Phébos couronné d'or et l'aimable Thetis. Le plus jeune après eux naquit Cronos aux pensées fourbes, le plus terrible des enfants. Mais Cronos haït son père fécond"..

Si l'on met entre parenthèses le nom des entités énumérées pour ne retenir que les relations généalogiques, on retrouve un schéma comparable aux mythes africains du Mandé. Le schéma mythique oppose deux modes de naissance : par scissiparité à partir d'un terme unique (premier alinéa) ou par accouplement entre Terre et Ciel grâce à l'intermédiaire d'Eros (deuxième alinéa). Mais en Afrique un mythe de ce genre se terminerait par une liste de lignages c'est-à-dire par une allusion aux règles du mariage. Ici nous n'avons qu'une liste de Titans. Et, dans le texte d'Hésiode, le mythe cosmogonique prélude à l'histoire des aventures amoureuses de Zeus enlevant les filles qui lui plaisent. Ce thème du dieu amoureux ou des amours libres de Zeus est, certes, une idée géniale par son individualisme, mais c'est une idée romanesque. Ainsi chez les Grecs le mythe d'Eros débouche soit sur la mystique (Platon), soit sur le romanesque (cf. le roman d'Eros et Psyché). On remarquera comment la genèse cosmique est une transposition du schéma généalogique, mais au lieu de nous conduire, comme en Afri- 
que, aux règles matrimoniales d'un système de parenté, le mythe des origines débouche sur l'Egotisme du romanesque et de la mystique.

Si j'ai développé cet exemple, aux antipodes de la pensée dogon, c'est pour rappeler que la représentation du Cosmos peut avoir des fonctions religieuses non seulement diverses mais incompatibles entre elles. Lorsque Griaule découvre dans les propos de son informateur "une clé du système méditerranéen du Zodiaque, bien que, détail piquant, ce système fut inconnu comme tel des Dogon" (op. cit., p. 254), on ne peut que s'interroger sur le syncrétisme de cette conclusion. Revenons à notre problème initial. Après avoir dit que le caractère évocateur et souvent incantatoire des paroles rituelles étaient lié à la présence effective des êtres ou des forces mystérieuses dans le cérémonial liturgique, nous nous étions demandés comment il était possible à partir de là de reconstituer un système religieux. Nous avons achoppé sur une difficulté touchant les représentations du "monde".

Une autre tentative de synthèse, très intéressante, est celle que propose Nadel dans sa "Religion des Nupe" 56. Nadel expose "le Credo" des Nupe. En réalité, le mot "Credo" est employé ici de manière impropre. On appelle "Credo" le formulaire solennel d'une profession de foi à la première personne du singulier, ce qui suppose une orthodoxie où la confession personnelle de la foi est nécessaire au salut éternel. Or il n'y a rien de tel chez les Nupe. Leur conception de l'autre monde, comme l'explique très bien Nadel, n'a rien à voir avec l'idée de rétribution morale ou de sanction d'outre-tombe. L'éthique religieuse est celle de la fécondité et de l'obéissance aux anciens. Et Nadel décrit avec des notations très fines le morcellement des croyances religieuses au moment même où il reste hanté par le schéma du Credo monothéiste. Tous ceux qui ont travaillé au sein d'une population où l'influence islamique est assez forte, comme c'est le cas dans le Nord Nigeria, connaissent bien cet embarras; on se trouve aux prises avec deux types de religions, dont l'un met l'accent sur "la Doctrine", l'autre

56 S. F. Nadel : Nupe Religion, Roufledge-Kegan, London, 1954. 
sur "la Coutume", mais avec des interférences fréquentes entre les deux.

"Nous devons noter ici, écrit Nadel 57, que les Nupe n'ont aucun nom spécial pour désigner globalement leur religion. Ils ont des noms seulement pour des conceptions particulières, des pratiques singulières, des cérémonies locales. En ce qui concerne le Credo total, les Nupe ne peuvent le décrire que par le biais de détours et d'énumérations (circuitously and enumeratively), comme étant concernés par le dieu Soko et non pas telle autre divinité nommée différemment, par tel rituel ou "médicament" et non pas tel autre, par tel esprit et non par tel ancêtre etc... Cependant il y a néanmoins pour eux un Credo total. Si l'on objecte que cela ne peut être puisque, dans ce cas, les gens auraient trouvé le moyen de sommer tous les aspects dans un nom indicatif de leur unité dominante (comme lorsque nous parlons du christianisme, de l'Islam, du Bouddhisme), la réponse est qu'ils ne pensent pas leur Credo de cette façon. Tel qu'ils le pensent, il n'a aucune identité à part sa validité pour une société, de telle sorte, qu'il n'y aurait aucun sens à le définir comme un concept séparé. En d'autres termes, la religion des Nupe est une religion tribale, et elle n'a d'unité que dans la mesure où une tribu ou nation la revendique comme sienne".

Ce texte est remarquable. Nous verrons tout à l'heure que Nadel expose d'une manière très pénétrante le corps des croyances ou le système religieux des Nupe. Mais auparavant je voudrais faire quelques observations sur la formule qu'il utilise "le Credo total". Cette formule sonne bizarrement à des oreilles chrétiennes. Si Nadel avait lu la Grammar of Assent du cardinal J.H. Newman ${ }^{58}$, il aurait senti qu'en pareil contexte l'adjectif "total" souffre de désinvolture.

Arrêtons-nous un instant sur la grammaire de l'assentiment de Newman. Je m'excuse de recourir à une nouvelle digression, mais il le

57 op. cit, p. 2.

58 J. H. Newman : Grammar of Assent, London, 1891 (Longmans). 
faut bien si nous avons besoin de comparer les religions pour apercevoir l'originalité de chacune. Or une religion de la foi n'utilise pas tout à fait les mêmes genres de division et de composition qu'une religion de la coutume. Newman distingue dans l'énoncé d'une croyance deux parties : un verbe d'assentiment et une proposition. Lorsqu'une proposition sert de complément à un verbe d'assentissement, elle est mentionnée comme exprimant l'objet de l'assentiment à ce titre, eue n'est pas directement référentielle mais expressive or ce qu'elle exprime, dit Newman, c'est la signification "réelle" de l'assentiment. Par contre, lorsque la proposition est utilisée comme proposition indépendante,, elle se prête à des "inférences" (des raisonnements théologiques). Mais alors la prémisse théologique a la même fonction logique qu'une hypothèse ; le langage de la foi est utilisé d'une manière simplement "notionnelle" pour les besoins du raisonnement. Pour faire comprendre la pensée de Newman, prenons un exemple simple. Les articles de foi qui composent le Credo sont des unités "notionnelles" qu'utilise saint Thomas pour concevoir le plan de la Somme théologique. Par contre le chant (Newman dit bien "le chant") du Credo à la messe solennelle exprime l'assentiment "réel" du fidèle au mystère de la foi. Que veut dire ici le mot "mystère" ? Newman explique que le mystère n'est pas l'invisible (c'est même plus souvent le visible qui est mystérieux) ; le mystère est le tout de la foi, mais le propre de ce tout c'est d'être inimaginable. Selon Newman, le mystère naît du contraste entre la plénitude de l'assentiment qu'il requiert, et la partialité des images ou des notions qui le représentent comme inimaginable en sa totalité. ${ }^{59}$ On peut le comparer à la diffraction de la lumière. La lumière du vitrail est d'essence mystérieuse parce qu'elle est brisée. Le secret divin ne serait qu'une pâle abstraction sans la brisure intérieure qui le colore d'émotion. Il ne suffit pas que le ciel étoilé soit au-dessus de nos têtes pour que le sublime apparaisse, il faut que s'opposent le haut et le bas. Il faut que le devin se tourne vers le Sud, puis vers l'Ouest, puis vers le Nord et enfin, vers l'Est, pour que l'immensité se peuple

59 Grammar of Assent, p. 130 sq. - Sur la lumière brisée, p. 132, et le chant du Credo comme un hymne, p. 133. 
de signes. Ces images évoqués par Newman nous rappellent les religions de la Coutume. Mais vous voyez qu'il y a deux sortes de divisions : il y a les divisions notionnelles du théologien raisonnant sur les articles de foi ; et il $\mathrm{y}$ a les divisions rituelles où se propose à l'assentiment du fidèle le mystère de la présence réelle. Dans une religion de la Coutume, il n'y a pas de magistère formulant des dogmes, mais il y a le mystère, l'imagination fragmentée de l'inimaginable.

Essayons de voir comment. Et reprenons pour guide l'exposé de Nadel. Je m'en tiendrai aux grandes lignes, au cadre général de la religion, car ce cadre général me semble commun à beaucoup de religions ethniques en Afrique.

Au centre de cette religion, qu'y a-t-il ? il y a quelque chose qui a un nom ; ce quelque chose s'appelle chez les Nupe le "kuti" comme ailleurs on dit "le poro" etc... C'est un rituel qui est aussi un lien social. C'est cela que les Africains nomment en français "la Coutume", la Coutume par excellence, celle qui est possédée collectivement par une communauté ethnique ou villageoise. Ce rituel coutumier n'a rien à voir avec l'idée de ce que nous appellerions "la vraie religion". Le voir ainsi serait de notre part un contre-sens radical. Simplement le rituel coutumier a une certaine force pour faire ce qu'il a à faire. Si on en trouvait un autre qui ait plus de force, peut-être qu'on en changerait. Chaque peuple possède le sien, et grand bien lui fasse : On n'est pas intolérant. À chacun "ses affaires", comme l'on dit au Sénégal, pour désigner un sanctuaire. Les Nupe disent que Dieu a créé les hommes, les animaux, les esprits, et le rituel coutumier (le Kuti) ${ }^{60}$. Le rituel est énuméré parmi les créatures de Dieu ; il est une sorte d'être parmi les autres. Le rituel en soi est une sorte de machinerie surnaturelle qui a une fonction médiatrice ; comme dit Nadel, c'est "une chose dans l'entre-deux" ("a thing-in-between"); il aménage les rapports statutaires entre les hommes et les femmes, les vieux et les jeunes, et consacre de sa puissance le bon fonctionnement des institutions.

60 Nadel, op. cit., p. 13. 
En tant qu'il est la propriété collective du groupe, le rituel coutumier se distingue des "médecines" qui sont la propriété d'un spécialiste. Notons ici qu'il n'y a pas lieu d'opposer magie et religion. Si les historiens emploient très souvent l'expression "Magico-religieux", c'est qu'en effet la magie est elle-même une valeur religieuse, qui est présente dans toutes les religions. Si le mot "magie" a une connotation péjorative, c'est qu'on ne l'applique généralement qu'à la religion des autres. Mais l'idée du signe efficace est absolument générale; elle nous paraît plus religieuse quand elle procure des biens spirituels, et plus magique quand elle procure des biens matériels, mais ce n'est là qu'une question de contexte éthique et culturel. Plus importantes sont les différences dans le mode d'action. On confond trop souvent le mode d'opération magique, dont on peut discuter les caractéristiques, avec les buts auxquels on peut faire servir cette opération. C'est pourquoi lorsque nous ne partageons pas les valeurs idéologiques d'une religion, nous sommes davantage frappés par son mode d'opération. Il est donc indispensable de pouvoir regarder notre religion avec les yeux des autres.

Le rituel coutumier, qui est la possession de la communauté, et les "médecines", qui appartiennent à des spécialistes, sont caractérisées par leur efficacité magique ou symbolique. En cela ils se distinguent de la prière dont le succès demeure incertain. Les Nupe ont un joli dicton à ce propos : "Si quelqu'un dit : Donne-moi cela pour l'amour de Dieu, je ne lui donnerai rien; s'il me dit: donne-moi cela pour l'amour du gunnu, du rituel d'initiation, ça y est, je le lui donne" 61.

Nous avons désigné jusqu'ici ce qui est au centre du système religieux. Mais ce centre est lui-même situé entre deux pôles : d'un côté les Ancêtres, qui sont les principaux bénéficiaires du sacrifice, de l'autre la divination qui est une affaire de spécialiste mais qui est destinée à capter les messages de l'au-delà. Ainsi le schème de la Généalogie

61 Nadel, op. cit., p. 15. 
d'une part, et l'oracle ou le schème de la révélation d'autre part sont les deux colonnes extrêmes qui supportent le système et encadrent "la Chose dans l'entre-deux".

La première colonne, avec sa référence aux Ancêtres, aux origines cosmiques ou ethniques, aux genèses, aux héros fondateurs, est ce que j'appelle, pour faire image, le schème généalogique. La communauté y trouve ses racines, sa carte d'identité collective, en même temps qu'un certain nombre d'explications susceptibles d'être racontées. Et comme il ne dépend ni de vous ni de moi d'avoir tels ancêtres plutôt que d'autres, il est clair que les religions ethniques n'ont pas de "foi" qui serait exportable.

La seconde colonne, celle des oracles et de la divination, est le domaine des interrogations susceptibles de recevoir une réponse, le domaine des présages, des ordalies, des jugements divins, toutes choses concernant des cas singuliers ; l'interprétation des oracles est casuistique ; et lorsqu'elle généralise ses décrets, la prophétie se dit en paraboles et en énigmes. Alors que dans le schème généalogique domine le lien du sang ou l'éternel retour de la vie, dans le schème de la révélation dominent la menace vitale et le Signe venu d'Ailleurs. Les secrets divinatoires sont présentés souvent comme matière d'importation : à Rome ils venaient d'Etrurie ; à Delphes ils venaient du pays des Hyperboréens, dans le Cap Vert ils viennent du Mandé, et l'on m'a dit qu'au Mandé ils venaient de Dieu ; on n'en saurait situer plus loin l'origine, à moins d'imaginer par delà les dieux je ne sais quelle Moïra... Chez les Hébreux la révélation venait du Sinaï ou plus exactement d'un pays volcanique, le Horeb. La révélation est le côté exportable de la religion, le côté d'où les prophètes et les apôtres recevront leur mission. Sans doute, un peuple peut très bien adopter le rituel coutumier d'un autre peuple mais en cela il ne fait que s'approprier une bonne recette. La révélation des oracles, au contraire, a des affinités bohémiennes ; elle a la nature de ce qui arrive, et, comme tout ce qui arrive, elle arrive d'ailleurs. 
Il existe pourtant une relation entre les solidarités ancestrales et le signe venu d'ailleurs. Cette relation existe puisque ce qui arrive dépend, au moins en partie, de la volonté des ancêtres ou des dieux. Cette relation pourtant est mystérieuse. Et c'est à partir du culte qu'il nous faut chercher comment la dimension du mystérieux s'introduit dans la référence aux ancêtres. Seuls sont ancêtres les morts qui ont acquis la dignité du statut ancestral. Les funérailles sont destinées à conférer ce statut. De même on ne comprend pas ce qu'est une religion de la fécondité, si l'on ne voit que les mariages sont destinés à procurer aux ancêtres une descendance et par là un culte perpétuel. Lorsque le romain Claudius se fit adopter par une famille plébéienne et transforma son nom en "Clodius", il se vit reprocher par Cicéron de mettre fin, par sa faute, à la religion de la gens Claudia. C'est dans le même esprit qu'il faut entendre le thème africain de la fécondité. Nadel dit que la religion des Nupe est foncièrement "amorale", utilitaire, ce qui est exact si l'on prend notre morale comme étalon de mesure. Mais il faut changer d'étalon. Pour comprendre ce qu'est la fécondité, il faut partir des ancêtres. Et pour comprendre ce qu'est un ancêtre, il faut partir du culte, et non pas du seul fait de la mort. Les grands ancêtres sont les ancêtres fondateurs; ils ont une double fonction : ils ne sont pas seulement le point de départ d'une généalogie ou d'une descendance, ils sont aussi dans le présent les destinataires d'un culte, et à ce titre ils sont des entités spirituelles ou surnaturelles. À travers cette double dimension du statut ancestral, la référence à l'origine se donnera comme référence à une unité scindée, une scission primordiale dont les mythes développent le thème sous des images diverses. Le monde surnaturel pourra être plus ou moins peuplé ; il peut contenir non seulement des ancêtres, mais des esprits ou des dieux, mais, en Afrique au moins, toute cette population est poreuse ; ces entités sont aisément substituables l'une à l'autre par un simple glissement de la pensée. L'essentiel n'est pas dans les personnages, si je puis dire, mais dans le double caractère de la référence aux origines, à travers la suite des générations et le cycle liturgique de la vie communautaire. Le culte idéalise son objet ; ce faisant il atteint bien l'être des origines, mais il l'atteint comme perdu, et retrouvé seulement en esprit, comme une entité 
mystérieusement présente et agissante. À la limite, le secret de l'initiation est que le mystère n'est rien qui puisse se dire, mais seulement il se montre dans l'accomplissement du rite.

Le rapport entre l'origine et la révélation se montre en particulier dans le sacrifice puisque le sacrifice peut avoir la double fonction d'offrande faite par l'homme, et de signe divinatoire envoyé par les dieux ou les ancêtres. Le sacrifice existe lui aussi comme une chose en soi, une entité à qui l'on parle et qui agit. Cette conception nous paraît grossièrement magique, mais lorsqu'on demande pourquoi il en est ainsi, on vous répond que l'efficacité du rite est quelque chose que l'on ne peut pas comprendre. Cela échappe complètement à l'intelligence des hommes. Cette réponse est aussi raisonnable que n'importe quelle réponse théologique : l'efficacité sacramentelle est un mystère Que voulez-vous savoir ? Agenouillez-vous, prenez de l'eau bénite. La réponse de Pascal est exactement la même que celle des Maîtres de Sagesse dans les savanes africaines. Encore une fois, les valeurs et les fins que l'on se propose sont différentes, mais l'appareillage liturgique met en oeuvre des mécanismes ou des dialectiques semblables.

Le sacrifice n'est pas seulement une circulation de forces invisibles, de prestations et de contre-prestations entre l'ici-bas et l'au-delà. S'il a son efficace en lui-même, c'est qu'il est une manière de signifier à la limite, comme si l'on voulait faire exister un signe au lieu même où il n'y a pas de réponse. Le sacrifice n'est ni chose ni signe, mais l'on ne peut en parler qu'en le traitant tantôt comme chose et tantôt comme signe. Verser le sang, c'est rendre visible le secret de la vie, le lien mystérieux des générations, mais au moment même où cette vie fait paraître à la clarté du jour son propre symbole, elle s'écoule à jamais perdue, et les derniers sursauts du poulet dans la poussière semblent un sourire d'espoir qui sans écho se fige. Ce mouton égorgé sous les mouches est un symbole évanescent qui redevient chose brutale, hors l'instant presque insaisissable, l'instant rêvé de l'acte sacrificiel. À l'entour de la victime, dit l'épopée de Gilgamesh, "les dieux s'assemblent comme des mouches", à l'extrême limite de l'évanescence. 
Il est temps de conclure. Je me suis demandé pourquoi la pensée mythique s'égrène en formes allusives dans l'accomplissement des gestes rituels. Beaucoup de textes religieux africains ont une texture décousue, difficilement intelligible parfois. On pourrait n'y voir qu'un défaut de composition. Mais on retrouve ailleurs des phénomènes équivalents, abstraction faite des questions purement littéraires. Il y a là un fait dont on doit tenir compte lorsqu'on cherche à expliciter ce qu'à est convenu d'appeler "un système" religieux.

Que dirai-je pour finir ? il faut bien cueillir la rose pour l'offrir à la bien-aimée. Il faut bien sacrifier quelque chose pour que naisse la métaphore. On ne peut *pas gagner sur tous les tableaux. Il ne suffit pas de dire avec Freud que les constructions de la fantaisie masquent le retour de l'objet perdu, il faut ajouter la nécessité qu'une chose soit perdue pour que naissent en nous des possibilités intérieures qui nous soient propres. Pour mieux faire entendre ce que je veux dire par là, je préciserai que la religion et la psychose me semblent être deux manifestations d'un même drame humain, dans l'une et l'autre réapparaissent certains gestes élémentaires et fondamentaux. Je me souviens de l'enfant autistique qui, un soir, sur la grève, jette son jouet le plus aimé dans la marée descendante, et sûr désormais de ne plus le revoir, peut enfin prononcer : "Maman, ballon !". Les deux premiers mots qu'il eut jamais prononcés contenaient déjà tout ce qu'il faut pour faire un homme : pouvoir nommer les origines de la vie, et sacrifier quelque chose pour en faire un signe de révélation. 
Religions du livre. Religions de la coutume

\section{Chapitre V \\ Gémelléité, inceste et folie chez les Bambara et les Dogon *}

Les populations de l'Ouest Africain qui, à tort ou à raison, se prétendent issues du pays Mandé (Dogon, Bambara, Bozo, Samogo etc..) voient dans le principe de gémelléité l'origine de toutes choses et tendent à assimiler tout rapport d'alliance à un rapport de gémelléité 62 .

Formellement il y a là un paradoxe. En effet, tres faciunt collegium. Tout rapport de communication, d'échange ou d'alliance comporte nécessairement un minimum de trois termes (ou davantage) sans quoi la relation ne pourrait être conçue comme telle c'est-à-dire comme distincte des termes relatés ; toute relation symbolique, por-

* Texte polycopié : DAKAR. 1963.

62 Les mythes existent en plusieurs versions. Les principales sont : version Dogon (M. Griaule, Dieu d'Eau, Paris, 1948) ; version Bambara (G. Dieterien : Essai sur la Religion Bambara, Paris, 1950) ; version mandingue (G. Dieterlen, Mythe et organisation sociale au Soudan Français, in Journal de la Société des Africanistes, t. XXV, 1955 et t. XXIX, 1959). 
teuse de sens, est une relation médiate, le tiers médiateur étant au moins virtuellement impliqué dans "le point de vue" sous lequel on conçoit à la fois ce qui distingue deux termes et ce qui les unit, ce qui les pose comme valeurs distinctives dans un système.

Par contre la gémelléité (considérée non comme réalité objective mais comme valeur d'information ou de langage) est une relation du semblable au semblable où le Même est l'Autre de l'Autre et où l'Autre est le Même, dédoublement fantasmatique de la représentation qui définit la forme équivoque de l'imaginaire comme relation duelle ou spéculaire (en miroir), relation privée de médiation qui ne peut que se répéter indéfiniment (automatisme de répétition comme une image entre deux miroirs parallèles) ou se figer dans une représentation matérielle, une chosification, un double mortifère (Narcisse, Eurydice..). Cette forme duelle marque d'une place vide l'absence de médiateur, l'impossibilité de recevoir une réponse comme dans le rêve où l'émetteur et le récepteur tendent à s'identifier, tentative impossible qui reconstitue indéfiniment la dualité interne de l'appel.

\section{La gémelléité}

Le dialogue de l'alliance ne peut donc se réduire au cercle vicieux de la gémelléité, sinon dans la mesure où il y trouve sa propre limite. L'examen des mythes Bambara et Dogon montre que le rapport spéculaire tend à se produire en deux directions où la pensée se heurte à une contradiction, une limite pour elle infranchissable : soit dans le mouvement du retour à l'origine, soit dans le mouvement qui tend à constituer le groupe social comme une totalité. Ces deux mouvements sont solidaires : la façon même dont la société se totalise la ramène sans cesse à répéter le drame de l'origine.

Tous les alliés sont considérés comme des jumeaux : ce peut être deux individus comme l'époux et l'épouse, ou deux lignages parents par alliance, ou deux peuples comme Dogon et Bozo, ou enfin comme 
chez les Bambara une subdivision en deux séries de quatre classes des sociétés d'initiation et de la hiérarchie sociale dans son ensemble 63 .

Tous ces cas de gémelléité rentrent dans le problème général des organisations sociales dites dualistes. CI. Lévi-Strauss a montré que dans les cas de ce genre le caractère duel n'était pas un trait de structure qui puisse rendre compte de l'organisation effective mais un trait de représentation ${ }^{64}$. La représentation duelle est comme un degré zéro du signifiant qui correspond aux limites de cohérence d'un système.

Chez les Dogon chaque individu a pour jumeau son placenta où se trouve inscrit son signe social, son "blason totémique" 65. Chez les Bambara chaque individu est doué d'un principe vital "ni" et d'un double "dya" : mon ni est le dya d'un légataire mort et mon dya est du sexe opposé au mien ${ }^{66}$; c'est donc la capacité d'être assigné dans un système social de filiation (assimilée à la réincarnation d'un aïeul) et d'alliance (assimilée à une gémelléité ou communauté de naissance) qui définit l'individualité dans ses principes vitaux intérieurs; cette capacité d'assignation est son âme même. L'individu n'est pas vitalement isolable, il entre par ses principes vitaux dans un système de classification sociale destiné à rendre compréhensibles pour tous, les transformations qui se produisent à chaque naissance ou mort de telle sorte que chacun y trouve sa place. "À la mort, Faro reprend les principes spirituels du défunt et les conserve dans Peau pour les réintégrer dans un autre corps, utilisant ainsi des forces éternellement réemployables. Le produit de la mue (mana ou folo) des âmes qui restent dans les autels sont des témoins pour lui qui vérifie constamment le compte des vivants et des morts dont il est le gardien." 67

63 D. Zahan : Sociétés d'initiation Bambara, Paris, 1960, 1, p. 142-143.

64 C. Lévi-Strauss : Anthropologie structurale. Paris, 1958, p. 141-180.

65 G. Dieterten : Note sur le totémisme Dogon, in L'Homme, Revue Française d'anthropologie, T. Il, N. 1, 1962, p. 106-110.

66 G. Dieterlen Essai sur la religion Bambara, Paris, 1951, p. 58-59.

67 G. Dieterlen id., p. 53. 
Perdre cette place où chacun est reconnu socialement vivant est ressenti comme une menace de démembrement, de dislocation de l'image corporelle de soi, ce que le mythe traduit en disant que chaque clan totémique possède un organe, une partie du corps de Nommo ou de Faro, génie sacrifié au ciel dont le corps ressuscité est aujourd'hui représenté par le Niger, lequel est divisé en 22 parties du corps ou lieux dits ${ }^{68}$. La cohésion du corps social, fait à la fois de vivants et de morts, peut ainsi se concevoir comme une totalité close semblable à un capital de vitalité qui, variable chez les individus, demeure constant dans l'ensemble. Le principe de gémelléité clot la société dans une totalité qui est unité double, rythmiquement scindée par la génération et la mort mais se régénérant comme une espèce vivante. L'animal totémique, témoin du capital constant des huit graines vitales dévolu à chacun, est le garant d'une vie spécifique, immortelle. Et c'est à bon droit que les Dogon voient dans l'espèce élue pour totem un jumeau ${ }^{69}$, car la notion d'espèce vivante possède, outre sa fonction classificatoire formelle ${ }^{70}$ permettant de multiples correspondances cosmologiques, une valeur signifiante matérielle analogue à celle du principe de gémelléité : l'espèce qui perdure à travers les générations est l'unité double des naissances et des morts.

En assimilant les alliés à des jumeaux, on assimile le lien symbolique de l'alliance au lien naturel de la naissance gémellaire, la totalité culturelle à la communauté d'origine. Ainsi pour se concevoir comme un tout complet, la société tribale tend à se naturaliser, à ramener le cycle symbolique des échanges au cycle naturel de la Vie spécifique (totalité qui demeure néanmoins en elle-même scindée puisqu'à la

68 G. Dieterlen : Note sur le totémisme Dogan, in L'Homme, II, N. 1, 1962, P. 108. et G. Dieterlen : "Mythe et organisation sociale en Afrique Occidentale", in Journal de la Société des Africanistes, t. XXV, P. 50 et sq.

69 M. Griaule : Dieu d'Eau. Paris, 1948, p. 154.

70 CI. Lévi-Strauss a montré cette fonction classificatoire, de l'espèce dans $L a$ Pensée sauvage, Paris, 1962, Ch. V, en particulier p. 201, (l'opérateur totémique). 
dualité des désirs humains confrontés dans l'alliance, on substitue une image de Vie naturelle doublée pour masquer l'angoisse de mort).

Mais inversement le problème de l'origine oblige à différencier nature et culture. Suivant la tradition du Mandé, la genèse de l'univers produit des signes avant de produire des êtres substantiels, ce qui revient à nous laisser entendre, sous le langage de l'affabulation racontant l'origine des choses, un méta-langage exposant la genèse idéale des "signes", posant les conditions nécessaires à l'existence d'un système de symbolisation ou de socialisation. C'est ainsi que les spéculations arithmologiques des Bambara nous offrent une expression formalisée des structures du mythe.

À l'origine il y a l'impossibilité de l'Un (car un terme unique signifiant Tout et Rien, le Même et l'Autre, s'annule comme signe) : "Un était Rien, Rien était Un" 71. "Yo vient de lui-même... du Néant qui est lui-même" 72. "La vibration originelle (gla) pleine de son vide et son vide plein d'elle-même, étendait partout sa puissance. Elle émit une voie de vide qui créa d'abord son double "dya" 73. "Yori était la Transformation. Rythme origine, Cela, Rythme origine, Rythme origine, Grue couronnée. La Grue couronnée (Nguma) dit : Je parle (Nkuma)" 74 . La parole renvoie à son origine comme à une opposition de présence et d'absence, de positif et de négatif, relation duelle à quoi on ne peut se tenir, qui marque l'impossibilité de coïncider avec la nature ou qui inscrit dans la nature la scission intérieure. Sur ce fond, le langage et la culture apparaissent comme un devoir-être, une Loi, une Norme, car l'appel à un médiateur devient nécessaire pour ne pas sombrer dans la contradiction. Le désir humain a naturellement besoin d'une médiation culturelle pour prendre conscience de soi et de son objet : il devra passer par l'échange de demandes et de réponses (as-

71 S. de Ganay: Notes sur la Théodicée Bambara, Revue d'Histoire des Religions, Paris, t. CXXXV, 2-3, 1949, p. 188.

72 G. Dieterlen : Essai sur la Religion Bambara, p. 6.

73 G. Dieterlen : id. p. 3.

74 D. Zahan : Sociétés d'Initiation Bambara, 1, p. 366. 
sumer le risque d'erreur et de trahison), à devra passer par la communication avec le désir des autres comme par une castration symbolique qui le sépare de son objet en le lui signifiant. Si la gémelléité, l'unité double est la forme de l'origine, on n'en sortira que par "explosion de l'œuf primordial" afin d'assumer avec la loi culturelle le risque de l'échec et de la faute.

L'arithmologie mythique des Bambara repose sur deux "axiomes" :

1) L'unité originelle est une unité double.

2) Toute transformation numérique, ayant la forme d'une progression arithmétique ou géométrique peut être ramenée à une transformation identique (c'est-à-dire à l'unité double).

À quoi il faut ajouter quelques règles sémantiques dont la principale est la suivante : l'opposition distinctive homme/femme s'écrit 3/4 (trois étant par convention de lexique le chiffre des organes sexuels mâles et quatre celui des lèvres féminines) de sorte que 7 est le chiffre du couple et se ramène à la gémelléité.

Voici quelques applications : $10=1+2+3+4$ équivaut à la quadrinité gémellaire de l'Oeuf primordial ou œuf du monde ; il se ramène donc à l'unité, unité divine qui, englobant à la fois la masculinité et la féminité, est un tout complet. Et comment douter que 5 ne soit le secret de la création puisqu'il est le seul nombre qui doublé se ramène à l'unité ? L'organisation de l'univers, physique et moral, repose sur les 22 paroles ou 22 tournoiements initiaux car 22 est le chiffre de la relation ternaire ou médiate : $22=(3 \times 7)+1$, l'unité supplémentaire exprimant la connaissance totale. 'Ou encore : $22=7+12+3$ (ce qui est facile à déchiffrer, d'autant que $12=3 \times 4$ ). En décomposant par diverses transformations le nombre divin 28, le lecteur pourra lui-même calculer toutes les relations possibles entre féminité et masculinité. Il découvrira sans peine qu'un double mâle joint à l'unité donne la fécondité $(6+1=7)$, qu'inversement joint à la féminité il donne l'unité 
divine $(6+4=10)$. Cette unité divine est un monde doublé $(2 \times 5)$ à la fois céleste et terrestre, invisible, et visible, unité double, totalité en elle-même scindée, qui éternellement se réveille, se régénère, ressuscite : la Vibrante, la "Rythmorigine".

Il résulte de tout cela que la gémelléité peut signifier à la fois la totalité et l'origine Matériellement la gémelléité est une relation naturelle pouvant symboliser la complétude d'une totalité close, d'une Vie double (spécifique ou "totémique") par réduction de la culture à la nature. Formellement la gémelléité est une relation duelle, une opposition immédiate du Même et de l'Autre, signifiant la forme de l'origine, la scission intérieure du désir, la nécessité intérieure d'une médiation sociale et par conséquent l'exigence d'une différenciation inévitable entre la culture et la nature.

Le principe de l'unité double (non additive, non multiplicative, purement itérative). permet de se donner la société comme un tout que l'on dédouble intérieurement en autant de subdivisions qu'il sera nécessaire pour concevoir la complexité de l'organisation sociale. Mais par là toute dissymétrie se ramène à une symétrie, toute diachronie à une synchronie. Alors comment sortir de la gémelléité initiale, comment briser l'éternelle symétrie de cette totalité vibrante En y introduisant, avec la différence des sexes, la faute originelle.

\section{L'inceste}

L'interdiction de l'inceste est l'interdiction de faire coïncider absolument le lien culturel de l'alliance et le lien naturel de la parenté ; elle est une exigence de différenciation entre, nature et culture. La promiscuité sexuelle serait l'informe, l'anonymat, l'absence de la question humaine primordiale : "qui ?". Seule l'interdiction de l'inceste introduit un principe sélectif de positions distinctives entre les personnes permettant de donner un sens à la question "qui ?" 
À l'origine, dit le mythe 75 , les naissances étaient gémellaires. La première génération était un couple de jumeaux mixtes, mâle et femelle, ou un androgyne ; à la seconde génération il y eut quatre couples de jumeaux mixtes, pratiquant le mariage par échange des soeurs jumelles ; à la troisième génération, les individus actuels, "nés uniques" doivent reproduire symboliquement par les rites d'alliance un mariage de cousins croisés qui figure l'union primordiale entre deux jumeaux. La gémelléité qui était loi naturelle des naissances est devenue loi symbolique d'alliance.

Ce mythe donne la théorie de l'alliance, sa formule anthmologique. Nous comprenons que seule la femme troisième peut devenir épouse symboliquement substituable à la seconde; cette seconde est une soeur c'est-à-dire une femme échangeable puisque le mariage consiste en ce que deux hommes échangent leurs sœurs 76 ; quant à la première femme, qui n'est rien que Mère, l'ensemble de l'opération exige qu'elle demeure absolument interdite. Cependant il y a une différence entre le mythe et la pratique réelle : dans la pratique pour obtenir une épouse un homme doit pouvoir céder à un autre sa soeur, la soeur respective de chacun lui demeure de ce fait interdite. Mais dans le mythe il y a trois générations au lieu de deux : le mariage avec la femme 3 paraît un substitut du mariage avec la soeur (niveau 2) comme si l'inceste avec la soeur était à la fois un idéal (originel) et un interdit (actuel). Dans la pratique il y a substitution métaphorique entre l'épouse et la soeur ; dans le mythe la soeur est une combinaison métonymique entre la mère interdite et l'épouse permise.

En réalité l'équivoque dramatique qui s'abat sur la Soeur est le reflet d'une autre équivoque par laquelle le fils mâle, qui est d'une génération postérieure à son père, se conduit rituellement comme sil était

75 G. Dieterlen : Les rites symboliques du mariage chez les Bambara, in Zaire. Revue Congolaise, Bruxelles, t. VIII, oct. 1954, pp. 815-841.

76 Hypothèse théorique d'échange restreint. Mais les Dogon pratiquent l'échange généralisé. Le mythe cherche à déduire, par une transformation logique ou symbolique le passage de l'endogamie à l'exogamie. 
de même génération que le couple fraternel de sa mère et de son oncle ${ }^{77}$. Dans l'éternel roman de l'homme et de la femme, qu'il est donc difficile de savoir qui est qui !

Considérons en effet la situation masculine : c'est le récit de la chute ${ }^{78}$

Dans l'oeuf originel il y avait deux couples de jumeaux mixtes. L'un des mâles, Pemba (chez les Bambara), Yurugu (chez les Dogon) sort avant terme en arrachant un morceau de son placenta. Il descend, le morceau arraché devient terre sèche. Il remonte au ciel pour tenter de dérober le reste de son placenta et retrouver sa jumelle. Il échoue car Dieu a transformé le reste du placenta en soleil et confié sa jumelle à l'autre couple. Mais Pemba (Yurugu) vole dans les clavicules divines les huit graines mâles et les sème dans le morceau de placenta arraché devenu terre. Seul germe le fonio rouge à cause de l'humidité du placenta. Les autres ne peuvent germer à cause de la sécheresse. D'où l'impureté du fonio rouge et du sol, à cause du vol de Pemba (Yurugu) et de son acte incestueux car il avait semé dans le sein de sa mère.

Le mâle de l'autre couple ou plutôt l'androgyne Faro (chez les Bambara), Nommo (chez les Dogon) avait au ciel la forme d'un être aquatique double (silures, lamentin). Pour réparer la faute de Pemba (Yurugu) et purifier la terre, Faro (Nommo) est éviré et sacrifié au ciel. De son corps découpé naissent les arbres symbole d'une résurrection végétale et de la régénération effectuée par son sacrifice. Puis Dieu le ressuscite au ciel en forme humaine, le fait descendre sur terre au moyen d'une Arche faite d'un fragment de son placenta céleste. Sur

77 M. Griaule : L'oncle utérin au Soudan, in Cahiers Internationaux de Sociologie, 1. XVI, 1954, p. 40 - Et cf. infra pp. 12-15.

78 Exposé d'après la version mandingue. Mais les trois versions s'accordent sur l'essentiel. 
cette Arche descendent les huit premiers Ancêtres, les animaux et les végétaux.

Dans ce récit il s'agit encore de différencier nature et culture, de révéler l'un par l'autre le désir et la Loi. Pemba-Yurugu enfreint la Loi mais le lien gémellaire ou placentaire est naturellement infrangible, il se dédouble indéfiniment condamnant le désir incestueux à une quête infinie. Au contraire la castration céleste (= symbolique) ${ }^{79}$ de Faro Nommo a transformé la gémelléité naturelle en lien culturel d'alliance, car seul un allié peut accomplir les rites expiatoires. Si je viole un interdit, je perds une partie des huit graines déposées dans les clavicules de tout homme ; or seul mon allié a pour moi le double de ces graines $(2 \times 8)$ et seul il peut réparer ma perte. - En outre, le côte PembaYurugu correspond à la saison sèche, la saison sans culture, où nature et culture sont le plus indifférenciées (inceste agricole), alors que, du côté Faro-Nommo est la saison des pluies où la culture se différencie à nouveau de la nature : la castration symbolique de Faro-Nommo entraîne la résurrection végétale. Faro-Nommo sera l'ordonnateur, le classificateur universel alors que Pemba-Yurugu est enclin aux avatars, aux métamorphoses. Pemba-Yurugo est lié à la divination, aux commencements: c'est par lui qu'il faut commencer les rites, les femmes accouchent auprès de son madrier (pembele) ; Faro-Nommo, vient ensuite : il régénère, il classe tous les êtres dans leurs valeurs distinctives, il régit ce monde intermédiaire jusqu'à la venue des Eaux futures qui seront un retour à l'origine.

Dans un article qui est un classique de la littérature ethnologique, M. Griaule a montré que le mythe de Yurugu (Pemba) et du Nommo (Faro) traduit le destin du jeune premier, le candidat au mariage, le neveu utérin 80 .

79 La castration céleste est parallèle à la circoncision terrestre accomplie par le Forgeron, l'une et l'autre ont valeur sacrificielle. La genèse est toujours double : céleste avec les Génies jumeaux, terrestre avec le Forgeron circonciseur.

80 M. Griaule : Remarques sur l'oncle utérin au Soudan, in Cahiers Internationaux de Sociologie, Vol. XVI, t. 1, 1954, Paris, P.U.F., pp. 35-49. 
Ce jeune homme (Ego) se trouve à l'égard de son Père dans une relation dite "fadeña" (manière d'être père-fils") qui est le prototype de toute rivalité.

Son Oncle maternel est pour lui bienveillant. Mais Ego devra démêler son destin entre trois femmes : la Sœur de l'Oncle (Mère d'Ego), l'Épouse de l'Oncle et la Fille de l'Oncle (future épouse d'Ego).

À l'égard de son Oncle maternel et de ses Utérins en général, Ego se comporte en Yurugu : à chaque visite il vole des biens de son Oncle ; ces vols symbolisent un désir incestueux à l'égard de l'Épouse de l'Oncle, désir exprimé par des plaisanteries très libres; Ego et sa Tante sont "parents à plaisanterie", ils s'appellent "mon mari", "ma femme" et pourraient même avoir des relations sexuelles. C'est que l'Épouse de l'Oncle est un substitut de la Mère d'Ego, Soeur de l'Oncle. C'est en donnant sa Soeur à un autre homme, Père d'Ego, que l'Oncle a reçu les biens lui permettant d'acquérir pour lui une épouse. De ce fait l'Oncle est débiteur à l'égard du Neveu, à qui il devra donner en échange une autre femme, sa propre fille.

Dans un remarquable ouvrage sur l'inceste royal en Afrique, Luc de Heusch a cru voir dans ce double rôle du Père et de l'Oncle "un dédoublement du complexe d'Oedipe" ${ }^{81}$. Mais comment une structure symbolique pourrait-elle se dédoubler ? Cette formule est sur le plan théorique un non sens, et elle ne correspond pas aux faits. Luc de Heusch y a été conduit en faisant trop de concessions aux explications dites "culturalistes" (R. Linton) qui s'appuient sur la relation mèreenfant. Mais cette relation duelle ne devient socialement significative que par référence au Père. Comme disent très bien les Dogon : "Toutes les choses que vole le neveu mangu (parent à plaisanterie) de l'Oncle utérin, c'est à cause de sa mère ; c'est à cause de la colère qu'il res-

81 Luc de Heusch: Essais sur le symbolisme de l'inceste royal en Afrique, Bruxelles, 1958, p. 215. 
sent à l'idée qu'il n'y a pas eu mariage entre son oncle utérin et sa mère. Si le neveu insulte la femme de son oncle, c'est parce qu'elle est à la place de sa mère. La colère qu'on éprouve contre le père c'est, symboliquement, parce que la mère n'est pas restée avec l'oncle" 82. Sur quoi Luc de Heusch dit que les docteurs Dogon sont ici de mauvaise foi car ce n'est pas pour l'oncle maternel qu'Ego réclame sa mère mais bien pour lui ${ }^{83}$. L'auteur ne fait-il pas une confusion entre le symbolique et le réel, la Loi et le désir ? Que disent les Dogon ? Ego a la colère, "le cœur rouge" contre son Père. Mais son désir infantile d'union avec la Mère est trompé par la Loi (par l'organisation sociale effective) qui impose au désir d'Ego un destin défini par une série de substitutions symboliques : l'agressivité contre le Père et le désir infantile d'inceste avec la Mère équivalent à vouloir l'annulation d'un premier acte d'échange matrimonial, celui par lequel l'Oncle a donné sa Sœur au Père d'Ego. Tout se passe donc comme si Ego voulait que l'Oncle ait épousé sa Soeur. À l'inceste maternel d'Ego se substitue l'inceste sororal de l'Oncle. Mais cette première substitution ne saurait satisfaire le désir d'Ego, d'où une deuxième substitution : son désir incestueux se porte sur l'épouse de l'Oncle, ; or ce n'est là qu'un substitut dérisoire qui va obliger finalement le désir d'Ego à accomplir la Loi : l'Oncle ne pouvant pas lui donner sa femme, lui donnera sa fille, cousine utérine d'Ego. C'est justement ce que la Loi exigeait (mariage préférentiel avec la cousine croisée).

Faut-il parler d'inceste idéal ? Oui et non. Oui sans doute pour le désir, mais non pour la Loi. Cet idéal n'est qu'un leurre pour appâter le désir et lui faire accomplir finalement ce que veut la Loi. C'est ce que Griaule a très bien vu: "Il y a là (dans cette double substitution mère/tante/cousine) une imitation de l'inceste mythique, lequel est cependant tourné en dérision dans le même temps. En effet, l'union est en réalité licite et la manière de satisfaction qui serait donnée au Yu-

82 M. Griaule, art. cit., p. 37.

83 Luc de Heusch. Essais... p. 215. 
rugu par cet acte n'est qu'un leurre et une moquerie." 84 "En réalité, si (le personnage du Neveu-Yurugu) est si souvent évoqué et représenté, c'est pour le mieux ridiculiser et pour montrer l'inanité de ses efforts dans la recherche qu'il poursuit sans trêve de sa jumelle et la réprobation soulevée par son union avec sa mère" 85 . Le Neveu-Yurugu sera berné : aux yeux des Maternels il est Nommo ; il se veut pillard incestueux, il est pour eux promesse de richesse, de bénédictions et finalement réalisateur de la Loi ; s'il est l'aîné, son Oncle neutralise ses vols en l'élevant chez lui ; après son mariage ses frères cadets deviennent à ses yeux des Yurugu et sa jalousie envers eux l'oblige à se comporter en Nommo ; enfin par son mariage il perd le droit à devenir chef (Hogon). Quant à l'inceste royal attesté chez les Dogon et les anciens Bambara il fait que le symbolique en ce cas singulier devient immédiatement réel, ce qui a pour résultat de placer le chef dans l'ordre mythique et rituel en faisant de lui un pur représentant des Ancêtres, lesquels demeurent ainsi la seule autorité suprême.

En résumé, nous avons bien affaire à une structure œdipienne mais de telle sorte que l'agressivité contre le Père est déplacée sur la Fratrie Tout le système culturel tend à canaliser, "le destin des pulsions agressives" : le prétendu inceste idéal est un leurre du désir voulu par la Loi ; il tend à faire que le jeune homme se conduisant comme s'il était de la même génération que son Oncle, se trouve en rivalité avec ses collatéraux ; sa rivalité avec le Père, l'ascendant, est transformée par la Loi culturelle en rivalité qui s'exerce latéralement comme rivalité-solidarité de Fratrie. L'article de Griaule sur le Neveu utérin aboutit exactement à cette conclusion ${ }^{86}$. Cette rivalité-solidarité de Fratrie est d'ailleurs un fait d'observation banale en Afrique Occidentale (de cette rivalité latente procèdent la sorcellerie, les amulettes protectrices, les rites compliqués de politesse etc...). Tout cela est parfaitement résumé

$\begin{array}{ll}84 & \text { M. Griaule, art. cit., p. } 42 . \\ 85 & \text { M. Griaule, art. cit., p, } 45 . \\ 86 & \text { M. Griaule, art. cit., p. } 48 .\end{array}$ 
dans un conte Bambara rapporté par le vieux Travelé 87 : Le roi venait de mourir. Ses trois fils se disputaient son insigne, une queue de bœuf. Le griot (bouffon) prit la queue de bœuf, l'envoya en l'air ; elle retomba sur la place du village où elle devint l'Arbre à Palabres.

Le phallus symbolique demeure collectif; il n'y a en définitive qu'une place de Père, celle de l'Ancêtre mort, garant de la Fratrie. Non pas Oedipe-Roi mais Oedipe à Colone.

\section{La folie}

Reste cependant un problème. L'analyse précédente nous a conduit aux antipodes des interprétations à la manière de $\mathrm{R}$. Linton et à des conclusions différentes de celles de Luc de Heusch : pour étudier les variations culturelles du "complexe" d'Oedipe, l'école dite culturaliste utilise un schème naturaliste de la causalité en invoquant l'influence des premiers soins éducatifs dans la relation mère-enfant pour nous au contraire c'est la résolution finale de l'Oedipe qui est orientée de façon variable par la culture, orientation dont les effets se font sentir dès la naissance de l'enfant dans toutes les pratiques du "maternage". Le passage oedipien de la relation à deux (mère-enfant) à la relation à trois (fonction symbolique du Père), c'est-à-dire le passage de la nature à la culture sanctionné par l'interdiction de l'inceste, est universel mais il est diversement codé par les différents systèmes culturels : la résolution finale du drame est codée par la société et accomplie dans une histoire individuelle. Pourtant Luc de Heusch n'a pas eu tout à fait tort lorsqu'il a pressenti dans le mythe Dogon une dualité de la figure masculine qui ne rentre pas dans le schéma classique de l'Oedipe. Seulement il a mal situé cette dualité. Comme nous allons voir, l'autre élément dont il s'agit demeure en dehors du complexe d'Oedipe et de ses variantes ; il est par définition ou par essence Non-oedipien.

87 Moussa Travelé : Proverbes et Contes Bambara, Paris Gouthner, 1923, pp. 169-174 (Travelé est Bambara). 
Nous avons vu que la fonction symbolique du Père se répartit sur trois personnages : le père, l'oncle et l'Ancêtre. La fonction médiatrice de l'Oncle tend à déplacer sur la Fratrie l'agressivité primitivement dirigée contre le Père ; l'identification imaginaire d'Ego à son oncle aboutit à intégrer le jeune homme dans la fratrie de telle sorte que la place symbolique du Père demeure celle de l'Ancêtre avec lequel nul ne peut s'identifier sinon dans le cas unique du roi ou du chef mais alors sur un mode mythique ou sacral qui confirme la règle.

Si notre interprétation est exacte, elle laisse néanmoins planer une ambiguïté sur le personnage du Père, du Père qui est à la fois l'époux de la Mère et le géniteur d'Ego. Le système Dogon ou Bambara en reportant sur l'Ancêtre la fonction symbolique du Père représentant de la Loi, la place à distance de la fonction naturelle du père géniteur charnel. On peut donc s'attendre à ce que cette fonction du père géniteur réapparaisse autrement. C'est bien en effet ce qui se produit.

Griaule a noté que le jeune homme en veut à son Père de l'avoir fait naître unique, incomplet comme le Yurugu : "Le fils garde rancune à son père de son incomplétude initiale. Il lui en veut également de son intervention qui montre qu'il n'est pas un produit intégral de sa mère, il n'est pas en entier surgi de la racine (Du) maternelle et d'elle seule. Un palliatif consisterait pour lui à être le fils de sa mère et de son oncle utérin, c'est-à-dire de deux géniteurs de même racine. Cependant même dans ce cas il serait encore contre ce géniteur, car celui-ci, en procréant à nouveau, lui donnerait des frères semblables à lui. Le fils considère en effet que, lors des rapports sexuels, son père introduit dans sa mère un germe identique à celui qui lui a donné naissance. Le père semble donc tenir pour nul le produit précédent, puisqu'il désire en recréer un nouveau ${ }^{88}$. Le père géniteur est celui qui a déposé son germe dans le sein de la mère. Il ne faut pas confondre le père géniteur et le père œdipien. Le père œdipien se situe au niveau symbolique de la parole : il est celui qui reconnaît l'enfant en recon- 
naissant sa mère comme épouse ; il symbolise dans la société la Loi de reconnaissance réciproque ; enfin il apparaît à l'enfant comme un rival auprès de la mère. Au contraire, le père géniteur se situe au niveau de la nature muette, et il demeure par essence un père nocturne, mystérieux, incertain, douteux ; en lui les différences symboliques s'annulent : ainsi le fils reproche au géniteur de l'avoir fait unique et d'avoir fait les autres semblables à lui par un germe identique; nous retombons dans l'identité du Même et de l'Autre c'est-à-dire dans la forme contradictoire, insaisissable, qui caractérise la pensée de l'origine, en deçà de toute symbolisation. Le père géniteur, bien loin d'être un rival possible auprès de la mère, se situe dans le rapport d'Ego à son origine, comme une sorte de double fantasmatique, comme un Autre irréductible dans le rapport de moi à moi Cette mystérieuse dualité de l'origine est attestée partout : ce ne sont pas seulement les "sauvages" qui attribuent à un esprit ancestral le principe de la fécondation, ce sont aussi nos théologiens qui supposent, un double géniteur, Dieu pour l'âme, l'homme pour le corps. Nous voyons à présent ce qui se cache sous l'apparence d'un inceste idéal : c'est la question de l'origine.

La pensée de l'origine a dans l'humanité une forme duelle, insaisissable, parce qu'en deçà ou au-delà de la médiation symbolique, elle se donne toujours comme un signe vide et n'a finalement que deux issues extrêmes :'la visée d'union mystique ou la folie. Ces deux possibilités extrêmes se trouvent comme nous allons le voir, chez les Bambara.

Il est un cas où la question de l'origine apparaît Brutalement dans sa forme vide : c'est la schizophrénie. Tout ce que l'on a écrit sur les mères de schizophrènes peut être excellent mais la mère n'est telle que parce qu'elle renvoie à ce qui l'a faite telle. Le couple schizophrénique c'est le couple d'Ego et de son père géniteur, c'est le rapport du moi à son origine, à cette origine qui est moi et qui n'est pas moi, qui est le père et qui n'est pas le père, de sorte que le oui et le non deviennent ici équivalents, de sorte qu'utilisant des mots étymologiquement contradictoires nous parlons ici d'autisme et d'aliénation. La parole du schi- 
zophrène est une parole que l'on peut encore comprendre à la limite mais à laquelle il est impossible de répondre. La schizophrénie est la pensée de l'origine à l'état pur, qui désespérément cherche à sauter par-dessus son ombre, à se saisir avant toute symbolisation.

Cette conséquence n'a pas échappé au vieux Sage Bambara : La Sœur devient folle, Muso Koroni la jumelle de Pemba, devient folle. Je n'ai pas trouvé explicitement chez les Dogon le thème d'une folie de Yasigi, jumelle de Yurugu, mais cette lacune (quelle qu'en soit la cause) n'a pas grande importance, puisque les deux traditions s'accordent à faire sombrer les malheureux jumeaux dans une métamorphose animale, celle du renard pâle.

G. Dieterlen a rapporté dans la "Religion Bambara" une série de mythes dont la sombre beauté tourne au cauchemar ${ }^{89}$.

On y trouve d'abord un thème de métamorphose : Pemba métamorphosé en madrier rituel, Pembele, donne naissance sur terre à $\mathrm{Mu}-$ so Koroni ; puis Muso Koroni plante en terre le vieux bois qui devient l'arbre sacré appelé Balãza (accacia albida). On reconnaît dans cette génération réciproque le thème de l'un qui naît de l'un, chacun cherchant l'autre pour échapper à la solitude et se retrouvant toujours dans la même impossibilité d'être unique et double.

Ensuite le passage de l'indifférenciation entre nature et culture (côté Pemba, saison sèche) à la différenciation opérée par le rite sacrificiel, le langage et le travail (côté Faro, saison des pluies) est représenté par l'histoire des deux règnes le règne du Balãza et le règne de Faro.

Le Balãza est un arbre bien connu en Afrique Occidentale ; il suit un cycle de végétation inversé par rapport aux autres arbres : il verdoit en saison sèche et se défeuille en saison des pluies. Il va remplir dans le mythe la fonction logique d'un inverseur : il aura fallu que la domi-

89 G. Dieterlen : R.B., p. 16-30. 
nation de l'Arbre absorbe toute chose dans l'indifférencié originel pour qu'inversement toute chose puisse être restituée dans sa différence et sa juste place. La transition au règne ordonnateur de Faro sera marquée par la castration céleste du génie de l'air Teliko (variante du sacrifice céleste de Faro-Nommo). Il faut voir dans cette castration céleste une allusion à la circoncision qui joue en toute cette affaire un rôle central. En effet l'œuvre des Jumeaux célestes a son prolongement terrestre dans l'œuvre de l'Ancêtre Forgeron, fondateur de sanctuaires, maître de la circoncision, de la parole et de l'eau. L'opposition des deux règnes de Pemba et de Faro a son parallèle dans l'opposition fondamentale qui est en même temps une secrète solidarité entre la Femme et le Forgeron. Il faut toujours avoir présents à l'esprit ceux que les Bambara appellent "les trois Bases" : Faro, Muso Koroni et N'Domodyiri (le Forgeron) ${ }^{90}$. La Femme et le Forgeron représentent deux pôles symétriques inversés de la société : le pôle de la reproduction des hommes (dédoublement immédiat de la vie) et le pôle de la production des objets (origine des instruments, des intermédiaires grâce auxquels s'explicite la fonction symbolique du langage).

La Femme produit des incirconcis, le Forgeron des circoncis ; la Femme répète le mystère des origines naturelles, le Forgeron les actes du héros civilisateur. Le règne de l'Arbre (Balãza) correspond à l'échec de la médiation féminine et à la période d'indifférenciation entre nature et culture, brousse et village, qui tend à se reproduire chaque année en saison sèche ; le règne de Faro correspond à la médiation masculine du Forgeron circonciseur ; c'est le Forgeron qui apporte les huit graines femelles complémentaires des huit graines mâles volées par Pemba ; alors que Pemba avait semé incestueusement sur la terre sèche, c'est le Forgeron qui inaugure la saison des pluies et prononce les "premières paroles". La symétrie inversée entre la Femme et le Forgeron apparaît nettement dans le sens attaché à la circoncision. L'incirconcis (première classe du N'domo) est un être bi-sexué, le prépuce ayant une forme féminine et le clitoris une forme masculine.

90 D. Zahan : La dialectique du Verbe chez les Bambara, Paris, 1963, p. 15. 
Mais il s'agit là d'une androgynie indifférenciée qui doit être éliminée par la circoncision. La circoncision a une double valeur négative et positive, et une double origine qui se rattache à Muso Koroni et au Forgeron. Négativement il s'agit d'éliminer le wãzo, principe impur à valence de sorcellerie (domaine asocial du secret, de la présomption accusatrice, du soupçon), et à ce titre la circoncision se réfère aux agissements de Muso Koroni. Mais positivement il s'agit de conférer à la différence naturelle des sexes une valeur distinctive pertinente dans le système symbolique des alliances, ce qui relève de l'office masculin du Forgeron. Sans l'expérience vécue du négatif, de l'échec, de l'impossible "union intuitive", le signe ne nous serait pas nécessaire, il ne serait donc pas signifiant. Cette idée semble sous-jacente au mythe des deux règnes. De ce mythe je ne puis que donner un résumé :

Pemba et Muso Koroni n'avaient enfanté que des végétaux et des animaux.

1. a - Les humains, nés de Faro, sont dans un état indifférencié : immortels mais en un sens privatif, ils ignorent la mort, ils manquent du signifiant de la mort ${ }^{91}$; ils n'ont d'autre repère chronologique que l'évolution du système pileux ; sans langage, sans vêtement, ne se reconnaissant qu'au tatouage (enseignés par Muso Koroni) ; leurs membres sans articulation les rendent incapables de travail, ils reçoivent du ciel leur nourriture (chute de noix de karité).

1. b - Les femmes ont l'initiative en matière de culte : l'Arbre exige l'offrande rituelle du beurre de karité. Plus tard seulement les hommes imitèrent ce culte.

91 D. Zahan : La dialectique du Verbe des Bambara, p. 50 : "Dans la pensée Bambara l'état d'immortalité n'implique pas cependant l'inexistence de la mort. Il indique simplement qu'au début de leur existence les humains ignoraient ce phénomène. ils vivaient comme des animaux, sans être, d'une manière consciente, affectés par la cessation de la vie". 
À ce propos on notera que si le registre Pemba-Muso Koroni est régressif, il a aussi une valeur prophétique de commencement. Ce passage du mythe peut être rapproché des observations faites par L. Tauxier sur les sociétés cultuelles féminines du Musokadyri (Arbre des femmes) ${ }^{92}$. À noter aussi que l'Ancêtre Forgeron s'appelle N'domodyiri, Arbre du N'domo, la classe des incirconcis.

I. c - L'Arbre exige toutes les femmes pour des coïts nourriciers (indifférenciation femme nourricière/femme épouse); il se nourrit de leur liquide séminal. Les naissances se font en désordre.

II. - Muso Koroni jalouse, s'isole et devient folle. Elle part en brousse, seule, errante. Dans sa folie 1) elle répète le geste de planter des bouts de bois pour en faire des Balãza (en quête de l'Autre, elle se veut origine de son origine ; c'est le délire de l'un né de l'un) ; 2) elle répète sa propre excision sur le pembele en circoncisant avec ses angles et ses dents ceux qu'elle rencontre, d'où l'origine des menstrues impures et de la circoncision comme élimination du wãzo; son contact rend la terre impure (impureté qui rappelle l'inceste de Pemnba) c'est pourquoi il faudra désormais que l'agriculture circoncise la terre, la purifie ; 3) elle trahit les secrets d'initiation de Pemba mais son malheur est aussi à l'origine des techniques agricoles ; 4) Muso Koroni semble brouiller la distinction des saisons : elle sème les graines volées par Pemba, sur la terre sèche, afin de les soustraire à l'eau de Faro (qui par la suite reprendra ces graines). Ce faisant elle est toujours en quête du soleil vers le Sud (donc en saison sèche puisque le soleil est au nord en saison des pluies) ; 5) poursuivie par Pemba puis par Faro, Muso Koroni meurt enfin dans la misère et la solitude, ayant ainsi introduit dans le monde la folie, la misère et la mort.

III. a - Cependant lArbre règne et veut du sang, la multiplication des êtres l'oblige à chercher une nourriture plus forte que le liquide séminal des femmes. Mors au début de la saison sèche, les hommes

92 L. Tauxier : Religion Bambara, Paris, 1927, pp. 415-419. 
donnent à l'Arbre le sang de leur poignet, lui abandonnent leur wãzo et lui confient leur double dya. Ces trois éléments évoquent la circoncision, bien que la substitution du poignet au sexe 93 soit là pour suggérer une première forme imparfaite de circoncision. Les vieillards se font épiler pour rajeunir (cycle pileux du temps).

III. b - L'Arbre exige pour lui le sang des femmes : la défloration des vierges, le sang menstruel, et il veut que les accouchements se fassent auprès de lui.

Alors le cycle des naissances acquiert un certain ordre en s'intercalant dans le cycle de la nature : vierges et vieilles engendrent avec l'Arbre des animaux ou des végétaux ; à l'âge intermédiaire les femmes fécondables engendrent avec leurs maris des individus humains. En outre l'Arbre exige que des phallus de bois soient plantés dans son tronc, d'où la première opposition jouissance masculine/douleur féminine ; il enseigne à tailler des haches de pierre et à utiliser le feu.

IV. a - Déchéance du Balãza - Les humains sont épuisés de donner leur sang. Un soir une femme s'évanouit dans un champ de tomates. Faro prescrit que désormais, avant toute union sexuelle il faudra manger rituellement la tomate, fruit de vie dont les graines sont un multiple de sept (passage au plan symbolique). Faro lutte avec l'Arbre et triomphe. Les femmes d'abord puis les hommes abandonnent le culte de l'Arbre. L'Arbre les maudit, d'où l'origine du mal.

IV. b - Pour remédier à cet état de choses les huit Patriarches offrent à l'Arbre le sang de leur langue (on notera la progression : sang du poignet, de la langue, de la circoncision). En réponse ils obtiennent un rituel de résurrection qui les transformera en oiseaux de feu (valence Forgeron) : les vieillards devront frotter leur dos contre l'arbre jusqu'à ce qu'ils aient perdu tout leur sang, que leur chair se mêle au bois, leurs os à l'écorce, leur moëlle aux fruits rouges du Balãza, La

93 Sur le poignet et le sexe : D. Zahan, S.LB., I, p. 147 no. 1. 
gousse rougeâtre du Balãza rappellera désormais à la postérité qu'elle a été nourrie de sang humain.

IV. c - L'origine de la mort vient en deux temps :

Premier temps : les hommes meurent sans comprendre. Les sept premiers cadavres au pied de l'Arbre furent les derniers sacrifices. Depuis lors le Balãza suit un cycle de végétation inversée : il fleurit en saison sèche quand les récoltes sont rentrées, pour montrer que la nature en lui à de quoi vivre et que les hommes peuvent consommer en paix les fruits de leurs cultures.

Deuxième temps : les hommes invoquent Faro: "L'Arbre a mis l'obscurité entre toi et nous". Faro donne l'Eau fécondante et la Parole. Avec le langage il donne la connaissance de la mort : "Nous n'avions pas la Parole, nous l'avons reçue, il nous faut mourir", dit le huitième Ancêtre.

IV. d - Les cadavres des trois premiers Ancêtres étant jetés au Fleuve, l'eau rougit. Le quatrième Ancêtre comprend : Faro veut des sacrifices. Le quatrième devint le premier prêtre.

V. - Les femmes engendrent des jumeaux jusqu'au jour où le génie de l'air Teliko se révolte et doit être châtré par Faro. À la suite de cette castration céleste, les êtres naissent uniques et devront être circoncis. Les membres de Teliko ont été brisés, c'est l'origine des articulations propres au travail. La gémelléité est remplacée par le double symbolique, le dya, qui sera conservé dans les eaux de Faro, (ce reflet aquatique étant moins vulnérable aux sorciers que l'ombre terrestre, autre modalité du double). Le dya est du sexe opposé à celui de l'individu, il marque sa place classificatoire dans le système des alliances matrimoniales.

Le reste du mythe raconte l'oeuvre ordonnatrice de Faro. 
En résumé, toutes choses ont une double origine, (la circoncision, l'agriculture, le mariage, la mort...), chacune étant marquée d'un double temps : temps Pemba, temps Faro. L'Inverseur (le Balãza) sert de médiation entre les femmes et les hommes, entre la saison sèche et la saison des pluies. Il y a là comme un balancement, un rythme oscillatoire où les relations dissymétriques, progressives, peuvent se ramener àdes relations symétriques inversées ; la différenciation de la culture est limitée par le temps cyclique de la nature comme par une perpétuelle dénégation de la mort.

De même que la totalité ou unité collective de la société est en ellemême scindée par un rythme de mort et de renouvellement, de même le problème de l'origine apparaît sous un double jour.

En premier lieu, la fonction des Initiateurs ambigus (Pemba, Muso Koroni) se donne comme prophétique : elle annonce le retour à l'Origine dans un autre monde. C'est ce qui apparaît clairement dans la cosmologie Bambara où le monde actuel, qui est le monde des intermédiaires, construit suivant le chiffre trois, s'intercale entre l'unité double originelle, celle de Yori (qui est la Vibration, la Transformation, la "Rythmorigine"), et celle du monde à venir, des Eaux Futures, qui réalisera la plénitude de l'unité double ( 2 x $5=10)$. Cette perspective eschatologique montre ce qui se cachait sous l'apparence de l'inceste royal ou idéal, sous la hantise de la gémelléité perdue, c'est l'aspiration à l'union mystique. Le spécialiste des Sociétés d'initiation Bambara, D. Zahan, a été fort impressionné par la tension mystique de toute la religion Bambara ${ }^{94}$. Cela parait être en effet une conséquence de tout ce que nous a révélé l'analyse.

Mais en outre la fonction des Initiateurs ambigus s'exprime à la fois dans la faute originelle (inceste avec la Mère) et dans la folie originelle (isolement de la Soeur). Pourquoi est-ce la femme, et plus précisément la Soeur qui devient folle? Nous avons vu plus haut à pro-

94 D. Zahan : S.LB., t. 1, p. 350 et sq. 
pos du concept d'alliance, dans l'apologue des Trois Femmes, comment le personnage de la Soeur c'est-à-dire de la femme échangeable devait supporter le dédoublement équivoque de la représentation qui est à l'origine des échanges matrimoniaux ${ }^{95}$. Si le mécanisme des échanges se bloque (quand l'Arbre accapare toutes les Femmes), le personnage de la Soeur devient non-échangeable, donc contradictoire, asocial. En outre la fécondité féminine représente cette part de la nature qui demeure (comme la mort) irréductible et ne se laisse jamais tout à fait maîtriser par la culture. En elle le Père-Forgeron, le Père symbolique perçoit ce reste irréductible qui fait de lui un père selon la nature, un géniteur obscur. La parole de la Mère ne pourrait-elle donc pas lever l'incognito de celui qui a déposé le germe en son sein ? Sans doute, mais cette parole de femme reste une parole individuelle, faillible, qui ne suffit pas à assumer la nature dans la culture; il y faut pour cela tout le système symbolique de la société représenté par la parole du Père Ancestral. Et c'est pourquoi dans toutes les civilisations la parole féminine fut considérée comme parole à la laquelle on ne peut se fier : en elle se reflète l'ambiguïté de l'Origine, le Non-symbolisable.

Si l'on admet que la "folie" ne relève pas seulement des mécanismes ordinaires de refoulement et de régression, mais correspond à un défaut de symbolisation, à une faille qui s'oppose aux bases de la structure oedipienne, il apparaît que la tradition Bambara a marqué la place de cette faille originelle. La tradition collective, en ponctuant le lieu de la folie originelle, permet à la société d'accompagner en quelque sorte l'individu jusqu'au fond de son angoisse la plus primitive, la plus abyssale. Il y aurait là comme l'oscillation autour d'une limite extrême, qui peut être Mystique ou Folie. Cette limite extrême est la pensée de l'origine. C'est la question sans réponse qu'adresse un vieil hymne Bambara à un Dieu sourd et muet dont le silence est le digne Péril de la vie :

95 Cf. CI. Lévi-Straus : Anthropologie Structurale, Paris, 1958, p. 70. 
Savane verte toute nouvelle, Savane verte vraiment exposée au péril...

Calao Sourd-Muet, Chef de village Sourd-Muet.

Quelle sorte de chose est cela ? ${ }^{96}$.

96 Cité par D. Zahan : Sociétés d'initiation Bambara, 1, pp. 257-258. 
Religions du livre. Religions de la coutume

\section{Chapitre VI}

\section{Les origines augustiniennes de la philosophie de l'esprit *}

\section{$\underline{\text { Retour à la table des matières }}$}

Il est bien connu que la première formulation de l'argument "Cogito ergo sum" se trouve chez saint Augustin, dans une œuvre, le de Trinitate, que Descartes n'avait pas lue bien qu'il ait pu en subir indirectement l'influence ${ }^{97}$. Saint Augustin utilise le doute de la même manière que Descartes comme une procédure d'élimination des connaissances adventices acquises par les sens ou des opinions changeantes forgées par l'imagination de telle sorte que la pensée trouve dans la seule évidence de son activité la certitude de son existence et de sa distinction d'avec le corps. Cependant l'évidence que la pensée a d'elle-même, n'est explicitée chez saint Augustin que par la génération d'un verbe ou la formation d'un concept de l'esprit. C'est précisément dans cette capacité de se concevoir soi-même que réside l'essence de l'esprit. Le de Trinitate de saint Augustin apparaît ainsi comme la

* Kant-Studien (632), 1972.

97 Cf. E. Gilson : Études sur le rôle de la pensée médiévale dans la formation du système cartésien, Paris, Vrin, 1930, pp. 35, 191 ss.

N.B. - Les références au de Trinitate sont données d'après l'édition bénédictine de St Maur (t. 8.) ; le chiffre romain indique le livre ; le chiffre arabe le paragraphe. Je n'ai pas tenu compte de la division en chapitres. 
première élaboration spéculative de la notion chrétienne de l'esprit, l'origine de ce qui, à partir de Kant et de Hegel, s'appellera la philosophie de l'esprit et du concept c'est-à-dire de la manifestation de soi par soi. C'est avec l'idéalisme allemand plus encore qu'avec Descartes que la doctrine augustinienne gagne à être comparée. Il s'agit pour nous d'examiner comment la doctrine des relations trinitaires en Dieu est à l'origine de ce qui fut la philosophie "moderne", et de parcourir à nouveau le détour théologique par lequel le cercle de la connaissance de soi a déplacé son centre, du cosmos hellénistique à l'histoire biblique.

Toute comparaison entre Descartes et saint Augustin bute sur un obstacle philologique et fait apparaître un certain nombre de malentendus. Si par exemple la formule "Cogito ergo sum" ne se trouve pas littéralement chez saint Augustin, cela tient à plusieurs raisons: d'abord, comme nous le verrons, les mots "cogitare", "cogitatio" n'ont pas le même sens ni surtout les mêmes valeurs dans le latin vivant de saint Augustin et dans la langue scolaire de Descartes ; ensuite le sujet du verbe "cogitare" chez saint Augustin est la "mens" c'est-à-dire l'âme intellectuelle, l'esprit, alors que l'Ego désigne pour lui l'individu concret, âme et corps, de sorte que la formule en Ego n'est introduite par saint Augustin que secondairement à titre d'objection $(\mathrm{XV}, 42)$ : en passant de la troisième personne ("mens cogitat") à la première ("cogito"), on change la forme d'attribution car l'esprit est une intelligence mais le moi a une intelligence; dans le premier cas l'intelligence est un attribut essentiel du sujet, elle est dite de la substance ; dans le second cas, l'intelligence est dite être dans un sujet, ce qui réintroduit une attribution accidentelle, un individu pouvant être plus ou moins intelligent. Saint Augustin s'efforce de répondre à cette objection, mais le fait qu'elle ait pu surgir témoigne d'une perspective générale différente de celle de Descartes, bien que les deux auteurs admettent que la connaissance de l'esprit par lui-même soit une intuition intellectuelle et non pas une notion générale abstraite. Enfin dans la formule "Cogito ergo sum" on conclut à l'existence. Or pour saint Augustin attribuer l'être à l'esprit est la chose la plus pauvre que l'on puisse en dire, car "un cadavre aussi existe" ("sed est et cadaver", X, 
13), alors que le problème est de savoir "comment vit" une intelligence et de montrer que l'esprit n'est tout ce qu'il doit être qu'en engendrant son propre concept. Le texte augustinien qui serait le plus proche du Cogito cartésien ne se trouve pas au célèbre livre $\mathrm{X}$ du de Trinitate, mais plutôt au livre $\mathrm{XV}, 21$, à propos de la réfutation du scepticisme de la nouvelle Académie. En disant "je sais que je vis", Je ne puis ni me tromper ni mentir. L'affirmation d'existence "Scio me vivere" passe au premier plan dans ce contexte parce que le problème posé dans le débat avec la nouvelle Académie n'est pas celui de l'âme mais celui de la science :

"Celui qui est certain de la science de sa propre vie, ne dit pas dans cette science : je sais que je suis éveillé, mais je sais que je vis. Qu'il dorme ou qu'il veille, il vit. Et dans cette science il ne peut être trompé par des songes, car dormir et rêver est le propre du vivant. Contre cette science l'Académicien ne peut rien dire... Même celui qui se trompe vit" (XV, 21).

Dans ce contexte il n'est pas directement question de la nature de l'âme mais de la possibilité de la science c'est-à-dire de ce qui donne à notre activité de pensée (cogitatio) sa forme vraie : "ipsa scientia de qua veraciter cogitatio nostra formatur" (XV, 21). En outre l'intuition que la pensée a d'elle-même ne sert ici qu'à illustrer la thèse d'après laquelle les intelligibles sont connaissables par eux-mêmes à la différence des sensibles qui sont connus par relation à un autre c'est-à-dire à nos sens. L'intuition intellectuelle est avant tout conscience de la règle par quoi notre pensée se forme, et c'est pourquoi elle est présentée comme une condition analytique de nos énoncés ;

Cela permet-il de conclure que l'âme est une "res cogitans" ? Pareille formule ne se trouve pas chez saint Augustin. Chez les cartésiens le mot "cogitatio" en est venu à désigner la pensée en général. Spinoza par exemple ne voit aucun inconvénient à faire de Dieu une "res cogitans" alors qu'il refuse d'attribuer à Dieu l'intellectus réservé à l'homme. Saint Augustin au contraire, qui comprend ce qu'en latin parler veut dire, attribue à Dieu l'intellectus mais se garde bien de lui attribuer la cogitatio : "Lorsque les saintes Écritures, dit-il, parlent des 
Cogitationes Dei, elles utilisent le même mode de langage que lorsqu'elles parlent des oublis de Dieu, ce qui en Dieu, au sens propre, ne correspond à rien" (XV 25), Pour entendre au sens propre "Deus cogitat", il faudrait admettre que Dieu est versatile, qu'il peut oublier, changer d'idées. La principale différence entre le Verbe divin et le verbe humain réside en ceci que, : "Verbum nostrum nostra cogitatione dicitur" (XV, 25) alors que le Verbe divin exclut toute cogitatio : "Verbum Dei sine cogitatione" (XV, 25).

Chez saint Augustin la cogitatio désigne exclusivement la pensée consciente actuelle, transitoire et changeante ; c'est l'acte d'attention (intentio) qui se dirige tantôt d'un côté tantôt de l'autre au grès de nos soucis ou de nos intérêts. Plus exactement la cogitatio peut se trouver dans deux états différents. Dans son premier état la cogitatio est l'agitation de la pensée ; ce sont les "cogitationes volubiles" (XV, 25) que l'on "roule" dans sa tête ou dans son coeur : "Certes, il connaissait bien la valeur des mots, il avait bien vu la fonction (vim) de la cogitatio, ce locuteur célèbre qui dit dans son poème : "il roule en lui-même les vicissitudes changeantes de la guerre" (Virgile, Ennéide, X, 159$160)$ id est cogitat" $(X V, 25)$. Toutefois ces pensées tournantes, "volubiles" au sens étymologique de versatiles, agitées, possèdent la propriété d'être éducables, formables. La cogitatio est dans l'esprit humain le "formabile" (XV, 25), ce qui peut recevoir la forme d'une idée, d'un jugement. D'où un second état de la cogitatio ; la "cogitatio formata", l'activité attentive informée par une connaissance vraie : "Cogitatio quippe nostra perveniens ad id quod scimus, atque inde formata, verbum nostrum verum est" (XV, 25). Le problème augustinien de la cogitatio sera donc le problème de la formation du verbe exprimé par la parole en. quelque langue que ce soit.

C'est pourquoi, au sens technique proprement augustinien, la cogitatio est "la parole du coeur" ("Iocutiones cordis", XV, 18) du fait que le mot "verbe" désigne principalement un jugement d'approbation ("nosse et approbare", "quod excogitatum placet", X, 13). "Même si les paroles ne résonneni pas, il parle dans son coeur celui qui pense" 
(XV, 17). Pour l'homme "il ne peut y avoir de verbe sans cogitatio" $(\mathrm{XIV}, 10)$. Dans la mesure où la cogitatio opère la récollection des souvenirs et conçoit l'unité d'une proposition, on peut en jouant sur les mots affirmer que ce qui doit être pensé ("excogitanda") c'est ce qui doit être réuni ("cogenda") "id est velut ex quadam dispersione colligenda, unde dictum est cogitare. Nam cogo et cogito sic est ut ago et agito, facio et factito" (Conf. X, 18 ; de Trin. XI, 6). Si, par une étymologie fantaisiste, Augustin interprète le verbe "cogitare" comme un fréquentatif, c'est que pour lui la cogitatio, l'activité de l'attention, est une variable qui se définit par opposition à trois constantes : la mémoire, l'intelligence, la volonté. Pour Descartes l'âme pense toujours. Pour saint Augustin l'esprit est toujours connaissance de soi, mais il ne se pense pas toujours. Par exemple la mémoire (par opposition au souvenir) est une connaissance sans pensée, comme dans le cas du musicien qui connaît la musique même lorsqu'il n'y pense pas, ou du grammairien qui connaît sa discipline même lorsqu'il s'occupe d'autre chose. Contrairement à ce qui se passe chez Descartes la pensée consciente actuelle n'est pas immédiatement donnée comme l'attribut essentiel de la substance spirituelle. La pensée consciente est une activité temporelle, un procès susceptible de révéler les caractéristiques fondamentales de l'esprit en tant que celles-ci sont les conditions des expressions verbales, des jugements, que nous fermons. Ces trois caractéristiques, Mémoire, Intelligence, Volonté, sont moins des activités que des registres topiques, des lieux (quelque chose comme le lieu du soi sans pensée, le lieu des idées ou formes régulatrices, le lieu de l'aspiration au Bien); plus exactement nous verrons qu'elles sont un genre spécial de "relations" qui concourent à former le concept de l'esprit (verbum mentis).

Le mot "mens" que je traduis par "esprit" doit être soigneusement distingué des notions voisines issues de la philosophie grecque, telles

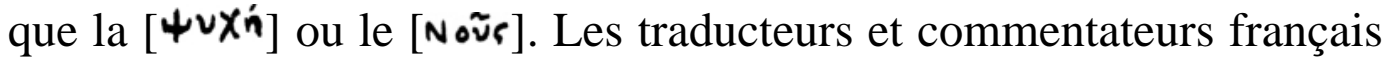
de saint Augustin traduisent habituellement le mot "mens" par "âme". Cette traduction risque d'égarer le lecteur. Le mot "anima" chez saint Augustin désigne la vie du corps ("anima vita est corporis", IV, 3), le 
principe vital qui nous est commun avec les animaux (XV, 1). L'âme sans doute s'oppose au corps puisqu'elle est immortelle, mais le mot "âme" est surtout employé dans des contextes où l'être humain se désigne comme créature vivante en face de Dieu. "Anima" évoque le problème de la création plutôt que celui de la connaissance. Lorsque l'âme est désignée comme principe de connaissance, saint Augustin dit le plus souvent "animus". Toutefois le mot "animus" dénote plutôt une fonction psychologique, comme on le voit bien par exemple au livre XI lorsqu'il s'agit d'analyser la dialectique trinitaire par laquelle se constituent la perception, puis le souvenir, enfin l'intellection ; il s'agit alors d'analyse psychologique. Au contraire "mens" a une connotation métaphysique ; il évoque l'essence "intelligible" de notre nature. D'autre part animus convient de préférence aux puissances intermédiaires de l'âme (mémoire, imagination, raisonnement calculateur), alors que la "mens" correspond à "ce qui est en nous le meilleur", l'âme intellectuelle et rationnelle $(\mathrm{XV}, 1)$. Et pour mieux préciser sa pensée saint Augustin dit que la "mens" n'est pas l'âme mais ce qui excelle en l'âme : "Non anima, sed quod excellit in anima mens vocatur" (XV, 11).

Pourtant, bien que la "mens" se rapproche de l'intellect que les Grecs appellent [Nov $\varsigma$ ] toute l'argumentation du de Trinitate se propose de montrer que la "mens" n'est pas seulement intelligence mais aussi mémoire et volonté. "Mens" a pour équivalent "spiritus", mais ce dernier mot, réservé à l'une des personnes de la Trinité, semble moins apte que "mens" à suggérer l'analogie trinitaire dans son ensemble. En outre si la "mens" est "spiritus", la réciproque n'est pas vraie : il y a des esprits qui ne sont pas "mens" c'est-à-dire qui ne sont pas l'esprit humain (XIV, 22). Enfin, puisque le de Trinitate a pour but de montrer que la notion chrétienne de l'esprit apporte une nouvelle solution au problème posé par le précepte de la sagesse : "Connais-toi toi-même", le meilleur moyen d'éviter les malentendus au départ sera de comprendre que la "mens" est, comme dit saint Augustin, le "toimême" qu'il s'agit de connaître. La "mens" est le "soi" de l'homme. 
C'est précisément le sens de ce pronom réfléchi qui va constituer pour Augustin un problème nouveau, celui de l'image de Dieu en l'homme.

Le de Trinitate peut être divisé en deux parties. La première partie (livres I à VII) expose la théologie trinitaire suivant les Écritures. La deuxième partie (livres VIII à XV) expose la doctrine de la sagesse c'est-à-dire de la véritable connaissance de soi obtenue par la connaissance du vrai Dieu. L'image de Dieu sera la réponse au précepte de Delphes : "connais-toi toi-même".

Cependant la principale difficulté que l'on rencontre dans l'interprétation du de Trinitate vient de ses défauts de composition. C'est un ouvrage sinueux, diffus, auquel l'auteur a travaillé pendant vingt ans (de 399 à 419) avec des interruptions. Augustin n'est arrivé à préciser sa pensée qu'au fur et à mesure de la rédaction. D'où de nombreuses redites avec changements de perspectives. Le plan général de l'ouvrage et la définition des termes principaux, tels que "mens" ou "cogitatio" ne sont pas donnés au départ mais seulement à la fin. Le livre XV remplit d'ailleurs un double office : d'une part il présente la via negativa du raisonnement par analogie c'est-à-dire insiste non plus sur les ressemblances mais sur les dissemblances entre l'homme et Dieu ; d'autre part il récapitule les idées exprimées en cours de route en apportant certaines mises au point. C'est dans les derniers livres, XIV et $\mathrm{XV}$, que saint Augustin parvient à donner de sa pensée une expression systématique, et c'est de là qu'il faut partir pour éclairer certaines questions particulièrement difficiles, comme le rôle de la mémoire par exemple.

Enfin, pour comprendre les intentions d'Augustin dans l'élaboration du de Trinitate, il importe de discerner les questions qu'il se pose, les thèses auxquelles il cherche à s'opposer. Or cela n'apparaît pas d'emblée. Seule une analyse interne de l'oeuvre permet de le reconnaître. Pour discerner les questions qui orientent la pensée d'Augustin dans le de Trinitate, il convient de rapprocher les livres $\mathrm{V}$ (contre les Ariens), VIII (doctrine de l'amour) et XII (la notion de sagesse). 
Nous commencerons par examiner les questions posées par ces trois livres V, VIII et XII.

La question qui domine la première partie (théologie trinitaire) est formulée au livre V contre les Ariens. Cependant l'arianisme n'est qu'un adversaire officiel. Il serait plus juste de dire qu'Augustin profite ici de l'héritage théologique, du trésor d'arguments et de vocabulaire, que lui a légué l'ère des grandes controverses trinitaires. Le véritable adversaire intérieur, le complice dont saint Augustin a besoin pour élaborer ses propres thèses dans cette première partie, c'est Aristote.

Le raisonnement des Ariens est le suivant : "Tout ce qui est dit ou compris de Dieu, est dit ou compris non suivant l'accident mais suivant la substance" $(\mathrm{V}, 4)$, puisqu'il n'y a pas en Dieu de changements. Donc en affirmant "Le Père est inengendré", on le dit suivant la substance. En affirmant "Le Fils est engendré", on le dit suivant la substance. La différence entre le Père et le Fils se dit suivant la substance. Donc le Fils n'est pas consubstantiel au Père.

Dans sa réponse ( $\mathrm{V}, 4 \mathrm{ss})$, saint Augustin rappelle la distinction aristotélicienne entre l'attribution essentielle (ce qui est dit du sujet) et l'attribution accidentelle (ce qui est dit être dans un sujet). Aristote range la relation (ad aliud, pros ti) parmi les accidents. Or la thèse d'Augustin sera la suivante : il est faux que toute relation soit accidentelle.

En effet le Père et le Fils ne se distinguent que par leurs relations mutuelles ; chaque terme n'est tel que par sa relation à l'autre (ad aliud). Mais chacun considéré par rapport à soi (ad se) exprime adéquatement l'essence divine (in se). La même essence ou substance se retrouve dans l'un et dans l'autre. Nous avons donc ici un cas où l'attribution relative (ad aliud) est égale à l'attribution essentielle (ad se). La relation n'est pas accidentelle, elle n'implique aucun changement. Mais saint Augustin ne dit pas pour autant que la relation est essen- 
tielle, puisqu'il est nécessaire de maintenir la distinction entre les attributs essentiels communs et la position relative des personnes l'une à l'égard de l'autre. Entre les deux formes d'attribution, essentielle et relative, le lien demeure synthétique : il n'y a pas identité mais "égalité". Il y a convertibilité de la relation à l'autre à la relation à soi par réduction à l'identité de l'essence. En outre les quatre relations (paternité, filiation, procession, spiration) sont asymétriques elles introduisent un ordre dans la position respective des personnes elles ne sont pas symétriques comme l'amitié. Ainsi, bien que saint Augustin rappelle le thème mystique ("la simplicité divine est au-delà de toute parole"), Dieu n'est plus simplement l'Un ineffable @'Un négatif) dès lors qu'en lui s'introduit la relation. Admettre l'égalité entre attribution essentielle et attribution relative revient à dire que Dieu est sa propre manifestation. Il se dit éternellement dans son Verbe (livre VII). Si Dieu est esprit, si Dieu est sa révélation ${ }^{98}$, d'où vient que celle-ci soit pour nous contingente ? C'est que la filiation du Verbe est éternelle, mais son incarnation parmi les hommes est contingente, historique. En soi Dieu est lumière, il est sa propre gloire ; c'est la même chose pour lui que d'être et de se dire éternellement dans son Verbe et de s'aimer dans son Esprit. Le dogme de la Trinité justifie la possibilité d'une révélation historique, puisque le Verbe est à la foi distinct et égal du père, que sa génération est éternelle et son incarnation temporelle, accidentelle (in alio). Ce que Dieu est en soi (in se) est révélé par le fait que chaque personne est à la fois distincte par relation aux autres (ad aliud) et égale aux autres par référence à soi (ad se).

C'est ce même principe d'égalité entre attribution relative et attribution essentielle qui, dans la seconde partie (doctrine de la sagesse ou du "Connais-toi toi-même") va servir à déterminer quels sont les véritables attributs de l'esprit. Comment se fait la transition entre les deux parties, entre la connaissance de Dieu (1-VII) et la connaissance de soi (VIII-XV)?

98 "Le Père est éternellement Disant, mises à part ces paroles de Dieu qui adviennent temporellement aux créatures" (VII, 1). 
Le livre VIII (doctrine de l'amour) commence par assimiler le Dieu chrétien (où chaque personne est égale à la Trinité) et la forme platonicienne du Bien qui, n'étant pas susceptible de plus ou de moins, est la grandeur même, toujours égale à soi. Le principe d'adéquation interne est l'essence de la vérité ; il est la loi intérieure de l'amour qui tend à égaler son objet à la source dont il procède (VIII, 1-3).

Pour comprendre ce livre VIII, particulièrement difficile, il convient de remarquer deux choses :

En premier lieu, ce qui est dit du Bien s'applique en conséquence à toutes les Formes. Il s'agit de montrer que la doctrine platonicienne des Formes se ramène à la thèse que Dieu est lumière, qu'il est la vérité que chacun doit apercevoir par une conversion intérieure (VIII, 4 5), sans intermédiaire, le maître humain ne pouvant donner qu'un avertissement ("commonitio") ou un rappel ("commemoratio").

En second lieu, le livre VIII est écrit tout entier dans la perspective d'animus. Le mot "mens" ne sera introduit qu'au livre IX avec la seconde formule trinitaire : "Mens, notitia, amor." La première formule trinitaire ou trinité de l'amour (amans, quod amatur, amor) énoncée au livre VIII, n'a qu'un caractère préparatoire. Il s'agit de montrer que l'analogie trinitaire ne consiste pas à faire comme les enfants qui jouent à compter sur leurs doigts ou comme la mythologie lorsqu'elle parle des trois corps de Géryon (VIII, 3). L'analogie trinitaire consiste à appliquer le principe de l'adéquation interne tel que la relation ad aliquid soit convertible avec une relation ad se, et réciproquement.

"Tu vois la Trinité, si tu vois l'amour. Je t'avertirai, si je peux, de voir que tu vois : que soit seulement présent un mouvement d'amour vers quelque bien... Il n'y a pas d'amour qui n'aime rien. Si l'amour s'aime lui-même il faut qu'il aime quelque chose (aliquid) afin de s'aimer soi aussi d'amour. De même qu'une parole (verbum) indique quelque chose (aliquid) et s'indique aussi elle-même (seipsum), mais que la parole ne s'indique pas ellemême à moins qu'elle ne s'indique indiquant quelque chose, ainsi l'amour 
s'aime, mais s'il ne s'aime pas aimant quelque chose il ne s'aime pas comme amour" (VIII, 12).

Comme on voit, l'expression "amour de soi", au livre VIII, ne signifie pas l'amour d'Ego, l'amour propre ; elle signifie au contraire que l'amour a en lui-même sa propre loi. L'amour n'est pas seulement une "relation" entre l'amant et l'aimé, il est par rapport à soi l'esprit même ; il se manifeste dans l'amant et l'aimé en les égalant à soi. Ainsi l'amour révèle aux êtres qui s'aiment le chemin de toute ipséité

La forme du Bien met animus en quête de soi, le met en demeure de concevoir son propre soi. Il convient de rappeler que la Forme platonicienne n'est pas un concept, elle n'est pas engendrée par nous. La Forme est la raison éternelle de ce qui existe, même si ce qui existe est temporel. La Forme est ce par quoi (principe quo ou a priori) les choses sont déterminées à être ce qu'elles sont ; elle est principe régulateur de nos jugements, règle de vérité (regula veritatis). Or une Forme intelligible ne peut être pensée que présente, bien qu'elle ne soit pas toujours pensée. Ainsi par exemple lorsque je parle de Carthage sans y être corporellement présent, mon verbe, "ce que je veux dire" est l'image (phantasia) d'une chose absente : Carthage ne peut être représentée qu'en autre chose que soi dans un souvenir (VIII, 9). Par contre lorsque je parle de la justice, dès lors que je comprends ce que "veut dire" le mot, le sens "justice" est présent à ma pensée. Même si je ne suis pas juste, l'intelligible ne renvoie à aucune absence ; il ne représente rien ; il est présent par soi,, non par autre chose, bien qu'il nous introduise toujours à la connaissance de quelque chose autre que soi, comme par exemple lorsqu'il s'agit d'apprécier la justice de tel individu ou de tel acte (VIII, 9). Donc le problème de l'intelligence des Formes relève d'une intuition directe au même titre que la conscience de soi. Si je connais l'animus d'un autre, ce n'est pas par connaissance générale abstraite, mais c'est, que j'ai moi-même un animus. Pourtant je ne suis pas enfermé dans ma solitude, car la véritable intuition intellectuelle de soi devra pouvoir "se dire" universellement. Pour être présent à moi, Animus n'aura pas besoin de se dédoubler, de se représen- 
ter dans une image autre que soi comme s'O s'agissait d'une chose absente. Étant originairement présent à soi, il ne lui manque que de se manifester, "se concevoir", de la même façon qu'en adhérant à la Forme même de la justice ("inhaerendo ipsi Formae"), animus se forme et devient juste. C'est pour les mêmes raisons que la connaissance de soi ne procède pas d'un dédoublement réflexif et que l'amour ne procède pas d'un manque (même lorsqu'il le révèle en nous). La connaissance a sa règle d'auto-manifestation comme l'amour a en luimême sa règle d'auto-réalisation. L'amour ne manque de rien, la lumière ne représente rien. Une parole du coeur pourra naître quand, ayant accepté de perdre bien de choses, on n'aura plus rien que soi à céder à l'amour.

En somme, dans le livre VIII, c'est un même mouvement qui tend d'un côté à ramener la lumière des Formes à l'auto-manifestation de la vérité divine, et d'un autre côté à montrer que l'amour ne procède pas d'un manque ni l'intelligence d'une dualité représentative entre connaissant et connu, mais de la nécessité de se manifester suivant un principe d'adéquation interne de l'esprit à l'esprit. Le mot pourtant n'est pas encore prononcé ; il ne le sera qu'au livre IX. Alors "amor" aura révélé à "animus" qu'il est "mens".

Le livre VIII est destiné à écarter la thèse de "ceux qui cherchent Dieu dans ces Puissances qui sont présentes au monde ou aux parties du monde" (VIII, 11), comme sont par exemple les trois hypostases plotiniennes (l'Un, l'Intelligence, l'Anie). Pour Plotin l'intelligence en tant que lieu des Formes est une puissance cosmique ; de même l'âme du monde, la vie universelle. Pour Augustin au contraire l'intelligence des Formes est liée à la nécessité pour animus d'accoucher de soi comme esprit dans la génération d'un verbe. La théorie plotinienne des trois hypostases ou puissances cosmiques suppose admise la préexistence des âmes individuelles dans le cosmos, dans l'âme universelle. Or bien que saint Augustin ait admis en quelques textes l'hypothèse d'une pré-existence des âmes en Dieu lors de la création d'Adam (péché originel), il lui est impossible d'accepter l'interprétation pythagori- 
cienne de la pré-existence. Pour bien saisir l'importance de cette question, nous allons faire un détour par le livre XII avant de reprendre de fil de notre lecture au livre IX.

Le livre XII définit la notion de sagesse. La science, qui a pour objet les conditions temporelles de l'action, doit être dirigée par la sagesse qui est la connaissance des vérités éternelles indispensables à la connaissance de soi. Une doctrine de la sagesse devra donc montrer comment les Formes éternelles sont présentes à nos esprits changeants. Or c'est précisément sur ce mode de présence des Formes à l'âme que saint Augustin s'écarte de Platon. À la fin du livre XII, la polémique contre la platonisme portera sur un point décisif : Platon explique la réminiscence des Formes par la pré-existence des âmes dans le cosmos.

"Ainsi, écrit Augustin, Platon, ce noble philosophe, s'est efforcé de nous persuader que les hommes ont vécu ici-bas avant d'habiter leurs corps actuels, en sorte que l'acquisition du savoir serait la réminiscence de choses antérieurement connues plutôt que la connaissance de choses nouvelles... Il ne faut pas croire ceux qui racontent que Pythagore de Samos se serait rappelé certaines choses dont il aurait fait l'expérience lors d'un précédent séjour ici-bas dans un autre corps" (XII, 24)

Mais alors que devient la réminiscence des Formes quand on ne croit plus à la pré-existence des âmes dans le cosmos ? Cette question, bien qu'elle ne soit posée qu'au livre XII, est sous-jacente à tous les développements du livre VIII sur l'amour de la sagesse. Il convient en effet de rappeler que pour Augustin (livre XI), comme pour Platon, la mémoire est la première Manifestation de l'âme se séparant du corps c'est-à-dire de la sensation actuelle, et aspirant à l'intelligible bien qu'elle soit encore prisonnière des images. Suivant la forte expression du Philèbe (36 d), "la mémoire pousse le désir", tend à réveiller en lui la réminiscence des Formes. Chez Plotin le problème de la mémoire (IVe Ennéade) sera d'emblée le problème de la mort, ultime séparation d'avec le corps : de quoi l'homme se souvient-il quand il est mort ? À quoi pensent les âmes séparées ? (IV EN. 3,25 - 4, 8, et 6). Et dans 
cette perspective Plotin opposera à la théorie aristotélicienne des empreintes ou vestiges laissées en nous par l'expérience acquise, la théorie de la mémoire comme diathèse ou disposition, car l'âme est disposée différemment suivant qu'elle s'attache au sensible ou s'élève vers l'intelligible. Cependant comme le néo-platonisme est conciliateur (Aristote est vrai pour le monde sub-lunaire et Platon pour le monde céleste), on admettra les deux théories en distinguant deux sortes de mémoires. C'est à peu près ce qu'admet saint Augustin : la théorie des vestiges est valable pour les "idées adventices", mais pour tout ce qui est présent par soi, c'est-à-dire pour les Formes et pour l'âme (car "l'âme n'est pas adventice à elle-même", XIV, 13), Augustin admet la théorie de la diathèse c'est-à-dire de la mémoire comme disposition du désir.

Alors que devient la réminiscence des Formes quand on ne croit plus à la pré-existence des âmes ? Augustin répondra (XII, 23 et passim) que les formes sont reconnues dans une évidence actuelle, qui ne sera que secondairement confiée à la mémoire. Cette impossibilité de maintenir en nous l'évidence tient au caractère changeant et transitoire de notre pensée consciente (cogitatio) ; nous ne pouvons avoir que "rei non transitoriae transitoria cogitatio" (XII, 23). Cependant, puisque l'on maintient la théorie de la mémoire-disposition, il faudra aussi maintenir son corollaire la réminiscence (recordatio). Que devient la réminiscence quand on ne croit plus à son interprétation pythagorienne ? Elle devient réminiscence de "soi". Comme nous le verrons par la suite, l'âme devra surmonter un "oubli de soi" pour engendrer un verbe égal à soi. Dans une parole du cœur "animus" accouchera de soi comme esprit et dévoilera en lui la lumière intellectuelle des Formes. Là où il n'y a plus pré-existence des âmes dans le cosmos, il faudra admettre la génération du verbe et l'union de l'esprit à son verbe dans l'amour. Le verbe aura le double effet "d'exprimer" notre ipséité spirituelle ("mens") et de "former" la vision de la pensée (cogitationis visio) d'après l'intelligence des Règles immuables.

Plus précisément, il y a deux espèces de verbes ; 
"Dans l'amour des choses charnelles et temporelles, comme dans la reproduction animale, autre est la conception du verbe, autre est son enfantement. Là ce qui est conçu dans le désir naît dans l'obtention d'un résultat. Il ne suffit pas à l'avare de connaître et d'aimer l'or s'il n'en a pas ; il ne suffit pas d'aimer la nourriture et l'union sexuelle, si l'on ne fait pas ce qu'il faut..." (IX, 14).

"Par contre, dans l'amour des choses spirituelles, la conception du verbe et sa naissance ne font qu'un, lorsque la volonté dans la connaissance même se repose. Par exemple, celui qui connaît et aime parfaitement la justice est déjà juste, même si n'existe aucune nécessité d'action extérieure par les membres du corps" (IX, 14).

L'esprit, comme l'intelligible, est de soi "présence vraie" ("vera praesentia", X, 16), il ne peut être pensé que présent ; mais il n'est pas toujours pensé de sorte que la "praesentia" (présence intelligible) n'est pas toujours un "conspectus" (présence consciente) :

"Si grande est la force de l'activité pensante (cogitatio) que l'esprit luimême ne se pose en présence consciente de soi (,,se in conspectu suo ponat"), sinon par sa pensée actuelle (cogitatio), de sorte que pas même l'esprit ne peut être autrement en présence de soi sinon en se pensant luimême" (XIV, 8).

Il pourra y avoir un oubli de soi dans la mesure où la présence intelligible (praesentia) ne devient pas toujours une auto-position consciente (conspectus). Par contre la connaissance de soi devra bien être comprise comme la genèse interne d'un "concept", la nécessité d'une auto-manifestation. "Et ainsi quand l'esprit par son activité pensante se retourne vers soi, il devient trinité (fit trinitas) dans laquelle alors un verbe peut être compris" (XV,13). Mais avant d'accéder à cette compréhension de soi, l'esprit qui est à lui-même "praesentia" sans "conspectus", présence inconsciente, est tout entier "mémoire" (memoria), mémoire sans pensée, sans souvenir actuel (recordatio), et ainsi "oublieux de soi" ("oblitus sui"), il se cherchera dans tout ce qui n'est pas lui. 
Après ce long détour et ces anticipations, revenons en arrière pour reprendre le fil de notre lecture au livre IX.

Le livre IX introduit le mot "mens" avec la formule : "mens, notitia, amor". Cette deuxième formule trinitaire comporte deux bizarreries de vocabulaire. D'une part, il n'y a que deux termes relatifs "notitia" et "amor" ; le mot "mens" tient ici la place du troisième terme absent, la "memoria". D'autre part les mots "notitia" et "cognitio" semblent être traités comme équivalents. Or il apparaîtra par la suite (surtout en XIV et XV) que la "notitia" est réservée aux connaissances incluses dans la mémoire, donc toujours présentes même quand on n'y pense pas (connaissance sans cogitatio) ; au contraire "cognitio" désignera la connaissance actuelle (avec cogitatio). Ces deux anomalies du vocabulaire semblent indiquer que la question de la mémoire est, pour l'instant, laissée en réserve.

À quoi sert donc la formule incomplète : Mens, notitia, amor ? Elle fournit le moyen de revenir au problème initial des deux formes d'attribution. Au livre VIII Augustin a surtout insisté sur le principe d'égalité interne suivant lequel pour se connaître et s'accomplir l'esprit doit rendre la connaissance et l'amour égaux à son essence. Au livre IX, après avoir rappelé ce principe, Augustin montre que chaque terme de la triade peut être considéré alternativement soit comme terme relatif (ad aliud) soit comme substance ou essence (ad se).

"L'esprit (mens) est en soi (in seipsa) puisqu'il est dit par rapport à soi (ad se), bien que le connaissant ou le connu ou le connaissable soit dit relativement (relative) à la connaissance ; et que l'amant ou l'aimé ou l'aimable soit référé (referatur) àl'amour dont il s'aime. De son côté bien que la connaissance soit référée (referatur) à l'esprit connaissant ou connu, cependant c'est par rapport à elle-même (ad seipsam) qu'elle est dite connue ou connaissante, car elle n'est pas inconnue à soi la connaissance par laquelle l'esprit se connaît. De même l'amour, bien qu'il soit référé (referatur) à l'esprit aimant dont il est l'amour, cependant c'est aussi par rapport à lui-même (ad seipsum) qu'il est amour, de sorte qu'il est aussi en lui-même (in seipso). Ainsi ces termes, pris un à un, sont aussi en soi. Et pris alternativement ils sont tels que l'esprit aimant est dans l'amour, l'amour dans la connaissance de l'amant, la connaissance dans l'esprit connaissant" (IX, 8). 
Ou encore : "Bien que l'amant ou le connaissant soit substance, et bien que la science soit substance et que l'amour soit substance" (IX, 6), on peut aussi considérer que l'amant et l'amour ou le connaissant et la science sont dit relativement à soi (relative ad se) suivant une relation symétrique ("sicut amici"), mais l'esprit (mens aut spiritus) n'est pas relatif de même que les hommes ne sont pas relatifs" (IX, 6).

Plusieurs siècles de philosophie de la connaissance nous ont habitué à dire que l'esprit est à la fois relation à l'autre et relation à soi, pour soi et pour un autre, ou qu'il se reconnaît dans autre chose que soi etc.. Ces idées, qui nous paraissent évidentes parce que nous n'en percevons peut-être plus l'ambiguïté, sont ici péniblement conquises par la voie du grand Détour qu'est Dieu. Augustin veut établir que la connaissance a deux aspects : en tant que relation à quelque chose, elle implique la dualité du connaissant et du connu, mais en tant que relation à soi la connaissance est l'esprit connaissant lui-même. Et de même pour l'amour. On montre que connaissance et amour se distinguent par relation mutuelle, mais aussi que pris un à un (in singulis) ou deux à deux (in alternis) ils peuvent être considérés par rapport à soi et sont alors l'esprit même, la substance. Pourtant cette dernière n'est jamais prise relativement, ce qui serait contradictoire. Il en résulte que la connaissance de soi repose non pas sur la réflexion psychologique qui dédouble connaissant et connu par représentation dans un autre, mais au contraire sur cette égalité logiquement réflexive par laquelle la relation ad aliud est convertible dans une relation ad se qui révèle l'essence in se. La réflexion psychologique dédoublante, en tant que représentation in alio, ne pourrait jamais donner l'essence. C'est seulement parce que l'amour et la connaissance sont des relations "spirituelles" qu'elles sont égales à l'essence.

Augustin précise encore (IX, 5) que la connaissance et l'amour, qui sont dits par relation à l'esprit, sont dits aussi pour eux-mêmes (ad se) "essentialiter, non tanquam in subjecto". La connaissance n'est pas dans un sujet à la manière dont un accident est dit exister dans la subs- 
tance, comme une couleur ou une figure est dans un corps ni comme une qualité ou une quantité est dans un sujet.

"En effet, tout ce qui est tel (c'est-à-dire tout ce qui existe comme attribut accidentel, in alio) n'excède pas le sujet dans lequel il est ("non excedit subjectum in quo est"). La couleur ou la figure de tel corps ne peut pas être la couleur ou la figure de tel autre corps. Au contraire l'esprit par l'amour dont il s'aime, peut aussi aimer autre chose que soi. De même l'esprit connaît non pas soi seulement mais beaucoup d'autres choses. C'est pourquoi l'amour et la connaissance ne sont pas dans l'esprit comme dans un sujet (tanquam in subjecto), mais ils sont substantiellement l'esprit luimême, car s'ils sont dits relativement l'un par rapport à l'autre, chacun dans sa singularité est la substance" (IX, 5).

C'est pourquoi la connaissance de soi ne devra pas procéder par représentation in alio (dédoublement psychologique) mais par automanifestation, développement interne de ce qu'enveloppe son essence : "Haec in anima existere et tanquam involuta evolvi ut sentiantur et dinumerantur essentialiter, non tanquam in subjecto" (IX, 5).

Le mot "connaissance de soi" est équivoque. Ce que je vois dans l'évidence rationnelle du vrai, je le vois en moi-même, mais la réciproque n'est pas vraie : si je raconte à un autre ce que je vois en moi, il pourra tout au plus le croire ; par contre ce que je vois dans la vérité éternelle, il devra le reconnaître en lui-même (IX, 9). C'est seulement par cette seconde voie que s'établissent les définitions (IX, 9). Les Formes régulatrices sont à la fois supérieures et intérieures à notre esprit (IX, 10).

"C'est donc dans cette vérité éternelle, à partir de laquelle toutes choses temporelles ont été faites, que nous regardons par l'intuition de l'esprit la Forme suivant laquelle nous sommes et suivant laquelle en nous ou dans les corps quelque chose opère par une droite raison; et à partir de là nous obtenons pour nous une véritable connaissance des choses conçue comme un verbe que nous engendrons en le disant et qui en naissant ne s'éloigne pas de nous" (IX, 12). 
Toute connaissance reproduit en nous une similitude de l'espèce de chose considérée. La connaissance des corps reproduit en nous leur similitude, à savoir l'image représentée dans la mémoire ; cependant la similitude est ici supérieure à l'espèce corporelle puisqu'en entrant dans la vie consciente elle manifeste sa généralité. D'autre part en connaissant Dieu, nous lui devenons semblables, mais non à égalité puisqu'il nous est supérieur. C'est donc seulement lorsque l'esprit se connaît et approuve sa connaissance, que le principe d'égalité est entièrement satisfait (IX, 16). La conception du verbe est donc une ratification de notre essence (cum amore notitia). C'est la volonté qui dirige l'attention, c'est elle qui unit et sépare (cf. XI, 5 ss). Le désir a précédé le concept ; à son tour la connaissance s'achève dans l'amour qui unit l'esprit à ce qu'il a conçu, lui en fait accepter soit l'usage (uti) soit la jouissance (frui). Ainsi la génération du verbe et la procession de l'amour concourent ensemble à la formation de la pensée et de l'action (IX, 18).

Nous en arrivons ainsi au livre $\mathrm{X}$ où ce que l'on appelle "le cogito augustinien" va servir à introduire la troisième et dernière formule trinitaire : la mémoire, l'intelligence, la volonté.

La formule du livre IX ne mentionnait pas la mémoire, car le livre IX avait laissé de côté le problème, entrevu au livre VIII de l'âme qui cherche et désire savoir. C'est ce problème que nous retrouvons au début du livre X. Que cherche notre esprit, que désire-t-il, qu'aime-t-il lorsqu'il cherche à se connaître ?

L'esprit se cherche de la même façon que l'on cherche la signification d'un mot mort ("emortuum"), dont le sens est oublié par exemple le mot "temetum" qui, en latin archaïque désignait le vin. Nul ne peut chercher ou aimer ce qu'il ignore absolument. Pour chercher l'inconnu, on s'appuie sur ce que l'on connaît déjà. L'esprit qui se cherche se connaît cherchant, il a une connaissance (notitia) de soi indéclinable, celle-là même qui précisément le pousse à chercher (X, 1-4, et 5). 
Quelle est la nature de cette connaissance indéclinable par laquelle l'esprit se sait ignorant, cherchant, désirant... ? Il s'agit d'une connaissance (notitia) que nous possédons même en l'absence d'une pensée consciente (cogitatio), de la même façon que le musicien et le grammairien ont la connaissance de leur métier même lorsqu'ils n'y pensent pas. Cette connaissance sans pensée appartient à la mémoire. La mémoire (memoria), en ce sens, ne doit pas être confondue avec le souvenir (recordatio) qui, lui, est une pensée (cogitatio). À ce niveau préconceptuel, le mot "mémoria" désigne une diathèse, une disposition de l'esprit qui se cherche sans parvenir encore à se penser comme tel. L'esprit alors se cherche à tâtons ; on ne peut pas dire qu'il s'ignore absolument car "il n'a jamais cessé de se connaître", mais il ne se pose pas dans une présence consciente de soi (in conspectu suo), il est caché à soi dans sa propre mémoire "comme s'il était lui-même pour soi mémoire de soi" ("tanquam ipsa sit sibi memoria sui", XIV, 18); dans cet état de mémoire, il s'est comme oublié lui-même ("tanquam sui sit oblita", X, 7) en ce sens qu'il ne peut éveiller en lui le souvenir, la réminiscence consciente, mais qu'il est pour soi comme la drachme perdue, ou comme le vieux mot "temetum" qui apparaîtrait indéchiffrable dans un mémoire en latin archaïque.

Cette doctrine de la "memoria" sans "recordatio" ou de la "notitia" sans "cogitatio", bien qu'elle soit esquissée au livre X, sera développée dans les livres XIV et XV, comme si Augustin, à mesure que s'achevait la rédaction de son oeuvre, prenait davantage conscience de son importance. Dans notre exposé nous suivrons à peu près la démarche d'Augustin. Ce n'est qu'après avoir exposé d'après le livre $X$, la théorie de l'illusion et l'argument du Cogito, que nous verrons mieux pourquoi saint Augustin ne pouvait échapper à ce problème de l'oubli de soi et de la réminiscence de soi, et pourquoi la compréhension, oeuvre de l'intelligence et non de la mémoire, ne pouvait être obtenue qu'en passant par le souvenir, pourquoi en un mot cette condition insuffisante était néanmoins nécessaire. 
Revenons à la question initiale : "Qu'est-ce que l'esprit aime lorsqu'il cherche ardemment à se connaître, inconnu de soi $(\mathrm{X}, 5)$ ? Quatre hypothèses peuvent être envisagées : il est poussé par la fiction d'un idéal, par la recherche du Bien, ou d'un bonheur perdu, ou par le désir de savoir $(X, 5)$. Toutes ces hypothèses se heurtent à une même objection : quel que soit le motif qui le pousse (la fiction, le bien, le bonheur, le savoir), comment l'esprit peut-il être soi-même -en question pour soi $(\mathrm{X}, 5)$ ?

Et d'où vient la possibilité de l'illusion? L'illusion consiste pour l'esprit à se chercher comme on cherche un absent. En réalité il fabrique la fiction de son absence par le mouvement même qui le porte à se saisir dans une représentation (phantasia) comme un œil, étranger à son propre regard, se cherche en un miroir (X,12). L'illusion spéculaire consiste en ce que, cherchant à se représenter à soi, il se représente en autre chose que soi (in alio). Il se cherche dans ces choses auxquelles le colle la glue du souci ("curae glutino"), ce qui le voue à s'identifier indéfiniment à ce qu'il n'est pas (cette identification imaginaire caractérise le "phantasma", à ne pas confondre avec la "phantasia") ; il attire à soi des images étrangères faites de soi et se perd dans cela qui est indéfiniment autre que soi $(\mathrm{X}, 7)$. Ne trouvant rien qui lui suffise, il devient trop attentif (nimis intenta), en d'inquiètes délectations, comme perdu dans l'impossibilité de se perdre (X, 7).

La même dialectique se retrouve chez les philosophes qui ont cherché le secret de l'âme dans un "quelque chose" (aliquid) (X, 9 et 13) : le sang, le cerveau, le corps, le souffle de l'air, le feu, les atomes ou "je ne sais quelle quinte essence ajoutée aux quatre éléments habituels" (X, 9 et 14). Tous ont prétendu rendre compte de l'intelligence en la référant à "quelque chose", de la volonté en lui proposant "quelque chose" et de la mémoire en racontant "quelque chose" (X, 13). Mais la multiplicité des opinions philosophiques montre que tous les "quelque chose" sont bons pour tenir ce rôle et que chacun peut également être révoqué en doute puisqu'on a soutenu tantôt ceci, tantôt cela. Or l'esprit qui doute se sépare de tous les "quelque chose": 
"Alors qu'il se sépare de tout ce qu'il croit être, qu'il regarde ce qu'il sait, que lui reste cela seul dont personne n'a pu douter" (X, 13).

Qui douterait qu'il vit, qu'il se souvient qu'il comprend, qu'il veut, qu'il pense, qu'il sait, qu'il juge ? Car même s'il doute, il vit ; s'il doute de ses raisons de douter, il se souvient ; s'il doute, il comprend qu'il doute ; s'il doute, il veut être certain s'il doute, il pense ${ }^{99}$; s'il doute, il sait qu'il ne sait pas s'il doute, il juge qu'il ne doit pas consentir témérairement. Quiconque doute de quoi que ce soit, ne peut douter de ces choses sans lesquelles aucun doute ne pourrait exister" (X, 14).

L'argument du "cogitat" prouve qu'on ne peut attribuer à l'esprit une relation ad aliquid (variable) sans lui attribuer du même coup une relation ad se constante, de telle sorte que l'esprit ne peut être pensé que présent ; "Donc qu'il ne cherche pas à se voir absent, mais qu'il cherche à se discerner présent" $(\mathrm{X}, 12)$.

En second lieu, ce qui ne peut être pensé que présent dans l'acte de douter, devient le critère permettant de discerner parmi tous les attributs possibles ceux qui conviennent à l'esprit. C'est ainsi que le doute, après avoir éliminé toutes les connaissances extrinsèques, révèle ses propres conditions immanentes parmi lesquelles la mémoire, l'intelligence, la volonté ainsi que la pensée. Le doute est pensée (si dubitat, cogitat) qui en s'explicitant soi-même fait passer d'une attribution relative variable à une attribution relative constante, et donc révèle l'existence de relations non accidentelles.

En effet, en soulignant tout à l'heure le renversement du rapport de l'absence à la présence, de l'ad aliquid à l'ad se, j'ai un peu simplifié le problème. Il est bien vrai que l'intelligence revient de la référence ad aliquid à une référence ad se, mais elle retrouve alors une autre réfé-

99 "Si dubitat, cogitat." Truisme pour un cartésien, cette formule signifie que l'esprit dans sa relation à un autre, a toujours une relation à soi. Inversement cogito ergo sum" paraît bien pauvre à un augustinien : "Si on lui dit de se connaître, en comprenant ce qu'on lui dit, il sait du même coup qu'il existe... Mais un cadavre aussi existe, un animal aussi est vivant, pourtant ni l'animal ni le cadavre ne comprend" $(\mathrm{X}, 13)$. 
rence ad aliud qui sera cette fois interne puisque la compréhension puise dans la mémoire et s'achève en consentement. En ce qui concerne la volonté la question est encore plus complexe. Nous devons distinguer l'usage (uti) en vue d'autre chose, et la jouissance (frui) d'un bien pour lui-même. Or lorsque l'esprit se cherchait dans l'absence c'est-à-dire en s'identifiant à la représentation d'autre chose que soi, la concupiscence n'arrivait pas à se reposer dans une jouissance stable. Par contre en obtenant le repos dans la vérité, l'esprit vient en présence de soi par amour d'une vérité éternelle à laquelle il ne s'identifie pas. Les dernières lignes de $X, 13$, résument ce mouvement complexe, où par un double renversement de rapport, l'intelligence revient à soi quand l'amour revient à Dieu. Mais saint Augustin déclare qu'il ne peut s'étendre là-dessus car il faudrait parler du mal et de la faute "de qua non est nunc disserendi locus".

Or le rôle de la mémoire n'est pas sans rapport avec cette dernière question puisqu'en X, 7, c'est "par un désir pervers" que s'est produit "l'oubli de soi". Nous avons vu que cet oubli n'est pas absence de mémoire, mais au contraire mémoire sans souvenir explicite, recherche vaine d'une réminiscence. Mais pourquoi fallait-il faire intervenir la nécessité d'une réminiscence pour évoquer cela même qui ne peut être pensé que présent?

On peut répondre d'abord : par ce que cela n'est pas toujours pensé. Sans mémoire ni volonté nous aurions un intellect éternel recteur du cosmos mais non un intellect lié à une pensée temporelle (cogitatio) qui doit engendrer son verbe. Mais il est encore d'autres raisons plus particulières.

En premier lieu ; il fallait rendre compte de l'illusion spéculaire ou l'esprit se cherche dans un quelque chose "tanquam in speculo" qui ne peut produire en lui qu'un effet d'absence à soi. Dans ce cas l'esprit fonctionne comme s'il n'était que mémoire c'est-à-dire comme s'il ne pouvait penser que par des images qui sont la représentation de choses absentes. Saint Augustin ici se commente lui-même : 
"Puisque nous avons dit vers la fin du livre X que l'esprit s'est toujours gardé en mémoire, qu'il s'est toujours compris et aimé, bien qu'il ne se soit pas toujours pensé distinct (discretam) de ces choses qui ne sont pas lui, il faut se demander de quelle façon l'intellect appartient à la pensée (à la cogitatio). En effet la connaissance (notitia) d'une chose quelconque qui est intérieure à l'esprit même lorsqu'il n'y pense pas, est dite appartenir à la seule mémoire. S'il en est ainsi l'esprit n'avait pas ces trois choses (non habebat haec tria), la mémoire, l'intelligence et l'amour de soi, mais il était seulement mémoire de soi (meninerat tantum sui), et c'est ensuite seulement qu'il a commencé à se penser, et alors à se comprendre et à s'aimer" $(\mathrm{XIV}, 9)$.

Ainsi la mémoire comme diathèse ou disposition fait comprendre le rôle actualisateur de la pensée (cogitatio). Celle-ci actualise une intelligence qui était d'abord dissimulée à soi dans la mémoire. Mais alors disons-nous que les Formes intelligibles étaient dans la mémoire ? Oui, la conséquence est inévitable, puisque les Formes sont les règles de l'intelligence, et suivent le même sort qu'elles. En effet les Confessions aussi bien que le de Trinitate disent que la mémoire ne contient pas seulement des idées adventices mais qu'il existe en elle une obscure profondeur ( $\mathrm{XV}, 40)$, un abîme où demeure la présence latente des intelligibles. Là est "la mémoire principale" (XV, 41), celle que les animaux n'ont pas (XV, 43), elle contient les res intelligiibiles (XV, 43), les choses connues par soi ("per seipsa cognita", XV, 22) et non seulement celles qui sont connues par les sens. Elle fonde la possibilité de se connaître par une conversion, un retour à la source : "science de science, vision de vision, intelligence par la pensée de l'intelligence en mémoire" (XV, 40). Cette mémoire abyssale est en nous "la similitude du Père" (XV, 43). Il y a en elle quelque chose de paradoxal. En effet nous savons que les intelligibles, expression de la vérité éternelle, n'appartiennent pas à nos esprits changeants, et pourtant :

"ces choses qui sont connues comme ne pouvant être exclues puisqu'elles sont présentes, appartiennent à la nature même de l'âme ("ad ipsius animi naturam pertinent") comme par exemple le fait que nous vous savons vivants... et c'est en elles que doit être vue principalement l'image de Dieu" $(\mathrm{XV}, 23)$. 
Il y a là en effet comme un abîme où l'on sent passer la hantise vertigineuse qui est à la fois la plus démoniaque tentation et le plus amoureux devoir, d'être tout à fait semblables à Dieu.

En second lieu, la mémoire, du fait qu'elle permet de distinguer la "praesentia" et le "conspectus", la présence intelligible et son aperception consciente, montre que l'intelligence humaine doit être formée par l'activité d'une pensée temporelle. Suivant que la pensée consciente intervient ou non, il y a deux rapports possibles entre la mémoire et l'intelligence :

"De même que l'intelligence est intérieure (inest) et que l'amour est intérieur à cette mémoire principale, en qui nous trouvons préparé et caché ce à quoi en pensant nous pouvons parvenir, et parce que nous trouvons là ces deux choses lorsqu'en pensant nous trouvons que comprendre quelque chose et l'aimer étaient déjà là ; de même aussi la mémoire est intérieure et l'amour est intérieur à cette intelligence qui est formée par la pensée, ce verbe vrai que nous disons indépendamment de toute langue nationale lorsque nous exprimons ce que nous savons. En effet sans réminiscence (nisi reminiscendo) l'intuition de notre pensée ne revient pas à quelque chose ni sans amour elle n'aurait aucun souci de revenir" (XV, 41).

L'intelligence était d'abord intérieure à la mémoire. Par la réminiscence, la mémoire devient intérieure à l'intelligence. Chercher la connaissance de soi c'est chercher à retrouver ce qui était déjà là mais n'avait pas conscience de soi.

Dans un texte malheureusement trop long pour être cité tout entier (XIV, 8 et 9), saint Augustin résume l'essentiel de sa pensée :

"L'homme trouvera non ce qu'il ne savait pas mais d'où il ne pensait pas... Si grande est la puissance de la pensée que même l'esprit ne peut se poser en présence consciente de soi sinon quand il se pense. Ainsi rien n'est en présence de l'esprit sinon de là où il pense, de sorte que l'esprit lui-même qui pense tout ce qui est pensé, ne peut être autrement en présence de soi sinon en se pensant lui-même. Mais comment, lorsqu'il ne se pense pas, il n'est pas en présence de soi, alors qu'il ne peut jamais être soi-même sans soi, comme si autre chose était soi-même, autre chose sa présence, c'est ce 
que je ne puis trouver. Cela pourrait être dit sans absurdité de l'œil du corps... L'œil n'est pas en présence de soi ; il ne se voit pas lui-même sinon par l'interposition d'un miroir, ce dont nous avons parlé au livre X. Mais ce n'est pas ce qui se produit lorsque par la pensée l'esprit se constitue en présence de soi... D'où l'esprit a-t-il été enlevé sinon de lui-même ? Où est-il posé en présence de soi sinon devant lui-même ? Il ne sera donc pas là où il était quant il n'était pas en présence de soi, puisqu'ici posé, de là il a été enlevé. Mais si présenté à soi il a émigré, où demeurera-t-il quand sa présence lui est future ? Est-il comme géminé pour être ici et là, là où on peut voir et là où l'on peut être vu ?... Il reste que sa présence soit quelque chose appartenant à sa nature, et qu'en elle lorsqu'il se pense il est rappelé par une conversion incorporelle. Mais lorsqu'il ne se pense pas, sans doute il n'est pas en présence de soi (in conspectu suo) et son intuition n'est pas formée à cet égard, pourtant, il se sera connu comme étant lui-même pour soi mémoire de soi... C'est pourquoi la façon dont nous parlions de la trinité nous permettait de placer dans la mémoire cela même d'où se forme l'intuition de notre esprit, la conformation, l'image imprimée à partir de là, et aussi l'amour ou la volonté qui joint l'un à l'autre... L'esprit était seulement mémoire de soi et ensuite lorsqu'il a commencé de se penser, il s'est compris et aimé"(XIV, 8-9).

La mémoire a donc un double rôle : soit comme disposition inconsciente, préconceptuelle, soit comme terme relatif à l'intelligence qui tire d'elle le contenu de la connaissance. Entre ces deux états de la mémoire se déploie le champ de possibilités de la pensée (cogitatio). La pensée est le procès par lequel l'essence spirituelle engendre sa propre manifestation.

Cette théorie va permettre de résoudre une dernière difficulté. En effet, les trois puissances que nous avons discernées en notre esprit, constituent une seule personne, et non pas comme en Dieu trois personnes.

"Alors quelqu'un pourrait dire : ces trois choses, la mémoire, l'intelligence et l'amour sont miennes, elles ne sont pas à elles-mêmes (mea sunt, non sua) ; ce n'est pas pour elles mais pour moi qu'elles font ce qu'elles font, et moi par elles... Il n'y a ici qu'une seule personne qui a ces trois choses mais qui n'est pas ces trois choses" (XV, 42). 
En somme l'objection consiste à dire : les attributs de l'esprit ne sont pas autoprédicables; ce n'est pas la mémoire qui se souvient d'elle-même, ni l'intelligence qui se comprend elle-même, ni l'amour qui s'aime lui-même, c'est moi qui agis par ces trois facultés, elles ne sont pas en soi elles sont pour moi ; pour que la généralité de l'essence rejoigne l'individu concret, il faut réintroduire des particularités accidentelles, comme le fait d'avoir "plus ou moins" de mémoire ou d'intelligence ou d'amour on revient de l'être à l'avoir. La réponse d'Augustin sera la suivante D'abord il ne faut pas dire que l'image de Dieu est en moi comme dans un sujet, il faut dire que Dieu est en moi ou dans l'esprit humain comme dans son image, comme dans un autre, 'in re alia" Au lieu de considérer que l'image est dans le tableau, on peut aussi appeler le tableau une image, et dire que la réalité elle-même ("res ipsa") est dans le tableau, dans l'image (XV, 43). Ce n'est donc pas l'image de Dieu qui est en l'homme comme dans un tableau : c'est Dieu qui est en l'homme comme dans son image.

En outre la similitude avec Dieu comporte une inégalité. En effet la pluralité des personnes n'introduit aucune séparation dans l'essence divine alors qu'elle divise l'espèce humaine en des individus séparés. L'inséparabilité de l'essence n'est parfaite qu'en Dieu. C'est pourquoi en l'homme les trois termes relatifs, mémoire, intelligence, amour, peuvent être séparés par des grandeurs inégales ("magnitudinibus separantur"). Dans l'individu la mémoire, l'intelligence et l'amour admettront le plus ou le moins. À ce titre ces trois termes apparaîtront non pas comme des Formes pures, des Règles toujours égales à soi, excluant le plus ou le moins, mais comme des dispositions psychologiques, au niveau de l'avoir plutôt que de l'être. Cependant nous avons vu, en étudiant le double rôle de la mémoire, qu'il ne fallait pas confondre le niveau de la disposition (diathèse, habitus) avec celui de l'essence. Si l'on définit les trois termes uniquement par leurs relations respectives, leur distinction réciproque, alors ils n'introduisent dans l'essence aucune séparation: chacun aussi bien que l'ensemble est l'esprit humain. Il reste seulement qu'en l'homme la disposition et l'essence peuvent diverger, de sorte qu'alors l'esprit humain est comme 
séparé d'avec soi, oublieux de soi, et c'est pourquoi on a pu sans absurdité parler d'une mémoire de ce qui est de soi présent ("in re presenti") sans être posé par la pensée dans une présence consciente ("in conspectu suo, in visione cogitationis, in verbi visione). Enfin la possibilité pour la disposition de trouver sa règle dans l'essence mesure la possibilité propre de la pensée, la rend capable de reconnaître la règle de la vérité qui est en elle et qui est la lumière de Dieu. C'est ainsi qu'être à l'image de Dieu, c'est être capable de Dieu, capax Dei. "En oubliant Dieu, l'homme avait oublié sa propre vie ; à était spirituellement mort; en revivifiant par la réminiscence sa propre vie, il se convertit par commémoration à Celui qu'il avait en oubli" (XIV, 17). La distance entre l'oubli et la réminiscence mesure le champ des possibilités offertes à la pensée. "Donc cette trinité de l'esprit n'est pas image de Dieu parce que l'esprit se souvient de soi, se comprend et s'aime, mais parce qu'il peut aussi se rappeler, comprendre et aimer Celui par qui il a été fait. Lorsqu'il fait cela, lui-même devient sage (XIV, 14-15).

En résumé, la véritable présence à soi, pour saint Augustin, est celle où l'esprit se désigne lui-même comme image de Dieu. La présence à soi s'exprime dans des verbes de pensée ou des prédicats psychologiques tels que se souvenir, connaître, aimer... La désignation est une fonction du nom : on nomme ce que l'on veut désigner, la personne ou son image. Saint Augustin tente d'égaliser le nom et le verbe, la désignation et la prédication : c'est comme amour que l'esprit s'aime ou comme connaissance qu'il se connaît. Le même terme est pris une fois comme nom et une fois comme verbe. Pour échapper au vide de la répétition, le théologien n'a d'autre recours que le temps de la mémoire. Il laisse osciller la pensée entre les relations asymétriques de l'avant et de l'après et les relations symétriques de l'esprit à l'esprit. Avec des moyens plus habiles, la philosophie hégélienne de l'esprit tentera aussi de supprimer la dualité du nom et du verbe à l'intérieur 
de la proposition spéculative. Mais toute tentative de ce genre nous engage sur les voies du paradoxe ou de la contradiction fascinante. Comment donner un nom à ce qui ne peut être décrit par aucun verbe ? Le problème de la transcendance se résume en un mode paradoxal de désignation, par la double impuissance du Nom et de l'Image. La théologie augustinienne de l'Imago Dei voit dans l'inquiétude humaine le sens caché du nom divin. Elle enseigne que la religion naît de la mémoire, comme les Muses, filles de Mnémosyne. Enfin, ce sont les controverses trinitaires qui ont définitivement introduit dans le christianisme la forme de ce qu'on appelle "un dogme", une proposition de foi. Bien que, chez les chrétiens comme chez les Dogon ou les païens, la pensée de l'origine tente toujours de rendre les relations asymétriques égales ou équivalentes à des relations symétriques, c'est seulement dans le dogme trinitaire du christianisme que, pour la première fois, la tradition enseignante s'est donnée pour forme canonique la forme logique de la proposition. 
Religions du livre. Religions de la coutume

\section{Chapitre VII \\ PHILOSOPHIE DU DROIT ET PHILOSOPHIE DU LANGAGE 100}

$\underline{\text { Retour à la table des matières }}$

J'avais commencé cet article comme un compte-rendu de lecture. Il s'est transformé en un débat beaucoup plus large sur la nature de l'analyse philosophique et sur les difficultés que soulève son application à un domaine passablement embrouillé, celui de l'éthique et du droit. Je commencerai donc par résumer sommairement l'ouvrage de Georges Legault qui a été le point de départ de mes réflexions ${ }^{101}$.

\section{Une thèse sur le droit}

Dans le titre qu'il a donné à son livre : "La structure performative du langage juridique", G. Legault résume son dessein. Il se propose de montrer que les théories linguistiques du performatif fournissent "un modèle d'intelligibilité" pour l'analyse philosophique du droit.

100 Publié dans la revue canadienne : Dialogue, vol. XVII, no 3, 1978, pp. 528-547.

101 G. A. Legault : la structure performative du langage juridique, Presse de l'Université de Montréal, 1977, 522 pp. 
Le livre se divise en trois parties. La première partie pose le problème à partir d'une discussion des thèses de Kelsen. Kelsen, dans sa théorie pure du droit, n'a pas réussi à expliquer les notions de "normes" et de "validité" juridiques. Il n'a pas réussi parce qu'il n'a pas clairement distingué les différentes fonctions de la norme juridique. Kelsen enferme le langage juridique dans le lit de Procuste de la proposition hypothétique; "Si tu transgresses la loi, tu seras puni." La réduction du droit à un ordre de contrainte et de sanction convient peut-être à certains codes archaïques comme celui d'Hammurabi, mais ne convient pas aux législations modernes qui distinguent mieux le droit civil du droit pénal. C'est à Ross que revient le mérite d'avoir attiré l'attention sur les fonctions du langage juridique. En introduisant la notion de "directives" adressées aux juges, Ross dépasse le simple "modèle de l'affirmation" avec ses préjugés positivistes ; il enrichit la notion de validité de motivations psychologiques, en prenant en considération ce qui motive l'obéissance d'un individu à une directive. Legault examine ensuite les travaux d'Olivecrona, Hedenius et Hart. Il apparaîtra en définitive qu'en statuant sur ce qui doit être, le droit dirige la conduite des citoyens. Ce qu'il faut expliquer, ce n'est donc pas seulement le pouvoir de sanctionner, mais le pouvoir de juger. D'où la nécessité de comprendre les actes créateurs de droit comme des "performatifs" c'est-à-dire des actes qui tout ensemble expriment et réalisent notre engagement social. Cependant certains auteurs (Ross, Olivecrona) ont reproché au performatif ses effets magiques ou suggestifs. Nous ne pourrons donc utiliser cette notion avant de l'avoir soumise à double examen, dans la philosophie du langage et la philosophie du droit.

La deuxième partie du livre s'appuie sur J.L. Austin, Searle et von Wright pour dégager la structure des performatifs. Cette étude très détaillée montrera la nécessité de distinguer deux sortes de règles. Les premières règles sont celles qui prévoient l'opération et en déterminent le contenu. Les secondes règles dirigent l'exécution du performatif compris comme un acte de communication. Si la promesse, par exemple, est le modèle linguistique du performatif, c'est non seulement 
parce qu'elle apporte aux actions prévues une garantie d'exécution mais aussi parce qu'elle est réponse à une demande. Le performatif doit satisfaire non seulement à des conditions de vérité mais à des conditions de succès ou de finalité interne qui sont celles d'une communication sociale conforme à des règles.

La troisième partie montre que ce qui a été dit du modèle linguistique peut être généralisé par voie d'analogie à divers modèles juridiques : le contrat, la propriété, le droit criminel, les institutions. Les performatifs sont des actes de communication par lesquels se créent de nouveaux faits, des faits institutionnels. Par cet effet propre, de création institutionnelle, le performatif se distingue de la force illocutionnaire et de l'effet perlocutionnaire tels que les concevaient Searle.

Il est difficile de résumer un ouvrage aussi considérable que celui de Legault qui compte plus de 500 ages. Il offre au lecteur un dossier très fourni, très détaillé, sur "la philosophie linguistique ou analytique" du droit. Ouvrons le dossier. Examinons les arguments.

\section{Discussion}

D'abord que veut dire "modèle d'intelligibilité ?" L'auteur écrit dans son introduction : "La philosophie analytique du droit veut établir une définition de la norme juridique... Cette entreprise analytique présuppose une unification des diverses manifestations juridiques existant dans un système juridique donné. C'est pourquoi la validité de la définition de la norme dépend de l'unification présupposée. Les véritables problèmes inhérents à l'élaboration d'un modèle d'intelligibilité sont donc ceux posés à propos de l'unification des manifestations juridiques." (p. 27) Dans ce texte, le terme "philosophie analytique" est caractérisé par une recherche de la définition. La recherche de la définition "présuppose" une unification qui rende intelligible les diverses manifestations du droit. L'unification est obtenue par "un modèle d'intelligibilité". Ce modèle est celui du performatif c'est-à-dire 
de la parole qui accomplit socialement ce qu'elle énonce (comme par exemple : "je vous déclare unis par les liens du mariage"). Le domaine auquel s'applique ce modèle ne se limite pas aux "phénomènes" institutionnels c'est-à-dire aux formes extérieures du droit, mais englobe ce que l'auteur appelle "la réalité juridique" c'est-à-dire la réalisation effective de certaines fonctions sociales par les actes juridiques. Le modèle d'intelligibilité est donc ce qui unit forme et fonction, langage juridique et accomplissement social.

Dans ces conditions, il semble que nous aboutissions à une théorie fonctionnaliste de la pratique juridique. Legault emprunte à ce qu'il appelle "la philosophie linguistique ou analytique" un thème plutôt qu'une méthode. Il emprunte le thème du performatif dont il fait un paradigme. Cependant la méthode qu'il décrit est classique : recherche de la définition, explication des présupposés grâce à l'exégèse du sens, détermination sinon d'une essence, en tout cas d'une réalité qui devient intelligible par unification de la diversité phénoménale. Si cette méthode était naturaliste, elle serait aristotélicienne. Mas comme elle est intuitionniste sans être naturaliste, elle mérite d'être appelée "phénoménologique". Et je ne vois pas ce qui distingue l'œuvre de Legault d'une phénoménologie du droit.

Ce que les Analystes logiciens reprochent à cette méthode, c'est de prétendre aborder les problèmes sémantiques sans avoir éclairci au préalable les problèmes de syntaxe logique. Lorsque Frege, par exemple, s'appuie sur la distinction entre fonction et argument pour tenter d'expliquer ce qui dans une phrase compte comme "objet" (objet de référence), il s'appuie sur des critères syntaxiques et non pas psychologiques ou intentionnels. Dès lors la tâche assignée à l'analyse philosophique du langage se distingue radicalement d'une exégèse psycholinguistique et fonctionnaliste. Nous allons pouvoir constater la différence des points de vue en confrontant les thèses de Kelsen avec l'interprétation qu'en donne Legault. 
On sait que "la théorie pure du droit" de Kelsen est un livre difficile, qui a été souvent mal compris parce qu'on l'a lu dans la perspective qui nous est la plus habituelle, à savoir la perspective d'une philosophie pratique du droit. Or il s'agit d'autre chose ; il s'agit d'une philosophie de la science juridique. Son point de vue est strictement épistémologique, et sa méthode franchement analytique. L'analyse étant, comme chacun sait, un procédé qui consiste à supposer un problème résolu pour voir à quelles conditions, logiquement, il peut l'être, l'épistémologue kelsénien se demandera : en supposant qu'il existe! une science juridique (ce qui, à ses yeux, n'est pas encore prouvé), recherchons à quelles conditions ses propositions (entendues comme énoncés descriptifs) pourraient être vraies ?

Mais Legault voit-il bien les choses ainsi ? Il intitule le premier paragraphe de son exposé sur Kelsen : "Les différentes fonctions de la norme." Et il écrit : "Kelsen attribue à la norme une fonction spécifique, celle de prescrire ou d'autoriser une conduite. La signification des termes "prescrire", "autoriser" et "conduite" dans cette affirmation peut engendrer différentes interprétations de la norme." (p. 37) Legault reproche à Kelsen d'avoir donné de la norme juridique des interprétations différentes en lui attribuant, d'un écrit à l'autre, des fonctions différentes. Malheureusement je crains que le mot "fonction" n'ait engagé Legault dans un malentendu. Pour voir comment Legault entend ici le mot "fonction", lisons la suite du texte ci-dessus. Après avoir cité quelques exemples d'expressions normatives, Legault écrit : "L'identification des normes dépend donc de la conduite qui s'y rattache." (p. 38) Un habitué des méthodes kelséniennes répondrait aussitôt qu'eu égard à leur contenu descriptif ou à la nature des conduites concernées, les textes juridiques peuvent remplir toutes sortes de fonctions sociales : morales, politiques, économiques, religieuses, et aussi des fonctions de sécurité collective, d'hygiène, de pudeur vestimentaire etc... Il ajouterait que ces fonctions sociales sont inséparables de la pratique du droit ; elles dépendent des orientations de la politique législative et même jurisprudentielle. Par contre, la, réponse du kelsénien serait tout à fait différente si on lui demandait quelle est la fonc- 
tion logique de la norme au regard d'une science juridique (à supposer qu'une telle science existe, ce qui pour un kelsénien reste à prouver). Le premier chapitre de la Théorie pure du droit, au paragraphe 4 sous le titre "La norme", ajoute en sous-titre ; "La norme, schéma d'interprétation". Pourquoi Legault n'a-t-il pas relevé et exploité cette formule ? Une norme, selon Kelsen, est un schéma d'interprétation des actes humains, schéma d'interprétation qui consiste à donner à certaines conduites des significations telles que: "Obligatoires, permises, interdites, exercées en vertu d'une habilitation etc.." Les significations que la norme donne aux actes humains figurent dans des expressions qui ont ici la fonction logique de prédicats. Ces prédicats de deuxième ordre peuvent s'analyser comme des opérateurs permettant de construire des phrases complexes : "il est obligatoire que...", est permis de..." Quoiqu'il en soit, essayons d'exposer le point de vue de Kelsen avant d'en revenir à Legault.

En définissant les normes comme des schémas d'interprétation ou des fonctions prédicatives applicables sur un certain domaine Oc domaine des actes humains), la science juridique commence à préciser la nature de son objet. La science juridique a pour objet la relation sémantique qui va des normes aux actes qu'elle considère "sub ratione Legis". Par contre, la converse de cette relation (converse qui va des actes aux normes) pourra s'entendre de deux façons :

$1^{\circ}$ : ou bien les textes juridiques sont pris comme expression des activités qui les produisent, et dans ce cas les expressions textuelles sont des symptômes historico-psychologiques, comme dit Ross, des témoins d'une époque et d'un milieu. Les sciences historiques et psychologiques, pour étudier la genèse de ces documents et de leur contenu, feront appel à des schémas d'interprétation causale (ou génétique.)

$2^{\circ}$ : ou bien on considère que la possibilité d'effectuer des actes créateurs de droit est prévue à l'intérieur du système juridique, sous forme d'un organe habilité à légiférer. Cela revient à dire que le sys- 
tème contient des boucles de rétro-actions, des mécanismes d'autorégulation. Dans ce cas, nous restons à l'intérieur de la science du droit. Toute activité créatrice de normes y apparaîtra sous couvert d'une norme supérieure (telle que les règles habilitant un organe officiel à exercer certaines fonctions). Nous devons alors considérer non plus seulement des normes mais des classes de normes hiérarchisées.

Cette classification hiérarchique des diverses classes de normes soulève une difficulté : que voulons-nous dire quand nous parlons d'un système juridique (par exemple le système canadien) ? À quoi se réfère le mot "un"? Quel genre d'unification introduisons-nous en nommant et nominalisant une classe de classes de normes ? Kelsen répond en postulant pour chaque système une "norme fondamentale" qui joue le rôle d'une "hypothèse logique-transcendantale" c'est-à-dire d'un opérateur d'abstraction. On sait que l'opérateur d'abstraction (que l'on exprime parfois en logique par un accent circonflexe sur la variable) a pour effet de nominaliser une classe. La norme fondamentale est un opérateur d'abstraction qui postule qu'en nommant un système juridique existant nous le posons comme classe ultime de toutes les sous-classes de normes qu'il contient. Kelsen postule l'existence d'une classe ultime, destinée à bloquer la régression indéfinie dans un langage stratifié. En parlant d'hypothèse logique transcendantale, il veut dire que l'on postule l'existence d'une entité abstraite ${ }^{102}$. Il est intéressant d'observer que Quine procède d'une manière analogue à propos du concept d'espèce biologique: il postule l'existence de l'espèce comme classe ultime et entité abstraite. 3 L'avantage de cette solution, c'est que, dans les deux cas, le postulat pourra être levé à une étape ultérieure de la recherche, par exemple en biologie par une théorie de l'évolution, et en droit comparé par une relativisation éventuelle du concept de souveraineté.

102 N. O. Quine : Relativité de l'ontologie et autres essais, Aubier, Paris, 1977, ch. 5 : Espèces naturelles, p. 146. 
Mais il ne suffit pas de fixer par une clause d'abstraction nominale l'unité supérieure d'un ordre juridique, il faut encore montrer comment, à l'étage inférieur, celui des actes humains, s'établit l'objectivité sociale du droit. En quoi consiste cette objectivité ? Elle consiste en ce que la phrase : "Telle norme est valide dans tel Corpus de droit positif" est équivalente à la phrase : "Telle norme existe, officiellement dans ce Corpus de droit positif." La validité (au sens du droit positif) est l'existence spécifique de la norme. La norme possède par là une objectivité sociale propre qui ne se confond pas avec un mode d'existence symptomatique ou expressionniste (suivant le schéma d'interprétation causale privilégié dans les diverses écoles historicisantes, psychologisantes ou sociologisantes). Les schémas d'interprétation que sont les normes juridiques possèdent une existence spécifique, une validité, une objectivité sociale, distincte du genre d'objectivité que peuvent avoir les actes de volonté qui leur ont donné naissance. "La norme, observe Kelsen, peut valoir alors que cet acte de volonté n'existe plus. Il faut même aller beaucoup plus loin ; la norme n'acquiert validité, elle n'entre en vigueur, qu'à un moment où cet acte de volonté a cessé d'exister." 103 Peu importe l'inventeur ou le promoteur accidentel de la loi, il est abandonné aux contingences de l'histoire. Il ne faut pas confondre schéma d'interprétation causale et schéma d'interprétation normative. Une loi n'a pas d'auteur de la même façon que les oeuvres littéraires en ont un. Une loi n'a que des destinataires et des organes habilités à la proclamer. Eue n'a pas de souveraineté derrière elle, mais seulement en elle : Lex facit populum.

Il apparaît donc que la science juridique a un objet formellement distinct de l'objet des sciences historiques, sociologiques ou psychologiques. Nous ne serons pas obligés de supprimer la Faculté de Droit pour envoyer ses occupants ailleurs. La science juridique pourra formuler des "propositions de droit" ayant pour objet les normes juridiques. Les propositions de droit, pour pouvoir être universelles, prendront une forme conditionnelle, mais il est évident qu'il ne faut pas 
confondre la norme juridique qui appartient au langage-objet (le Corpus Juris) avec la proposition de droit qui appartient au méta-langage du Commentateur. Bien entendu, rien n'empêche le commentateur de se faire historien, psychologue ou sociologue, lorsqu'il s'agit d'expliquer la genèse des textes, mais en tant que juriste, son objet propre demeure l'étude des actes humains en tant qu'ils sont soumis à des rapports de droit. Les rapports de droit se distinguent des rapports moraux en ce qu'ils sont des rapports de contrainte légale c'est-à-dire supposent l'arbitrage d'un tiers, le législateur, le juge, à qui le droit confie précisément le monopole dans l'usage de la contrainte et de la force. La proposition de droit est conditionnelle, car la validité de ce pouvoir contraignant n'est jamais qu'hypothétique : si telle disposition de droit est en vigueur, alors telle contrainte est légale. La validité ne se confond jamais avec l'efficacité. En outre, il est bien clair que la décision du tribunal est un acte de volonté ; une décision est catégorique (comme dit le proverbe : "Avec des si et des si, on ne ferait jamais rien"). C'est bien pourquoi la décision du tribunal, pour Kelsen, n'est pas seulement un acte juridique, c'est aussi un acte moral et politique. Legault s'interroge sur les rapports entre l'hypothétique et le catégorique chez Kelsen, mais on voit ici que le recours au métalangage est indispensable pour distinguer les divers genres de prédicats. La pratique du droit est complexe : les aspects juridiques y interfèrent avec d'autres aspects.

Il semble malheureusement que Legault ait tendance à confondre langage et méta-langage. Il croit par exemple faire à Kelsen une objection en disant : "Les textes légaux ne formulent pas nécessairement la norme légale selon la proposition de droit" (p. 45) (exception faite, nous suggère-t-on, pour Hammurabi et le code pénal). Legault ajoute plus loin que, selon Kelsen, "la structure 'si... alors' énoncée par la proposition de droit constitue la norme elle-même." (p. 125) C'est là un contre-sens. Pour Kelsen la proposition de droit a un objet formel : elle nous fait connaître quelque chose comme norme, mais elle ne "constitue" pas la norme (il ne s'agit pas ici de constitution phénoménologique). Dès son introduction Legault écrivait : "Les activités hu- 
maines les plus diverses revêtent un sens déterminé grâce aux propositions du droit." (p. 14) Mais pour Kelsen une proposition de droit n'est aucunement "une proposition du droit." D'où vient le malentendu ? Il vient de ce que Legault entend "matérialiter" des fonctions sociales ce que Kelsen énonce "formaliter" de la syntaxe prédicative. Ce que Legault appelle "langage" est une question de lexique, une exégèse phénoménologique des effets de sens. La mauvaise réputation des Mots "sanction" ou "contrainte légale" semble avoir favorisé le glissement de la fonction logique et syntaxique des prédicats à la fonction sociale et lexicale des "contenus intentionnels." Or non seulement Kelsen ne confond pas sanction pénale et sanction civile, mais en disant que le droit positif est un ordre de contrainte (de contrainte arbitrale ou légale), il ne préjuge aucunement des finalités politiques ou sociales dont la contrainte légale n'est jamais qu'un moyen.

Legault suggère qu'il faudrait remonter jusqu'à Hammurabi pour trouver un code kelsénien : "Si tel crime, alors telle sanction." La remarque est amusante, car précisément le code d'Hammurabi confond ce qui est distingué par Kelsen. J'ai eu la curiosité de m'intéresser aux écrits de spécialistes sur l'étrange stéréotype de la forme conditionnelle "si... alors..." qui caractérise le style d'un certain nombre d'écrits babyloniens ou même parfois bibliques en matière de droit, de divination et de médecine. D'où vient que les textes divinatoires, judiciaires et médicaux possèdent la même construction conditionnelle ? C'est que les jugements du destin et ceux des chancelleries royales avaient le même pouvoir à la fois causal et normatif, unissant l'ordre social à l'ordre sacré du monde. D'ailleurs le prétendu "code" d'Hammurabi n'est précisément pas un "code de lois" mais un recueil de cas, un traité de jurisprudence, de la même façon que les recueils d'oracles sont des traités de divination. Or si les décrets des dieux et les décrets des rois étaient écrits dans le même style, c'est que l'énigme du destin ne se formulait pas, comme plus tard dans l'héllénisme, en termes de prévision "Que puis-je prévoir ?" mais en termes de faute-et-malheur à éviter "Que puis-je me permettre sans devenir coupable ? Que puis-je faire sans enfreindre l'ordre du monde établi par les dieux ?" En ce 
temps-là, les gens n'avaient pas seulement un passé judiciaire (par décision du tribunal), ils avaient aussi un avenir judiciaire (par décision de l'oracle) ${ }^{104}$. Nous sommes loin, comme on voit, des propositions juridiques de Kelsen s'acharnant à distinguer deux schémas d'interprétation, l'interprétation causale et l'interprétation normative. Entre Hammurabi et Kelsen, la théorie de la conséquence a fait certains progrès. Elle ne mêle plus les astres et les rois.

La confusion des niveaux de langage chez G. Legault se retrouve a propos du concept de "validité." Ross fait de la validité une "Motivation" psychologique, extra-juridique. (p. 127-128) Là encore les questions de syntaxe sont masquées par les questions lexicales. La validité tend à se confondre avec la motivation psychologique (chez Ross) ou avec l'efficacité sociale de la communication réussie (chez Legault). A propos du débat entre Kelsen et Ross, Legault écrit :

"L'affirmation du point de vue interne [(tel comportement doit être) doit être]" répond à l'interrogation : Est-ce que la règle prescrivant tel comportement est suivie? Cette interrogation pose le problème de la validité d'une loi. La question : pourquoi doit-on obéir aux lois? se situe ainsi au centre du phénomène juridique. Kelsen y répond grâce à la norme fondamentale. Ross, en opposition à ce dernier, refuse tout crédit à cette question." (pp. 87-88).

On notera que la première question "Est-ce que la règle est suivie ?" concerne l'efficacité, non la validité. De plus, il n'est pas tout à fait exact de dire que la norme fondamentale chez Kelsen répond à un problème de validité (elle répond, comme nous allons voir au problème des rapports entre deux points de vue, subjectif et objectif). J'ai montré plus haut que les deux notions (norme fondamentale et validité), bien que solidaires, demeurent distinctes. Et il est facile de voir comment les deux notions concourent ici de manières différentes à résoudre le problème des deux sens, juridique et moral, du mot "doit être." D'une part, la notion de validité juridique ne répond pas à la

104 J. Bottéro : Symptômes, signes, écritures en Mésopotamie ancienne in Divination et Rationalité, Le Seuil, Paris, 1974, p. 142. 
question : "Pourquoi ?" niais à la question: "Quoi ?" Quoi vaut comme loi positive ? Qu'est-ce que qui est légal ? Quelles dispositions légales existent officiellement dans tel Code ? D'autre part, la norme fondamentale, en tant qu'elle impose une classe ultime incluant les sous-classes de normes existant dans un système juridique, fait le départ entre ce qui existe à l'intérieur de ce système, et ce qui, au delà du système, se présente comme langage moral et politique. La norme fondamentale permet le bon usage des parenthèses logiques en distinguant les deux sens du mot "doit être", le sens juridique et le sens moral, la question de droit : "Quelle loi est en vigueur et la question de conscience : "Pourquoi obéir ?"

Si fa question des niveaux de langage n'est pas traitée de manière suffisamment claire chez Legault, c'est que sa méthode n'était pas dirigée principalement sur l'analyse de la syntaxe logique. Il en est résulté un malentendu dans l'interprétation des thèses de Kelsen. Le fonctionnalisme socio-linguistique de Legault le portait à mêler deux séries de questions qui, aux yeux de Kelsen, sont distinctes. L'épistémologie de la science juridique ne traite pas des mêmes questions que la philosophie pratique du droit. La Théorie "pure" du droit, qui est oeuvre d'épistémologie, montre que la pratique parlementaire et judiciaire du droit n'est pas "purement" juridique mais aussi morale et politique. C'est pourquoi, pour un kelsénien, la philosophie pratique du droit ne peut être qu'une philosophie morale et politique du droit. Il rejoint donc, sur ce dernier point la conception traditionnelle. Chez Legault, l'expression "langage du droit" risque d'être un masque, un écran, un voile d'innocence, dissimulant le fait que la pratique du droit n'est pas purement juridique. Legault a d'ailleurs senti que ce langage est mêlé, pluri-fonctionnel, dans sa partie descriptive. Il appartient à l'épistémologie de distinguer formellement c'est-à-dire analytiquement ce que l'action unit forcément dans la pratique. Désormais, dans la seconde partie de cette discussion, nous allons pouvoir retrouver les problèmes traditionnels de la philosophie pratique c'est-à-dire morale et politique du droit. 
Le second problème posé par Legault est celui du performatif et de son usage en philosophie du droit.

La première difficulté, là encore, est une difficulté de méthode. Legault ne pose pas les problèmes de référence, qui sont pourtant au cœur de la philosophie analytique. Tout énoncé introduit par la formule "je promets que" se trouve dans une construction en style indirect de sorte que sa référence est opaque (cf. Frege). L'énoncé n'est pas utilisé comme une phrase indépendante, mais mentionné comme expression d'une promesse. Le contenu de la promesse pourra donc faire l'objet d'une citation ou d'une attestation, mais il n'est pas analysable à l'aide de quantificateurs et de variables de sorte qu'il est soustrait au libre examen du raisonnement que voudrait faire un observateur quelconque ; il ne peut plus faire l'objet d'une délibération. Il est étrange qu'on nous présente comme modèle d'intelligibilité du droit un modèle qui a pour effet de soustraire les énoncés à toute délibération ou discussion publique. Pour illustrer la difficulté, prenons un exemple. Considérez les promesses de Dieu dans la Bible. Dieu promet aux enfants d'Abraham le salut, l'avènement du royaume eschatologique. Ces promesses ne sont pas revisables. À juste titre, les théologiens ont insisté sur la nécessité de ne pas confondre "les paroles de Dieu" qui sont le texte même de l'Écriture, avec "les propositions théologiques" formulées par un commentateur. Les paroles de Dieu ne sont pas, comme telles, objet de libre examen ; leur signification surnaturelle ne peut être adéquatement interprétée que par le témoignage du Saint Esprit dans le "consensus Ecclesiae" sous l'autorité du Pape et des Évêques. Il est vrai que l'interprétation du Code civil requiert aussi une autorité compétente pour faire jurisprudence. Mais il y a une grande différence entre une orthodoxie théologique et une orthopraxie juridique. La structure de l'autorité n'est pas la même. Comment analyser cette différence ? Us "conditions de succès" du performatif sont-elles un critère suffisant ? Legault nous propose de "généraliser" le modèle de la promesse. Alors pourquoi ne pas en généraliser l'usage en droit public ? C'est ce que fait le tyran qui exige des promesses de fidélité et des serments d'allégeance à sa personne, afin de rendre ses ordres in- 
discutables. Tous les performatifs n'ont donc pas les mêmes conséquences sur les possibilités d'interprétation analytique et de délibération publique. Mais si nous les jugeons d'après ce critère, il ne s'agit plus seulement des "conditions de succès de la communication réussie", nous introduisons des conditions de succès morales d'acceptabilité. Je sais bien que la théorie de Searle sur la promesse est, à certains égards, irréfutable parce qu'à toute objection elle répond par une solution ad hoc. Non seulement on accepte que la promesse soit "une institution" (ce qui n'est pas toujours évident, elle n'est le plus souvent qu'une coutume), mais encore on multiplie les règles pour assurer son bon usage, en restreindre l'objet aux intérêts du demandeur (von Wright) ; on surdétermine tellement cette notion de promesse qu'à la fin la prestidigitation dialectique fera sortir du chapeau tous les lapins que l'on voudra. Par exemple, on introduit des "critères objectifs de la communication" du genre suivant : "L'émetteur exprime la proposition que $p$ lors de l'énonciation de P." (p. 254) C'est faire bon marché des objections de Quine à la proposition comprise comme "sens" d'une expression, et à la synonymie dont on ne peut faire usage sans précaution pour autant qu'elle exige des critères empiriques d'acceptabilité ou de consensus 105. Lorsque le saint Esprit fit inscrire dans la Bible les Promesses de Dieu, il aurait dû suivre les conseils de Searle. Il aurait dû garantir qu'en énonçant l'expression hébraïque "P", il voulait dire en latin ou en grec la proposition théologique "p", cela eût évité bien des controverses, des schismes et des hérésies.

Bref, il est équivoque de prétendre analyser le performatif d'après ses "conditions de succès". Le critère de la communication réussie peut servir à justifier n'importe quelle complicité. Ce qu'il faudrait déterminer, ce sont des conditions non seulement "linguistiques" mais morales d'acceptabilité. Cela suppose une analyse des rapports entre la nature de l'engagement moral (exprimé par le performatif) et les conséquences qui en résultent pour la sémantique des énoncés offerts

105 N. O. Quine, From a logical Point of view, Harper, N. Y., 1953/61 : Two Dogmas, p. 20-46. 
au dialogue. La deuxième partie du livre de Legault nous présente la promesse comme modèle éthique. À cet égard, il aurait été utile de comparer plusieurs "modèles" c'est-à-dire plusieurs opérateurs pour montrer que tous n'imposent pas les mêmes restrictions sur les énoncés mentionnés ; tous ne se prêtent pas de la même manière à cette activité morale par excellence qu'est la délibération. Par exemple, l'expression "je crois" est un performatif quand elle énonce une profession de foi, un choix public en faveur d'une opinion. La croyance professée introduit comme la promesse une construction en style indirect, donc un contexte opaque. Cependant les conditions morales de l'engagement sont ici autres que dans la promesse. En effet, si la croyance professée est sincère, à quoi nous engage-t-elle ? Croire, c'est tenir pour vrai un énoncé. Croire nous engage à accepter les conditions de vérité d'un énoncé. Or ces conditions de vérité sont indépendantes de nous. Croire avec sincérité nous engage donc a accepter que la valeur de vérité de l'énoncé soit objet de discussion publique. L'honnêteté intellectuelle de la croyance ouvre les possibilités du dialogue alors que la promesse les clôt.

Legault se défie des "préjugés positivistes", ce qui l'incline peutêtre à négliger les problèmes de référence. Il ne voit pas que ces problèmes peuvent au contraire nous servir indirectement à l'analyse des conditions pratiques d'acceptabilité alors que les prétendues "conditions de succès" (ou de "bonheur") de la communication se laissent ployer à tout vent d'opportunisme et conduisent à béatifier le fait acquis. Les conditions d'acceptabilité sont tout autre chose que les conditions de succès. D'abord elles font appel à un critère empirique, l'alternative du oui et du non, de l'acceptation et du refus. En outre, si des valeurs morales comme la sincérité peuvent être comptées parmi ces conditions, il ne s'agit pas d'une règle ad hoc destinée à produire je ne sait quel "heureux" effet social. Cela nous oblige au contraire à expliciter les conditions morales de la délibération et de la décision. Or le principe le plus général ou le fondement de la vie morale est tout à fait indépendant de la distinction entre les fins et les moyens, car la vertu morale est à la fois la fin et le moyen de son accomplissement. 
Si la fin consiste à être honnête et généreux, alors le seul moyen pour atteindre cette fin est d'être honnête et généreux. Les relations morales entre les personnes (telles que la sympathie ou le respect) sont d'une autre catégorie que les relations instrumentales qui rendent séparables la fin et les moyens. Le fondement de la vie morale est donc en vous comme en moi ce qui caractérise universellement nos individualités personnelles d'êtres vivants et parlants; eue est le respect de notre commune humanité. Nous verrons par la suite que cette condition nécessaire de la vie bonne, n'en est pourtant pas une condition suffisante. Mais, de toutes façons, l'engagement personnel qu'exprime un performatif ne relève pas des conditions de succès d'un "modèle linguistique", il relève but simplement de conditions morales.

Legault semble croire que la notion de performatif peut nous aider à résoudre les problèmes philosophiques posés par la distinction entre ce qui est et ce qui doit être. Je me demande àce propos si la fascination qu'exerce aujourd'hui sur certains esprits la théorie du performatif ne vient pas d'une confusion. Les confusions sont toujours fascinantes. Comme chacun sait, la philosophie morale fait appel a deux sortes de distinctions : d'une part la distinction entre "jugement de réalité" et "jugement de valeur", d'autre part la distinction entre ce qui est et ce qui doit être. Ces deux sortes de contrastes n'ont pas le même statut épistémologique. Dans le premier cas, il s'agit d'une distinction réelle entre deux classes de prédicats (descriptifs et appréciatifs); dans le second cas, il s'agit d'une distinction modale (modalité déontique). Les prédicats appréciatifs sont admis "par hypothèse" c'est-à-dire comme notions primitives ou termes premiers en philosophie morale; il ne peut en être autrement puisqu'ils introduisent le problème pratique qui, sans eux, ne se poserait pas. Ces termes premiers sont des biens et des valeurs. Les biens se caractérisent par le genre de satisfaction, qu'ils procurent. Les valeurs ordonnent les conditions d'acceptabilité suivant des relations d'ordre entre les biens ou les satisfactions espérées, relations d'ordre qui rendent possibles des choix préférentiels. Par contre la distinction entre ce qui est et ce qui doit être n'est qu'une distinction modale. Le concept d'un devoir-être est le concept d'une nécessité qui 
peut être diversement qualifiée de nécessité logique, physique ou morale, suivant la nature des prémisses sur lesquelles s'appuie le raisonnement. La distinction modale ne joue donc qu'un rôle subordonné par rapport aux notions primitives ou termes premiers introduits dans les prémisses. Un bien vaut nécessairement lorsqu'il vaut universellement, dans tous les cas (ou "univers") possibles, la nécessité morale d'un bien est l'universalité de sa valeur ; elle ne peut être établie que par voie de raisonnement. La référence à des univers possibles n'est qu'une manière d'exprimer le caractère hypothétique du raisonnement; le raisonnement moral demeure hypothétique jusqu'au bout ; dans l'ordre pratique, seule une décision peut être catégorique ; or le raisonnement ne vise qu'à déterminer la rectitude de la décision, sans préjuger d'autres considérations laissées à l'initiative individuelle. Par son caractère hypothétique le raisonnement moral ressemble au raisonnement mathématique ; mais il ne peut, comme le raisonnement du physicien, s'achever en détermination catégorique par simple application de l'hypothèse aux faits qui la vérifient ; il demeure modal, régulateur de l'action ; il conclut à ce qui doit être.

Il appartient à la philosophie morale d'apprécier c'est-à-dire de classer les diverses sortes de bien. Or un bien est un objet intentionnel, ce qui signifie qu'une chose est dite "bonne" sous une certaine description, en vertu de telle ou telle qualité. Mais chaque chose se prête à un nombre indéfini de descriptions ou de qualifications possibles. Le jugement de valeur c'est-à-dire l'acte de classer quelque chose comme un bien, opère un choix parmi les qualifications possibles en ne retenant d'une manière sélective que les traits descriptifs estimés pertinents pour cette appréciation. Suivant que cette appréciation sélectionne la qualification des acteurs ou celle des utilités, nous aurons affaire à deux sortes de biens différents.

Les premiers des biens sont ceux qui s'attachent à la qualité des acteurs décrits comme être personnels, agents raisonnables et responsables, capables de se reconnaître réciproquement à égalité, dans une communauté de personnes. Ces biens valent universellement, incondi- 
tionnellement, pour toute hypothèse d'univers moral concevable ; ils ont donc le maximum de nécessité morale. Les traits qui caractérisent une existence comme personnelle : conscience de soi, raison, liberté, qualités de cœur, d'intelligence et de sensibilité.... sont les biens primordiaux parce qu'ils s'enrichissent en se communiquant et font concevoir, entre tous les êtres capables de se répondre, un univers moralement unique (bonum diffusivum sui). Le bien ne fait pas nombre avec les êtres, il est le lien qui les unit, l'unique nécessaire que nous puissions aimer en tous et en chacun ; il est l'amour de ce qui existe. On appelle "vertu" la valeur universelle des relations singulières où les libertés se reconnaissent. L'honnêteté et la générosité, qui sont le principe de la vertu, confèrent à tout bonheur possible sa qualité humaine. Ce cercle universel où les êtres se reconnaissent est la condition nécessaire d'une vie bonne, qui vaille la peine d'être vécue, mais à n'en est pas la condition suffisante. Les biens premiers ne sont pas complets sans la recherche des moyens destinés à nous procurer des biens utiles, dont la possession est aléatoire. Les valeurs d'utilité se prêtent au calcul rationnel de la prévision, combinant préférences et aléas.

Les modèles de rationalité utilitaire peuvent éclairer les moyens de coopération entre les hommes. Mais leur fonction est technique. Pour que nous puissions tirer de là la moindre idée de norme et d'obligation, il ne suffirait pas d'y ajouter la maxime utilitariste : "Agis pour le plus grand bien de tous." La vertu la plus généreuse ne peut rien changer au fait que le nombre des choix possibles parmi les traits descriptifs estimés pertinents dans l'appréciation des biens utiles peut varier à l'infini ; les qualifications préférentielles se diversifient dans chaque itinéraire biographique. Nos aspirations sont suffisamment semblables pour nous faire craindre les mêmes maux, mais suffisamment différentes pour que mon désir ne soit pas le vôtre. Vous dites que nos intérêts personnels sont comparables, mais comparables à quel point de vue ? Qui décidera de ce point de vue ? La possibilité d'être satisfait ne se délègue pas. Qui jugera pour tous ? Qui sondera les reins et les cœurs? Le principe de la contingence des qualifica- 
tions préférentielles affecte toutes les utilités, individuelles ou collectives, donc toute l'organisation sociale. Aucune vertu ne suffit à éliminer les variations contingentes dans l'appréciation des biens aléatoires. Le problème de la vie bonne dans une société universelle est donc insoluble. Il est insoluble à moins d'introduire, comme font les géomètres une construction auxiliaire. Cette construction auxiliaire est la convention, le contrat social. Il faut convenir entre nous d'un ordre de justice, construire un ensemble de normes ou de critères publics, pour rendre artificiellement comparable ce qui ne l'est pas (ou l'est de façons trop diverses.) La philosophie morale pose un problème qu'elle ne peut résoudre sans faire appel à la nécessité morale d'une convention, d'une institution. Tel est le problème fondamental du droit. La philosophie du droit fait partie intégrante de la philosophie morale, puisque les conditions d'une vie bonne dans une société contingente seraient indécidables et irréalisables sans une construction auxiliaire, introduite par convention. Mais, avant de pousser plus loin, nous allons voir que l'étude du performatif nous ramène invinciblement à ce problème philosophique de la convention.

Qu'est-ce qu'un performatif ? Legault applique avec raison ce qualificatif aux actes de communication, mais il l'utilise aussi de manière plus large : il parle "d'institutions performatives" (p. 502), de "structures" qui seraient "performatives"... Essayons de voir ce qu'il en est.

Les performatifs sont des verbes qui spécifient le genre d'acte social que l'on effectue en parlant. Bien que l'acte social soit imputable en deuxième ou troisième personne, il n'est vraiment effectuable qu'à la première personne de l'indicatif présent. Si je dis à mon interlocuteur : "Qu'est-ce que tu insinues ? ",je lui impute une insinuation mais c'est bien lui qui est censé l'effectuer. Si le président d'une assemblée, après vérification du scrutin, prononce les mots : "Je déclare élu Monsieur Un tel", c'est un performatif. Par contre la phrase : "La Constitution déclare que les représentants à l'assemblée législative seront élus au suffrage universel", cette phrase n'est pas un performatif ; elle est seulement descriptive, bien que ce qu'elle décrit soit une norme, une 
prescription légale. Seul serait un performatif, en l'occurrence, l'acte de promulguer la Constitution, lorsque cet acte est accompli par un personnage ou un organe habilité à remplir cette fonction. Au sens strict, le performatif ne concerne que l'effectuation présente (contextuellement liée) d'un acte destiné à produire par convention un certain effet social. L'acte produit cet effet par application d'une convention préalable (comme nous l'avons vu en étudiant Kelsen). Par contre, si vous imaginez qu'il existe des actes dits performatifs parce qu'ils seraient capables de produire causalement une norme, vous êtes victimes d'une confusion magique entre un schème d'interprétation causale (genèse historique) et un schème d'interprétation normative (justification doctrinale). Or précisément que veut dire le titre du livre de Legault: "Les structures performatives du langage juridique ?" Nous aurions compris si Legault avait parlé des structures juridiques du performatif, puisque le performatif est un acte, un acte de communication régi par certaines conventions qui en déterminent la structure en assignant un rôle à chaque partenaire. Nous comprenons ce que peuvent être des structures juridiques (ou ludiques ou religieuses etc...) du performatif, mais que peuvent être "les structures performatives" du juridique ? Elles produisent, parait-il, des faits institutionnels et créent des obligations. Elles font cela grâce à leur "virtus performativa", laquelle n'est plus contextuellement liée à un acte présent puisqu'il existe même des "institutions performatives." Quel est ce mélange hybride de norme et de causalité ? Ces structures performatives semblent avoir la même structure logique que le lièvre de Mars, composé de mammifère et de calendrier, dans Alice au pays des merveilles. En quoi ce mélange hétéroclite se distingue-t-il du "mana", dont parle ironiquement Ross cité par Legault?

Pour ma part, je m'exprimerai autrement. Chaque verbe au performatif actualise une certaine configuration sociale des rapports interlocutifs ; il assigne aux partenaires des rôles dans un scénario ; il introduit un cadre pour les jeux de langage ou d'échange. Par exemple, si je vous pose une question, je vous assigne un rôle corrélatif à celui que je remplis, ce qui nous engage l'un et l'autre dans le scénario d'un dia- 
logue. L'effet de sens produit par le performatif est purement symbolique ou régulateur; il engage les personnages à remplir leurs rôles conformément à certaines règles conventionnelles. Ce sont des conventions qui déterminent la structure, la distribution des rôles. Un performatif peut donc actualiser diverses structures conventionnelles suivant le genre de rapports qu'à assigne aux interlocuteurs dans une configuration sociale, régulatrice des échanges. Un performatif peut donc avoir diverses structures morales, religieuses, juridiques, ludiques etc... suivant la nature des conventions qui le régissent. Tout dépend des conventions que l'on adopte. Ce sont là des structures conventionnelles. Où voyez-vous des "structure performatives ?" Pourquoi imaginer la puissance occulte d'une "virtus performativa ?" Ce sont des conventions, et rien de plus.

Legault croit que la promesse a "une structure performative", et qu'en cela "elle ressemble au contrat." (p. 319, et cf. p. 294) Cette analogie lui permet de faire la transition entre la deuxième partie ("linguistique") et la troisième partie ("juridique") de son exposé. La promesse lui apparaît à la fois comme une institution et un acte susceptible de créer des faits institutionnels. Le passage de la promesse au contrat est justifié par deux arguments : un argument d'analogie et un argument historique. "La promesse, écrit-il, était conçue par les canonistes comme un engagement dont la violation constituait un péché, et quelquefois un parjure, lorsqu'il était accompagné d'un serment. L'influence de cette conception sur la nature du contrat fut déterminante historiquement, et c'est pourquoi le contrat représente le type idéal du performatif juridique, tout comme la promesse en philosophie du langage." (p. 320) Notez le "c'est pourquoi" ; il combine les deux arguments, l'influence historique et l'analogie.

Les influences religieuses, à date ancienne, sont un fait bien connu. Il serait plus intéressant de savoir comment le contrat s'est dégagé de ses anciennes accointances avec la promesse. Qu'est-ce qui s'est produit quand on est passé du "Fas" au "Jus" ? Ourliac et Malafosse, dans leur histoire du droit privé, observent que l'importance du "jusju- 
randum" n'a cessé de diminuer alors que la "sponsio", qui est une convention "par stipulation", a fourni le moule préfigurant la forme de l'engagement contractuel : "À la différence de la sponsio, écrivent-ils, le serment ne s'est pas imposé comme mode général de contracter. Après la laïcisation du droit par la loi des XII Tables, il ne subsiste plus que sous une forme très spéciale : le serment de l'affranchi (jusjurandum liberti)." 106 Cette évolution suggère qu'au cours de l'histoire du droit certaines structures conventionnelles se sont révélées fécondes, et d'autres plus ou moins stériles. Pourquoi ? Elles étaient toutes également "performatives." Mais la nature des conventions était différente ; toutes ne dessinaient pas la même matrice, le même genre de configuration sociale. À ce point de vue, ce sont moins les analogies que les contrastes qui sont significatifs.

On notera que la promesse n'a pas la même structure suivant que nous l'envisageons comme un engagement moral, justifié par la coutume, ou comme un engagement sacré, sanctionné par les dieux, ou comme un engagement juridique, légalisé par une institution. Dans le premier cas, la structure coutumière de la promesse comporte deux personnes, le prometteur et le bénéficiaire, alors que, dans le dernier cas, pour être légalisée, la promesse exige l'intervention d'un tiers habilité à remplir une fonction officielle, par exemple un notaire enregistrant une promesse de vente. La promesse pourra donc avoir tantôt une structure dyadique d'engagement moral, tantôt une structure triadique d'engagement légal, ce qui n'entraînera pas les mêmes conséquences. Quant à la promesse sacralisée sous forme de vœu ou de serment, elle a également une structure triadique, le juge divin tenant ici la place du tiers officiel. Ces variations de structure nous interdisent de choisir la promesse comme un cas pur, un modèle univoque ; elle est au contraire ambiguë. Par elle-même, elle n'est qu'une relation morale entre deux personnes ; elle n'emprunte la forme légale ou sacrée d'une relation à trois qu'en faisant appel à des institutions ou des croyances venues d'ailleurs, comme facteurs externes. Or la différence

106 Ourliac et Malafosse : Histoire du droit privé, PUF, Paris, 1969, 1, p. 32. 
entre une relation à deux et une relation à trois joue un rôle capital en philosophie du droit. Si le contrat est devenu le type idéal de l'acte juridique, c'est précisément parce qu'Il fait apparaître la relation à trois comme le minimum de structure indispensable pour être "juridique". La structure triadique du contrat est l'atome du droit. Tres faciunt Collegium. C'est ce qui nous reste à montrer.

Les théoriciens du Contrat social, tels que Locke, Hobbes et Rousseau, avaient pris un risque en essayant d'expliquer le droit public à partir du droit privé (car la notion de "contrat" appartient au droit privé). C'était vouloir soumettre à une très forte réduction analytique l'ancienne conception de la Lex, pour qui toute autorité vient d'en haut. Ce coup d'audace, qui fut appelé par la suite "principe d'individualisme méthodologique", pouvait néanmoins s'appuyer sur de solides raisons. Vidée de contrat ne contient-elle pas tous les éléments nécessaires à l'idée de justice ? La théorie contractuelle de la justice n'a-telle pas trouvé récemment dans la théorie des jeux un prolongement technique et un procédé fécond d'analyse rationnelle ? Les théoriciens classiques, de Locke à Rousseau, ont pensé que le contrat était le minimum de structure indispensable pour concevoir un ordre de justice, le terme le plus simple où la réduction analytique devait s'arrêter. Peut-on franchir cette limite ? Pousser encore plus loin le principe d'individualisme méthodologique pour descendre jusqu'à des formes plus élémentaires ou plus ambiguës, telles que la promesse ? Il est vrai que Legault ne nous propose pas cette réduction, mais il pense que la philosophie du droit peut rester immanente au "langage" juridique pour en expliciter les formes et les fonctions sociales. La justice n'est pas son problème. Il ne procède pas par analyse régressive pour rechercher hypothétiquement à quelles conditions doit satisfaire une structure conventionnelle pour rendre possible un ordre juste du droit. Notre désaccord ne porte pas sur les détails, mais sur le statut global, épistémologique et pratique, de la philosophie du droit. Pour illustrer cette divergence d'orientation, nous n'avons pas à nous occuper de tout ce qui, chez Hobbes, Locke et Rousseau, concerne la philosophie politique. Notre question est plus limitée, plus abstraite; elle concerne 
uniquement la forme juridique de la convention sociale, le choix d'un "modèle conceptuel" ou d'un paradigme en philosophie du droit. Pourquoi la structure relationnelle du contrat est-elle l'atome du droit, la condition minima d'un ordre de justice ? Si le contrat a pu être considéré comme l'acte juridique-type, c'est qu'on admettait que, pour faire exister une structure juridique, il fallait que les partenaires sociaux instituent entre eux l'arbitrage d'un tiers qui $1^{\circ}$ : ne soit pas partie prenante dans le débat, mais représente au-dessus des intérêts particuliers une règle commune, et qui $2^{\circ}$ : dispose seul de la force ou du pouvoir de contraindre puisqu'en l'installant comme arbitre les deux parties renoncent à résoudre leurs différends par la violence.

Si l'on s'en tient aux conditions minima de structure, il faut bien voir que l'existence d'une règle commune doit être représentée, symbolisée ou attestée publiquement, et qu'elle ne peut qu'être représentée, confiée à titre de magistrature publique. L'existence de la règle doit-être attestée, car si la règle demeurait une idée pure, un singulier abstrait, une "intention", comment pourrions-nous l'identifier? La règle doit être reconnaissable à des critères publics, communs. Pour que la règle puisse agir, il faut qu'elle ait un organe d'action, qu'elle soit représentée par quelqu'un, législateur ou juge, capable de s'opposer à la violence anarchique en usant de contrainte légale. Mais d'autre part la règle ne peut qu'être représentée, car elle n'est de soi qu'une fonction institutionnelle, impersonnelle, publique ; cette fonction est à la fois législative (s'il faut prévoir) et judiciaire (s'il faut sanctionner), mais nous n'avons pas à nous occuper ici de son aménagement politique. La seule condition décisive, la condition minima nécessaire à l'institution d'un ordre de justice, est que la fonction arbitrale du tiers soit représentée comme telle, qu'elle ne se confonde pas avec l'acteur qui en est l'organe, sans quoi cet acteur redeviendrait purement et simplement un partenaire parmi les autres, et nous serions renvoyés à notre point de départ. La chaire du législateur et du juge est une chaise vide, le pur symbole d'une fonction. Remarquez bien que si cette fonction institutionnelle et impersonnelle n'est pas symbolisée, c'est la vie sociale tout entière qui demeure informe et indicible. D'ailleurs le be- 
soin d'attribuer à un dieu la fonction suprême d'autorité traduit bien, historiquement, le sentiment de l'indicible qui réapparaît chaque fois que l'activité de symbolisation n'arrive pas à construire abstraitement ses règles sociales; elle recourt alors à des entités imaginaires pour soutenir sa représentation défaillante; elle imagine des compromis entre le schème d'interprétation normative et le schème d'interprétation causale. Les solutions symptomatiques ou de compromis peuvent prendre diverses formes religieuses ou idéologiques, mais l'origine du compromis vient du fait que, dans l'histoire, ce sont généralement les plus forts, les plus riches ou les plus habiles qui proposent aux autres le contrat social. La fonction arbitrale de l'autorité publique est donc d'avance plus ou moins accaparée, "compromise" dans les intérêts des puissants ; elle n'est donc pas symbolisée sans équivoque. Cet échec de la symbolisation a des effets comparables à ceux d'une névrose : les dés sont pipés, les possibilités de délibération publique et de décision véhiculent un inexprimable, un indicible qui se déguise sous des formations de compromis, des symptômes qui font peser sur les événements leur opaque fatalité. Mais la philosophie morale doit pouvoir juger l'histoire sans attendre la révélation finale apportée par les dieux ou les infrastructures. C'est pourquoi notre raisonnement doit rester strictement modal ou hypothétique. Peu importe la cause, fût-elle première. Si la "cause" appartient au langage-objet, la "valeur" appartient au méta-langage, Pour raisonner correctement, il faut choisir entre deux niveaux d'interprétation, causale ou normative. Il ne faut pas confondre l'empirique et le symbolique, l'individu et la fonction, les parties et l'arbitre, la position des partenaires et celle du tiers officiel. En morale, c'est l'hypothèse (le "ought") qui juge le fait le ("is"). L'arche d'alliance est vide par construction, non par allusion à un je ne sais quoi. Elle est vide par construction juridique. Nous n'avons envisagé que la forme générale de l'institution, sa structure minima. Il appartient aux décisions politiques de mettre en place les modalités particulières de nos institutions historiques et d'habiliter telles ou telles gens à remplir ces fonctions institutionnelles. Mais si la décision est historique, son objet final et régulateur ne l'est pas. La structure ternaire ou contractuelle de l'institution définit une fonction arbitrale qui est, de 
soi, impersonnelle et intemporelle. Il serait contradictoire qu'elle soit opportuniste et circonstantielle. La vouloir, c'est la- vouloir intemporellement. Car la vouloir, c'est vouloir le droit. Vouloir le droit, c'est vouloir une instance publique, en faveur de laquelle les parties renoncent à faire usage par eux-mêmes de force, de contrainte et de violence. Mais il ne faut pas hypostasier les abstractions. A quoi nous servent ces formulations de principe ? Elles servent à faire l'analyse logique et sémantique de notre langage. Les principes en morale comme ailleurs, sont des règles d'inférence; ils sont une manière formelle, et non matérielle, de parler ; ils permettent de raisonner pour savoir de quoi l'on parle. On voit en quel sens, pour moi aussi, la philosophie du droit est une philosophie linguistique. Les compromis historiques sur la justice et le droit sont une question de langage à peu près dans le sens où les compromis névrotiques sont une question de langage. Il faut être très attentif à ces compromis, ces formations symptomatiques, si l'on veut en débrouiller les fils. Car nul ne détient la solution. Elle passe par là. On ne peut qu'aider le patient à se guérir lui-même puisque son mal consiste à ne pas savoir ce qu'il veut ; on ne pourrait qu'aggraver son cas en désirant quelque chose à sa place ; il demande un sauveur mais par un cercle vicieux c'est là son mal ; son inhibition, son impuissance à se tirer d'affaire naît d'un perpétuel quiproquo sur soi-même; il est la victime de ses propres alibis. Notre raisonnement philosophique n'est qu'un effort pour n'être pas complices, mais il n'y a pas d'observatoire privilégié. Les acteurs sont tous logés à la même enseigne. On ne devient sage que pour avoir trouvé dans l'épreuve le moyen d'en sortir. La politique est l'art de surmonter les épreuves c'est-à-dire de trouver le remède dans l'analyse du mal, car de remède ailleurs il n'en est point.

Pour montrer que les principes philosophiques peuvent servir à l'analyse du langage et de l'histoire, je reprendrai l'exemple que nous propose Legault la théologie du serment et de la promesse de fidélité chez les canonistes du Moyen Age. L'Antiquité et le Moyen Age avaient admis une catégorie juridique appelée le "nexus", le lien qui fie un homme à un autre homme par un serment d'allégeance. Ce lien 
apparaissait, par exemple, dans le jusiurandum liberti, le serment par lequel l'esclave affranchi devenait le client de son Maître. Mais il pouvait être aussi utilisé en sens inverse Pour réduire un débiteur en esclavage lorsqu'il était insolvable. S'appuyant sur cette catégorie juridique, les théologiens du Haut Moyen-Age (avant Abélard et Saint Anselme) considéraient que l'homme par son péché était devenu le débiteur insolvable, et par suite l'esclave du démon. L'homme déchu était lié au diable par un "nexus." Or Dieu voulait affranchir ou libérer l'homme. Mais pour cela il ne pouvait faire appel à son "imperium" ou à sa "potestas", car en faisant usage de sa puissance il n'aurait pas respecté la justice du "nexus" C'est pourquoi Dieu se fit homme pour effectuer le rachat, payer la rançon due au légitime créancier, le démon. Un vieux sermon médiéval, égaré dans les oeuvres de saint Augustin, proteste que Dieu n'est pas un voleur d'esclave : "Chose indigne, mes frères, si celui que le diable avait justement acquis par droit d'occupation ("juste occupaerat"'), si celui-là eût semblé injustement ravi ("auferri") par Dieu... Dieu n'aurait-il pas pu libérer l'homme par son commandement? Mais délivrer l'homme ainsi eût été le fait de sa puissance, non de sa justice. Celui-là qui est vraiment le juste juge ne considère pas ce qu'il peut faire par son impérium, mais ce qu'il doit juger par l'équité. L'homme devait être libéré du diable, mais libéré salva justitia" ${ }^{107}$. Ainsi l'homme fut racheté ; Dieu en paya le prix ; la justice fut sauve. Ce vieux mythe illustre parfaitement ce que j'ai appelé plus haut "les formations de compromis." Il éclaire par contraste le modèle conceptuel de la structure ternaire du contrat social. En effet, d'après notre analyse, il existe entre les hommes deux types de rapports: des rapports personnels de réciprocité et des rapports conventionnels d'appartenance à une même communauté institutionnelle ou une même juridiction. légale. Il nous a paru rigoureusement nécessaire que ces deux sortes de rapports ne soient jamais confondus. Le contrat social introduit une loi de liberté dans la mesure où il ex-

107 Augustini Opera, ed. Caillau, Paris, 1836-1842, t. XXIII, pp. 179-180. Caillau a réuni dans les tomes XXIII et XXIV les apocryphes médiévaux de saint Augustin. 
clut qu'un homme puisse appartenir à un autre homme. Le lien qui me lie aux institutions de mon pays est un lieu impersonnel ; obéissant au magistrat je n'obéis qu'à la loi. Deux adages résument notre théorie minimale du contrat social : Tres faciunt Collegium, Lex facit populum. Par contre, dans le mythe médiéval de la rédemption, le lien ("nexus") de la promesse de fidélité est un lien d'allégeance féodale qui fait qu'un homme appartient à un autre homme. Les rapports personnels de réciprocité et les rapports conventionnels d'appartenance communautaire tendent à se replier l'un sur l'autre au risque de se confondre. Il en résulte un compromis symptomatique qui nous apparaît non seulement comme une caricature naïve de justice mais aussi comme un échec à symboliser la construction d'une structure abstraite. Ce qui n'a pu être symbolisé formellement dans une construction impersonnelle détachable de nos individualités empiriques et corporelles, cela même réapparaît imaginairement dans un symbolisme inhérent à nos êtres de chair : il a fallu que le sang coule pour payer le diable, comme, dans le Marchand de Venise, il faut une livre de chair pour payer la dette à Shylock. Tout se paye. Les incohérences se payent dans la chair et le sang quand nous manquons à "dire le droit." Pourtant il faut tenter de dire. Le seul droit qui existe est le droit positif, celui qui peut être dit, "Juris dictio". 
Religions du livre. Religions de la coutume

\section{Chapitre VIII}

\section{Écritures et traditions au Concile de Trente}

Les débats du concile de Trente, les comptes rendus de séances, sont restés dans les archives du Vatican jusqu'au vingtième siècle. C'est seulement à partir de 1901 que la société Görres, de Fribourg en Brisgau, entreprit leur publication. Vers la fin de la dernière guerre, en un temps où les divisions internes de l'Europe avaient de quoi laisser perplexe un jeune étudiant, je m'étais plongé dans les énormes volumes de la Societas Goerresiana, édités par Ehses et Merkle 108, me demandant ce qu'il en était de ces fameuses "traditions" au nom desquelles le monde moderne, il y a quatre siècles, s'était ouvert sur une déchirure. Je m'aperçus bientôt, à ma grande surprise, que le célèbre décret de Trente sur ce que l'on appelait alors "les sources de la Révélation" (de Fontibus revelationis) n'avait pas le sens que lui avaient donné par la suite les théologiens de la Contre-Réforme. Pour la grande majorité de ces derniers, il était entendu que les traditions dites

108 Ehses : Concilium Tridentinum, Societas Goerresiana, Freiburg-in-B. 1900 SS. 
"orales" étaient "complétives" et non pas seulement "interprétatives" de l'Écriture, celle-ci ne contenant qu'une partie de la Révélation. Or non seulement le concile n'avait pas voulu trancher ce genre de débat, mais il avait construit son décret dans une tout autre perspective, beaucoup plus proche de la théologie médiévale que de la théologie post-tridentine. Cela ressortait de la façon dont le décret avait été rédigé. Dans le texte du projet initial, il était dit que "la Règle" (de l'enseignement et de la discipline) était contenue "en partie" dans les Écritures et "en partie" dans les traditions qui, depuis les Apôtres, "ont été transmises comme de la main à la main et sont parvenues jusqu'à nous". Dans le texte définitif, les mots "partim-partim" ont été remplacés par la conjonction "et", en même temps qu'au mot "Règle", était substitué le mot "Source". Cette modification avait été demandée par le général des Servites, Agostino Bonuccio. Bonuccio, personnellement, croyait que les traditions n'avaient qu'une fonction interprétative ; il croyait cela non point par quelque influence luthérienne mais par attachement à la théologie médiévale comme cela ressort de ses autres interventions (par exemple, à propos de la formation des clercs, il voulait que l'on reprenne pour manuel les Sentences de Pierre Lombard). Mais, en acceptant la modification demandée, le concile n'a pas pour autant fait siennes les opinions de Bonuccio. Pour comprendre ce qu'ont fait les rédacteurs du décret, sous l'impulsion du cardinal Cervini, il faut tenir compte de plusieurs éléments apparus aux cours des débats.

Je vais donc présenter successivement l'histoire des discussions qui ont marqué la quatrième session du concile de Trente sur les Écritures et les Traditions.

Je proposerai ensuite une exégèse du décret conciliaire. 
J'ajouterai enfin quelques remarques sur la signification de ce décret dans l'histoire de la théologie. 109

\section{I \\ Les débats du concile de Trente}

La première session du concile de Trente s'était ouverte le 13 Décembre 1545, sous la présidence des légats pontificaux : del Monte, Cervini et un anglais le cardinal Pole. Les premières semaines furent, consacrées à l'organisation de l'assemblée. Sur la proposition du cardinal del Monte, l'assemblée fut divisée en trois "classes" qui devaient se réunir en congrégations particulières sous la présidence de chacun des trois légats et préparer les décisions qui devaient être prises en congrégation générale. On s'arrangea pour que les diverses tendances fussent représentées dans chaque classe et que dans l'une d'elle ne se

109 J'avais présenté une première version de cette étude sur le concile de Trente en 1946 à la première session oecuménique qui put avoir lieu, dans les environs de Genève, après la guerre, grâce aux initiatives de l'abbé Couturier. Une première rédaction de mon travail fut publiée en 1949 dans les Recherches de sciences religieuses (t. 36, pp. 271-299), à laquelle se réfère H. Jedin : Geschichte des Konzils von Trient, Frieburg, 1957, t. II. A Paris en 1952 le pasteur Charles Westphal m'avait demandé de présenter la question à l'assemblée générale des pasteurs de l'Église Réformée de France. C'est cette dernière version légèrement modifiée que je publie aujourd'hui. Si je ne l'ai pas publiée plus tôt, c'est qu'en cette même année 1952 un événement sans rapport avec l'exégèse tridentine m'avait obligé, de renoncer à ce genre de recherche. Cet événement est le suivant :

Un de mes camarades ayant fait l'objet d'une dénonciation anonyme au Saint Office, je fis savoir à l'autorité romaine que j'étais solidaire de mon collègue, ce que j'expliquais dans un mémoire de 50 pages intitulé :"Le problème de la liberté d'expression dans les structures actuelles de l’Église." La réponse vint bientôt, elle fut radicale. Je compris qu'elle devait l'être aussi de mon côté.

Aujourd'hui l'exégèse du décret de Trente est chose banale et bien connue. Mais il n'y a pas de raison de laisser dormir dans un tiroir un vieux papier qui n'est peut-être pas encore complètement dépourvu d'intérêt, d'autant plus que le concile du Vatican Il n'a rien ajouté, pour le fond, à ce qu'avait dit le concile de Trente au cours de sa quatrième session. 
constituât pas un parti trop important. Nous sommes particulièrement bien renseignés sur les travaux de la Classe de Cervini grâce aux comptes rendus de son secrétaire Massarelli. Au début, le secrétariat n'était pas organisé ; c'est seulement au cours de la quatrième session que Massarelli fut nommé secrétaire du concile. D'ailleurs Cervini allait s'affirmer comme le principal animateur des travaux. Le premier président, del Monte, était plus juriste que théologien, et son activité était parfois gênée par la maladie (il souffrait de la goutte).

La deuxième session, en Janvier 1546, avait établi un programme : il avait été décidé que l'on s'occuperait parallèlement des décisions dogmatiques et de la réforme des abus.

La troisième session avait entrepris de poser les fondements sur lesquels repose la doctrine catholique. On avait donc reçu le symbole de Nicée-Constantinople comme expression de la foi commune. Et dans la même ligne ; la quatrième session devait s'occuper de l'Écriture et des abus qui se produisent à son sujet.

C'est le 8 février 1546 qu'eut lieu l'ouverture de la quatrième session. Il apparut tout de suite que l'on ne pouvait traiter des Écritures sans mentionner les traditions, d'où une première discussion, qui allait se prolonger quelques séances, pour savoir dans quel ordre on devait procéder: Écriture puis réforme des abus, puis traditions, ou bien Écriture, traditions et ensuite réforme des abus. On s'en tint finalement à la seconde hypothèse.

Dans la congrégation générale du 12 février, le président del Monte propose ainsi la marche à suivre dans le travail :

"Vos Paternités, dit-il, savent comment toute notre foi vient de la révélation divine. Celle-ci nous est transmise par l'Église en partie grâce aux Écritures qui sont dans l'Ancien et le Nouveau Testament, en partie aussi par simple tradition de la main à la main. Donc afin de procéder par ordre il est naturel que nous approuvions d'abord les Écritures sacrées, puis que nous traitions des traditions ecclésiastiques, et enfin des abus s'il s'en 
trouve soit dans les versions de l'Écriture soit dans l'enseignement et la prédication" 110 .

Il convient de souligner les termes de cette déclaration. La division "partim-partim" sera maintenue dans la première rédaction du décret ; nous verrons comment elle sera éliminée de la rédaction définitive. Quant au concept de tradition, il s'exprime au départ dans un vocabulaire assez flottant: le singulier "tradition" est peu fréquent et sans valeur spéciale ordinairement, il équivaut à la désignation générale des "traditions" au pluriel. Del Monte avait parlé de "traditions ecclésiastiques". Mais celles-ci vont être éliminées au profit des "traditions apostoliques", grâce surtout à l'influence du cardinal Cervini. Il convient de noter la déclaration de Cervini, car on retrouvera quelque chose de son schéma général dans le décret du concile :

"Pour nous telle est la voie qui nous a paru la plus convenable : après la profession du symbole, que soit faite la réception des livres saints comme des premiers fondements où toutes nos conclusions doivent se fonder. Car le saint synode doit traiter beaucoup de choses ardues et difficiles, et si elles n'étaient établies sur des fondements fermes elles crouleraient.

Donc après le premier fondement du symbole il semble bon de poser les autres principes. Or nous trouvons trois principes de notre foi, car notre doctrine n'est connue que par la révélation faite à des époques différentes.

D'abord aux anciens Pères dont nous connaissons la foi par les Livres saints., et c'est ce que nous appelons l'Ancien Testament.

Dans la suite des temps il a plu à la divine bonté de, révéler aux hommes par son Fils unique ces mêmes choses, et beaucoup d'autres. Celui-ci, non par écrit mais oralement, non sur le papier mais dans le coeur, a planté son Évangile selon que l'avaient prédit d'ailleurs ces mêmes prophètes ; c'est là ce que nous appelons le Nouveau Testament. Parmi ces choses qui sont émanées du Christ, certaines furent mises par écrit, d'autres furent laissées dans le coeur des hommes. Tel est donc le deuxième principe de notre foi.

110 Concilium Tridentinum (éd. Société Görres, Freiburg-en-B., 1901 ss.), V/2, 7-8 c'est-à-dire : volume $\mathrm{V}$, tome 2 , pages 7 -8. Je me servirai par la suite de cette notation pour toutes les références à l'édition de la Société Görres. 
Or voici le troisième : comme le Fils de l'Homme ne devait pas toujours rester avec nous, il a envoyé son Esprit Saint dans le monde afin qu'il déclarât les secrets de Dieu et les choses douteuses parmi les hommes.

Tout cela étant mûrement considéré, nous avons entrepris de recevoir ces principes. Mais puisqu'ils sont établis dans les Écritures de l'Ancien et du Nouveau Testament, nous recevons ces Écritures grâce à la bénédiction de Dieu... En outre dans l'ensemble de ces choses que les Apôtres ont professées parmi les hommes, nous croyons que certaines ont été faite et non écrites ; nous devons donc affirmer que beaucoup de choses ont été dites, non écrites. Les Apôtres en effet étaient si occupés à prêcher qu'ils ne purent même servir à leurs propres tables. Cela montre que bien des choses qui sont venues du Seigneur aux Apôtres à nous n'ont pas du tout été confiées par écrit. Nous croyons qu'il faut commencer par les traditions (avant de traiter de la réforme des abus). Cependant entre les Écritures et les traditions apostoliques, il n'y a aucune différence sinon que les unes ont été écrites tandis que les autres ont été possédées par insinuation : les unes et les autres proviennent de la même façon du même Esprit saint" I/I, 485.

On notera dans cette déclaration deux idées importantes : d'une part l'économie historique de la révélation est reliée à la théologie trinitaire, d'où le rôle de l'Esprit saint dans l'Église ; d'autre part Écritures et traditions apostoliques ont une égale autorité. Ces idées se retrouveront dans le décret.

L'argument du surmenage oratoire chez les Apôtres illustre une confusion fréquente chez les apologistes catholiques ; l'importance de. la transmission orale ou vécue ne prouve rien contre les Protestants puisque tout le différend porte sur le principe d'autorité, la règle de droit. Néanmoins au cours de cette première discussion qui ne portait que sur l'ordre du programme (devait-on traiter de la réforme des abus avant ou après la question dogmatique des traditions ?), certaines différences se font jour sur le concept même de "traditions".

Certains Pères ne distinguaient pas clairement traditions "apostoliques" et traditions "ecclésiastiques". 
Ainsi l'évêque de Belcastro : "Il faut, dit-il, commencer par les traditions" (avant la réforme des abus), et il propose de nommer "les traditions de l'Église et ses coutumes, puisque toutes ces choses sont les principes de nos conclusions" (1/1, 484 et V/2, 10). On observera que dans ce texte comme dans celui de Cervini, le vocabulaire est celui de la théologie "positive" (ponere principia).

Parmi les opposants à la thèse de Cervini, il convient de mentionner deux personnages destinés à jouer un rôle important au cours du débat.

D'abord le dominicain Pierre Bertano, évêque de Fano. Il proposait d'introduire dans le décret de réception des Livres saints la phrase suivante : "Et après les Écritures ici énumérée, nous devons laisser place au saint Esprit qui par révélation nous a suggéré certaines choses. C'est pourquoi nous recevons ce que le saint Esprit nous a révélé dans les traditions" $(1 / 1,484)$. Ce serait une erreur de croire que, sous prétexte qu'il envisage des traditions "révélées" au sens médiéval du terme (moins fort qu'aujourd'hui) Bertano leur accorde une autorité égale à celle de l'Écriture. C'est le contraire qui est vrai, comme nous le verrons par la suite. Mais contrairement à Cervini qui insiste sur l'origine commune des Écritures et des traditions apostoliques, Bertano considère, avant tout, leur réception par le magistère ou le consensus de l'Église. De ce point de vue, il veut souligner la différence entre ce qui est variable et ce qui est invariable dans les traditions. Ce qui est invariable se rattache à l'antiquité apostolique principalement par l'intermédiaire du Dépôt scripturaire. Ce qui est variable relève du magistère ou du consensus de l'Église. Telle est la raison pour laquelle il ne veut recevoir les traditions qu'en seconde position, "après" les Écritures.

Dans une perspective plus nettement médiévale, le général des Servites, Augustin Bonuccio, refuse la conception antithétique du scripturaire et du traditionnel. Il considère que les traditions ne s'ajoutent pas à l'Écriture, mais qu'elles en fournissent seulement "l'exposi- 
tion", l'intelligence correcte ou le commentaire autorisé. C'est dans cet esprit qu'il faut comprendre la déclaration suivante au premier abord étonnante pour un esprit moderne : "Outre les Livres recensés dans les autres congrégations (chargées de dresser la liste du canon scripturaire), il en est plusieurs autres qui doivent être nommés parmi les écritures sacrées (inter scripturas sacras) comme par exemple les canons apostoliques, les décisions des conciles généraux et les décrétales des souverains pontifes" $(1 / 1,484)$. De même qu'au Moyen Age, le maître en théologie était chargé d'exposer la Doctrina Sacra ou Pagina sacra c'est-à-dire l'intelligence de l'Écriture suivant l'interprétation traditionnelle qu'en donne l'Église, ainsi Bonuccio voit dans les interventions du magistère une exposition authentique des Écritures, donc un seul contenu qui est l'intelligence spirituelle de la foi. L'exposition authentique ("authentica") est supérieure aux expositions magistrales ("magistralia").

Quoi qu'il en soit, deux tendances se font jour : l'une qui, à la mention de l'Écriture, veut joindre celle du Magistère, l'autre, avec Cervini, qui, à l'Écriture, veut joindre les traditions apostoliques. Cervini précise d'ailleurs sa position. "En ce qui concerne l'autorité de l'Église, il ne serait pas possible d'en traiter avant la réception des saintes Écritures, c'est pourquoi nous y viendrons progressivement par la suite quand il y aura lieu" (I/I,485).

Après consultation des théologiens ("theologi minores", non. votants) la première phase des discussions se termine le 25 février en congrégation particulière, et le 26 Février en congrégation générale, par l'adoption du programme : Écritures et traditions, puis réforme des abus.

Mais dans ces dernières séances, de nouvelles questions apparaissent concernant l'idée de "traditions apostoliques". Ce mot évoquait généralement des pratiques, des usages liturgiques, des coutumes... Or dans cet ensemble ne fallait-il pas distinguer diverses sortes de tradi- 
tions ? C'est ce que fait remarquer le jésuite Claude Lejay, procurateur du cardinal Otto Truchsets d'Augsbourg :

"Puisqu'elles sont d'autorité diverses dans l'Église, il faut les recevoir de diverses manières En effet celles qui concernent la foi doivent être reçues avec la même autorité que l'Évangile. Les autres non puisque plusieurs ont été changées : telle l'interdiction des secondes noces, celle des viandes non saignées et autres choses semblables" (V/2, 13).

Cervini approuve la distinction faite par Lejay :

"Parmi les traditions certaines sont écrites et d'autres non ; certaines sont essentielles, d'autres cérémonielles, comme l'a dit le procurateur d'Augsbourg. En ce qui concerne les sacrements, certaines (traditions) nous ont été transmises par les Apôtres, et ces sacrements sont essentiels à notre foi. Parmi les traditions cérémonielles nous avons le Carême, et l'on ne peut guère l'établir à partir de l'Écriture ; nous savons cependant avec certitude que les Apôtres nous l'ont transmis. Mais qu'il y ait des traditions apostoliques écrites et d'autres non, on peut le lire dans le texte Ecclesiasticarum" (V/2, 14 et I/I, 492).

Par les mots "traditions apostoliques écrites" Cervini entend désigner les pratiques, les usages consignés dans l'Écriture ; mais nous verrons qu'à propos du texte "Ecclesiasticarum" auquel il est fait ici allusion, s'élèvera une controverse : pour les uns il s'agira de traditions (usages) mentionnées dans l'Écriture, pour d'autres il s'agira de traditions non-scripturaires mais qui ont pu être ou non consignés dans un écrit quelconque.

Dans la Classe de Cervini, le 23 Février, avait été donnée une liste d'Auctoritates concernant l'autorité des traditions. C'est dans ce recueil que se trouve le texte "Ecclesiasticarum", texte de saint Basile mais qui est cité d'après le code de droit canonique de Gratien ${ }^{111}$. Si l'on se reporte à l'original, on voit que saint Basile y soutient l'existence de

111 Dans Gratien : Decret, la Pars, D. II, c. 5 (cf. ed. Friedberg, col. 24). Dans saint Basile : de Spiritu sancto, c. 27. On n'est pas allé voir l'original. Certains pères du concile attribueront le texte, par erreur, à saint Augustin au cours des discussions. 
traditions "secrètement transmises" depuis les Apôtres, réservées à ceux qui ont reçu l'initiation sacramentelle et se trouvent aptes à comprendre les mystères. Parmi ces traditions, saint Basile nomme la prière tournée vers l'Orient, le texte de l'épiclèse, la triple immersion du baptême, l'onction de l'huile etc..., toutes choses "qui ne sont pas dans l'Écriture." C'est à ce texte que le décret du concile empruntera la formule suivant laquelle aux Écritures et aux traditions non écrites est due une égale vénération "par pietatis affectus" 112

Dans la congrégation générale du 26 Février, Cervini reprend la distinction faite par Lejay mais sous une forme un peu différente : au lieu des mots "traditions concernant la foi" il dira "traditions reçues par l'Église".

"Je veux que vous sachiez, mes Pères, que dans la congrégation qui s'est tenue sous ma présidence, certains ont fait remarquer qu'il ne fallait pas recevoir purement et simplement les traditions apostoliques de peur que celles qui ont été abolies ne soient reçues comme celles qui sont encore en

112 Voici le texte selon Gratien : "Ecclesiasticarum institutionum quasdam (Scripturis, quasdem) vero apostolica traditione per successores in ministerio confirmatas accepimus, quasdam vero constetudine roboratas approbavit usus quibus par ritus et idem utrisque pietatis debetur affectus. Unde quis vel aliquantulum sacrarum expertus Scripturarum haesitavit? Si enim attentaverimus.consuetudines Ecclesiae non per scripturas a patribus traditas nihil existimare, quantum religio detrimenti sit latura, intente inspicientibus liquide constabit".

À titre de comparaison, voici la traduction que propose le P. Benoit Pruche d'après un texte grec notablement différent : "Parmi les doctrines et les définitions conservées dans l'Église, nous tenons les unes de l'enseignement écrit et nous avons recueilli les autres, transmises secrètement, de la tradition apostolique. Toutes ont la même force au regard de la piété, nul n'en disconviendra, s'il a tant soit peu l'expérience des institutions ecclésiastiques ; car, si nous essayions d'écarter les coutumes non écrites comme n'ayant pas grande force, nous porterions atteinte, à notre insu, à l'Évangile, sur les points essentiels eux-mêmes..." (Basile de Césarée, éd. Sources chrétiennes, Paris, 1945, p. 233.

De toutes façons, il s'agit dans les exemples donnés par saint Basile du même genre de traditions que celles énumérées par les Pères de Trente.

En empruntant les citations d'Auctoritates au Droit canonique, les Pères du concile se conformaient à une vieille coutume théologique. 
vigueur. Par exemple l'abstinence des viandes étouffées et du sang. Mais ils ont pensé qu'on devait recevoir seulement celles qui, reçues par l'Église, sont parvenues jusqu'à nous".

\section{Et il ajoute :}

"D'autres ont désiré en outre que le concile fasse une énumération des traditions. Mais cela n'a pas été approuvé (par la majorité). Nous voulons savoir s'il y a des traditions (an sint) mais lesquelles (quae autem et quales) cela sera discuté en son lieu" (V/2, 18 et I/I, 33).

En son lieu c'est-à-dire à propos des diverses questions dogmatiques que devait aborder le concile par la suite.

Au cours de ces mêmes séances se produisit une intervention plus, singulière, celle de Giacomo Nacchianti, évêque de Chioggia. Il proposait d'exclure toutes les traditions.

"Car personne n'ignore que dans les saints Livres sont contenues toutes les vérités concernant le salut". Et comme pour dresser le canon des Livres saints on s'était appuyé sur le concile de Florence représenté par la bulle d'Eugène IV "Cantate Domine", Nacchianti faisait observer que la bulle promulguée en 1441 ne pouvait avoir reçu l'approbation d'un concile terminé en 1439. Et il concluait : "Quant à recevoir les traditions ecclésiastiques ou en faire quelque mention dans le décret, je ne puis absolument pas l'approuver alors que tant de jeûnes et de cérémonies la plupart illusoires (frustratoriae) accablent le peuple chrétien" (V/2, 18, 19).

Dans cette intervention, ce n'est pas le rejet de toutes traditions qui fit scandale mais l'affaire du concile de Florence. Plusieurs Pères sur ce point étaient de l'avis de Nacchianti ${ }^{113}$. Et malgré les rectifications

113 Ancien dominicain, Giacomo Nacchianti devait avoir par la suite quelques difficultés avec l'inquisition. Il fut cependant un évêque zélé dans l'administration de son diocèse. Deux volumes de ses oeuvres ont été édités à Venise en 1567, et la bibliothèque vaticane conserve de lui plusieurs manuscrits (Vat. Lat. 4637-4640, 4657, 4663). Cf. Hubert Jedin : Geschichte des Konzils von Trient, II, 1957, p. 458-459. Et C. Fischer : J. Nacchianti, O.P., évêque de Chioggia, et sa théologie de la primauté absolue du Christ, dans : La France Franciscaine, 20, 1937 ; pp. 97-174. 
apportées par Del Monte qui avait lu "de ses propres yeux" la bulle en question et savait que le concile de Florence avait été prolongé, après le départ des grecs, jusqu'en 1442, il fallut demander à Rome d'envoyer une copie authentique de la bulle pour vérification. La confusion faite par Nacchianti et quelques autres venait de ce que -la traduction latine des actes du concile s'arrêtait à la fin du texte grec c'està-dire au moment où les grecs avaient quitté Florence (1439), mais le concile s'était poursuivi, et la bulle d'Eugène IV pour l'union des Jacobites faisait partie de cette dernière section.

Le 23 Février avait été nommée une commission chargée de préparer la rédaction du décret. Cette commission comprenait deux membres par classe, un théologien et un juriste : les archevêques de Sassari et de Matéra dans la classe de Del Monte, les évêques de Feltre et de Belcastro dans celle de Cervini, ceux d'Armagh et de Badajoz dans la classe de Pole. Confirmée dans ses fonctions le 26 Février, cette commission allait achever la rédaction du décret le 22 Mars.

Pour faciliter l'intelligence des discussions qui vont suivre, nous reproduisons ici :

1) le texte provisoire du projet de décret présenté le 22 Mars pour être discuté les jours suivants. Dans ce texte nous signalerons par des mots en italiques ou des points de suspension les passages modifiés par la suite.

2) le texte définitif du décret promulgué le 8 Avril 1546, texte que nous ferons suivre de sa traduction française.

On notera qu'après un intitulé général le décret se divise en trois parties : 1) le prologue est une déclaration d'intention introduite par le mot "proponens" ; 2) la deuxième partie est un considérant introduit par le mot "perspiciens" ; 3) enfin la conclusion est une décision dogmatique présentée sous le patronage des Pères de l'Église. 
1) Texte provisoire du 22 Mars.

Sacrosancta oecumenica et generalis Tridentina Synodus, in Spiritu Sancto legitime congregata, presidentibus in ea eisdem tribus Apostolicae Sedis legatis,

- hoc sibi perpetuo ante oculos proponens ut, sublatis erroribus, puritas Evangelli Dei (...) conservetur,

quod promissum ante per prophetas ejus in Scripturis sanctis Dominus noster Jesus Christus ejus Filius proprio ore primum promulgavit.

deinde per suos apostolos tanquam Regulam omnis et salutaris veritatis et morum disciplinae omni creaturae predicari jussit,

- perspiciensque hanc veritatem (...) partim contineri in libris scriptis, partim sine scripto traditionibus quae vel ipsius Christi ore ab apostolis acceptae vel ab ipsis apostolis Spiritu sancto dictante quasi per manus traditae, ad nos usque pervenerunt,

- Orthodoxorum Patrum exempla secuta, omnes libros tain Veteris quam Novi Testamenti, cum utriusque unus Deus sit auctor,

necnon traditiones ipsas (...) tanquam vel oretenus a Christo vel a Spiritu sancto dictatas, et continua successione in Ecclesia catholica conservatas,

Quibus par pietatis debetur affectus,

Summa cum reverentia pro sacris et canonicis suscepit et veneratur, suscipi et ab omnibus Christi fidelibus statuit et decernit. 
(suite la liste des livres canoniques, liste destinée à mettre fin auxcontroverses sur les "proto" et "dentéro-canoniques" et a reconnaître la valeur officielle de la Vulgate).

2) Décret du 8 Avril 1546 (texte définitif)

Sacrosancta oecumenica et generalis Tridentina Synodus, in Spiritu Sancto légitime congregata, presidentibus in ea esidem tribus Apostolicae Sedis legatis,

- hoc sibi perpetuo ante oculos propenens ut, sublatis erroribus, puritas ipsa Evangelii in Ecclesia conservetur,

quod promissum ante per prophetas in Scripturis sanctis Dominus noster Jesus Christus Dei Filius proprio ore primum promulgavit,

deinde per suos apostolos tanquam fontem omnis et salutaris veritatis et morum disciplinae omni creaturae predicari jussit,

- perspiciensque hanc veritatem et disciplinam contineri in libris scriptis et sine scripto traditionibus, quae ab ipsius Christi ore ab apotolis acceptae, aut ab ipsis apostolis Spiritu Sancto dictante quasi per manus traditae, ad nos usque pervenerunt,

- orthodoxorum Patrum exempla secuta, omnes libros tam Veteris quam Novi Testamenti, cum utriusque unus Denus sit auctor,

necnon traditiones ipsas tum ad fidem tum ad mores pertinentes,

tanquam vel oretenus a Christo, vel a Spiritu Sancto dictatas, et continua successione in Ecclesia catholica conservatas,

pari pietatis affectu suscipit et veneratur.

(suit la liste des livres canoniques). 
Traduction française (décret du 8 Avril 1546)

Le très saint concile oecuménique et général de Trente, légitimement réuni dans l'Esprit Saint, sous la présidence effective des trois mêmes légats du Siège Apostolique,

- se proposant comme un but perpétuellement sous les yeux qu'après extirpation des erreurs soit conservée dans l'Église la pureté même de l'Évangile,

(Évangile) qui fut promis autrefois par les prophètes dans les saintes Écritures,

et que notre Seigneur Jésus Christ, fils de Dieu, a d'abord promulgué de sa propre bouche, puis qu'il a ordonné à ses apôtres de prêcher à toute créature,

comme source de toute vérité salutaire et discipline des mœurs,

- et considérant que cette vérité et discipline est contenue dans les livres écrits et dans les traditions non-écrites qui, reçues par les apôtres de la bouche du Christ lui-même ou transmises de la main à la main par les apôtres eux-mêmes sous la dictée de l'Esprit saint, sont parvenues jusqu'à nous,

- suivant l'exemple des Pères orthodoxes, (le concile) reçoit avec une égale piété et révérence,

tous les livres de l'Ancien et du Nouveau Testament puisque Dieu est l'unique auteur des deux,

et aussi les traditions elles-mêmes concernant la foi et les mœurs, lesquelles ont été comme dictées ou oralement par le Christ ou par 
l'Esprit Saint, et ont été conservées dans l'Église catholique par une succession continue.

Le 23 Mars, en congrégation particulière, commença la discussion du texte. L'évêque de Sinigaglia objecte que les formules employées sont trop générales et semblent accepter des traditions tombées en désuétude (par exemple l'interdiction des viandes non kasher). L'un des rédacteurs, Thomas Campeggio, évêque de Feltre, répond à cette objection et à quelques autres, en disant : "Au sujet des livres saints, les députés n'ont rien ajouté au concile de Florence". Au sujet des traditions "les députés ont suivi sur ce point le 7e concile qui a parlé en général des traditions. Quant aux traditions des apôtres qui ne sont plus en usage, c'est à cause d'elles qu'il a été dit : "que continua successione ad nos usque pervenerunt" afin d'exclus les viandes immolées et le sang, la forme du baptême etc..." (I/I, 522). Par "7e concile" il faut entendre le 2e de Nicée (787) qui avait condamné l'iconoclasme en invoquant les traditions de l'Église en général (Dz. 304) ${ }^{114}$. En ce qui concerne la forme du baptême, l'expression des Actes : "Baptiser au nom du Seigneur Jésus" passait alors pour une formule liturgique, ce qui n'est pas sûr du tout. Retenons seulement l'essentiel de la réponse qui consiste à relier l'apostolicité des traditions à la continuité de la succession. L'autre rédacteur, l'évêque de Belcastro fait une réponse analogue : "Les députés n'ont pas voulu dire qu'on devait recevoir toutes les traditions qui, à n'importe quelle époque, furent dictées par l'Esprit saint, mais celles qui sont parvenues jusqu'à nous" (I/I, 522). Rappelons au passage que l'expression "dictées par l'Esprit saint" n'a rien à voir avec une théorie psychologique de l'inspiration, mais doit être comprise comme une formule juridique du genre : "dic-

114 La notation "DZ" renvoie à Denzinger : Enchiridion Symbolorum, recueil des textes dogmatiques, publiés chez Herder, à Fribourg-en-Brisgau. 
ter un testament, dicter un ordre". Au sens légal "dicté par" veut dire "prescrit par".

La plupart des discussions qui eurent lieu le 23 Mars dans la classe de Cervini furent reprises le 27 en congrégation générale. D'autre part, comme la séance du 27 Mars n'aboutit à aucune conclusion, il fut décidé de rédiger une série de "dubia" ou questions auxquelles les Pères devraient répondre par oui ou par non (placet ou non placet), sauf à profiter de l'occasion pour donner des explications de vote s'ils le désiraient. Il serait fastidieux de suivre dans leur déroulement chronologique des discussions souvent confuses. Dans l'ensemble, on retrouve toujours deux tendances principales. La première, représentée par les évêques de Sinigaglia, de Fano etc..., refuse de mettre Écriture et traditions sur le même plan ;elle propose de distinguer trois degrés : les Écritures, puis les traditions apostoliques, enfin les traditions ecclésiastiques. La seconde tendance, représentée par Cervini et les rédacteurs du décret, reconnaît aux Écritures et aux traditions apostoliques une autorité "égale" (et non pas seulement "semblable"), mais ne veut pas qu'il soit fait mention des "traditions ecclésiastiques" dans le décret. Cette seconde conception, qui finira par l'emporter, semble avoir été le fait d'une minorité agissante. Pour la comprendre, il est nécessaire d'étudier en détail certaines interventions qui ont donné aux rédacteurs l'occasion de préciser leur pensée. Parmi les opposants émergent trois figures nettement distinctes : celle de Pierre Bertano, évêque de Fano, celle d'Augustin Bonuccio, général des Servites, et celle de Jacques Nacchianti, évêque de Chioggia.

Pierre Bertano était un homme influent. La veille de l'assemblée générale il était allé voir les légats pour leur présenter sa thèse. Or la séance du 27 fut une séance confuse et interminable ; elle se prolongea la plus grande partie de la nuit, si bien que les participants étaient morts de fatigue ; et l'on n'aboutit à aucune conclusion. Estimant que le projet initial avait échoué, l'évêque de Fano put croire un moment qu'il avait gagné la partie, comme il le dit dans une lettre au cardinal de Mantoue : "Hoggi nelle congregatione generale s'è stabilito de far il 
dogma di quella maniera qu'io narro" (X, 434 sq.). Quelle était donc l'opinion de Bertano ?

Ses arguments contre les traditions apostoliques étaient les suivants. D'abord comment "les allemands" vont-ils lire le décret ? Ils vont nous dire, par exemple, que la communion sous les deux espèces et le mariage des prêtres sont des traditions apostoliques, et que par conséquent nous devons les accepter. Si nous prétextons que ces traditions n'ont pas été reçues dans l'Église jusqu'à nos jours, ils vont nous dire qu'en fait ces traditions ont été reçues dans l'Église orientale, que l'état de celle-ci a toujours été différent de l'état de l'Église occidentale. Ils concluront que notre décision n'est pas conforme à l'usage de l'Église universelle, mais seulement à l'usage d'une Église particulière, celle de Rome. Ainsi la "malitia Germanica" nous tournera en dérision.

On voit que les objections de Bertano ne manquaient ni de vigueur ni d'à propos. Mais ce n'est pas tout. Il serait injuste ("iniquum"), disait-il, d'attribuer aux Écritures et aux traditions une autorité égale, "par affectus". Car les livres saints sont immuables et indélébiles alors que les traditions sont changeantes. Elles peuvent être supprimées ou modifiées par le jugement de l'Église. Il est vrai de dire que les Livres et les traditions proviennent d'un seul et même Esprit, mais ce n'est pas une raison pour les mettre sur un pied d'égalité. Toute vérité vient de l'Esprit saint ; pourtant toute Écriture, bien que contenant la vérité, n'est pas d'une autorité identique et égale (V/2, 39-40 et 1/1, 523). Les matières traitées dans les Écritures n'ont pas toutes même importance, De même pour juger de la valeur des traditions il faut considérer leur matière, leur contenu. Or la nature des traditions est variable suivant les besoins de l'Église aux différentes époques. Il ne faut donc pas mettre sur le même plan l'Écriture qui est constante, et les traditions qui sont variables.

Pour combattre les thèses luthériennes, pense Bertano, il suffirait d'ajouter au décret les mots suivants : 
"Parce que ce saint Synode sait que d'autres choses furent dictées par l'Esprit saint dans l'Église et qui ne sont pas dans les saintes Lettres, celles-là aussi il les reçoit et les vénère".

Par-là le concile explique mieux sa pensée. Il ne laisse plus de place à la calomnie qui dirait: "Us reçoivent les traditions mêmes dont ils se font les violateurs". En effet, la communion sous les deux espèces, la prière debout de Pâques à la Pentecôte, la prière tournée vers l'Orient... sont des traditions apostoliques, mais elles sont tombées en désuétude et ont été changées par l'Église. La formule "ad nos usque pervenerunt" n'est donc pas un critère suffisant, puisque c'est nous qui jugeons de ce que nous acceptons ou refusons (V/2, 39-40).

L'évêque de Fano perçoit donc très bien la difficulté majeure, à savoir qu'en toute cette affaire l'Église romaine n'a d'autre référence qu'elle-même. Cependant quelle aurait été la signification du décret si la thèse de Pierre Bertano avait été acceptée ? Pour en juger, il faut d'abord déterminer exactement la place où devait s'introduire dans le décret la modification proposée. C'est ce que nous pouvons savoir à la lumière des diverses motions proposées concurremment à celle de Pierre Bertano. Par exemple, Thomas Casella, évêque de Bertinoro, formule sa motion en commençant par les mots : "Necnon traditiones ipsas" (I/I, 524). Ces termes se trouvent dans le projet de décret; et c'est bien là, en effet, que s'insère la petite phrase proposée par Pierre Bertano :

"(necnon traditiones ipsas) quoniam sancta haec synodus scit quam plura alia esse in Ecclesia a Spiritu sancto dictata quae in sacris Litteris non sunt prodita, propterea illa quoque suscipit et véneratur".

Les deux derniers verbes sont ceux que l'on retrouve en fin du décret. Si la proposition de Bertano avait été acceptée, le sens général du décret aurait été le suivant : 
La Règle de foi ("Regula") est contenue dans les Écritures et les traditions. C'est pourquoi nous recevons les Écritures et aussi les traditions qu'il appartient au magistère de déterminer suivant les besoins de l'Église.

On voit immédiatement surgir deux difficultés : 1) Us traditions, "apostoliques" ne sont plus qu'un cas particulier des tradition "ecclésiastiques" ; 2) Le magistère est seul juge de ce qu'il reçoit de sorte que, pour échapper aux objections qu'il a lui-même formulées, Pierre Bertano ne peut retenir qu'une seule chose en dehors de l'Écriture, à savoir l'existence de traditions ecclésiastiques changeantes, respectables sans doute mais secondaires. En somme, si la proposition de l'évêque de Fano l'avait emportée, "les allemands" auraient pu faire la paix et des compromis eussent été possibles. Nous aurions eu une sorte de High Church avant la lettre. Mais inutile de rêver. Essayons plutôt de comprendre le fonctionnement subtil des sociétés religieuses.

La motion de Pierre Bertano ne fut pas inutile. Le projet de décret fut modifié, mais dans une perspective différente. Après les mots "necnon traditiones ipsas", on introduisit la formule technique : "tum ad fidem tum ad mores pertinentes" A la place même où Pierre Bertano voulait introduire la fonction "adaptative" du magistère, on ajouta la formule consacrée pour désigner la matière propre ou le domaine du "dépôt" confié à l'Église. Cette formule fait allusion au critère interne de la doctrine, à ce que les théologiens nomment "l'analogie de la foi" c'est-à-dire la juste proportion des parties au tout, l'harmonie interne du Mystère chrétien ou de la vérité révélée. Aux yeux de la foi, la révélation est un tout indivisible et qu'il n'est pas au pouvoir de l'homme de changer. Nous rencontrons ici une sorte de "réalisme idéologique", un réalisme du mystère, dont le texte du décret porte bien d'autres traces, et sans lequel on ne peut comprendre en quoi la notion moderne de "document historique" diffère des vieilles notions théologiques exprimées par les mots : testimonia, auctoritates, sacra- 
menta vel mysteria, instrumenta fidei etc... Nous reviendrons plus loin sur ces questions.

Les réponses que l'on fit aux objections de Pierre Bertano confirment bien l'importance attribuée tout ensemble à l'inspiration divine et à la finalité interne orientant l'intelligence de la foi. Ainsi Corneille Mussi, évêque de Bitonto, observe que si toute vérité vient de Dieu, ce n'est pas de la même manière ; l'inspiration divine est réservée aux apôtres, et c'est pourquoi tout ce qui émane d'eux, Écritures et traditions, a même autorité. Mais surtout il ajoute : "Il ne suffit pas de dire que certaines traditions des apôtres ont été abolies, car il faut ajouter que tout ce qui a été dit et transmis par les apôtres n'a pas été transmis pour être observé toujours. Mais certaines traditions sont perpétuelles, celles qui concernent la foi, d'autres temporaires, comme le sang et les viandes étouffées ; d'autres encore données comme des conseils. Il n'y a donc rien d'étonnant à ce que certaines soient aujourd'hui abolies, même si elles sont écrites dans les Livres; on ne les observe pas car elles étaient de conseil" (V/2, 40). On voit que* le même problème se pose non seulement pour les traditions mais aussi pour les Écritures : qu'est-ce qui fait l'unité des Écritures ? qu'est-ce qui fait l'unité des traditions ? Les luthériens rencontrent ici la même difficulté que les catholiques : ce qui fait l'unité des Écritures aussi bien que des traditions, et donc ce qui permet d'en juger, c'est le Christ, c'est la Réalité vivante du Mystère divin. Pétition de principe ou paradoxe, ce réalisme de la foi, c'est la foi même. Luther, sur ce point, parle exactement comme le concile, du moins en ce qui concerne l'intelligence des Écritures, l'unité "réelle" des deux Testaments dans le Christ. C'est vraiment par leur foi que catholiques et luthériens sont séparés. On se souvient que le cardinal Cervini, dans son introduction inaugurale, avait lui-même insisté sur le critère interne, doctrinal, qu'est la révélation trinitaire dans l'histoire du salut. Or c'est sur la base de ce discours inaugural qu'a été construite l'architecture interne du décret : l'Évangile de Dieu, révélé dans l'histoire sainte, comme la source de toute vérité du salut et discipline des mœurs. 
Une autre intervention importante, fut celle d'Augustin Bonuccio, le général des Servites.

Dans la première partie du décret, celle qui définit l'Évangile révélé dans l'histoire sainte comme règle de foi, Bonuccio critique le mot "primum". Il croit y lire que l'Évangile a été promulgué "pour la première fois" par le Christ. Mais, dit-il, la révélation divine n'a pas commencé avec Jésus-Christ ; elle a commencé avec Adam, puisque dès l'origine les hommes ont reçu la promesse d'un rédempteur (Gen. $13,15)$ et n'ont pu trouver qu'en lui le salut. Bonuccio fait ici un petit contre-sens. Le mot "primum" (promulgavit) ne s'oppose pas à ce qui précède (la promesse prophétique) mais au "deinde" per suos apostolos de la proposition suivante : Jésus a d'abord promulgué de sa propre bouche... puis ensuite a ordonné à ses apôtres de prêcher. Néanmoins on voit très bien l'intention de Bonuccio. Il pense à l'unité des Testaments dans le Christ, car c'était là que se trouve la "Regula" ou, comme dit saint Irénée, l'hypothesis, le sujet traité par les Écritures. C'était là le sens de la question posée par les scolastiques quae materia sacrae Paginae vel Doctrinae ? Et tel est bien le sens général du mot "Evangelium" dans le décret de Trente ; il désigne l'Évangile spirituel, la Révélation.

Il faut comprendre dans cette perspective la seconde objection de Bonuccio, concernant la seconde partie du décret. Celui-ci disait que l'Évangile était contenu "en partie" dans les Écritures, "en partie" dans les traditions. La polémique entre luthériens et romains avait conduit à voir dans le couple "Écritures" et "traditions" deux termes antithétiques, exclusifs l'un de l'autre. Or Bonuccio refuse le "partim-partim" parce qu'il refuse le principe même d'une antithèse entre deux termes exclusifs qui s'ajouteraient l'un à l'autre: "Judico omnem veritatem evangelicam scriptam esse, non ergo partim". "Je juge que toute la vérité évangélique est écrite, et non pas en partie" $(1 / 1,525)$. Les théologiens de la Contre-Réforme, soucieux de classer les divers "lieux théologiques" capables de fournir les prémisses d'une conclusion théologique, répéteront pour la plupart que la Révélation est 
contenue en partie dans les Écritures, en partie dans les traditions. Bonuccio, raisonnant non pas sur des lieux théologiques, non pas sur les "signa" mais sur la "Res" ou la "Veritas", tient pour équivalents les termes "vérité évangélique" et "vérité scripturaire", pour les mêmes raisons qui avaient poussé les scolastiques à tenir pour équivalentes la Doctrina sacra et la Pagina sacra.

L'expression "partim-partim" avait été empruntée à une traduction latine du pseudo-Denys (sans doute celle d'Ambroise Traversari, 1436). "Les paroles divines, disait ce texte, sont de deux sortes : certaines qui nous sont adressées dans les saints Livres théologiques, .d'autres qui, sans lettres, sont transfusées de l'âme dans l'esprit (ex anima in animum) par le moyen occasionnel d'un verbe corporel sans doute mais excédant complètement l'intelligence de la chair. Ainsi nos premiers chefs sacerdotaux nous ont transmis ces paroles suprêmes et supersubstantielles par des institutions en partie écrites et en partie non écrites" (Cf. Hierarchia Eccl. I, ch. 4). Ce texte faisait partie des "auctoritates" recueillies par les commissaires du Concile. On voit à quel point la conception des "auctoritates" étaient bien loin de ce que nous appellerions aujourd'hui un document historique susceptible d'être invoqué à l'appui d'une thèse précise. Les considérations mystiques du pseudo-Denys n'ont pas grand chose à voir avec les controverses du XVIe siècle. 'De toute façon, l'idée sinon la formule des deux sources de la Révélation se trouve dans les traités composés aux alentours de Février-Mars 1546 par plusieurs Pères du concile. Ainsi dans le traité 68 de Jérome Séripando, général des Augustins (dont avait fait partie Luther) (XII/1, 5 17); dans le traité 69 attribué au .Jésuite Claude Lejay (XX/1, 522-524); dans les traités 70 et 71 (XII/1, 524-528). Et la correspondance des légats avec le cardinal Farnese confirme bien que l'on se propose de fermer la bouche à ceux qui disent : "Si cela n'est pas écrit, cela n'est pas vrai".

Enfin Bonuccio fait deux objections à la dernière partie du décret. D'une part, il refuse le "par affectus", l'égalité de respect due aux Écritures et aux traditions puisqu'il ne voit dans ces dernières qu'une "ex- 
position" officielle du sens des Écritures. Mais d'autre part il demande que soient précisés les mots "continua successione', par ceux-ci : "et per successores in ministerio continua successione" En proposant cette formule un peu lourde, il veut expliciter le principe de la succession apostolique qui voit dans les évêques, non point isolément mais en corps constitué, les successeurs des apôtres dans le ministère évangélique. Il ne faut pas confondre succession apostolique et magistère. Le magistère est une fonction actuelle. La succession apostolique est une "tradition" qui fournit au magistère sa base institutionnelle. La conception de Bonuccio rejoint ici celle de Cervini qui voulait considérer les traditions apostoliques dans leur principe institutionnel ("an sint"), et non pas comme un ensemble dénombrable d'usages particuliers ("quales sint"). La position de Bonuccio est donc finalement assez proche de celle du cardinal Cervini : lorsqu'il refuse de placer les traditions sur le même plan que les Écritures, c'est qu'il les considère alors dans leurs particularités (en quoi il comprend mal la pensée de Cervini, semble-t-il) ; mais lorsqu'il considère les traditions apostoliques dans leur principe institutionnel, à les juge inséparables du principe de la succession apostolique, ce qui est bien le sens du décret de Trente. Pour soutenir son argumentation, Bonuccio veut montrer que le texte "Ecclesiasticarum" (cité parmi les auctoritates et attribué à tort à saint Augustin) ne prescrit qu'un égal respect aux traditions écrites ou non écrites ; il pense qu'il s'agit là de traditions littéraires ou non littéraires, mais pas du tout de ce qui est scripturaire. Là-dessus l'évêque de Feltre intervient pour avancer une autre interprétation du texte. Malheureusement l'évêque de Feltre était sourd comme un pot ; l'orateur doit lui crier dans l'oreille, si bien que le débat dégénère. Pour mettre fin au brouhaha, le président Cervini impose le silence aux deux partis.

Bonuccio reviendra encore sur la question du "partim-partim" à l'occasion d'une explication de vote le 1er Avril. "Non placere veritatem Evangelii partim in scriptis, partim in traditionibus contineri $(V / 2,47)$. On comprendra mieux la position de Bonuccio en la comparant à celle de Nacchianti, évêque de Chioggia. 
Nacchianti affirme la suffisance pleine et entière de l'Écriture au sens des "modernes", humanistes ou réformateurs, comme un lieu théologique. Il cite des textes patristiques où se trouve affirmée la suffisance de l'Écriture. A propos de ces textes, Cervini lui répond : "Ces paroles doivent s'entendre formellement, à savoir pour recevoir la foi au Christ afin d'être sauvé. Mais en ce qui concerne l'institution des moeurs et de la vie chrétienne, certainement tout n'est pas écrit" (1/1, 494495). La perspective institutionnelle du cardinal de sainte Croix, Cervini, s'affirme ici très clairement. Un autre dialogue entre les deux hommes va dans le même sens. Nacchianti déclare "impie" le "par pietatis affectus" D'où scandale général : sommes-nous donc des impies ? Le malheureux est obligé de battre en retraite. Il n'a pas voulu dire que le saint concile était impie, mais enfin, tout de même, faudrat-il recevoir "avec un égal sentiment de piété" la prière tournée vers l'Orient et l'Évangile de saint Jean ? Cervini intervient alors pour lui demander : "La tradition du canon de la messe doit-elle être vénérée "pari affectu" ? - Oui, dit Nacchianti, comme l'Évangile" (V/2, 71). On voit qu'à travers un problème particulier il s'agit bien, par le double canal de l'Écriture et de la succession continue, de se référer à une même Réalité évangélique, source de l'enseignement et de la discipline. À la fin, Nacchianti votera : "Obediam !" (au lieu du traditionnel "placet'). Quant à Bonuccio, il aura obtenu la suppression du partim-partim.

Lors de la promulgation du décret le 8 Avril 1546 fut célébrée une messe de clôture de la quatrième session. Qui donc à cette occasion allait être chargé de prononcer le sermon ? On ne sait pas exactement qui prenait la responsabilité de désigner l'orateur, mais l'on peut supposer que les présidents se mirent d'accord sur son choix. Augustin Bonuccio fut désigné.

Il est intéressant de savoir quel fut le premier commentaire qu'un théologien a donné du célèbre décret Tridentin. 
Bonuccio prit comme thème de son sermon l'Évangile de la Croix, Evangelium Crucis. Dans l'atmosphère de l'époque, le choix de ce thème faisait écho à la théologia Crucis de Luther. Bonuccio parle de la justice de la foi dans une perspective augustinienne. Il annonce le plan de son sermon par ces mots : l'Église est engendrée par la foi, la foi par l'Évangile, l'Évangile par la croix. l'Église est l'assemblée de tous les fidèles en tant qu'elle forme le corps du Christ par la foi. La foi n'est pas seulement une adhésion intellectuelle, car, à ce titre, la foi des chrétiens ne serait pas différente de la foi des démons. La foi véritable est la foi parfaite, "fiducia de bonitate et clementia Dei nobis per Christum peccata condonantis". C'est dans cette confiance que l'intention propre de la foi (fidei ratio et proprietas) semble être située et posée (sita ac posita). Bonuccio fait ici allusion à une conception de la théologie "positive" que nous retrouverons plus loin, celle qui Il pose" le fondement, l'Évangile de la Croix. La foi n'est pas engendrée seulement par la doctrine ou l'érudition mais par l'Évangile qui est une action "positive" de Dieu apportant la justice. Us juifs possédaient bien la justice légale ; celle-ci est insuffisante ; la justice de la foi se trouve dans la grâce de Dieu qui justifie l'impie. Le lien entre la foi, l'Évangile et la Croix n'évoque pas seulement l'ascétisme, mais la condition historique de l'Église présente. "C'est pourquoi les erreurs, les schismes, les hérésies, la dépravation des mœurs qui s'est produite à notre époque, sont des marques et des stigmates de la Croix ellemême. C'est ce qui fait que les événements peuvent être interprétés de deux manières différentes. Ces marques de la Croix ont été à la fois imaginées dans les conseils de Satan et permises par la sagesse de Dieu, bien que le motif de l'un et de l'autre ne soit pas le même". Ainsi Dieu a déposé les trésors de sa sagesse et de sa rédemption dans une Église visible où se mêlent les justes et les injustes, le bon grain et l'ivraie. Il y a beaucoup d'hypocrites. l'Église des justes, celle des prédestinés, est celle que Dieu seul connaît ; elle demeure pour nous invisible. l'Église triomphera de Satan par les afflictions que lui suscite celui-ci et qui sont pour elle la puissance de la Croix. 
Cette Croix a été préparée pour vous. Il est nécessaire de réformer l'Église. Les hérétiques ont voulu faire cette réforme. Ils se sont égarés, car, en voulant tout tirer de l'Écriture, ils ont perdu la véritable intelligence des Écritures. Ils veulent statuer à partir des Écritures, mais ils leur font violence en s'arrogeant l'intelligence des Écritures. Par contre, le droit, l'équité, les Écritures mêmes et les traditions apostoliques plaident en votre faveur, parce qu'avec vous sont les docteurs de l'Église, la coutume de nombreux siècles chrétiens, les jugements des anciens ; enfin parce que l'Église entière est avec vous dans ce coin de l'occident (in hoc Occidentis angulo).

Mais il ne faut pas exagérer. Il ne faut pas confondre les véritables traditions avec les habitudes d'une école. N'en rajoutons pas. "Ne quid nimis", rien de trop ! On ne peut en aucune façon admettre que les choses transmises par l'autorité des anciens et le long consentement des siècles soient, abolies et détruites. Cependant ceux-là aussi sont inadmissibles qui utilisent des formes d'enseignement familier à certains auxquels ils ont adhéré comme à un autre Paul, pour ne pas dire un autre Christ. Ils y adhèrent de façon si opiniâtre (tam mordicus) que s'ils entendent quelque chose de différent de la doctrine dont ils sont imbibés, ils s'écrient avec je ne sais quelle folie ou quelle frénésie : Hérésie ! Dogme luthérien ou zwenglien ! Au carcan ! Au bûcher ! Ad furcas! Ad ignem ! Comme s'ils étaient les seuls maîtres du jeu et que tout doive être soumis à leur censure. Vous devez conserver au concile sa majesté. Qu'il s'occupe de définir ce qui est essentiel à la foi, mais qu'il laisse à chacun la liberté d'abonder dans son sens pour tout le reste.

Nous devons corriger les abus, réformer les moeurs des princes, des prélats et du peuple. Car des temps pourraient venir pires que ceux d'aujourd'hui. Sans doute nous savons que le Christ conservera son Église.... mais si dès aujourd'hui nous n'y mettons la main, il faut nous attendre à ce que vienne un nouveau Nabuchodonosor qui, par de plus durs moyens, nous enseignera à apprécier les choses avec plus de sagesse. Suivant l'adage, médecin guéris-toi toi-même. Amen. 
Tel fut le premier commentaire théologique du décret du concile de Trente sur les Écritures et les Traditions. Les jours suivants des accusations malveillantes circulèrent sur le compte de Bonuccio. L'évêque de Castellamare (Espagne) le traitait de Hussite, à cause de ses propos sur l'Église invisible. Le théologien espagnol, Dominique Soto, procurateur des Dominicains, conduisait la polémique. L'affaire fut portée devant les Légats. Dominique Soto est mis en demeure de répéter ses accusations. Il refuse de répondre avant d'avoir lu le discours. Qu'à cela ne tienne ! Bonuccio a le texte sur lui. On reprend la lecture, mais Soto refuse toujours de répondre; À ne répondra pas avant d'avoir étudié le texte. Alors Bonuccio : "À la seule audition tu as osé me condamner partout. Maintenant que tu viens d'entendre une seconde lecture, tu n'oses rien dire ? Pourquoi la parole te manque-t-elle ? Pourquoi ne profères-tu pas ici ce que partout tu as dit contre moi ?". Mais Soto n'en démord pas. "Il fut répondu par Soto qu'il voulait d'abord voir le discours". Les Légats furent donc obligés de renvoyer l'affaire à plus tard. Le 18 Avril, en présence du cardinal del Monte et des évêques de Fano, Bitonto, Bertinoro et Astorga, le dominicain expose enfin ses critiques. Malheureusement nous ne savons pas ce qu'il en dit; nous savons seulement que les réponses de Bonuccio furent jugées satisfaisantes ; et l'incident fut clos (I/I, 534-538 et II, 383).

\section{2 Analyse et interprétation du décret}

À la lumière des débats qui ont préparé la rédaction du décret tridentin, nous pouvons tenter maintenant d'en faire l'exégèse.

En premier lieu, les rédacteurs ont complètement écarté la question de savoir quelles étaient les traditions apostoliques ("quales sint") pour se concentrer uniquement sur une question de principe ("an sint"). Cette intention était satisfaite par la suppression du "partimpartim" qui faisait inutilement allusion àun contenu particulier ; elle était satisfaite également par le mot "Fons" qui permettait aux rédac- 
teurs d'éviter les ambiguïtés du mot "Regula". En effet, l'expression "Regula fidei" avait jadis servi à désigner soit un formulaire comme le Credo, soit la vérité révélée, la "Res revelata" et non pas seulement le "Signum". De leur propre initiative les rédacteurs ont remplacé Regula par Fons, ce qui écartait toute allusion à un formulaire. Bref l'intention des rédacteurs était d'éliminer la moindre allusion au quales sint, à l'inventaire des traditions considérées dans leurs particularités comme un ensemble dénombrable, alors que l'intention de Bonuccio était d'affirmer positivement la fonction interprétative des traditions. Ces deux intentions se recoupaient comme l'a très bien compris Cervini, mais elles n'étaient pas identiques. L'autorité concilaire laissait la porte ouverte à une démarche théologique comme celle de Bonuccio, mais elle jugeait que son office était de faire autre chose. Autre chose mais quoi?

C'est ce qui apparaît en second lieu si l'on considère attentivement la composition du décret. Le décret se divise en trois parties : la première partie est une déclaration d'intention introduite par les mots "sibi proponens". La deuxième partie est un considérant introduit par le mot "perspiciens". La troisième Partie énonce une conclusion ou décision indiquée par les mots "pari pietatis affectu suscipit et veneratur."

Le prologue est une déclaration d'intention : le concile se propose que soit conservée dans l'Église la pureté de l'Évangile comme source de toute vérité salutaire et discipline des mœurs. Le mot "Évangile" désigne ici la révélation chrétienne, et non pas simplement un livre. Plus exactement il désigne la révélation trinitaire dans l'histoire, ce qu'en termes médiévaux on appelait le "Res-et-Signum", l'Évangile divin dans l'Église. On disait au XVIe siècle "I'Évangile vivant". Malheureusement les polémistes catholiques parlaient de l'Évangile vivant par opposition à l'Évangile écrit. Les deux termes formaient un couple antithétique destiné à souligner que la tradition n'était pas seulement interprétative mais complétive de l'Écriture. Le texte conciliaire ne prend pas le mot avec ce sens restrictif ou antithétique. Cela ressort de plusieurs considérations : d'abord le discours de Cervini en début de 
session dont la perspective est visiblement tout autre que celle du discours de Del Monte. Ensuite la suppression du "partim-partim". Enfin les autres brouillons de prologue qui sont restés dans les archives du concile (In cod. Vatic. Lat. 4896, f. 71ss ; Cf. V/2, 32, n. I). Plusieurs de ces brouillons, en particulier celui du cardinal Pacheco (f. 85r) et d'autres (f. 74r) introduisaient dans le prologue le début de l'épiîre aux Hébreux: "Multifariam multisque modis Deus loquens Patribus in prophetis...", ce qui était une manière d'insister sur la multiplicité des voies et des modes par lesquels s'était accomplie la révélation évangélique. L'intention du concile est l'intention de la foi qui a pour objet la plénitude de la révélation.

Le considérant affirme la conjonction des deux autorités, Écritures et Traditions apostoliques. Le concile n'a pas adopté la thèse de la tradition complétive puisqu'il a éliminé l'idée d'une Révélation qui serait contenue en partie dans l'Écriture, et en partie dans la tradition. Mais il n'a pas adopté formellement la thèse de la tradition interprétative. Que signifie exactement la conjonction "et" entre les livres écrits et les traditions non scripturaires ? Quel est exactement l'objet du considérant ("perspiciens") ? L'objet du considérant c'est le critère d'apostolicité. Le critère d'apostolicité ne se réduit pas au critère scripturaire. Ce critère affirme aussi l'existence de traditions apostoliques (an sint). Étant donné qu'il s'agit d'un critère normatif, donc d'une question de principe, on n'envisage pas ces traditions apostoliques dans leurs particularités dénombrables (quales sint) sauf sur un point, un point unique mais fondamental à savoir que ces traditions apostoliques sont transmises par succession continue "de la main à la main" depuis les apôtres jusqu'aux évêques assemblés désignés par le mot "nous" (ad nos usque pervenerunt). C'est le principe de la succession apostolique des évêques qui permet d'associer apostolicité et continuité dans les traditions. Le critère d'apostolicité et de perpétuité de la foi est la condition préalable à l'exercice du magistère ; il en est le fondement au sens de la théologie positive (celle qui "pose" les fondements historiques de la foi). 
Enfin la conclusion reconnaît une égale autorité ("pari affectu suscipit") à l'inspiration divine de l'Écriture et à l'institution divine de l'Église dont le principe de la succession apostolique garantit la continuité. On notera que la succession apostolique a donné lieu à diverses interprétations dans les Églises orientales, anglicanes et romaines. Mais la thèse protestante est plus radicale : elle affirme que l'Église est fondée sur la Parole de Dieu annoncée dans l'Écriture ; elle tient que les traditions ont une fonction purement interprétative et une autorité simplement morale, donc qu'elles sont réformables, le protestantisme ne reconnaissant qu'une seule espèce de traditions, les traditions dites "ecclésiastiques". Les catholiques distinguent deux sortes de traditions : les unes ecclésiastiques et variables, les autres apostoliques et perpétuelles.

Dans le décret du concile de Trente, les traditions apostoliques sont définies par trois caractéristiques :

1) L'origine apostolique. Cette affirmation d'origine se combine avec l'idée que l'Église ne tient pas son autorité de l'Écriture, ni l'Écriture de l'Église, mais que chacune tient son autorité directement de Dieu, l'Écriture par inspiration divine, l'Église par institution divine.

2) La succession continue dans le ministère évangélique allant des apôtres aux évêques pris collectivement.

3) La pertinence doctrinale "tum ad fidem, tum ad mores pertinentes". Ce critère doctrinal suppose l'harmonie interne des dogmes. On le nomme habituellement "critère de l'analogie de la foi", le mot "analogie" désignant la "proportion" des parties au tout, la relation de chaque article de foi avec tous les autres dans un ensemble équilibré.

Le concile de Trente, en sa quatrième session, n'a défini qu'une seule chose, à savoir l'apostolicité des Écritures et des Traditions. Il affirme que les unes et les autres ont une même autorité, l'autorité apostolique en relation directe avec l'autorité divine du Christ. En 
d'autres termes, le concile ne définit pas autre chose que le fondement de l'Institution chrétienne. Mais il n'est pas difficile de voir que les trois caractéristiques de ce fondement apostolique et divin correspondent aux trois fonctions de l'Église catholique : fonction de gouvernement, de sanctification et d'enseignement, s'exerçant par trois organes : la hiérarchie, le sacerdoce et le magistère, sous trois formes canoniques : la juridiction, le sacrement et le dogme. La définition juridique de l'autorité est conçue suivant le principe non pas contractuel niais légitimiste de référence à l'origine ; d'autre part la succession apostolique des évêques est fiée au caractère sacramentel de la communion ecclésiastique; enfin le magistère est infaillible en matière dogmatique. En résumé, bien que la décision conciliaire concerne le seul fondement de ces trois fonctions et non pas ces fonctions en ellesmêmes, elle s'intègre à l'ensemble de l'ecclésiologie catholique.

3 La signification du décret dans l'histoire de la théologie

Il nous reste à dire quelques mots de la signification du décret de Trente dans l'histoire des méthodes théologiques.

Il n'est plus guère contesté aujourd'hui que la thèse luthérienne sur le principe scripturaire trouve de nombreux échos dans la littérature médiévale et patristique. Et surtout la Haute Église anglicane ou les, Églises orientales n'ont guère changé depuis le Moyen Age. Le problème devant lequel se trouvait l'Église romaine était d'établir non pas l'autorité morale des traditions ecclésiastiques (ce qui n'était pas le fond du débat) mais l'origine apostolique et donc le caractère irréformable de certaines traditions. En fait d'arguments patristiques, le concile s'est appuyé sur les citations que l'on trouvait dans le code de droit canonique de Gratien. Nous avons signalé en passant que ces citations n'ont pas été contrôlées d'après les textes originaux. Par exemple on attribue à saint Augustin une citation de saint Basile; on ne s'est pas préoccupé du contexte historique (comme la soi-disant discipline de l'arcane) pour savoir si ces textes disaient bien ce qu'on 
voulait leur faire dire. Quoi qu'il en soit, les conclusions qu'un théologien pourra tirer du décret conciliaire dépendent en grande partie de la place qu'il assigne à ce décret dans l'histoire de la théologie. Nous avons vu que le décret de Trente n'est pas... post-tridentin ; il n'a pas soutenu la thèse des traditions "complétives". On a longtemps interprété le décret dans l'optique de la Contre-Réforme. On peut aussi l'interpréter à la lumière des conceptions médiévales, ce qui ne va pas sans soulever, comme nous allons voir, la difficile question des rapports entre la théologie et l'histoire.

Au Moyen Age la théologie est la science de l'Écriture sainte. Et comme l'on prend volontiers le signifiant pour le signifié, le livre pour son contenu, les mots : "Scriptura sacra", "Doctrina sacra", "Theologia", "Scriptura theologica" sont à peu près équivalents. C'est là le vocabulaire habituel des scolastiques, que l'on retrouve encore chez saint Thomas : "Theologia quae sacra Scriptura dicitur" (In Boet. de Trin. q. 5, a 4). Ou encore : "Revelatio divina super quam fundatur Seriptura seu sacra Doctrina" (S.T., Q. I, a. 2, ad 2m). On trouve un peu partout en abondance des formules comme celle d'Anselme de Laon: "Jésus-Christ a semé dans les Écritures, dans les sources d'eau. Ces sources d'où naissent les fleuves symbolisent pour nous l'Évangile qui est la source et la somme de toute notre foi. De là naissent les fleuves c'est-à-dire les expositions en qui nous retrouvons toujours la double intelligence propre aux fidèles, historique et allégorique" (Enar. in Apoc., P.L. 162, col. 1531 C). Toutefois, pour comprendre des textes de ce genre, il faut tenir compte du fait que les théologiens médiévaux avaient tendance à incorporer au canon scripturaire les "expositions authentiques" faites par les Pères ou les Docteurs de l'Église (authentifiés par le décret de Gélase) et qui, étant lus solennellement dans la liturgie, sont placés, comme dit Lanfranc, "dans la citadelle de l'Autorité" (arx auctoritatis) (Liber de corpore et sanguine Domini, P.L. 150, col. 408 A et cf. 428-429 ; 435 CD). Par exemple Hugues de Saint Victor écrit : "Nous ne devons croire sans hésitation que ce que nous lisons dans l'Écriture" (De sacramentis P.L. 176, col. 200 C). Mais il déclare aussi : "L'ancien Testament contient la loi, les prophè- 
tes, les hagiographes. Le nouveau contient l'évangile, les apôtres, les Pères" (De scripturis et scriptoribus sacris P.L. 175, c. 6, col. 15 AB ; et cf. P.L. 176, col. 779). Cela donne en exégèse des résultats parfois curieux. Par exemple Hugues de Reading (XIle) discutant la double thèse, créationiste ou traducianiste, sur l'origine de l'âme, écrit : "D'où la femme a-t-elle reçu l'esprit ? l'Écriture n'en dît rien. Scriptura tacuit.. Alors que dirai-je ? Voici que me vient en mémoire la sentence d'un docteur catholique, je veux dire le prêtre Jérome. Il me parait évident que cette doctrine (le créationisme) est celle que lit et soutient (legit et tenet) le Siège apostolique et l'Église universelle" (Dialogorum libri septem P.L. 192, col. 1206 D). Étonnant contraste : Scriptura tacuit... Ecclesia legit Mais ce qu'on lisait dans les expositions orthodoxes de l'Écriture, on le recevait comme partie intégrante de la doctrine scripturaire. Les mots "Ecclesia docet, tenet", étaient spontanément ressentis comme équivalents à "Ecelesia legit, exponit" L'assimilation du patristique au scripturaire chez les écrivains médiévaux peut provoquer chez l'historien moderne diverses méprises, car on ne cessait pas de distinguer ce que l'on avait assimilé. Suivant le Père Spicq, par exemple : "Rupert est le premier à dissocier l'autorité des écrivains inspirés de celle des docteurs de l'Église" 115. Les apparences, en effet, semblent justifier ce jugement. Rupert de Deutz avait récusé l'autorité de saint Grégoire et celle de saint Augustin comme n'étant pas dans le canon. Une polémique s'en était suivie: "Ils ont entrepris de me diffamer parce que j'avais dit que saint Augustin n'était pas dans le canon". Méfions-nous cependant. La phrase qui semble justifier l'appréciation du Père Spicq est la suivante : "En dehors des apôtres, écrit Rupert, tout ce qui a été dit par la suite doit être écarté et n'a plus d'autorité. Quelque saint que soit un homme après les Apôtres, quelle que soit sont éloquence, il n'a pas d'autorité" (In Apoc. P.L. 169, col. 1017 AB). N'aurais-je pas déjà lu cette phrase quelque part ? Mais oui ! elle est de saint Jérome (In Ps. 86, P.L. 26, col. 1084) ; Abélard la cite également dans la préface du Sic et Non (P.L.

115 Spicq : Esquisse d'une histoire de l'exégèse latine au M.A., Paris, 1944, p. 74. 
178, col. 1348). Rupert n'avait pas innové, mais, comme cela est fréquent au Moyen Age, il avait pratiqué l'art de la citation implicite. On n'a donc jamais oublié de distinguer diverses sortes "d'auctoritates", et le Xllle siècle surtout s'est efforcé de les classer.

Pour définir la nature de la théologie, les scolastiques posaient une question classique, que l'on trouve par exemple dans l'introduction à la Somme d'Alexandre de Halès : "Quelle est la matière ou le sujet de l'Écriture ou Doctrine sacrée ?". Le rédacteur distingue la "materia circa quam" que sont les "Res et Signa", et la "materia de qua agitur" qui est ainsi présentée: "Si nous considérons la matière des divines Écritures en raison de l'oeuvre divine, nous dirons que la matière des divines Écritures est l'oeuvre de Rédemption du genre humain. Si nous considérons la matière des divines Écritures en raison de la puissance opérante, nous dirons que la matière des divines Écritures est le Christ puissance de Dieu et sagesse de Dieu. Si nous considérons la matière des divines Écritures en raison de son essence, nous dirons que la matière des divines Écritures est Dieu ou la substance divine. Par conséquent la théologie est la science de Dieu devant être connue par la puissance du Christ dans l'oeuvre de Rédemption" (S.T., I, q. I, a. 3). Pourquoi ces distinctions ? À quoi pouvaient-elles bien servir ? Tout simplement à incorporer à la méthode de la théologie les divers sens de l'Écriture : Dieu (sens analogique) devant être connu par la puissance du Christ (sens allégorique) dans l'oeuvre de rédemption (sens moral). Telle était la matière ou le sujet de la Doctrina sacra, le sens "unus multiplex" de l'Écriture.

L'originalité de saint Thomas est d'avoir cherché à unifier lamatière de la théologie sous un seul concept, celui du "Revelabile", du Révélécomme-tel (les finales en "-bile" n'indiquent pas le possible mais le formel). Dans la conception que saint Thomas se fait de la théologie l'Écriture intervient à deux niveaux : elle intervient d'une part comme un lieu théologique (locus $a b$ auctoritate), un lieu où l'on puise les arguments (argumentari ex auctoritate) (S.T., I, q. I, a. 8, ad 2m); d'autre part elle intervient dans la théorie du "moyen terme" ou du mo- 
tif qui oriente l'adhésion de la foi : "Quiconque n'adhère pas comme à la Règle infaillible et divine à la Doctrine de l'Église qui procède de la Vérité première manifestée dans les saintes Écritures, celui-là n'a pas la disposition de la foi mais il tient les choses de la foi autrement que par la foi, de même qu'un homme qui s'attache à une conclusion en ignorant le moyen de la démontrer (medium demonstrationis) n'a pas la science mais seulement l'opinion" (S.T., II II, q. 5, a. 3 c). Et encore : "(Le croyant) adhère à tous les articles de foi à cause d'un seul moyen terme (propter unum medium), à savoir la Vérité première qui nous est proposée dans les saintes Écritures suivant la doctrine de l'Église les interprétant correctement. C'est pourquoi celui qui abandonne ce moyen terme manque totalement de la foi" (III Sent. D. 25, q. I, a. I, sol. I, ad 4m). Autrement dit, l'intelligence de la foi est déterminée par sa finalité interne ; la Règle de foi qui l'oriente n'est pas un formulaire mais la Vérité divine que manifeste l'Écriture interprétée par l'Église ; c'est par-là que l'on remonte de la diversité des "testimonia" à l'unité de la révélation (ad unum). Si l'on appliquait ce principe, aujourd'hui, cela pourrait vouloir dire par exemple que les "développements" du dogme, même lorsqu'ils ne se déduisent pas de l'Écriture, doivent être réduits à l'unité par le moyen de l'Écriture, puisque le medium demonstrationis de la théologie est la reductio ad unum, à l'Evangelium dont parle le concile de Trente. On pourrait imaginer que l'intelligence de la foi "progresse" en simplicité.

Ce ne fut pas le cas. Pourquoi ? Parce que la conception finaliste ou téléologique de la "Vérité" comprise comme la réalité véritable et parfaite est le piège séducteur de toute idéologie qui, devenant incapable de distinguer jugement de réalité et jugement de valeur, ne pourra plus jamais retrouver qu'elle-même dans l'univers entier. Cette conception téléologique de la soi-disant Réalité Véritable, que l'on retrouve aujourd'hui dans les dialectiques totalisantes ou théologicopolitiques du marxisme, ouvre sur toutes choses l'ère du soupçon : plus rien n'est simplement ce qu'il est, mais autre chose. Vous ne pouvez plus flâner dans la rue en regardant les passants, car le trottoir n'est pas simplement un trottoir, les arbres ne sont pas simplement des 
arbres, et les passants ne sont plus simplement des hommes, tout rappelle un perpétuel Ailleurs. Bien sûr il existe entre les choses des connexions multiples, mais quand toute chose n'est plus que le prétexte d'une appréciation seule "véritable", cet univers idéologiquement clos devient irrespirable. Peu importe alors que "la réalité véritable" soit un dieu ou une société parfaite qui adviendra demain, laissons cet être parfait jouir de sa définition, il est l'infinie complaisance en soimême.

C'est précisément cette confusion de la vérité avec le souhaitable qui allait être remise en cause par des procédures plus effectives de discrimination entre le vrai et le faux, d'abord à l'intérieur de la scolastique puis dans l'humanisme. On sait que la notion critique et historique du "document" au sens où nous l'entendons aujourd'hui, s'est lentement élaborée depuis les humanistes jusqu'au XIXe siècle. Mais son origine lointaine remonte aux théories de la grammaire et de la logique que le Moyen Age avait élaborées. Déjà en 1387 lorsque l'université de Paris condamna le dominicain Jean de Montzon, c'est que son thomisme était devenu trop grammairien ; on lui reprochait d'avoir dit que l'Écriture pouvait s'interpréter à partir de son seul texte, de même qu'on peut interpréter une grammaire à partir des règles qu'elle donne elle-même. Mais ce sont surtout les développements de la logique qui introduiront des exigences plus précises dans l'exégèse, avec la théorie de l'inférence déductive et celle de la "suppositio" ou référence. On commence alors à s'interroger sur "les divers genres de vérités catholiques". Ainsi Guillaume d'Ockam : "Le premier genre comprend les vérités qui se trouvent dans l'Écriture ou qui peuvent en être inférées par un argument nécessaire. Le second genre comprend les vérités qui, depuis les Apôtres, nous sont parvenues par la relation de leurs successeurs et les écritures des fidèles, bien qu'elles ne se trouvent pas dans l'Écriture ou ne puissent en être conclues par un argument nécessaire. Le troisième comprend celles que nous trouvons dans les relations des fidèles, histoires ou chroniques dignes de foi. La quatrième comprend les vérités qui peuvent être déduites clairement du premier genre ou du second ou des deux en même temps que du troisième. Le 
cinquième comprend tout ce qui, en plus des vérités révélées aux Apôtres, a été révélé ou inspiré à d'autres par Dieu" (Dialogus I,2, c. 5). Alors commence un cheminement plus austère de la pensée, qui, lentement, pas à pas, va mettre plusieurs siècles pour savoir où il va. $\mathrm{Au}$ lieu de confondre la vérité avec le souhaitable, on s'efforce de déterminer, à propos de chaque proposition tenue pour vraie, si c'est en vertu d'une autorité préalablement acceptée, ou d'un constat, ou d'une inférence. On s'est beaucoup moqué de ce travail de fourmi et il est vrai qu'il n'avait pas encore à sa disposition les moyens scientifiques d'une recherche positive, mais le principe de l'analyse est déjà posé : "Illud quod est minimum in perfectione sub tali specie est mensura omnium aliorum"(In Sent. II, q. XI G).

Après cela, les méthodes de la théologie ne pouvaient que subir une transformation radicale. Le travail des logiciens aura été de courte durée, mais après lui rien n'est plus comme avant. Guillaume d'Ockam avait posé le principe qui, lentement, devait permettre d'effectuer la transition entre la conception juridico-théologique des "auctoritates" et la conception critique du "document". C'est là qu'il faut chercher l'origine lointaine de ce qui va devenir la théologie positive. Cependant il faudra plusieurs siècles encore pour que l'argument d'autorité cède la place aux critères empiriques de l'honnêteté intellectuelle.

\section{Fin du texte}

